\author{
Universidade de São Paulo \\ Instituto de Física
}

\title{
Análise do Aerossol Atmosférico em Acra, Capital de Gana
}

\author{
Thiago Gomes Veríssimo
}

Orientador: Prof. Dr. Américo Adlai Franco Sansigolo Kerr

Dissertação de mestrado apresentada ao Instituto de Física para a obtenção do título de Mestre em Física

Banca Examinadora:

Prof. Dr. Américo Adlai Franco Sansigolo Kerr (Instituto de Física)

Prof. Dr. Alexandre Lima Correia (Instituto de Física)

Prof. Dr ${ }^{a}$. Maria de Fátima Andrade (Instituto de Astronomia e Geofísica)

São Paulo 
FICHA CATALOGRÁFICA

Preparada pelo Serviço de Biblioteca e Informação do Instituto de Física da Universidade de São Paulo

Veríssimo, Thiago Gomes

Análise do aerossol atmosférico em Acra, Capital de Gana. São Paulo, 2016.

Dissertação (Mestrado) - Universidade de São Paulo. Instituto de Física. Depto. Física Aplicada.

Orientador: Prof. Dr. Américo Adlai Franco Sansigolo Kerr Área de Concentração:

Unitermos: 1. Poluição atmosférica; 2. Espectroscopia de raio X; 3. Inferência não paramétrica.

USP/IF/SBI-040/2016 
Aos meus pais, Maria Aparecida e José Petrucio. 


\section{Agradecimentos}

Ao Arthur, meu filho, e sua trupe, Júlia, Martim, Francisco e Caetano, pelos constantes momentos de brincadeiras, conforto e paz.

À Thais do Val, minha companheira e amiga, que me acompanhou durante essa dura jornada.

Ao meu pai, José Petrucio, pelo incentivo (e insistência) aos estudos que me deu desde criança, e à minha mãe, Maria Aparecida, por sempre me acolher durante esses anos de USP.

Ao meu orientador, Américo, pelos ensinamentos científicos e políticos ao longo da última década.

Ao meus irmãos, Julio Cesar e Bruno, à minha irmã Hilda, que foram compreensíveis e pacientes em minhas ausências nos encontros de família (devido principalmente à pesquisa acadêmica).

À professora Fátima pelos ensinamentos na sua disciplina e pelas dicas de análises estatísticas durante o curso.

À Lia da FAP e à Paula da Pós-Graduação pelos encaminhamentos dos trâmites burocráticos durante o curso.

Ao Luís, Atenágoras, Luciana, Mariana e Gregori pela ajuda essencial nas medidas laboratoriais, diurnas e noturnas, além das discussões técnico-científicas do trabalho.

À Rosana, do LAPAt, pelas irradiações realizadas e conversas sobre a situação política da USP.

Ao Majid, Zheng, Kathie e Raphael por nos acolher na Harvard School of Public Health, nos EUA.

Ao Mozart e a Patrícia Ribeiro pelas inúmeras leituras e sugestões no texto.

Ao Alberto, amigo e pesquisador moçambicano, pela leitura da dissertação e conferências das tabelas e fórmulas.

Aos amigos que direta ou indiretamente me acompanharam nessa trajetória, entre eles: Ana Paula, Nakamura, Ricardo, Augusto, Normando, Deidson, Zé, Carlos, Márcio e Isa.

E a toda comunidade de Software Livre que fornece gratuitamente as ferramentas computacionais utilizadas na produção desse trabalho. 


\section{Resumo}

\section{VERISSimo, T., G. Análise do Aerossol Atmosférico em Acra, Capital de Gana.}

2016150 p. Dissertação (Mestrado em Física) - Instituto de Física, Universidade de São Paulo, São Paulo, 2016.

Cidades dos países da África Subsariana (SSA) têm passado por um intenso processo de urbanização, implicando em crescimento das atividades econômicas em geral e industriais em particular, assim como, o aumento do tráfego de veículos e da produção de lixo, dentre outras mudanças que afetam diretamente o meio ambiente e a saúde dos habitantes. Neste cenário, a identificação de fontes poluidoras do ar é essencial para a fundamentação de políticas públicas que visam assegurar o direito a uma boa qualidade de vida para a população.

Esta pesquisa de Mestrado esteve integrada a um projeto internacional denominado Energy, air pollution, and health in developing countries, coordenado pelo Dr. Majid Ezzati, à época professor da Harvard School of Public Health, e integrando também pesquisadores da Universidade de Gana. Este projeto tinha por objetivo fazer avaliações dos níveis de poluição do ar em algumas cidades de países em desenvolvimento, voltando-se, neste caso particular para Acra (capital de Gana e maior cidade da SSA), e duas outras cidades de Gambia, onde até então inexistiam estudos mais substantivos, relacionando-os com as condições socioeconômicas específicas das diferentes áreas estudadas.

Contribuímos com as análises de Fluorescência de Raios X (XRF) e de Black Carbon(BC), com as discussões e interpretações dos dados meteorológicos e no emprego dos modelos receptores. Mas do ponto de vista do aprofundamento de estudos da qualidade do ar e do impacto de fontes, este trabalho concentrou-se na região de Nima, bairro da capital de Gana, Acra. A partir da caracterização do aerossol atmosférico local, empregou-se modelos receptores para identificar o perfil e contribuição de fontes majoritárias do Material Particulado Atmosférico Fino $M P_{2,5}$ e Grosso $M P_{2,5-10}$.

Foram coletadas 791 amostras (de 48 horas) entre novembro de 2006 e agosto de 2008 em dois locais, na principal avenida do bairro, Nima Road, e na área residencial, Sam Road, distantes 250 metros entre si.

A concentração anual média em 2007 para $M P_{2,5}$ encontrada na avenida foi de $61,6 \pm 1,0$ $\mu \mathrm{g} / \mathrm{m}^{3}$ e $44,9 \pm 1,1 \mu \mathrm{g} / \mathrm{m}^{3}$ na área residencial, superando a diretriz de padrão anual máximo 
de $10 \mu \mathrm{g} / \mathrm{m}^{3}$ recomendada pela Organização Mundial de Saúde (OMS). A porcentagem de ultrapassagem do padrão diário (OMS) de $25 \mu \mathrm{g} / \mathrm{m}^{3}$ foi de $66,5 \%$ e $92 \%$ para a área residencial e avenida, respectivamente, durante todo experimento.

As concentrações químicas elementares foram obtidas por XRF e o BC por refletância intercalibrada por Thermal Optical Transmitance (TOT).

Neste trabalho desenvolvemos uma metodologia de calibração do XRF e de intercalibração entre refletância e TOT, baseada em Mínimos Quadrados Matricial, o que nos forneceu incerteza dos dados ajustados e boa precisão nos valores absolutos de concentrações medidos.

Análise de Fatores (AF) e Positive Matrix Factorization (PMF) foram utilizadas para associação entre fonte e fator, bem como para estimar o perfil destas fontes. A avaliação de parâmetros meteorológicos locais, como direção e intensidade dos ventos e posicionamento de fontes significativas de emissão de MP auxiliaram no processo de associação dos fatores obtidos por esses modelos e fontes reais.

No período do inverno em Gana, um vento provindo do deserto do Saara, que está localizado ao nordeste do país, denominado Harmatão, passa por Acra, aumentando de um fator 10 a concentração dos poluentes relacionados à poeira de solo. Assim, as amostras dos dias de ocorrências do Harmatão foram analisadas separadamente, pois dificultavam a identificação de outras fontes por PMF e AF.

As fontes majoritárias indicadas por esses dois métodos (AF e PMF), mostraram-se concordantes: Mar (Na, Cl), solo (Fe, Ti, Mn, Si, Al, Ca, Mg), emissões veiculares (BC, Pb, Zn, $\mathrm{K})$, queima de biomassa (K, P, S, BC) e queima de lixo sólido e outros materiais a céu aberto $(\mathrm{Br}, \mathrm{Pb})$.

A redução da poluição do ar em cidades da SSA, caso de Acra, requer políticas públicas relacionadas ao uso de energia, saúde, transporte e planejamento urbano, com devida atenção aos impactos nas comunidades pobres. Medidas como pavimentação das vias, cobertura do solo com vegetação, incentivo ao uso de gás de cozinha e incentivo ao transporte público, ajudariam a diminuir os altos índices de poluição do ar ambiental nessas cidades.

Palavras-chave: Poluição atmosférica, espectroscopia de raios x e inferência não paramétrica. 


\section{Abstract}

Sub-Saharan Africa (SSA) cities have been intense developing process, resulting in generalized economical activities growing, specially industrial, as well as increase in the vehicular traffic and waste generation, among other changes directly affecting the environment and public health. Therefore, identifying the air pollution sources is an essential issue for public decisions to assure people rights to healthy life.

This Master work has been integrated to an international project called Energy, air pollution, and health in developing countries, under coordination of Dr. Majid Ezzati, then at the Harvard School of Public Health, grouping also researchers from the University of Ghana. The aims of this project were to evaluate the air pollution level at some developing countries, by this time devoted to Accra (the capital of Ghana and the main city of SSA), and two other cities of Gambia. Since then, no substantive study was performed there, connecting air pollution to the regional social-economical levels.

This Master project, provided the XRF and Black Carbon determination for all samples of the main project, and gave, else, support for meteorological and receptor modeling issues. But concerning the improving of the study of air quality and sources impact, the work focus Nima town, at Accra, the Ghana Capital. The characterization of species in the local atmospheric aerosol was used in Receptor Models to make factor to sources profile association, and respective apportionment in the local $P M_{2.5}$ and $P M_{10}$.

Between November/2006 and August/2008, 791 filters (sampled for 48 h) collected the local atmospheric aerosol, in two sites separated by $250 \mathrm{~m}$. One was at the main avenue (Nima Road) and other in a residential street (Sam Road).

The $P M_{2.5}$ annual average concentration to 2007 was $61,6 \pm 1,0 \mu \mathrm{g} / \mathrm{m}^{3}$ near to the avenue and $44,9 \pm 1,1 \mu \mathrm{g} / \mathrm{m}^{3}$ in the residential area, surpassing 5 times the Word Health Organization (WHO) guidelines to annual mean $\left(10 \mu \mathrm{g} / \mathrm{m}^{3}\right)$. Another WHO guideline is not surpass 25 $\mu \mathrm{g} / \mathrm{m}^{3}$ in more than $1 \%$ of the samples collected in one year - in each of these sites, $66,5 \%$ and $92 \%$ of the samples are above this limit.

X-Ray Fluorescence (XRF) provided the elemental concentrations, while reflectance, inter calibrated by Thermal Optical Transmittance (TOT), gave the Black Carbon (BC) levels.

In this work we performed a methodology for the XRF calibration and for the inter calibration between TOT and reflectance, using Matrix Least Square Fitting that gives the uncertainties of fitted data and improves the precision of the adjusted values. 
Factor Analysis (FA) and Positive Matrix Factorization (PMF) enabled the association between source and the determined factors, as well as, estimated the sources profile. Local meteorological data, like wind intensity and direction, and the identification of some heavy MP emission sources, helped the process of factors to sources association.

During the winter period (January-March), Accra received the Harmattan wind, blowing from Sahara deserts, that increased the concentrations from soil in 10 times. Therefore, the samples from this period were separately analyzed, providing better detection of the other source by PMF and FA.

The local main source detected by both methods showed coherency: sea salt ( $\mathrm{Na}, \mathrm{Cl})$, soil (Fe, Ti, Mn, Si, Al, Ca, Mg), vehicular emissions (BC, Pb, Zn, K) and biomass burning (K, $\mathrm{P}, \mathrm{S}, \mathrm{BC})$.

Reduction of air pollution levels in SSA cities, like Accra, requires public actions providing clean energy sources, health care, public transportation, urban planing and attention to they impact for the poor communities. Relatively simple providences, like roads paving, vegetation covering of the land, use of gas for cooking, public transportation, should decrease the high air pollution level in those cities.

Keywords: Air pollution, x-ray spectroscopy and nonparametric inference.

Atmospheric Aerosols, Sub-Saharan Africa SSA, X-ray Fluorencence, Black Carbon, Receptor Models. 


\section{Lista de Figuras}

1.1 Média mensal de direção e intensidade do vento sobre o continente Africano em 875 hPa (aproximadamente 1200 m) em janeiro de 2008. . . . . . . . . . 19

1.2 Pirâmide etária, Gana 2010. (Ghana, 2013) ～. . . . . . . . . . . . . . 20

1.3 Comparação do produto interno bruto (PIB) per capita anual entre Brasil e Gana, Banco Mundial (2015) _. . . . . . . . . . . . . . . . . . 21

1.4 Queima de lixo a céu aberto em Nima. Por Raphael Arku (reprodução autorizada pelo autor). . . . . . . . . . . . . . . . . . . . 23

1.5 Foto do depósito de lixo eletrônico (e-waste) situado no bairro de Agbogbloshie em Acra. Fotografia de Jack Caravanos, Professor da School of Public Health em Hunter College, CUNY Nova Iorque, Estado Unidos da América (reprodução autorizada pelo autor). . . . . . . . . . . . . . . . 24

1.6 tro-tro e congestionamento em Nima. por Raphael Arku (reprodução autorizada pelo autor). . . . . . . . . . . . . . . . . . 24

1.7 Fotos de cozinha residencial e comercial de Nima, por Raphael Arku (reprodução autorizada pelo autor).

1.8 Esquema da distribuição de tamanho do aerossol atmosférico proposta por Finlayson-Pitts \& Pitts Jr (1999) e adaptada por Oliveira (2007). . . . . . . . 27

2.1 Mapa de Nima. NM-1 ponto de amostragem na área residencial e NM-2 ponto de amostragem na avenida. Porcentagem do uso da queima de biomassa para preparação de alimentos em residências usando dados do censo de 2000 (Ghana, 2003). Imagem reproduzida do artigo Zhou et al. (2013). . . . . . . . . . . . . 31

2.2 Levantamento de algumas fontes poluidora de Acra. . . . . . . . . . . . . . 32

2.3 Ilustração clássica do fenômeno de fluorescência de raios X no átomo. Figura que acompanha o manual da Shimadzu da série de equipamentos EDX 700. $\quad$. 34

2.4 Transições de elétrons entre os subníveis das camadas K, L e M. Figura extraída de Jenkins et al. (1991). . . . . . . . . . . . . . . . . . 35 
2.5 XRF-ED Shimadzu modelo EDX 720HS - LAPAt.

2.6 Software da XRF-ED Shimadzu 720HS, tela de verificação do estado do equipamento.

2.7 Carrossel de 8 posições adquirido para XRF-ED Shimadzu 720HS. 38

2.8 Suporte para filtros de PTFE, projetado no LAPAt para carrossel de 8 posições e produzido pela oficina do Departamento de Física Aplicada do Instituto de Física da USP.

2.9 Fatores de respostas, $\mathrm{R}(\mathrm{Z})$, para alvos padrões da Micromatter irradiados em maio de 2010 . . . . . . . . . . . . . . . . . . . . . . . 41

2.10 Espectros para amostra branca e carregada de Nima. . . . . . . . . . . . . . . 44

2.11 Limite de detecção para XRF-ED em termos de concentrações típicas para amostra branca e carregada. . . . . . . . . . . . . . . 45

2.12 Refletômetro da Diffusion System modelo ELL43D e peças auxiliares de fixação

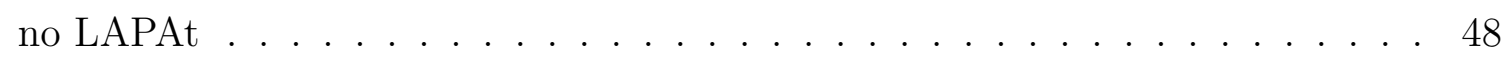

3.1 Comparação das calibrações do XRF-ED nos 3 períodos. . . . . . . . . . . . 56

3.2 Comparação das calibrações da XRF-ED nos 3 períodos. . . . . . . . . . . . 63

3.3 Comparação das análises de XRF no LAPAt e na US-EPA. . . . . . . . . . . . 65

3.4 Calibração do refletômetro do LAPAt em 2007 usando alvos padrões M71. . 67

3.5 Reflêtancia e pesagem dos padrões produzidos na CETESB com BC de referência ASTM-N762. . . . . . . . . . . . . . . . . . . . . 69

3.6 Intercalibração TOT e Reflêtancia para amostragem paralela no túnel Jânio Quadros.

3.7 Comparação da massa de BC das amostras do túnel Jânio Quadros calculada usando calibração por TOT versus calibração a partir dos alvos padrões produzidos na CETESB. . . . . . . . . . . . . . . . . 73

3.8 Intercalibração entre TOT e refletância em Acra. . . . . . . . . . . . . . 75

3.9 Razão dos valores de BC medidos por refletância e calibrados por TOT e M71 para Recife e Acra. . . . . . . . . . . . . . . . . . . . . . 75

3.10 Concentrações de $M P_{10}$ ao longo da campanha de amostragem. . . . . . . . . 79

3.11 Concentrações de $M P_{2,5}$ ao longo da campanha de amostragem. Padrão da OMS para média diária de $M P_{2,5} 25 \mu \mathrm{g} / \mathrm{m}^{3}$ sinalizado. . . . . . . . . . . . . . 83

3.12 Rosa do ventos para Acra/2007. . . . . . . . . . . . . . . . 89

3.13 Rosa do ventos horária para Acra/2007. . . . . . . . . . . . . . . . . . 90 
3.14 Rosa do ventos mensal para Acra/2007.

3.15 Intensidade e direção do vento médio na altitude de 1000 metros sobre o continente Africano.

3.16 Intensidade e direção do vento médio na superfície (10 metros) no continente Africano. . . . . . . . . . . . . . . . . . . 93

3.17 Contribuição dos fatores na massa total para $M P_{2,5}$ na área residencial excluindo dias de ocorrência de vento Harmatão. seed $=123 \mathrm{n}=123 . \quad$. . . . . . 101

3.18 Contribuição dos fatores na massa total para $M P_{2,5}$ na avenida excluindo dias de ocorrência de vento Harmatão. seed $=123 \mathrm{n}=122 \ldots \ldots$. . . . . . . . . 102

3.19 Contribuição dos fatores na massa total para $M P_{2,5-10}$ na área residencial excluindo dias de ocorrência de vento Harmatão. seed $=123 \mathrm{n}=123 . \quad$. . . . 106

3.20 Contribuição dos fatores na massa total para $M P_{2,5-10}$ na avenida excluindo dias de ocorrência de vento Harmatão. seed $=123 \mathrm{n}=116 . \quad$. . . . . . . . . 107

3.21 Contribuição dos fatores na massa total para $M P_{2,5}$ na área residencial somente nos dias de ocorrência de vento Harmatão. seed $=123 n=51 . \quad$. . . . . . . . . 112

3.22 Contribuição dos fatores na massa total para $M P_{2,5}$ na avenida somente nos dias de ocorrência de vento Harmatão. seed $=123 \mathrm{n}=59 . \quad$. . . . . . . . . . 113

3.23 Contribuição dos fatores na massa total para $M P_{2,5-10}$ na área residencial somente nos dias de ocorrência de vento Harmatão. seed $=123 \mathrm{n}=49 . \quad$. . . 115

3.24 Contribuição dos fatores na massa total para $M P_{2,5-10}$ na avenida somente nos dias de ocorrência de vento Harmatão. seed $=123 \mathrm{n}=58 . \quad$. . . . . . . . . 116

B.1 Contribuição dos fatores na massa total para $M P_{2,5-10}$ na área residencial excluindo dias de ocorrência de vento Harmatão. seed $=123 \mathrm{n}=123$. . . . 127

B.2 Contribuição dos fatores na massa total para $M P_{2,5-10}$ na avenida excluindo dias de ocorrência de vento Harmatão. seed $=123 \mathrm{n}=116 . \quad \ldots \ldots$. . . . . 128 


\section{Lista de Tabelas}

1.1 Frota veicular de Gana segundo o Driver and Vehicle Licensing Authority (DVLA) (2015).

2.1 Percentual relativo dos tipos de fontes de energia usadas para preparação de alimentos em Gana (2013). . . . . . . . . . . . . . . . . . 33

2.2 Limite de detecção para XRF-ED em termos de concentrações típicas para amostra branca e carregada. . . . . . . . . . . . . . . . 46

3.1 Calibração da Fluorescência de Raiox X linha K . . . . . . . . . . . . . . . . . 57

3.2 Calibração da Fluorescência de Raiox X linha L . . . . . . . . . . . . . . . . . 59

3.3 Calibração do refletômetro do LAPAt em 2007 usando alvos padrões M71. . . 68

3.4 Reflêtancia e pesagem dos padrões produzidos na CETESB com BC de referência ASTM-N762. . . . . . . . . . . . . . . . . . . 70

3.5 Comparação da massa de BC das amostras do túnel Jânio Quadros calculada usando calibração por TOT(1) versus calibração a partir dos alvos padrões produzidos na $\operatorname{CETESB}(2) \ldots \ldots \ldots \ldots \ldots$

3.6 Intercalibração entre TOT e refletância para Acra. . . . . . . . . . . . . 76

3.7 Padrões de Qualidade do Ar para $M P_{10}$ Ambiental em Gana Ghana (2015a) 78

3.8 Padrões para média anual de $M P_{10}$ no Brasil (CONAMA, 1990), Gana (Ghana, 2015a) e OMS $(\mathrm{WHO}, 2015) . \ldots \ldots \ldots \ldots \ldots$

3.9 Estatística descritiva das concentrações de $M P_{10}$ conjunta (área residencial e avenida) somente para os dias de ocorrência de vento do Harmatão. 54 amostras na área residencial e 59 na avenida . . . . . . . . . . . . . . . . . . 80

3.10 Estatística descritiva das concentrações de $M P_{10}$ conjunta, (Sam Road e Nima Road) excluindo-se os dias do Harmantão. . . . . . . . . . . . . . . . . . . . . 81

3.11 Médias de $M P_{10}$ para o ano de 2007. . . . . . . . . . . . . . . . 81

3.12 Estatística descritiva da área residencial (Sam Road) e avenida (Nima) para

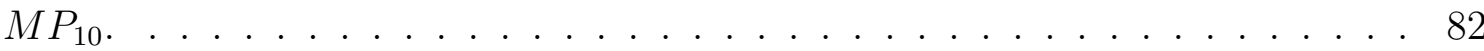


3.13 Médias de $M P_{10}$ para o ano de 2007. . . . . . . . . . . . . . . . . 84

3.14 Estatística descritiva das concentrações de $M P_{2,5}$ conjunta (residencial e avenida) excluindo-se os dias do Harmantão . . . . . . . . . . . . . . . . . . . . . 84

3.15 Médias elementares e média da massa de $M P_{2,5}$ encontradas em Nima e comparadas com outras regiões do mundo: Kwabenya (Aboh et al., 2009), Ashaiman (Ofosu et al., 2012), Cidade do México (Díaz et al., 2014), Cairo (Boman et al., 2013), Pequim (Yang et al., 2011), Nairóbi (Gaita et al., 2014), Brasil ${ }^{d}$ (Miranda et al., 2012), Rijeka (Ivošević et al., 2015) e Córdoba (Achad et al., 2014).

3.16 Estatística descritiva da área residencial (Sam Road) e avenida (Nima) para $M P_{2,5}$.

3.17 Análise de Fatores na área residencial para $M P_{2,5}$ excluindo dias de ocorrência de vento Harmatão. $\mathrm{n}=123$.

3.18 Análise de Fatores na avenida para $M P_{2,5}$ excluindo dias de ocorrência de vento Harmatão. $\mathrm{n}=122$.

3.19 Perfis (\%) do fatores na área residencial $M P_{2,5}$ excluindo dias de ocorrência de

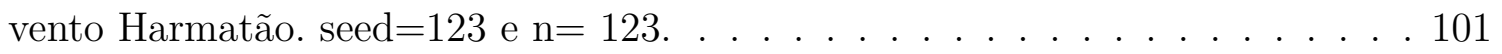

3.20 Perfis (\%) do fatores avenida $M P_{2,5}$ excluindo dias de ocorrência de vento Harmatão. seed $=123$ e $n=122 . \quad \ldots \ldots \ldots$. . . . . . . . . . . . 102

3.21 Análise de Fatores na área residencial para $M P_{2,5-10}$ excluindo dias de ocorrência de vento Harmatão. $\mathrm{n}=112 \ldots$. . . . . . . . . . . . . . . 104

3.22 Análise de Fatores na avenida para $M P_{2,5-10}$ excluindo dias de ocorrência de

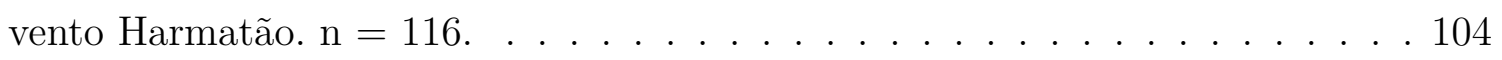

3.23 Perfis (\%) do fatores na área residencial $M P_{2,5-10}$ excluindo dias de ocorrência de vento Harmatão. seed=123 e $n=112 \ldots \ldots$. . . . . . . . . 106

3.24 Perfis (\%) do fatores avenida $M P_{2,5-10}$ excluindo dias de ocorrência de vento Harmatão. seed=123 e $\mathrm{n}=116$.

3.25 Síntese das associações dos fatores extraídos na AF e PMF com fontes polui-

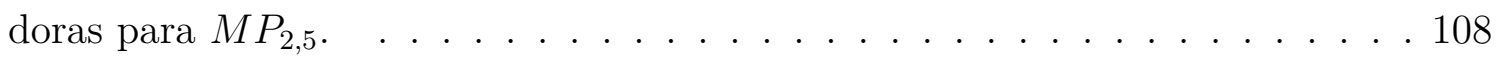

3.26 Síntese das associações dos fatores extraídos na AF e PMF com fontes poluidoras para $M P_{2,5-10} \ldots \ldots \ldots$. . . . . . . . . . . . . . . . . . . . .

3.27 Análise de Fatores na área residencial para $M P_{2,5}$ somente do dias de ocorrência de vento Harmatão. $n=51 . \ldots \ldots$. . . . . . . . . . . . 111 
3.28 Análise de Fatores na avenida para $M P_{2,5}$ somente dias de ocorrência de vento Harmatão. $n=59 . \ldots \ldots \ldots$. . . . . . . . . . . . . . . . . . . .

3.29 Perfis (\%) do fatores para $M P_{2,5}$ na área residencial, somente nos de ocorrência de vento Harmatão. seed=123 e $n=51 . \quad \ldots \ldots \ldots$. . . . . . . . . 112

3.30 Perfis (\%) do fatores na avenida $M P_{2,5}$ somente nos de ocorrência de vento Harmatão. seed=123 e $n=59$. . . . . . . . . . . . . . . . . . 113

3.31 Análise de Fatores na área residencial para $M P_{2,5-10}$ somente dos dias de ocorrência de vento Harmatão. $\mathrm{n}=49$. . . . . . . . . . . . . . . . . . 114

3.32 Análise de Fatores na avenida para $M P_{2,5-10}$ somente dos dias de ocorrência de vento Harmatão. $n=58$. . . . . . . . . . . . . . . . . . . . . . . . . 114

3.33 Perfis (\%) do fatores para $M P_{2,5-10}$ na área residencial, somente nos de ocorrência de vento Harmatão. seed=123 e n=49. . . . . . . . . . . . . . . . . 115

3.34 Perfis (\%) do fatores na avenida $M P_{2,5-10}$ somente nos de ocorrência de vento

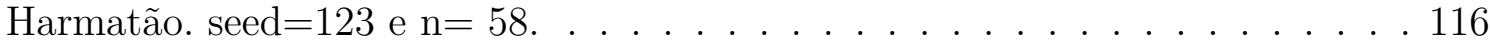

3.35 Síntese das associações dos fatores extraídos na AF e PMF com fontes poluidoras para $M P_{2,5}$ somente para os dias de Harmartão. . . . . . . . . . . . . . 117

3.36 Síntese das associações dos fatores extraídos na AF e PMF com fontes poluidoras para $M P_{2,5-10}$ somente para os dias de Harmartão.

B.1 Análise de Fatores na área residencial para $M P_{2,5}$ incluindo dias de ocorrência

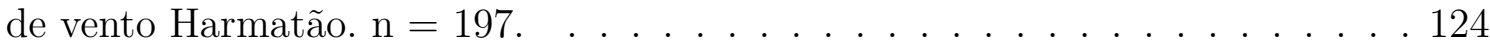

B.2 Análise de Fatores na avenida para $M P_{2,5}$ incluindo dias de ocorrência de vento Harmatão. $\mathrm{n}=200$.

B.3 Análise de Fatores na área residencial para $M P_{2,5-10}$ incluindo dias de ocorrência de vento Harmatão. $\mathrm{n}=183$.

B.4 Análise de Fatores na avenida para $M P_{2,5-10}$ incluindo dias de ocorrência de vento Harmatão. $\mathrm{n}=196$.

B.5 Perfis (\%) do fatores na área residencial $M P_{2,5-10}$ excluindo dias de ocorrência de vento Harmatão. seed=123 e $\mathrm{n}=112$.

B.6 Perfis (\%) do fatores avenida $M P_{2,5-10}$ excluindo dias de ocorrência de vento Harmatão. seed=123 e $n=116$. 


\title{
Lista de Abreviaturas
}

\author{
AF Análise Fatorial \\ BC Black Carbon \\ BQM Balanço Químico de Massa
}

BS Black Smoke

CETESB Companhia Ambiental Do Estado De São Paulo

DVLA Driver and Vehicle Licensing Authority

e-waste Electronic Waste (depósito de lixo eletrônico)

EC Carbono Elementar

ECMWF The European Centre for Medium-Range Weather Forecasts

EPA-GH Ghana Environmental Protection Agency - Agência de Proteção Ambiental de Gana

EUA Estados Unidos da América

FMI Fundo Monetário Internacional

GEPA Grupo de Estudos da Polução do Ar

HSPH Harvard School of Public Health

IAEA Agência Internacional de Energia Atômica

IAG Instituto de Astronomia, Geofísica e Ciências Atmosféricas da USP

IBGE Instituto Brasileiro de Geografia e Estatística

IFUSP Instituto de Física da USP

IPT Instituto de Pesquisas Tecnológicas do Estado de São Paulo 
LAPAt Laboratório de Análise dos Processos Atmosféricos

LD Limite de Detecção

LFA Laboratório de Física Atmosférica

M71 Black Carbon de Referência Monarch 71

MP Material Particulado

$\mathrm{MP}_{10}$ Material Particulado Inalável - diâmetro aerodinâmico menor ou igual à $10 \mu \mathrm{g} / \mathrm{m}^{3}$

$\mathrm{MP}_{2,5-10}$ Material Particulado Grosso - diâmetro aerodinâmico entre 2,5 $\mu \mathrm{g} / \mathrm{m}^{3}$ e $10 \mu \mathrm{g} / \mathrm{m}^{3}$

$\mathrm{MP}_{2,5}$ Material Particulado Fino - diâmetro aerodinâmico menor ou igual à 2,5 $\mu \mathrm{g} / \mathrm{m}^{3}$

MQM Mínimos Quadrados Matricial

NOAA National Oceanic and Atmospheric Administration - United States Department of Commerce

OC Carbono Orgânico

OMS Organização Mundial de Saúde

PIB Produto Interno Bruto

PMF Positive Matrix Factorizarion

PTFE Politetrafluoretileno

RMA Região Metropolitana de Acra

RMSP Região Metropolitana de São Paulo

SSA Sub-Saharan Africa

TOR Thermal Optical Reflectance

TOT Thermal Optical Transmittance

US-EPA US Environmental Protection Agency - Agência de Proteção Ambiental do Estados Unidos

USP Universidade de São Paulo 
WinQxas Quantitative X-Ray Analysis System for Windows

XRF Fluorescência de raios X

XRF-ED Fluorescência de raios X dispersivo em energia

XRF-EDP Fluorescência de raios X polarizada

XRF-T Fluorescência de raios X por reflexão total

XRF-WD Fluorescência de raios X dispersivo em comprimento de onda

ZCIT Zona de Convergência Intertropical 


\section{Conteúdo}

$\begin{array}{lc}\text { Lista de Figuras } & 6\end{array}$

$\begin{array}{ll}\text { Lista de Tabelas } & 9\end{array}$

1 Introdução $\quad 17$

1.1 África Subsariana . . . . . . . . . . . . . . . . . . . . . . 17

1.2 Gana . . . . . . . . . . . . . . . . . . . . . . . 19

1.2.1 Aspectos geográficos . . . . . . . . . . . . . . . . . 19

1.2 .2 Indicadores sociais . . . . . . . . . . . . . . . . . 20

1.3 Região Metropolitana de Acra (RMA) . . . . . . . . . . . . . . . 22

1.3.1 Nima. . . . . . . . . . . . . . . . . . . . 24

1.4 Poluição do $\mathrm{Ar}$. . . . . . . . . . . . . . . . . . . . . . . . . . 25

1.4.1 Material Particulado . . . . . . . . . . . . . . . 25

1.4 .2 Black Carbon . . . . . . . . . . . . . . . . . 27

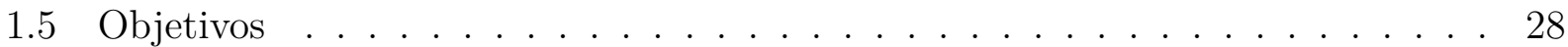

2 Metodologia 30

2.1 Amostragem . . . . . . . . . . . . . . . . . . 31

2.2 Fluorescência de Raios X . . . . . . . . . . . . . . . . . . . . 34

2.2.1 Tipos de XRF . . . . . . . . . . . . . . . . . . 35

2.2.2 Características da XRF-ED utilizada . . . . . . . . . . . . . 37

2.2.3 Calibração do XRF-ED . . . . . . . . . . . . . . . . . . . . . . . . . 39

2.2.4 Incertezas dos ajustes com Mínimos Quadrados Matricial . . . . . . . . 41

2.2.5 Fontes de erro no branco (amostras de controle) . . . . . . . . . . . 42

2.2.6 Integração dos espectros . . . . . . . . . . . . . . . . . . . . 43

2.2.7 Limite de detecção . . . . . . . . . . . . . . . . . . . . . . . . . . 45

2.3 Black Carbon . . . . . . . . . . . . . . . . . . . 47

2.3.1 Refletância . . . . . . . . . . . . . . . . 48 
2.3.2 Thermal Optical Transmittance . . . . . . . . . . . . . . . . . . . 49

2.4 Modelos Receptores . . . . . . . . . . . . . . . . . . . . . . 50

2.4.1 Análise de Fatores . . . . . . . . . . . . . . . . . . . 51

2.4.2 Positive Matrix Factorizarion _ . . . . . . . . . . . . . . 52

3 Resultados e Discussão $\quad 54$

3.1 Calibração da Fluorescência de Raiox X . . . . . . . . . . . . . . . . . . . 54

3.1.1 Comparação interlaboratorial com a US-EPA . . . . . . . . . . 63

3.2 Black Carbon . . . . . . . . . . . . . . . . . 66

3.2.1 Calibração da refletância usando BC Monarch 71 . . . . . . . . . . . 66

3.2.2 Calibração com TOT - Experiência nos túneis Jânio Quadros e Rodoanel 72

3.2.3 Intercalibração de TOT e refletância para Acra . . . . . . . . . . . . 74

3.3 Concentrações Ambientais . . . . . . . . . . . . . . . . . . . . . . . 77

3.3.1 Material Particulado Inalável $M P_{10} \ldots \ldots \ldots$. . . . . . . . 78

3.3.2 Material Particulado Fino $\left(M P_{2,5}\right) \ldots \ldots \ldots$. . . . . . 83

3.4 Meteorologia local e Harmatão . . . . . . . . . . . . . . . . . . . . . . . . . 89

3.5 Identificação das fontes . . . . . . . . . . . . . . . . . . . . . . . 94

3.5.1 Material Particulado Fino $\left(M P_{2,5}\right) \ldots \ldots \ldots \ldots$

3.5.2 Material Particulado Grosso $M P_{2,5-10} \quad \ldots \ldots$. . . . . . . . 103

3.6 Composição elementar da poeira do Harmatão . . . . . . . . . . . . . . . . . . 109

4 Conclusão $\quad 118$

A Apêndice A: Software PMF EPA 5.0 121

B Apêndice B: Outros resultados de PMF e AF 124

$\begin{array}{ll}\text { Bibliografia } & 129\end{array}$ 


\section{Introdução}

\section{1 África Subsariana}

A poluição do ar ambiental nas cidades dos países em desenvolvimento guarda algumas similaridades com as cidades dos países desenvolvidos, pois ambas possuem fontes poluidoras comuns a meios urbanos, dentre as quais se destacam o tráfego intenso veículos automotivos, as indústrias e a geração de eletricidade por usina hidrelétrica ou termelétrica.

No entanto, em cidades de países industrializados tardiamente, soma-se a esta poluição agravantes decorrentes da má distribuição de renda e incapacidade do Estado em atender toda a população nas demandas urbanas por infraestrutura. É o caso, por exemplo, da insuficiência de energia para realização de atividades cotidianas de transporte, iluminação e alimentação. A queima de biomassa para cozimento de alimentos, o uso de querosene para iluminação noturna e a frota veicular velha e com tecnologias ultrapassadas são alternativas encontradas pelas populações para lidar com tal realidade (Brauer et al., 2012).

Os fatores supracitados e a urbanização rápida e descontrolada ocorrida na última década fazem com que cidades da Ásia, África e Oriente Médio possuam os maiores níveis de poluição do ar ambiental do mundo (Brauer et al., 2012). Ainda de acordo com as Nações Unidas (2015), o crescimento da urbanização nestes países é acompanhado da proliferação de favelas e acampamentos nas periferias das cidades, forçando as pessoas a fazerem mais uso de veículos, público ou individual, em distâncias e tempos longos.

A África é o terceiro maior continente em extensão, com área territorial de 30 milhões de quilômetros quadrados, abrigando 54 países independentes. Em 2015, contava com 1,2 bilhões de habitantes, ficando atrás apenas da Ásia, que possuía 4,4 bilhões de habitantes no mesmo ano.

Em relação ao relevo, destaca-se uma barreira natural formada pelo deserto do Saara separando norte e sul, barreira não só geográfica, como social, étnica e econômica, pois o sul, conhecido como África Subsariana (SSA), conta com os países mais pobres do mundo (UN, 
2015).

Os países da SSA iniciaram nas últimas décadas um intenso processo de urbanização e industrialização e são os que atualmente possuem a maior taxa mundial de transição da população rural - ainda predominante - para as cidades (Montgomery, 2008).

Até 2003, nenhuma cidade da SSA possuía sistemas de monitoramento sistemático de poluição do ar. Havia somente medidas esporádicas realizadas por universidades, mas que revelaram concentrações de poluentes altíssimas e acima das recomendados pela Organização Mundial de Saúde (OMS) (Ezzati et al., 2004).

Segundo Aboh et al. (2009) ainda há poucos estudos caracterizando o aerossol atmosférico e suas fontes em países africanos, em especial os da SSA; entretanto, este número vem crescendo, devido ao fato do aerossol atmosférico africano afetar o clima em escala mundial, além dos altos níveis de concentrações encontrados em estudos acadêmicos (esporádicos).

Diferentemente dos países industrializados, onde as principais fontes de poluição são os setores da indústria e do transporte, nos países da SSA a queima de biomassa para preparação de alimentos e a queima de lixo doméstico a céu aberto assumem posição destacada, pois são empregadas tanto em regiões rurais, quanto urbanas, principalmente em bairros pobres, em parte por não disporem de sistema de coleta de lixo frequente ou até mesmo como forma de evitar o pagamento de serviços de coleta (Smith et al., 2004).

Resumidamente, os seguintes fatores ampliam as diferenças entre as cidades da SSA e as dos países industrializados no que diz respeito a efeitos na poluição do ar:

- População predominantemente rural, mas em transição;

- Excesso de vias não pavimentadas, mesmo nos centros das cidades;

- Alta taxa de crescimento populacional, sem a correspondente melhoria na infraestrutura de serviços públicos;

- Emprego de queima de biomassa ou de lixo a céu aberto;

- Inexistência de sistemas de monitoramento de parâmetros ambientais, sistemáticos e em larga escala, realizados por agências de controle. 


\subsection{Gana}

\subsubsection{Aspectos geográficos}

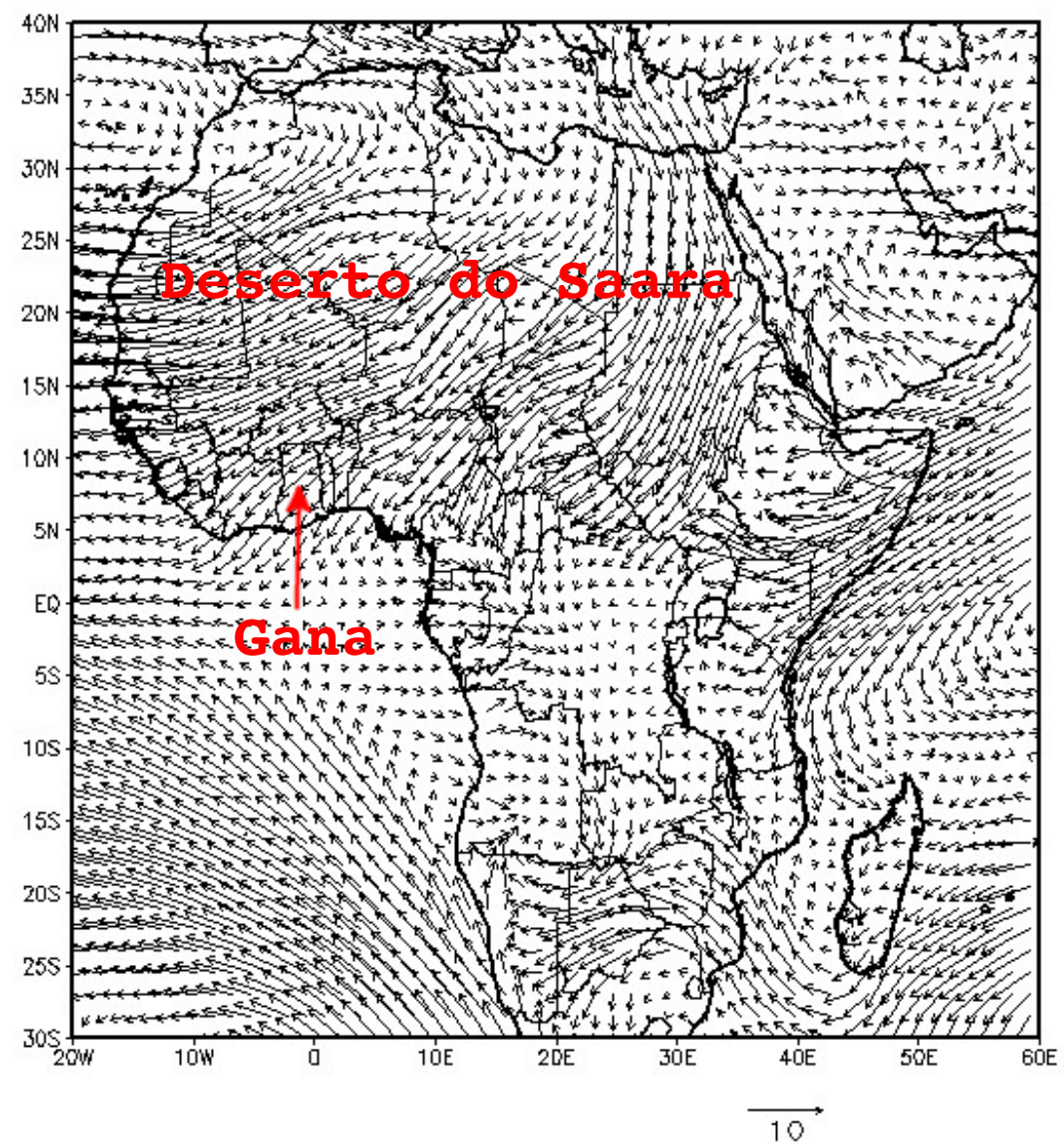

Figura 1.1: Média mensal de direção e intensidade do vento sobre o continente Africano em $875 \mathrm{hPa}$ (aproximadamente $1200 \mathrm{~m}$ ) em janeiro de 2008.

Gana situa-se no continente Africano, na SSA, de 5 à 10 graus no hemisfério norte e faz fronteira com Costa do Marfim a oeste, ao norte com Burkina Faso e a leste com Togo, sendo a costa sul litorânea e voltada para o oceano atlântico. De clima equatorial, possui praticamente duas estações climáticas: entre novembro e março, com ar quente e seco, caracterizada pela chegada de poeira do deserto do Saara, fenômeno conhecido como Harmatão, e a estação chuvosa, entre abril e outubro, com maior intensidade de chuvas entre abril e julho.

O mapa da figura 1.1 posiciona Gana e o deserto do Saara, ao norte, e ilustra a média mensal da direção e intensidade do vento sobre o continente Africano (longitudes -20E à 60E graus e latitudes de $-30 \mathrm{~N}$ à $40 \mathrm{~N}$ graus) durante o mês de janeiro de 2008 em altitude em torno dos 1200 metros em relação ao solo, usando dados de reanálise disponibilizados pela 
European Centre for Medium-Range Weather Forecasts (ECMWF).

O deserto do Saara é considerado a maior fonte de poeira do mundo segundo BreuningMadsen \& Awadzi (2005) e Prospero et al. (2002), sendo o Harmatão um fenômeno que ao espalhar essa poeira por locais onde passa, como Chade, Nigéria, República do Níger, Gana, entre outros, influencia o clima e a poluição do ar na região.

Análises de modelos receptores realizadas tanto neste trabalho quanto em Aboh et al. (2009), Dionisio et al. (2010a), Zhou et al. (2011), Ofosu et al. (2012) e Rooney et al. (2012) mostram que ele representa a principal fonte de partículas de Gana, tanto na fração fina $M P_{2,5}$, quanto na grossa $M P_{2,5-10}$.

\subsubsection{Indicadores sociais}

Os últimos censos demográficos em Gana foram realizados em 2000 e 2010 e publicados em 2003 e 2013, respectivamente. O relatório final, tabelas e gráficos estão disponíveis publicamente no portal de dados abertos do Governo Federal de Gana (Ghana, 2015b).

Em uma década, a população no país teve aumento de $30 \%$, saindo de 18,9 milhões em

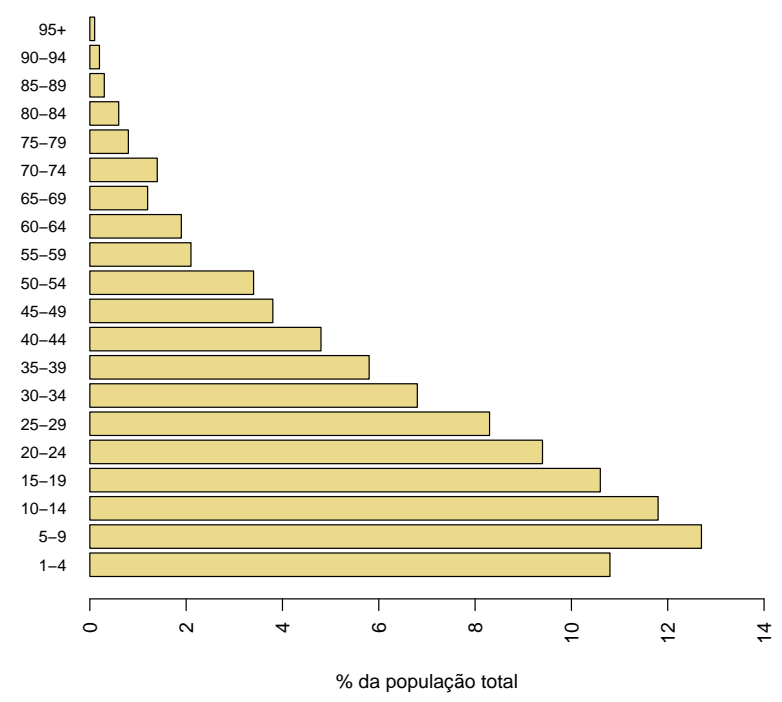

Figura 1.2: Pirâmide etária, Gana 2010. (Ghana, 2013)

serviços 51\%. As indústrias, fabricam e exportam aparelhos digitais, automóveis e navios. Em termos de matéria primária, há significativa exportação de hidrocarbonetos na forma de óleo crú e de minerais, como bauxita, diamantes e manganês (Ghana, 2013).

Apenas como uma base de comparação, o produto interno bruto (PIB) per capita anual de Gana em 2010 foi de $\$ 1,3$ mi USD (United States Dollar) e no Brasil \$ 12 mi USD. O 
gráfico da figura 1.3 apresenta a evolução do PIB per capita brasileiro e ganense nos últimos 50 anos.

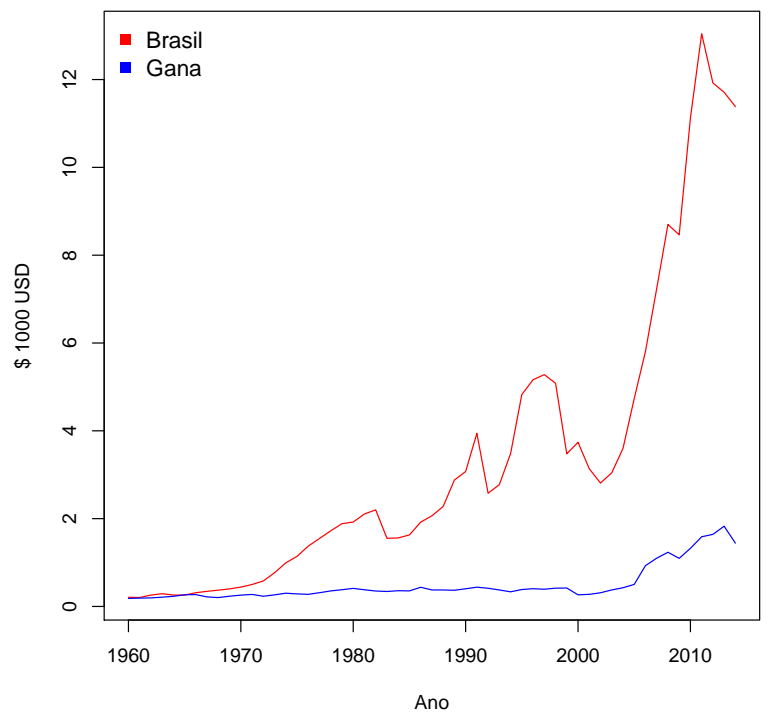

Figura 1.3: Comparação do produto interno bruto (PIB) per capita anual entre Brasil e Gana, Banco Mundial (2015) 


\subsection{Região Metropolitana de Acra (RMA)}

Acra é uma cidade litorânea e está localizada no Golfo da Guiné com área total de mais de $2500 \mathrm{~km}^{2}$ e elevações que variam de 0 até 60 metros do nível do mar. Desenvolveu-se em torno do porto, principal meio de escoamento de ouro e diamante para a Inglaterra durante o período em que era colônia. Em 1957, Gana torna-se independente, e Acra vira a capital do país, modernizando-se rapidamente e adquirindo problemas ambientais comparáveis aos enfrentados pelas cidades de países desenvolvidos.

A Região Metropolitana de Acra (RMA) agrega outras nove cidades e tinha em 2010 população total de 4 milhões de habitantes e densidade populacional de 1205 habitantes $/ \mathrm{km}^{2}$ (Ghana, 2013). A título de comparação, na Região Metropolitana de São Paulo (RMSP) a densidade no mesmo ano era de 2476 habitantes $/ \mathrm{km}^{2}$ segundo Instituto Brasileiro de Geografia e Estatística (IBGE, 2011).

Com economia baseada majoritariamente na indústria e em serviços, 90,5\% da população da RMA está alocada em área urbana (Ghana, 2013). Em 2010 havia somente cerca de 1000 fazendas urbanas, com produção de vegetais e frutas para consumo local (Lente et al., 2014).

O departamento do governo de Gana responsáTabela 1.1: Frota veicular de Gana segundo o Driver and Vehicle Licensing Authority (DVLA) (2015).

\begin{tabular}{cc}
\hline Ano & Veículos \\
\hline 2000 & 511.083 \\
2001 & 567.780 \\
2002 & 613.153 \\
2003 & 643.824 \\
2004 & 703.372 \\
2005 & 767.067 \\
2006 & 841.314 \\
2007 & 841.314 \\
2008 & 1.033 .140 \\
2009 & 1.128 .138 \\
\hline
\end{tabular}

vel pelo licenciamento de automóveis, o Driver and Vehicle Licensing Authority (DVLA), registrou em 2009 cerca de 1,13 milhões de veículos, e conforme observado na tabela 1.1, houve aumento de $120 \%$ da frota na última década. ${ }^{1}$

Além dos veículos legalizados, Gana opera com veículos velhos e mal conservados, muitas dos quais não registradas pelo Governo, trazendo consequências para a qualidade do ar, tendência comum em países em desenvolvimento, que operam frotas com tecnologias ultrapassadas.

Segundo a Ghana Environmental Protection Agency (EPA-GH) as principais fontes poluidoras do ar de Acra são:

\footnotetext{
${ }^{1}$ No site da DVLA não há frota por estados, somente a do país.
} 
- Emissões veiculares, em especial das unidades antigas e sem manutenção frequente;

- Emissões industriais;

- Queima de lixo e outros materiais a céu aberto;

- Poeira de ressuspensão de solo, devido às muitas vias ainda não pavimentadas;

- No inverno, poeira e vento seco do deserto do Saara, trazidos pelo Harmatão.

A queima de lixo a céu aberto representa um problema sério para qualidade do ar em Acra, pois é uma prática largamente empregada pela população a fim de eliminar os resíduos domésticos. Situações como os da figura 1.4, são comuns em bairros pobres como Nima.

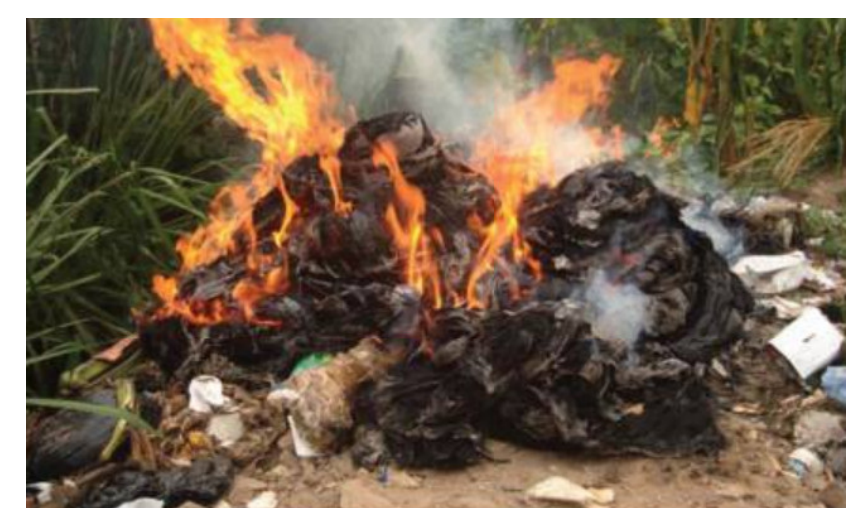

Figura 1.4: Queima de lixo a céu aberto em Nima. Por Raphael Arku (reprodução autorizada pelo autor).

Por fim, Acra é mundialmente conhecida por receber ilegalmente lixo eletrônico de países industrializados, principalmente europeus, que são impropriamente derretidos para a obtenção de cobre pela população local (Asampong et al., 2015). O depósito de lixo eletrônico ou Electronic Waste (e-waste) está localizado no bairro Agbogbloshie, apenas $4 k m$ a sudoeste de Nima, bairro analisado nesta pesquisa. O bromo (Br) compõe plásticos antichama, particularmente em fios, enquanto o zinco (Zn) é o principal composto de baterias de eletrônicos. Altas concentrações de $\mathrm{Al}, \mathrm{Co}, \mathrm{Cu}, \mathrm{Zn}, \mathrm{Cd}$, In, Sb, Ba, e Pb foram encontradas no solo do e-waste de Agbogbloshie por Asante et al. (2012), que também observou altos nível de Fe, Sb, e Pb nas urinas de trabalhadores de Agbogbloshie, em contraste com pessoas de referência (que não tenha tido contato com e-waste). 


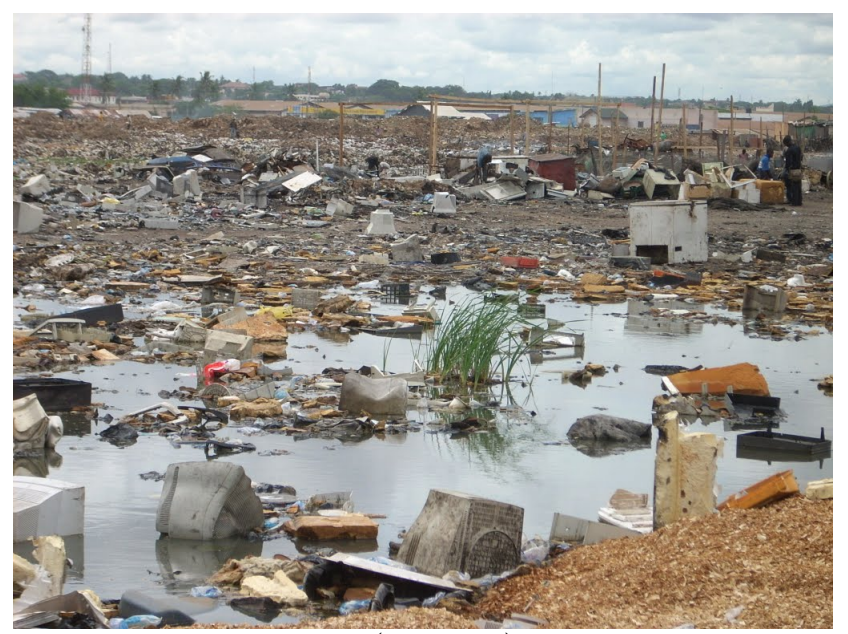

Figura 1.5: Foto do depósito de lixo eletrônico (e-waste) situado no bairro de Agbogbloshie em Acra. Fotografia de Jack Caravanos, Professor da School of Public Health em Hunter College, CUNY Nova Iorque, Estado Unidos da América (reprodução autorizada pelo autor).

\subsubsection{Nima}

Nima é um dos bairros mais pobres de Acra. É formada de assentamentos não planejados, compostos principalmente de migrantes das partes rurais e imigrantes de países vizinhos que buscam oportunidades de empregos na capital, tornado o bairro diversificado cultural e religiosamente. É conhecido por uma feira de comidas típicas permanentemente instalada na região, The Nima Market, que atende a população local e é visitada por turistas que transitam por Acra.

Com moradias extremamente improvisadas e vias não pavimentadas, esse bairro carece de sistema de tratamento de esgoto, fornecimento de água potável e eletricidade. O meio de transporte dos trabalhadores de Nima para a zona industrial e de serviços de Acra é feito por tro-tro (vans, no Brasil), podendo ser vistas na foto 1.6, que também mostra o congestionamento, característico de meios urbanos.

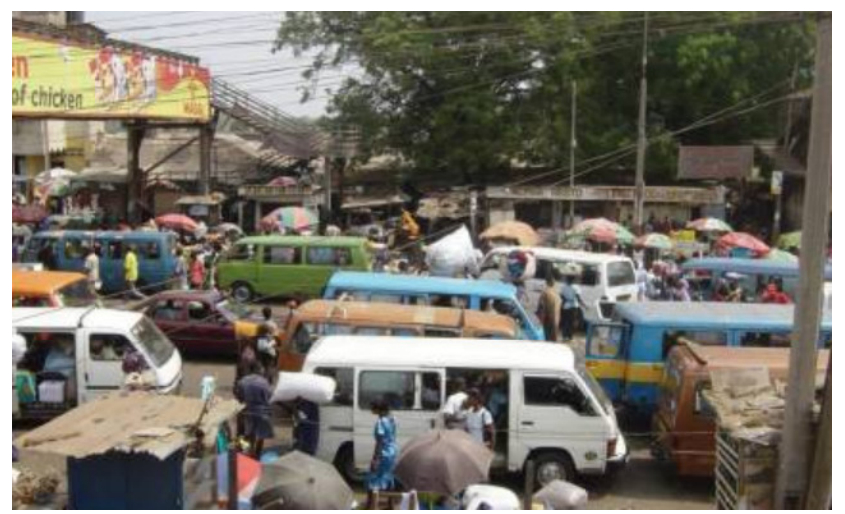

Figura 1.6: tro-tro e congestionamento em Nima. por Raphael Arku (reprodução autorizada pelo autor).

As cozinhas dos moradores de Nima são instalações simples, adaptadas para o uso de 
carvão e lenha, podendo ser observadas nas imagens da figura 1.7.

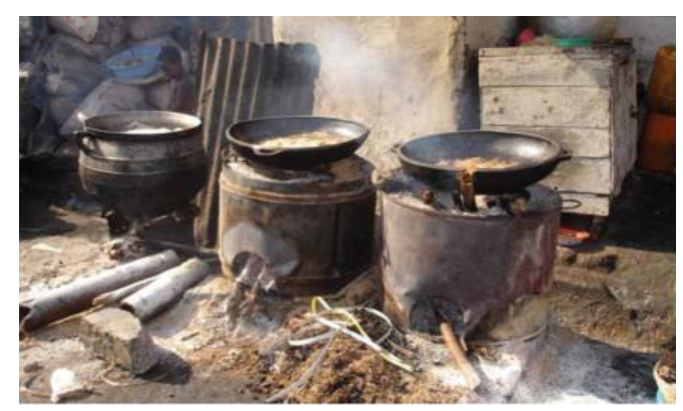

(a) Cozinha residencial em Nima adaptada para o uso de lenha.

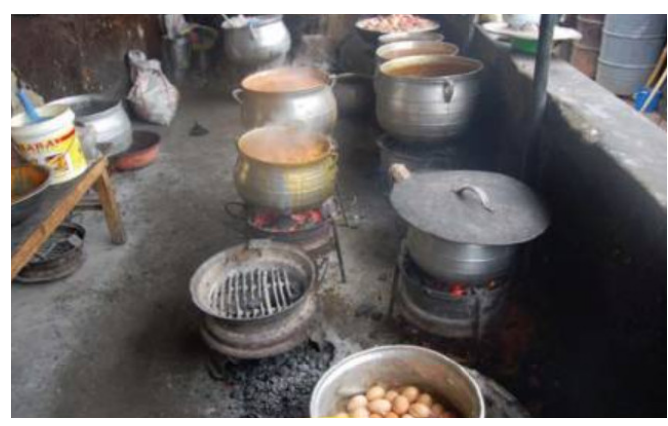

(b) Cozinha de comércio em Nima adaptada para o uso de carvão.

Figura 1.7: Fotos de cozinha residencial e comercial de Nima, por Raphael Arku (reprodução autorizada pelo autor).

\subsection{Poluição do Ar}

Estima-se que a poluição do ar seja responsável por 3,2 milhões de mortes por ano no mundo todo (Lim et al., 2013), sendo as partículas, em especial, as de pequenas dimensões, a oferecem maiores riscos à saúde humana, pois têm maior facilidade de penetração no sistema respiratório.

A poluição do ar ocorre quando gases ou partículas contaminantes, provindas de emissões naturais ou antropogênicas, em suspensão na atmosfera, estão em concentrações que degradam a qualidade do meio ambiente, afetando visibilidade, balanço energético, formação de nuvens ou a saúde humana. Pode causar doenças respiratórias, cardiovasculares, morbidade ou até mortes. Nesta pesquisa, estuda-se somente a poluição causada por partículas, também chamadas de Material Particulado (MP).

\subsubsection{Material Particulado}

Aerossol atmosférico é o conjunto de partículas sólidas, líquidas ou mistas em suspensão em um gás, no caso, a atmosfera, com diâmetro aerodinâmico equivalente compreendido entre 0,001-100 $\mu \mathrm{m}$. A parte considerada inalável por seres humanos tem diâmetro menor que $10 \mu \mathrm{m}$ e se comporta praticamente como um gás, as partículas maiores que $10 \mu m$ têm dificuldade em penetrar no sistema respiratório.

O MP pode ser classificado por tamanho, formação (primária ou secundária), pelas formas de remoção da atmosfera, composição química ou formato geométrico da partículas (Seinfeld \& Pandis, 2012). A figura 1.8 é uma representação clássica das características do MP em função do diâmetro proposta por Finlayson-Pitts \& Pitts Jr (1999) e adaptada para o português por Oliveira (2007), que exemplifica os processos de formação e remoção para cada fração. 
Inicialmente o MP era divido em apenas três modas, as partículas grossas, com diâmetro aerodinâmico $(\phi)$ maior que 2,5 $\mu m$, moda de acumulação $(0,1 \mu m<\phi<2 \mu m)$ e núcleos de Aitken $(0,01 \mu m<\phi<0,1 \mu m)$. Com os avanços tecnológicos das últimas décadas, foi possível detectar um outro grupo de partículas, com processos de formação próprio, nucleação homogênea, e $\phi$ menor que 0,01 $\mu m$, que devido ao tamanho, essa moda ficou conhecida como ultrafinas.

A seguir, estão resumidas, as características de cada moda do MP.

- ultra-finas: formada pela nucleação homogênea de vapores de baixa volatilidade;

- núcleos de Aitken (ou moda de nucleação): gerada especialmente a partir da condensação de vapores quentes, durante o processo de transformação de gás em partícula. São removidas da atmosfera por coagulação;

- moda acumulação: partículas na moda de acumulação são formadas a partir do crescimento das partículas ultrafinas e dos núcleos de Aitken através do processo de coagulação ou por condensação de vapores. São removidas da atmosfera majoritariamente por deposição úmida (especialmente chuva) e deposição seca.

- moda grossa: são oriundas de processos mecânicos como fragmentação, movimentação e manuseio. São removidas da atmosfera por sedimentação.

Nesta pesquisa, foi estudado o material particulado fino $\left(M P_{2,5}\right)$ que engloba as partículas ultrafinas, núcleos de Aitken e moda de acumulação, e o material particulado grosso $\left(M P_{2,5-10}\right)$, com até $10 \mu m$ de diâmetro, pois acima disso não há penetração no sistema respiratório humano. O $M P_{2,5-10}$ tende a sofrer maior retenção nas vias superiores, ficando retido na mucosa do septo do nariz, atigindo ao máximo a nasofaringe, enquanto que $M P_{2,5}$ atinge os alvéolos pulmonares, bronquíolos e a corrente sanguínea, comprometendo trocas gasosas e gerando problemas cardiovasculares. O próprio corpo consegue remover partículas através do macrófago alveolar e do sistema linfático (Arbex et al., 2012).

O MP pode ter origem primária, quando emitido diretamente na atmosfera, ou secundária, quando é convertido através de reações fotoquímicas, químicas ou físico-químicas, como por exemplo na conversão gás-partícula. Processos naturais como ação do vento em solos e rochas, atividades vulcânicas, emissão biogênica (polens), poeira marinha e processos mecânicos gerais realizados por humanos (ex. fuligem, movimentação de veículos) emitem MP na fração grossa. Atividades antropogênicas de combustão e processos industriais, emitem MP na fração fina, que são compostos muitas vezes por espécies tóxicas, como carbono elementar (ou Black Carbon), carbono orgânico, sulfatos $\left(\mathrm{SO}_{4}^{2-}\right)$ e nitratos $\left(\mathrm{NO}_{3}^{-}\right)$(formados secundariamente na atmosfera a partir da reação de amônia $\mathrm{NH}_{3}$ com dióxido de enxofre $\mathrm{SO}_{2}$ e óxido de nitrogênio $N O_{x}$, respectivamente) (Finlayson-Pitts \& Pitts Jr, 1999). 


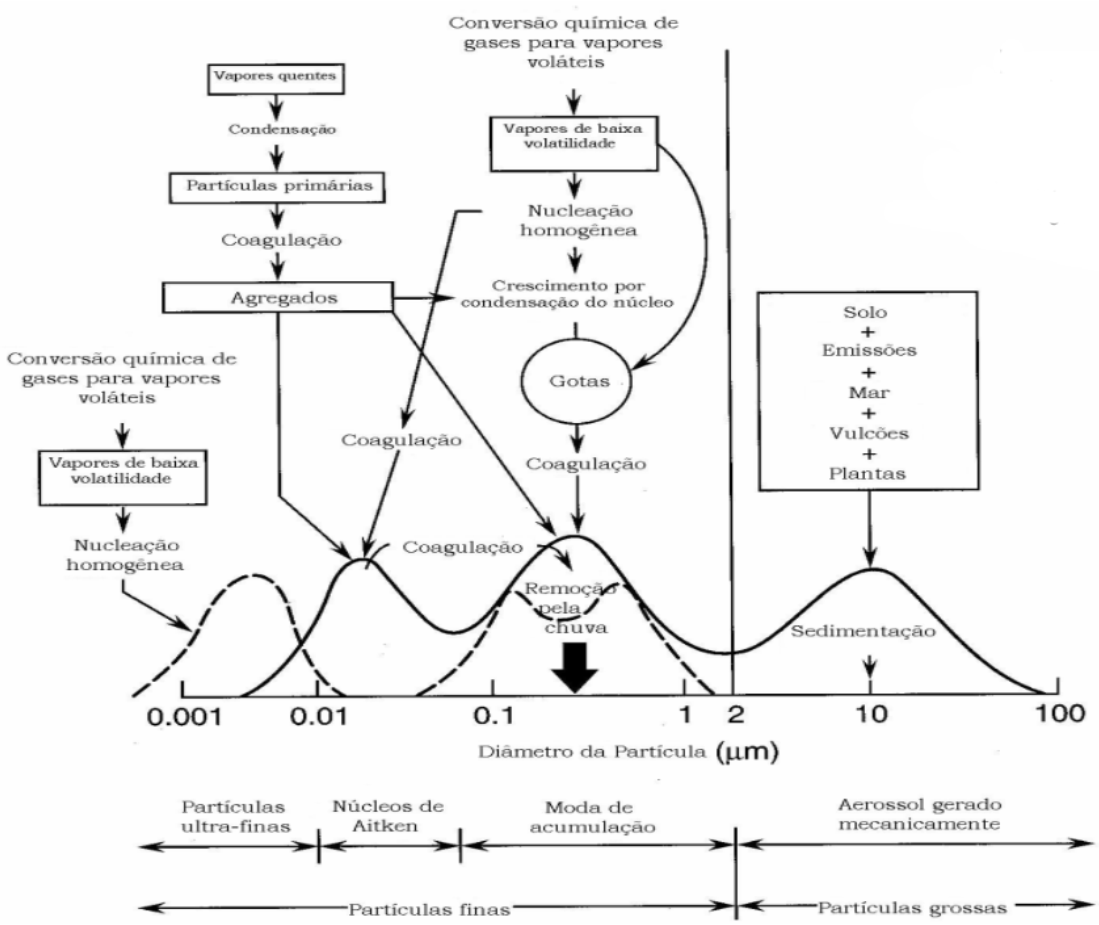

Figura 1.8: Esquema da distribuição de tamanho do aerossol atmosférico proposta por Finlayson-Pitts \& Pitts Jr (1999) e adaptada por Oliveira (2007).

\subsubsection{Black Carbon}

Black Carbon (BC) é um nome genérico dado aos compostos do material particulado constituído de carbono não orgânico absorvedores de luz visível, sendo formado pela combustão incompleta de combustíveis fósseis, biocombustível e biomassa. Na ausência de chuva, reside de 1 a 2 semanas na atmosfera e tem temperatura de vaporização perto de $4000 \mathrm{~K}$, sendo insolúvel em água e solventes orgânicos comuns. Depois do dióxido de carbono é o segundo agente mais importante para mudança climática segundo Bond et al. (2013).

Com diâmetros entre 10 e $50 \mathrm{~nm}$ é encontrado predominantemente na fração fina do material particulado e, dependendo da região, representa mais da metade da massa do $M P_{2,5}$. Por causa do seu pequeno tamanho, o BC pode atingir o trato respiratório inferior e segundo Jacobson et al. (2014) é um dos poluentes ambientais urbanos mais danosos à saúde humana, causando problemas respiratórios, cardiovasculares e morte prematura. Tanto que, desde o início de 1980, a Organização Mundial de Saúde (OMS), reconhecendo os efeitos do BC na saúde humana, formulou as primeiras diretrizes para limites de exposição a BC e, posteriormente, reclassificou-o de provavelmente cancerígeno para cancerígeno (Scovronick et al., 2015).

A OMS realizou uma publicação que traz extensa revisão de efeitos do BC na saúde, discutindo também, em função disso, caracterização das fontes e métodos de medida das 
diferentes formas em que encontramos o carbono orgânico e elementar na atmosfera (Janssen et al., 2012). Destaca-se neste trabalho que as associações do BC com danos à saúde são mais fortes do que com o $\mathrm{MP}_{2}, 5$, reforçando, portanto a importância em medi-lo, nesta perspectiva. Observa, entretanto, que provavelmente são os componentes que vêm agregados ao BC, fruto de seu processo de geração, os promotores desses danos.

Segundo Petzold et al. (2013) sua principal fonte em cidades são veículos automotores, especialmente os movidos a óleo combustível, que geralmente compõem uma fração menor da frota, mas que, em contrapartida, têm maior contribuição para as concentrações totais de BC.

\subsection{Objetivos}

O objetivo desse estudo foi analisar as concentrações ambientais e fontes de material particulado fino e grosso em dois locais de Acra, um com característica residencial e o outro em zona comercial e de alto tráfego de veículos. Para tal, além das coletas dos filtros e posterior análise laboratorial, foram levantados dados econômicos, políticos, sociais, ambientais e meteorológicos do país, que deu suporte na interpretação dos resultados quantitativos, olhando-os sob um prisma crítico e contextualizado, permitindo inclusive comparações com a realidade brasileira no âmbito das causas e consequências atribuíveis à poluição do ar.

Dada a natureza intrinsecamente interdisciplinar do tema, tornando qualquer pesquisa pobre quando realizada isoladamente, envolve minimamente as seguintes áreas de conhecimento: saúde, estatística, física, química, meteorologia e geologia. Assim, a interação entre grupos de pesquisa dessas diferentes áreas é fundamental e largamente empregada pelos que trabalham com o tema.

Na Universidade de São Paulo (USP), o Laboratório de Análise dos Processos Atmosféricos (LAPAt), pertencente ao Instituto de Astronomia, Geofísica e Ciências Atmosféricas (IAG) agrega pesquisadores com reconhecida experiência em medidas de poluentes atmosféricos (gases e partículas) e devido a isto foi procurado em meados de 2010 pela Harvard School of Public Health (HSPH) para compor parceria nesses estudos ambientais em cidades de países em desenvolvimento.

O Dr. Majid Ezzati, à época professor da HSPH e atualmente no Imperial College London, na Inglaterra, estava à procura de um laboratório com competência técnica para analisar, rapidamente e com qualidade, 3000 amostras de teflon com MP coletadas em Gana. Contactou para isso, o Dr. Paulo Saldiva, professor da Faculdade de Medicina da USP. Seu grupo, LAPAE 
(Laboratório de Poluição Atmosférica Experimental) já realizou diversos trabalhos conjuntos com o LAPAt. Dentro de seis meses, medidas de fluorescência de raios X e refletância, foram realizadas em todas as amostras, sendo que destas, as referentes ao bairro de Nima, em Acra, aproximadamente 800, foram objeto de pesquisa desse Mestrado.

Portanto, este estudo, intitulado Análise do Aerossol Atmosférico em Acra, Capital de Gana, faz parte no projeto internacional Energy, air pollution, and health in developing countries coordenado pelo Dr. Majid Ezzati, e é um dos ramos da pesquisa desenvolvida em Gana, focada exclusivamente no bairo de Nima, na capital, e tratará resumidamente dos seguintes tópicos:

- Identificar e quantificar as fontes majoritárias de poluição do ar ambiental em Acra;

- Aperfeiçoar a metodologia numérica empregada na quantificação de elementos químicos, buscando particularmente mais precisão e a determinação consistente das incertezas nos valores medidos;

- Apresentar uma proposta de calibração de medidas de BC por refletância utilizando o método absoluto Thermal/Optical Transmittance TOT.

- Apresentar uma proposta de calibração do equipamento de fluorescência de raios X por dispersão em energia para melhorar a qualidade das medidas;

- Comparar resultados dos métodos estatísticos multivariados Positive Matrix Factorization (PMF) e Análise de Fatores (AF);

- Discussão dos resultados quantitativos face aos aspectos da realidade de Gana, propondo sugestões de como lidar com a questão da qualidade do ar no país, através de medidas viáveis. 


\section{Metodologia}

Neste capítulo, apresenta-se os métodos experimentais utilizados para quantificação das concentrações de massa total, das espécies químicas e do Black Carbon nas amostras. Empregou-se, respectivamente: análise gravimétrica, fluorescência de raios X (XRF), Thermal/Optical Transmittance (TOT) e refletância. Apresenta-se sinteticamente o desenvolvimento teórico de cada método, bem como as condições de uso, procedimentos de calibração, cálculo das incertezas, vantagens e desvantagens, entre outros.

Para resolução dos modelos receptores, expõe-se também os métodos estatísticos Análise de Fatores (AF) e Positive Matrix Factorizarion (PMF) usados na identificação dos perfis de fontes.

Desenvolve-se ainda, uma metodologia para estimativa das incertezas da calibração da XRF e Refletância, fundamentais para análises de PMF, que empregou procedimento matricial baseado na ponderação pelas incertezas. 


\subsection{Amostragem}

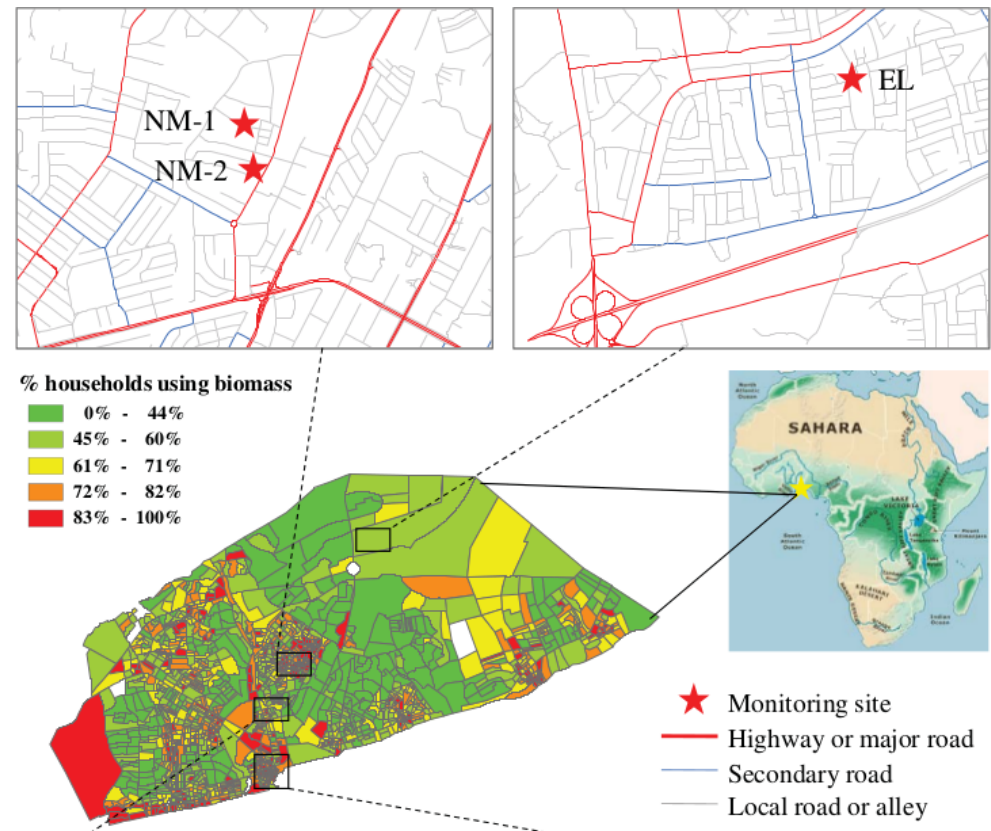

Figura 2.1: Mapa de Nima. NM-1 ponto de amostragem na área residencial e NM-2 ponto de amostragem na avenida. Porcentagem do uso da queima de biomassa para preparação de alimentos em residências usando dados do censo de 2000 (Ghana, 2003). Imagem reproduzida do artigo Zhou et al. (2013).

A localização geográfica dos dois pontos de medição, distantes entre si 330 metros, é apresentada na figura 2.1, sendo NM-1 na rua Sam Road, quarteirão residencial, e NM-2 na Nima Road, via arterial de 2,8 km na direção norte-sul, que direciona o tráfego de pequenas vias locais para o centro, atravessando áreas de comércios variados.

A figura 2.1 permite ter uma ideia de duas fontes importantes de MP na área de amostragem. Primeiramente, o sistema viário que circunda as estações, sendo que boa parte das vias secundárias não são pavimentadas. Oferece, ainda, a densidade de uso de biomassa para cozimento de alimentos nas residências, baseando-se nos dados do censo de 2000. A tabela 2.1 atualiza genericamente esta informação, considerando o censo 2010.

Percebe-se que no período de 10 anos a fração de uso de gás em Acra praticamente dobrou. Saltou de 21,8\% para 41,4\%, enquanto que a soma de carvão vegetal e biomassa crua reduziuse em 21\%, mas representando, ainda, $49 \%$ do total. Permanece, portanto, sendo o principal combustível utilizado no preparo de alimentos.

Aproveitamos aqui para caracterizar também as fontes em torno dos pontos de amostragem, identificados no mapa da figura 2.2, o que acreditamos facilitar a posterior discussão dos resultados de modelos receptores. 


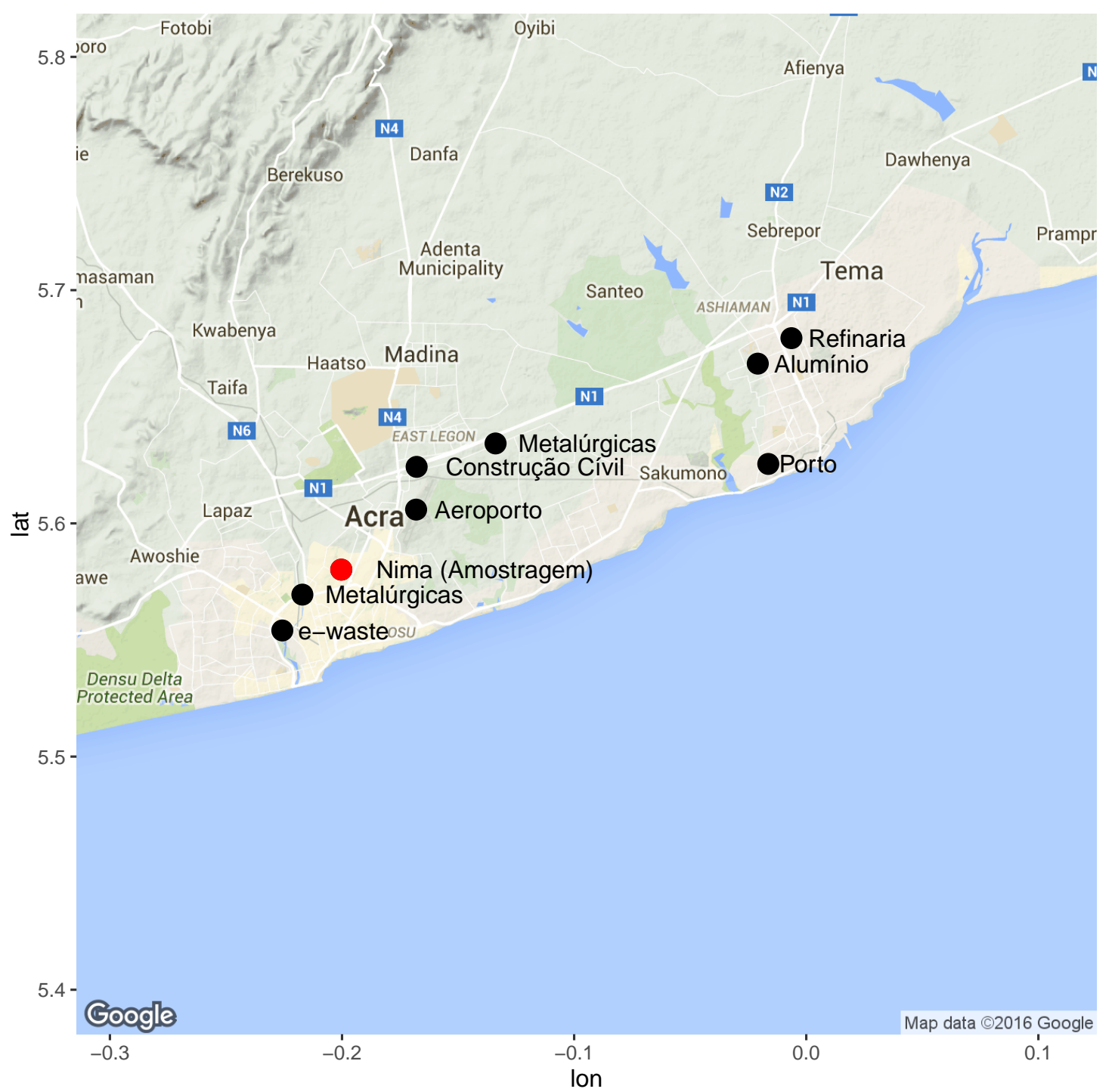

Figura 2.2: Levantamento de algumas fontes poluidora de Acra.

A campanha de coleta ocorreu entre 11 de novembro de 2006 e 15 de agosto de 2008, com amostragens de 48 horas. $\mathrm{O}$ experimento geral tomou 2898 amostras $\left(M P_{10}\right.$ e $\left.M P_{2,5}\right)$, em onze sítios localizados em quatro bairros diferentes. Deste total, 879 amostras referem-se ao bairro de Nima, tendo sido descartadas 67 devido a comprometimento por avarias como: falta de eletricidade, problemas com amostrador, contaminação na manipulação, ausência do operador no horário correto das trocas, dentre outros.

As amostras foram coletadas em filtro de composição de politetrafluoretileno (PTFE) com diâmetro de $37 \mathrm{~mm}$ e poros de 0,2 $\mu \mathrm{m}$. A área média de deposição, $7,32( \pm 0,44) \mathrm{cm}^{2}$, foi calculada medindo-se a mancha de deposição com um leitor de espectros (nônio de centésimos de $\mathrm{mm})$, sobre 12 filtros amostrados.

Para coleta do MP, utilizou-se amostradores Harvard descritos por Marple et al. (1987). Neste equipamento a seleção do diâmetro das partículas admitidas no amostrador é feita por 
impactação inercial. Para coleta de $M P_{10}$, o $D_{50}$ do sistema era de $10 \mu m$, com fluxo de 4,0 $\mathrm{L} / \mathrm{min}$, enquanto que para $M P_{2,5}$, o $D_{50}$ era de $2,5 \mu \mathrm{m}$, com fluxo de 5,0 L/min, medido com $10 \%$ de precisão.

Filtros brancos de campo e de laboratórios foram separados para avaliar possíveis contaminações de fábrica ou de manipulação das amostras.

Os filtros foram pesados no laboratório da HSPH em balança microanalítica (Mettler Toledo MT5) com precisão de $1 \mu \mathrm{g}$, e ambiente controlado, isto é, umidade (39 $\pm 2 \%$ ), temperatura $\left(20,5 \pm 0,2^{\circ} C\right)$ e eliminação de cargas eletrostáticas com fonte de polônio. Os filtros permaneciam ao menos 24 horas na sala antes da pesagem, calculando-se a média de duas pesagens que não diferissem por mais que $5 \mu \mathrm{g}$.

Tabela 2.1: Percentual relativo dos tipos de fontes de energia usadas para preparação de alimentos em Gana (2013).

\begin{tabular}{llrrr}
\hline \multicolumn{1}{c}{ Tipo da } & \multicolumn{2}{c}{ Gana } & (todo país) & \multicolumn{3}{c}{ Acra } \\
fonte de energia & 2000 & 2010 & 2000 & 2010 \\
\hline não cozinha & 3,5 & 5,60 & 4,8 & 6,90 \\
biomassa & 55,8 & 40,20 & 8,8 & 3,50 \\
gás & 6,2 & 18,20 & 21,8 & 41,40 \\
eletricidade & 1,1 & 0,50 & 2,2 & 0,90 \\
querosene & 2 & 0,50 & 4,3 & 1,10 \\
carvão & 30 & 33,70 & 57,3 & 45,40 \\
resíduo de plantação & $*$ & 0,80 & $*$ & 0,10 \\
pó de serra & $*$ & 0,10 & $*$ & 0,30 \\
esterco & $*$ & 0,00 & $*$ & 0,10 \\
outros & 1,1 & 0,10 & 0,8 & 0,30 \\
\hline
\end{tabular}




\subsection{Fluorescência de Raios X}

Para quantificar a composição elementar $(10<\mathrm{Z}<83)$ das amostras foi utilizada a técnica não-destrutiva de Fluorescência de Raios X (XRF), um método analítico quali-quantitativo, multielementar, que mede os raios $\mathrm{X}$ característicos emitidos pelos átomos da amostra, depois de também serem excitados por raios X. Permite análise simultânea dos elementos químicos e não exige pré-tratamento dos alvos.

Há basicamente três etapas envolvidas na técnica de medida de raios X característicos: excitação da amostra, emissão de raios X pelos átomos da amostra e detecção. A excitação pode ocorrer por feixe de raios $\mathrm{X}$ (ou raios gamas) produzido em fontes radioativas, por partículas aceleradas (elétrons, prótons, alfas etc) ou por tubos geradores de raios X quando submetidos a diferença de potencial (Jenkins, 1988).

No caso da XRF, a excitação ocorre por um feixe de raios $\mathrm{X}$ incidente, que expulsa os elétrons das camadas mais internas do átomo (K, L e M) produzindo vacâncias. Para tal, a energia do feixe incidente deve ser maior que a energia de ligação dos elétrons nessas camadas. Um átomo com vacância é instável e rapidamente elétrons das camadas mais externas preenchem as vacâncias, liberando fotóns e estabilizando o átomo, sendo a energia destes fótons correspondentes às energias de transição entre camadas do átomos, característica de cada elemento químico. O processo de excitação do átomo é ilustrado classicamente na figura 2.3 .

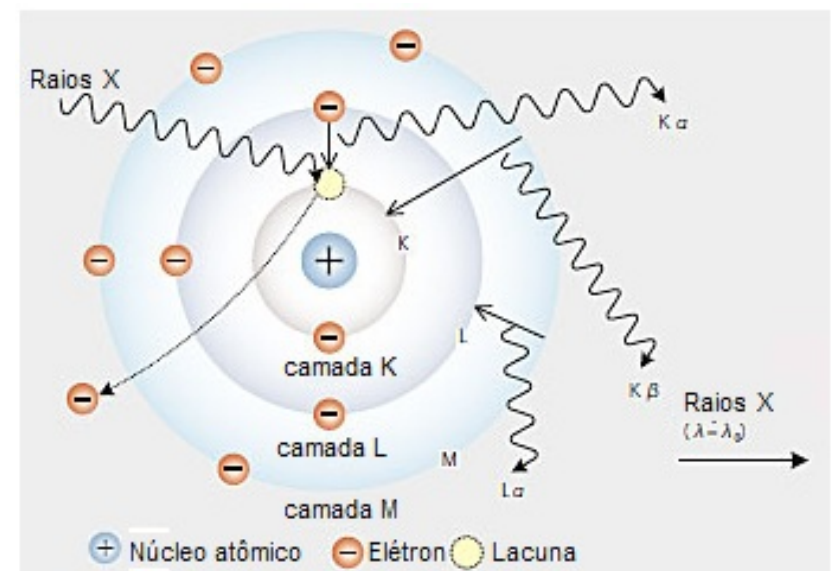

Figura 2.3: Ilustração clássica do fenômeno de fluorescência de raios X no átomo. Figura que acompanha o manual da Shimadzu da série de equipamentos EDX 700.

As transições dos elétrons entre os níveis quânticos K, L e M encontram-se tipicamente na faixa dos raios X, tendendo a ultravioleta (UV) e luz visível, conforme ocorram em transições atômicas de menor energia no átomo.

Transições da camada L para $\mathrm{K}$ são do tipo $K_{\alpha}$, de M para K são $K_{\beta}$ e de M para L são 
$L_{\alpha}$ ou $L_{\beta}$. As camadas L e M possuem ainda subníveis de energia, o que resulta em diversas combinações de transições, sendo algumas delas proibidas, e outras com diferenças de energia indistinguíveis para os detectores utilizados neste método analítico (XRF-ED).

As principais transições possíveis estão sintetizada na figura 2.4, segundo a notação desenvolvida por Siegbahn (Jenkins et al., 1991). A referida notação, permite identificar melhor os subníveis de origem e destino, por exemplo, a transição de $M_{I V}$ para $L_{I I I}$ é uma transição do tipo $L_{\beta_{1}}$.

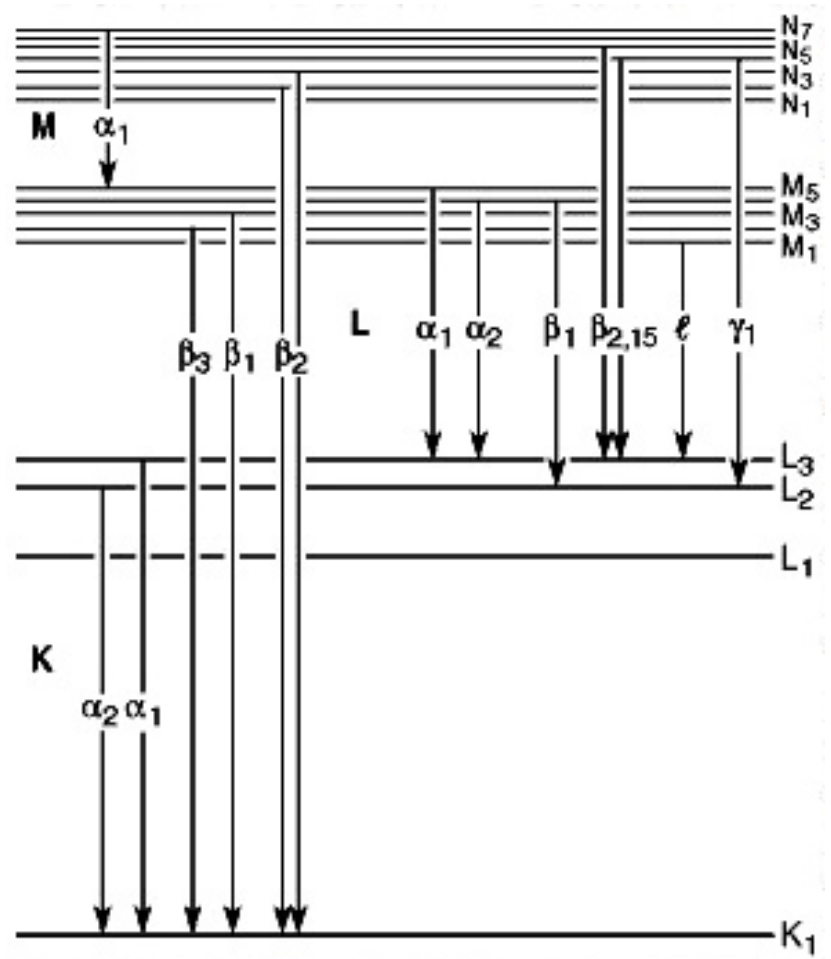

Figura 2.4: Transições de elétrons entre os subníveis das camadas K, L e M. Figura extraída de Jenkins et al. (1991).

Na prática, dependendo do modo de detecção dos raios X, agrupa-se transições dos subníveis e trabalha-se com as denominações de linhas $\mathrm{K}$ e L apenas. As linhas $K_{\alpha}$ são as mais intensas, oferecendo melhor limite de detecção para um elemento, mas quando muito energéticas, podem ultrapassar a faixa de sensibilidade do detector empregado. Nestes casos as linhas L passam a ser analisadas. No modelo de XRF usado nesta pesquisa, analisou-se as linhas K, desde o sódio $(\mathrm{Na})$ até o nióbio $(\mathrm{Nb})$, e as linha $\mathrm{L}$, do molibdênio (Mo) até o chumbo (Pb).

\subsubsection{Tipos de XRF}

Há essencialmente dois tipos principais de equipamentos de XRF que se diferenciam pelo modo como os raios X são detectados: fluorescência de raios $\mathrm{X}$ dispersivo em comprimento de onda (XRF-WD) e fluorescência de raios X dispersivo em energia (XRF-ED). 
Na XRF-WD os raios X da amostra sofrem difração em um cristal, quantificando-se os elementos químicos pela contagem de fótons nos ângulo de difração $\theta$, característicos dos elementos, segundo a lei de Bragg:

$$
2 d \operatorname{sen}(\theta)=n \lambda
$$

Onde, $d$ é 1a distância entre planos do cristal, $\theta$ o ângulo de incidência em relação ao plano considerado, $\lambda$ o comprimento de onda (e, portanto, a energia) da radiação incidente e $n$ um inteiro. Esse tipo de equipamento permite uma grande resolução dos comprimentos de onda (energia) característicos dos elementos, facilitando detectá-los e, geralmente, com bom limite de deteç̧ão (LD). Entretanto, apresentam diversos problemas práticos quando empregados em filtros de aerossol atmosférico. Em função disso há uma preferência pelos sistemas dispersivos em energia nesse campo de análise.

A XRF-ED usa detectores de semicondutores capazes de discriminar energias próximas com alta resolução temporal, viabilizando a detecção simultânea dos elementos químicos através da amplitude do pulso eletrônico produzido no detector, proporcional à energia do fóton incidente. O sistema eletrônico do equipamento faz a conversão analógica-digital da intensidade do pulso, acumulando a contagem por energia em um multicanal. O detector mais empregado é o de silício ativado com lítio $\mathrm{Si}(\mathrm{Li})$.

Neste sistema, o LD das análises é particularmente limitado pelos raios X de excitação que sofrem reflexão na amostra e também chegam ao detector. Formam assim uma contagem de fundo (background) que concorre com aquela proveniente dos picos característicos. Fluorescência de raios X polarizada (XRF-EDP) e fluorescência de raios X por reflexão total (XRF-T) são dois sistemas que têm sido empregados para reduzir o background e melhorar significativamente o LD.

Na XRF-EDP, excita-se a amostra com raios X polarizados e se ajusta o ângulo de detecção a $90^{\circ}$ deste feixe (Dzubay et al., 1974). Nesta direção a reflexão do feixe incidente polarizado é pequena, obtendo-se grande redução na intensidade do fundo e, consequentemente, no LD, tipicamente de fator 2 a 10 dependendo do elemento e das condições de irradiação comparadas (Meel, 2009).

A XRF-T emprega a propriedade da radiação eletromagnética incidente abaixo do ângulo crítico sobre uma superfície. Incidindo-se um feixe que resvale a amostra com um ângulo bem pequeno, este excitará uma fina camada da superfície, penetrando muito pouco no suporte. Desta forma um detector posicionado perpendicularmente à superfície receberá muitos fótons 
característicos gerados pela amostra e pouco fundo refletido no suporte, melhorando o LD (Yoneda \& Horiuchi, 1971) e (Aiginger \& Wobrauschek, 1974).

\subsubsection{Características da XRF-ED utilizada}

Neste trabalho foi utilizado uma XRF-ED da marca Shimadzu modelo EDX 720HS, apresentado na figura 2.5, pertencente ao Laboratório de Poluição Atmosférica Experimental (LAPAE) da Faculade de Medicina da USP e instalado no LAPAt.

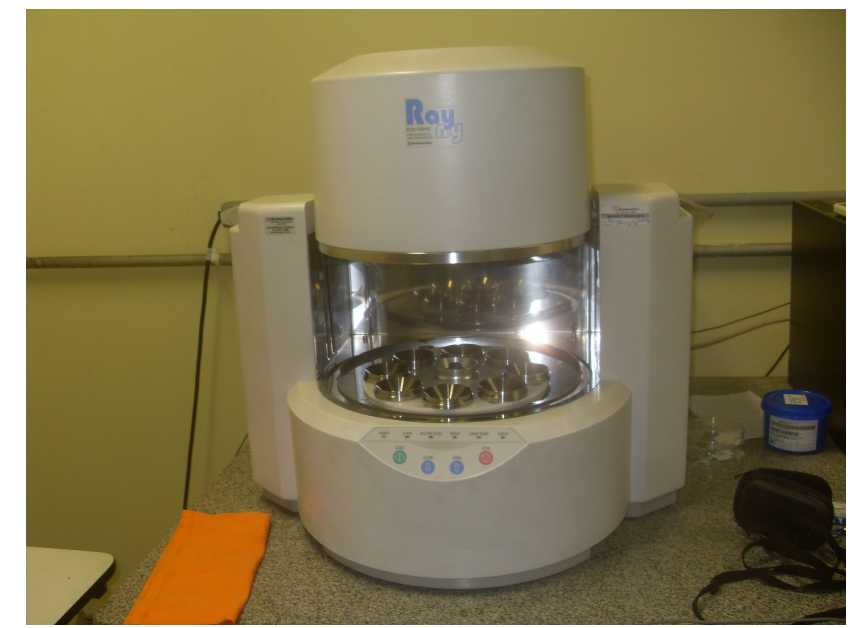

Figura 2.5: XRF-ED Shimadzu modelo EDX 720HS - LAPAt.

Um tubo de ródio (Rh) submetido a uma diferença de potencial de $50 \mathrm{kV}$ foi utilizado para geração do feixe de raios X. O detector de silício ativado com lítio $\mathrm{Si}(\mathrm{Li})$ possui sensibilidade para medida de fótons com energia entre 1 e $20 \mathrm{keV}$ acoplado a um sistema eletrônico com multicanal de 2048 canais capaz de quantificar simultaneamente os elementos desde o Na até o Pb. Para remoção da radiação da linha $\mathrm{L}$ do feixe de raios $\mathrm{X}$ do tubo de ródio, de energia próxima de 2,6 keV, um filtro de alumínio foi posto entre o feixe e a amostra, melhorando o limite de detecção dos elementos com energia igual ou menor que 2,6 keV. O diâmetro do feixe de raios X é definido por um colimador de $10 \mathrm{~mm}$, garantindo a irradiação de uma área representativa e homogênea da amostra.

O tempo vivo, quando o detector está de fato contando os fotóns incidentes, foi cerca de 960 minutos, ajustou-se a corrente para manter o tempo morto em 20\%. Desejava-se desta forma fixar a taxa de contagem, obtendo-se ao final o mesmo número total de fótons contados em cada espectro. Esse mecanismo permite melhorar o LD dos elementos presentes em amostras menos carregadas. Isso nem sempre foi possível já que a corrente máxima no tubo gerador de raios $\mathrm{X}$ era de $1000 \mu \mathrm{A}$.

A figura 2.6 foi extraída do software que acompanha o equipamento da Shimadzu e permite 
verificar em tempo real características da análise como a voltagem e corrente no tubo, presença e tipo de filtro, informação sobre o vácuo na câmera, dentre outros dados que ajudam no acompanhamento da análise.

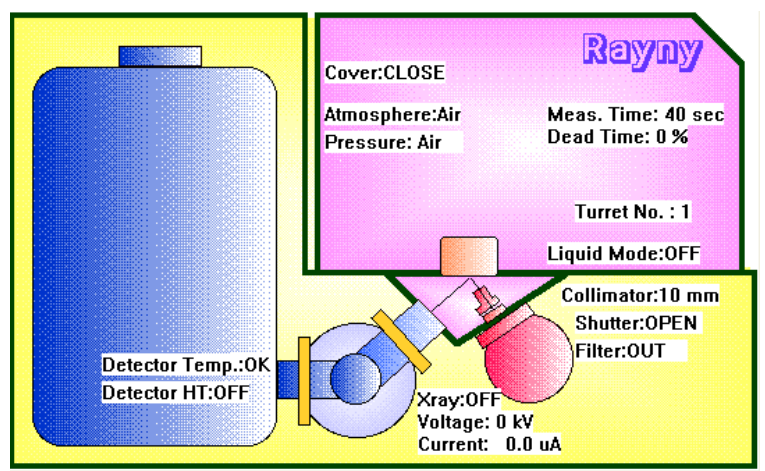

Figura 2.6: Software da XRF-ED Shimadzu 720HS, tela de verificação do estado do equipamento.

O EDX 720HS permite análise automática de amostras encaixadas em carrosséis de 8 ou 16 posições. O LAPAt contava então apenas com o carrossel de 16 posições. Foi necessário adquirir um com 8 posições, cujos receptáculos admitiam o maior diâmetro dos filtros de PTFE, que não podem ser cortados e remontados como os de policarbonatos (figura 2.7). A troca do carrossel implicou na necessidade de se realizar nova curva de calibração no XRF-ED.

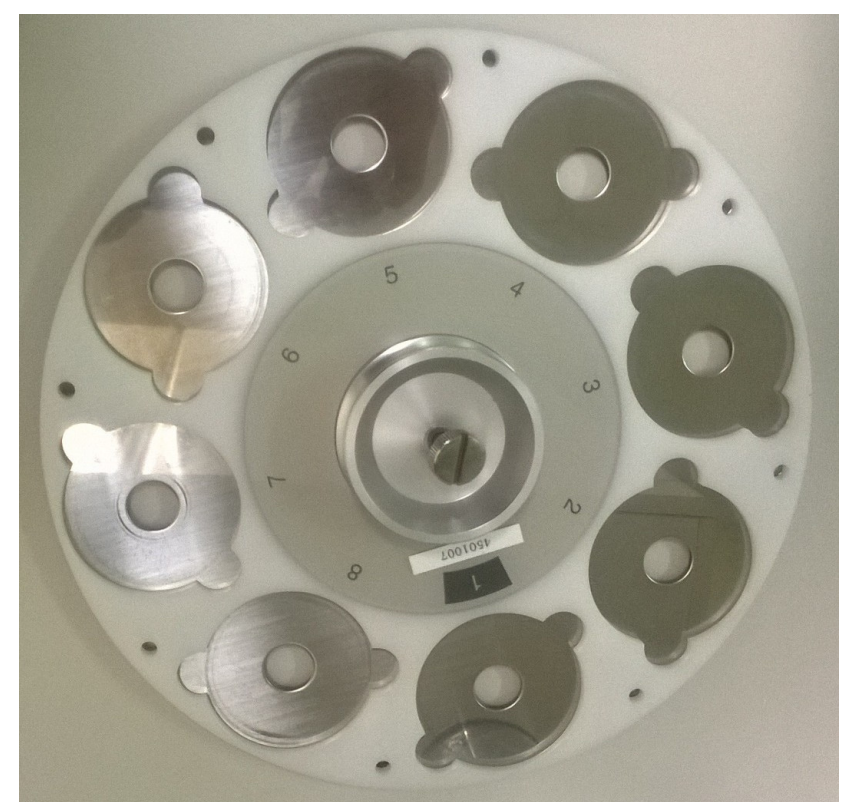

Figura 2.7: Carrossel de 8 posições adquirido para XRF-ED Shimadzu 720HS.

Para eliminar as ondulações típicas que ocorrem nos filtros de PTFE, projetou-se um suporte de aço inox que comprimia sua moldura, mantendo plana a superfície a ser analisada. Ao mesmo tempo, o peso deste suporte impedia que o filtro voasse quando era feito ou quebrado o vácuo na câmera (figura 2.8). 


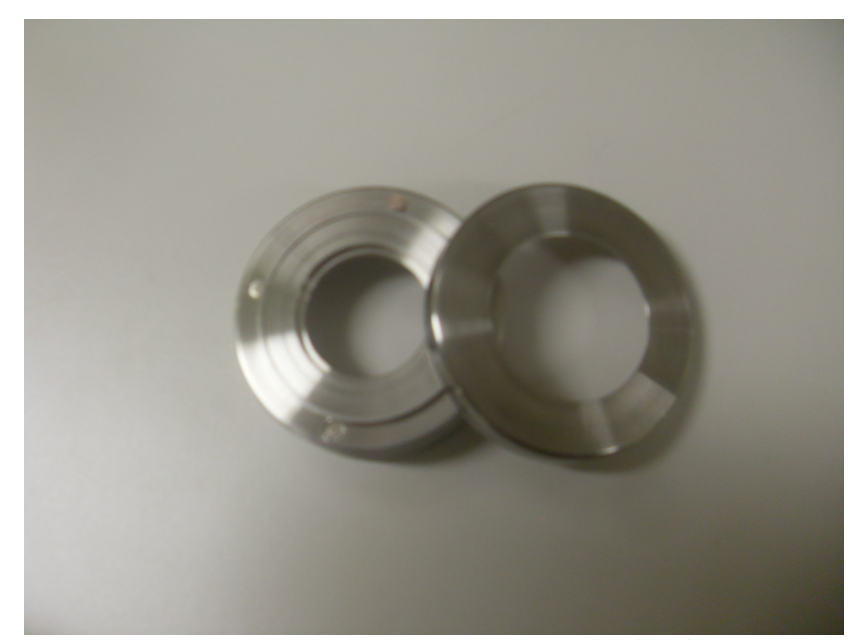

Figura 2.8: Suporte para filtros de PTFE, projetado no LAPAt para carrossel de 8 posições e produzido pela oficina do Departamento de Física Aplicada do Instituto de Física da USP.

\subsubsection{Calibração do XRF-ED}

A massa por unidade de área, depositada sobre os filtros tipicamente usados em pesquisas de aerossol atmosférico, permite tratá-los como amostras finas, ou seja, o efeito de matriz, interações dos raios X característicos com os elementos das amostras causando absorção ou reforço do número de fótons de raios $\mathrm{X}$ característicos, são pequenos diante da precisão do método, podendo desconsiderá-lo. Nesta aproximação, pode-se relacionar de modo simples o número de fótons contados sob o pico característico de um elemento, presente no espectro obtido, com a sua massa na amostra irradiada:

$$
N(Z)=R(Z) \cdot I \cdot \Delta t \cdot \frac{m(Z)}{A}
$$

Onde $\mathrm{R}(\mathrm{Z})$ é chamado de fator de resposta, I é a corrente de excitação do tubo de raios $\mathrm{X}$, determinando, portanto, o fluxo de raios $\mathrm{X}$ que chegam à amostra, $\Delta t$ é o tempo vivo de irradiação e m(Z)/A é a densidade superficial (massa por unidade de área) dos elementos Z presentes na amostra. Pressupõe-se distribuição uniforme da massa na superfície do filtro.

O termo $R(Z)$ depende da seção de choque de cada elemento com o feixe de raios $\mathrm{X}$ incidente (incluindo modificações por eventuais filtros moduladores de suas características), da curva de eficiência do detector de raios X, da eficiência de operação do tubo de raios X e da geometria do sistema, incluindo os diâmetros de colimadores selecionados. Mantendo estes parâmetros fixos e irradiando alvos padrões com densidades $(\mathrm{d}(\mathrm{Z})=\mathrm{m}(\mathrm{Z}) / \mathrm{A})$ conhecidas, pode-se calcular $\mathrm{R}(\mathrm{Z})$ :

$$
R(Z)=\frac{N(Z)}{d(Z) \cdot I \cdot \Delta t}
$$


Considerando que a incerteza da corrente e do tempo vivo são desprezíveis perto da incerteza da densidade e da contagem, a incerteza no fator de resposta pode ser calculada por propagação de erro destas variáveis:

$$
\sigma_{R(Z)}^{2}=R(Z)^{2} \cdot\left[\left(\frac{\sigma_{N(Z)}}{N(Z)}\right)^{2}+\left(\frac{\sigma_{d(Z)}}{d(Z)}\right)^{2}\right]
$$

Dados ambientais são reportados em medidas de concentração $\left(\mu g / m^{3}\right)$, razão da massa $\mathrm{m}(\mathrm{Z})$ pelo volume amostrado. Conhecendo o fator de resposta $\mathrm{R}(\mathrm{Z})$ pode-se calcular a massa $\mathrm{m}(\mathrm{Z})$ depositada na amostra, usando a equação 2.2, tomando como valor da área A aquela da deposição de aerossol no filtro:

$$
m(Z)=\frac{N(Z) \cdot A}{R(Z) \cdot I \cdot \Delta t}
$$

Empregando novamente a expressão da propagação de erro para variáveis independentes, a incerteza na massa será:

$$
\sigma_{m(Z)}^{2}=m(Z)^{2}\left[\left(\frac{\sigma_{N(Z)}}{N(Z)}\right)^{2}+\left(\frac{\sigma_{A}}{A}\right)^{2}+\left(\frac{\sigma_{R(Z)}}{R(Z)}\right)^{2}\right]
$$

Vê-se, entretanto, que para cada espécie química de interesse, seria necessário ao menos um alvo de calibração para calcular seu R(Z). Alvos padrões finos, com densidade elementar conhecida, podem ser comprados ou produzidos, dependendo da precisão desejada. Neste projeto foram adquiridos alvos padrões da Micromatter, com incerteza nominal de 5\%. Mas esta empresa não produz alvos com proporção estequiométrica quantificada para todas espécies químicas. Assim, trouxemos para a XRF-ED a metodologia usado por Tabacniks (2000) no sistema PIXE (Particle Induced X-Ray Emission) do IFUSP, na qual levanta-se uma curva de calibração a partir de fatores de respostas medidos com alvos padrões.

Adotou-se, ainda, uma metodologia estatística robusta para estimativa das incertezas da calibração usando MQM. Essa preocupação em definir adequadamente as incertezas deve-se, particularmente, ao fato de que elas ponderam o peso das variáveis na modelagem por PMF.

Como exemplo para conhecer a forma da curva de calibração, o gráfico da figura 2.9 apresenta os R(Z) dos alvos padrões da Micromatter irradiados em maio de 2010. 


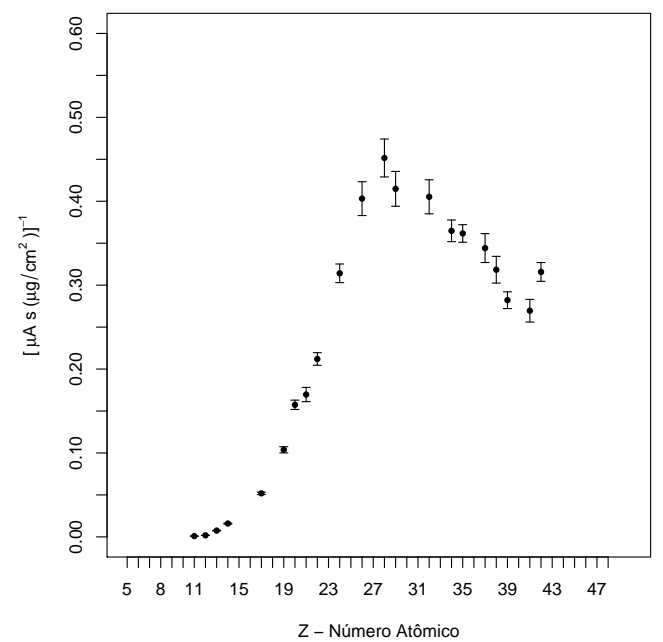

(a) linha $\mathrm{K}$

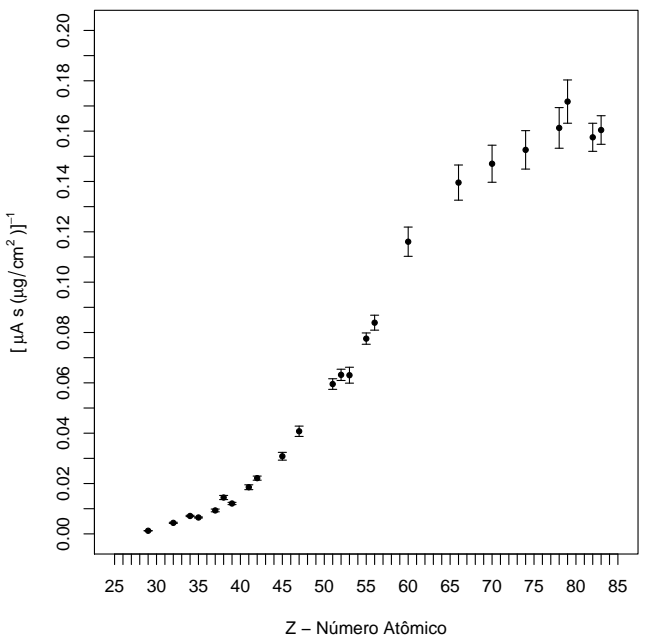

(b) linha L

Figura 2.9: Fatores de respostas, $\mathrm{R}(\mathrm{Z})$, para alvos padrões da Micromatter irradiados em maio de 2010.

Nota-se que é possível fazer um ajuste polinomial sobre esses dados, o que tanto melhora a precisão para todos os $\mathrm{R}(\mathrm{Z})$, quanto fornece seu valor para elementos que não possuem alvos padrões. O fator de resposta reflete o arranjo experimental, mudanças físicas nesse arranjo alteram o valor de $\mathrm{R}(\mathrm{Z})$, assim como a progressiva fadiga do detector ou do tubo. Portanto, a calibração deve ser realizada periodicamente.

\subsubsection{Incertezas dos ajustes com Mínimos Quadrados Matricial}

As incertezas dos ajustes polinomiais das calibrações do XRF-ED e da intercalibração de TOT e refletância de BC foram estimadas com o método Mínimos Quadrados Matricial (MQM) desenvolvida por Helene (2006) e parcialmente reproduzida a seguir (com adaptações).

Dadas as variáveis $Y_{i}$ e $X_{i}$ relacionadas polinomialmente:

$$
\begin{aligned}
& y_{1}=a+b x_{1}+c x_{1}{ }^{2}+d x_{1}{ }^{3}+\ldots \\
& y_{2}=a+b x_{2}+c x_{2}{ }^{2}+d x_{2}{ }^{3}+\ldots
\end{aligned}
$$

ou na forma matricial:

$$
[Y]=[A][X]
$$

Os coeficientes $[\mathrm{A}]$ ajustados, identificados por $[\tilde{\mathrm{A}}]$, são dados por: 


$$
[\tilde{\mathrm{A}}]=\left[V_{\tilde{\AA}}\right] \cdot\left([X]^{T}\left[V_{Y}\right]^{-1}[Y]\right)
$$

Sendo $\left[V_{\AA}\right]$ a matriz de covariância dos coeficientes, dada por:

$$
\left[V_{\tilde{\AA}}\right]=\left([X]^{T}\left[V_{Y}\right]^{-1}[X]\right)^{-1}
$$

A partir dos coeficientes ajustados $[\tilde{A}]$ na equação 2.9 , pode-se calcular os $[\tilde{Y}]$ ajustados,

$$
[\tilde{Y}]=[\tilde{A}][X]
$$

A diagonal da matriz de covariância de $[\tilde{Y}],\left[V_{\tilde{Y}}\right]$, representa a incerteza dos valores ajustados:

$$
\left[V_{\tilde{Y}}\right]=[X]\left[V_{\tilde{A}}\right]^{-1}[X]^{-1}
$$

No caso da XRF-ED, quando se calcula $R(Z)$ apenas a partir do alvo de calibração do elemento $Z$, é a incerteza de produção deste alvo que determina a precisão de $\mathrm{R}(\mathrm{Z})$. Mas com o procedimento de ajuste por MQM, sob os $\mathrm{R}(\mathrm{Z})$ disponíveis, é o conjunto destes valores e de suas incertezas, bem como a qualidade do ajuste que determinam a incerteza ajustada, oferecendo uma melhora significativa na precisão e na exatidão dos $R(Z)$.

\subsubsection{Fontes de erro no branco (amostras de controle)}

Um conjunto de 10 amostras brancas de controle (entre campo e laboratório) foram analisadas para eliminação da contaminação dos próprios filtros, assim como de transporte e manipulação.

A massa depositada no filtro amostrado $m(Z)_{\text {medido }}$ para um certo elemento Z é composta pela massa coletada na amostragem $\mathrm{m}(\mathrm{Z})$ mais a massa do filtro branco $m_{B}(Z)$.

A seguir, a equação 2.2 está escrita para representar o número de contagens de alvos amostrados, isto é, com sobreposição da massa coletada na amostragem $m(Z)$ e a massa do branco $m_{B}(Z)$ :

$$
N(Z)_{\text {medido }}=R(Z) \cdot I \cdot \Delta t \cdot\left(\frac{m(Z)}{A}+\frac{m_{B}(Z)}{A}\right)
$$

Quando as amostras brancas são irradiadas separadamente, o número de contagens é dado por: 


$$
N_{B}(Z)=R(Z) \cdot I_{B} \cdot \Delta t_{B} \cdot \frac{m_{B}(Z)}{A}
$$

Isolando-se $m_{B}(Z)$ em 2.14 e substituindo em 2.13, encontramos o número de contagens corrigido nos alvos amostrados (isto é, excluindo a contaminação das amostras brancas):

$$
N(Z)=N(Z)_{\text {medido }}-I \cdot \Delta t \cdot\left(\frac{N_{B}}{I_{B} \cdot \Delta t_{B}}\right)
$$

A incerteza da contagem corrigida (equação 2.15) é dada por:

$$
\sigma_{N(Z)}^{2}=\sigma_{N(Z)_{\text {medido }}}^{2}+\left(\frac{I \cdot \Delta t}{I_{B} \cdot \Delta t_{B}}\right)^{2} \cdot \sigma_{N_{B}}^{2}
$$

Calcula-se a razão $N_{B} /\left(I_{B} \cdot \Delta t_{B}\right)$ para um conjunto de alvos brancos para posterior inserção na equação 2.15 .

Foi criado colaborativamente por pesquisadores do LAPAt um programa em linguagem C que automatiza o cálculo teórico de concentrações apresentado, com as devidas correções de branco e propagações de incertezas ${ }^{1}$.

\subsubsection{Integração dos espectros}

Realizou-se a integração de todos os espectros obtidos na XRF-ED no Quantitative X-Ray Analysis System for Windows (WinQxas), programa desenvolvido para integração numérica de espectros sob o patrocínio da Agência Internacional de Energia Atômica (IAEA) (Capote et al., 2000).

Obtém-se os parâmetros iniciais da relação linear entre canal e energia, conhecendo-se ao menos dois picos no espectro, normalmente Ferro e Cálcio, no caso de poluição do ar ambiental.

Os parâmetros iniciais entre a largura do pico à meia altura (FWHM) dependem da energia (E), do nível geral de ruído (NOISE) no espectro e do FANO, dado pela relação:

$$
F W H M^{2}=N O I S E^{2}+2,35 \cdot F A N O \cdot E
$$

Os parâmetros iniciais foram determinados a partir de espectros com picos bem definidos, como o Ferro, que teve largura à meia altura (FWHM) para $K \alpha$ de 138,32 eV ou o Cálcio com $129,14 \mathrm{eV}$.

\footnotetext{
${ }^{1} \mathrm{O}$ código está disponível no repositório de versionamento git da USP e pode ser acessado pelo endereço: https://git.uspdigital.usp.br/5385361/xrfdensid
} 
Na figura 2.10 há dois exemplos de espectros abertos no WinQxas para amostras de Nima, sendo um de uma amostra branca e a outra carregada. Os picos característicos de elementos químicos encontrados estão indicados na figura.

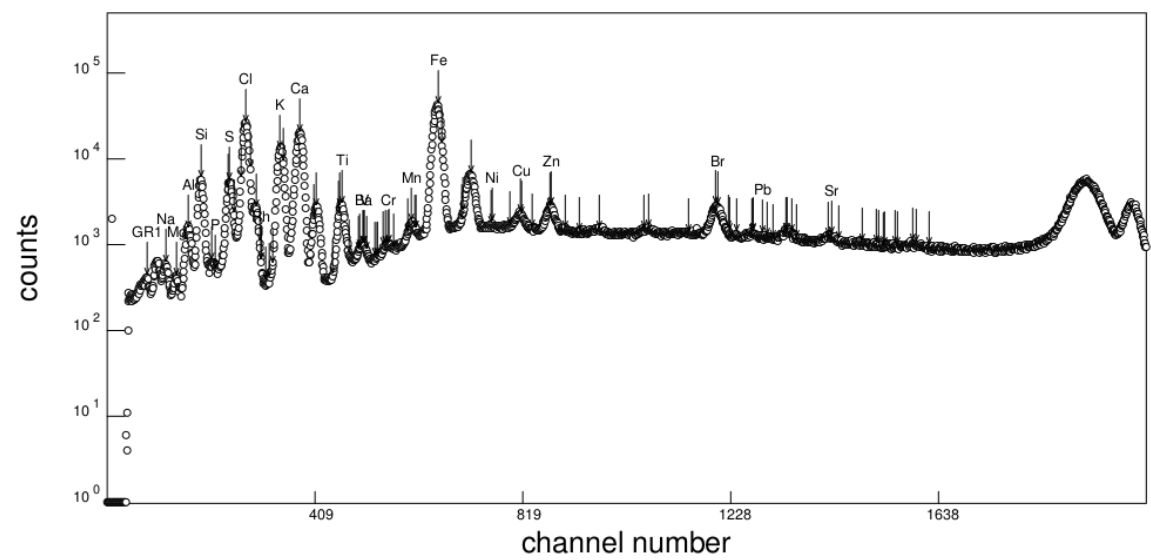

(a) Espectro de amostra carregada (GHA41) - Acra Nima

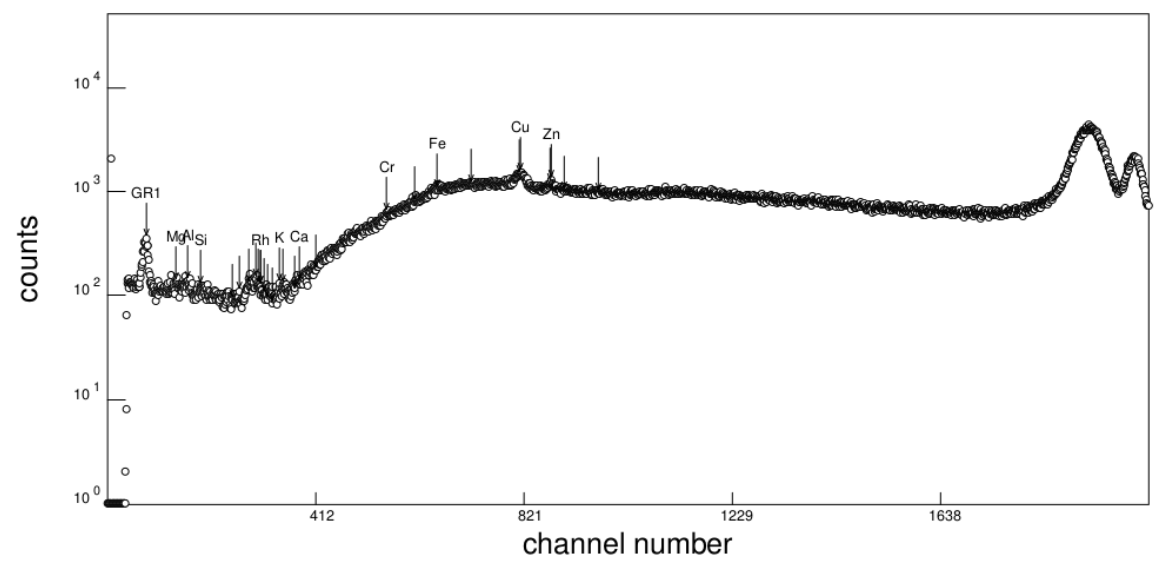

(b) Espectro de amostra branca (GPE770)- Acra Nima

Figura 2.10: Espectros para amostra branca e carregada de Nima.

$\mathrm{Na}$ integração dos espectros, pico a pico, deve-se ter atenção para identificação e correção dos seguintes eventos em picos com muitas contagens:

- pico soma: quando fótons de diferentes elementos são contados juntos pelo detector.

- pico escape: quando o fóton incidente excita o silício do detector e é contado com energia menor, pois parte foi perdida na excitação do silício.

A seguir, apresenta-se a calibração do multicanal, ajuste linear entre canal e energia encontrado a partir do Fe e Ca:

$$
E=0,0101 \cdot \text { Canal }-0,1335(k e V)
$$




\subsubsection{Limite de detecção}

O limite de detecção (LD) é a intensidade mínima do pico de um elemento para haver detecção da espécie se considerando o tipo de filtro e XRF-ED empregados. Irradiando uma amostra branca, obtém-se o número de contagens medidas $\left(N_{\text {fundo }}\right)$ sob o pico (fundo do espectro) de cada um dos elementos medidos. As contagens de fundo do espectro seguem uma distribuição de Poisson e portanto a incerteza para o valor de $\mathrm{N}$ contagens é $\sqrt{N}$. Desta forma, adota-se como LD para um elemento, a condição de que as contagens de seu pico característico seja pelo menos três vezes a incerteza na contagem de fundo:

$$
N_{L D}=3 \cdot \sqrt{N_{\text {fundo }}}
$$

Pode-se calcular o LD em termos da massa elementar com a equação 2.5. O limite de detecção muda conforme a quantidade de material coletado, sendo maior em amostras carregadas, devido à sobreposição de picos e a maior reflexão do feixe na amostra.

Assim, o ideal é calcular o LD em cada amostra, mas ele deve situar-se entre aquele medido em um filtro branco e uma amostra com bastante carga. Os LDs encontrados para os dois tipos de amostras estão apresentados nos gráficos da figura 2.11 em termos de concentrações típicas $\left(\mu \mathrm{g} / \mathrm{m}^{3}\right)$ para o volume médio de $13,9 \mathrm{~m}^{3}$. Note-se que na linha K o LD é alto para elementos de baixo número atômico, dificultando a detecção desses elementos, mas melhora com o aumento de Z.

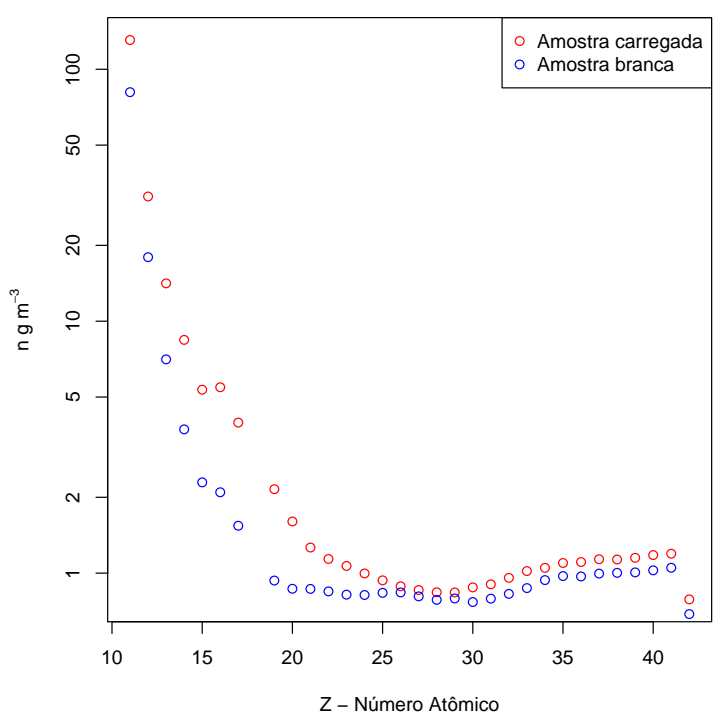

(a) linha $\mathrm{K}$

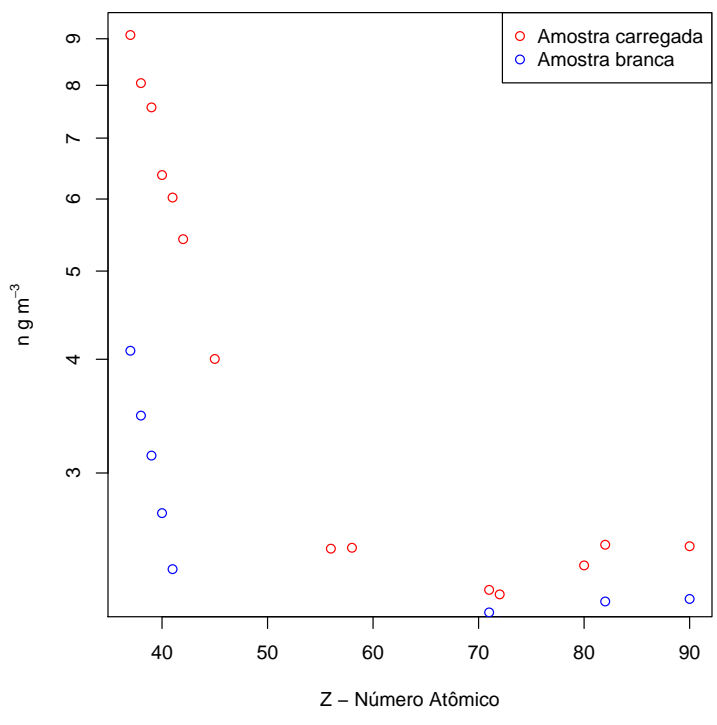

(b) linha L

Figura 2.11: Limite de detecção para XRF-ED em termos de concentrações típicas para amostra branca e carregada. 
Tabela 2.2: Limite de detecção para XRF-ED em termos de concentrações típicas para amostra branca e carregada.

\begin{tabular}{|c|c|c|}
\hline Elemento & $\begin{array}{r}\text { Amostra branca } \\
n\end{array}$ & $\begin{array}{l}\text { Amostra carregada } \\
\mathrm{g} / \mathrm{m}^{3}\end{array}$ \\
\hline $\mathrm{Na}$ & 81,13 & 130,70 \\
\hline $\mathrm{Mg}$ & 17,96 & 31,26 \\
\hline $\mathrm{Al}$ & 7,06 & 14,13 \\
\hline $\mathrm{Si}$ & 3,72 & 8,43 \\
\hline $\mathrm{P}$ & 2,29 & 5,35 \\
\hline $\mathrm{S}$ & 2,09 & 5,47 \\
\hline $\mathrm{Cl}$ & 1,54 & 3,96 \\
\hline $\mathrm{K}$ & 0,93 & 2,15 \\
\hline $\mathrm{Ca}$ & 0,87 & 1,60 \\
\hline $\mathrm{Sc}$ & 0,87 & 1,26 \\
\hline $\mathrm{Ti}$ & 0,85 & 1,14 \\
\hline $\mathrm{V}$ & 0,82 & 1,07 \\
\hline $\mathrm{Cr}$ & 0,82 & 1,00 \\
\hline $\mathrm{Mn}$ & 0,84 & 0,94 \\
\hline $\mathrm{Fe}$ & 0,84 & 0,89 \\
\hline $\mathrm{Co}$ & 0,81 & 0,86 \\
\hline $\mathrm{Ni}$ & 0,78 & 0,84 \\
\hline $\mathrm{Cu}$ & 0,79 & 0,84 \\
\hline $\mathrm{Zn}$ & 0,77 & 0,88 \\
\hline $\mathrm{Ga}$ & 0,79 & 0,90 \\
\hline $\mathrm{Ge}$ & 0,83 & 0,96 \\
\hline As & 0,87 & 1,02 \\
\hline Se & 0,94 & 1,05 \\
\hline $\mathrm{Br}$ & 0,97 & 1,10 \\
\hline $\mathrm{Kr}$ & 0,97 & 1,11 \\
\hline $\mathrm{Rb}$ & 1,00 & 1,14 \\
\hline $\mathrm{Sr}$ & 1,00 & 1,13 \\
\hline $\mathrm{Y}$ & 1,01 & 1,15 \\
\hline $\mathrm{Zr}$ & 1,03 & 1,18 \\
\hline $\mathrm{Nb}$ & 1,05 & 1,19 \\
\hline Mo & 0,69 & 0,79 \\
\hline $\mathrm{Rh}$ & 1,60 & 4,00 \\
\hline $\mathrm{Ba}$ & 1,77 & 2,48 \\
\hline $\mathrm{Ce}$ & 1,87 & 2,48 \\
\hline $\mathrm{Lu}$ & 2,11 & 2,23 \\
\hline Hf & 2,06 & 2,21 \\
\hline $\mathrm{Hg}$ & 2,05 & 2,37 \\
\hline $\mathrm{Pb}$ & 2,17 & 2,50 \\
\hline Th & 2,18 & 2,49 \\
\hline
\end{tabular}




\subsection{Black Carbon}

Apesar da importância do BC nos problemas ambientais atmosféricos, há muita ambiguidade em seu tratamento, começando pelo modo como é denominado e seguindo pelas propriedades das partículas, faltando precisão aos termos a ele relacionados como fuligem (soot), negro de fumo (BC), fumaça preta (BS) e carbono elementar (EC). Petzold et al. (2013), dentre outros trabalhos, destacam que, desta forma, termos como BC e EC referem-se a um conjunto de materiais cujas propriedades não estão bem definidas e ressaltam que material carbonáceo na atmosfera ocorre como misturas muito variáveis de compostos de carbono, com diferentes propriedades. Sugere, assim, definir o BC a partir de um conjunto de propriedades, compreendendo uma microestrutura similar ao grafite, uma morfologia fractal com cadeias de nanoesferas agregadas, um material refratário que volatiliza em torno de 4000K, gaseificandose apenas por oxidação em temperaturas acima de $340^{\circ} \mathrm{C}$, não sendo solúvel em água ou qualquer outro solvente. No trabalho de análise e revisão organizado pela OMS, Janssen et al. (2012) destaca que esse carbono pode ser carvão - que se origina de processos de pirólise (como na queima de biomassa), tendo cor mais próxima do castanho - ou fuligem, de cor negra e formada sob combustão em altas temperaturas, como ocorre nos motores diesel. A análise TOT consegue diferenciá-los. A US-EPA também gerou um relatório sobre BC (EPA, 2012) com a contribuição de algumas dezenas de autores. Com imagens bastante ilustrativas, tanto sobre sua geração quanto às suas características micro e macroscópicas - realizou uma ampla revisão e discussão sobre BC, caracterizando-o extensivamente e tratando de seus efeitos à saúde e ao meio ambiente, particularmente no que diz respeito ao clima, avaliando inclusive medidas mitigatórias para controlá-lo.

Todos esses trabalhos relacionam métodos de medida de $\mathrm{BC}$, que preconizam medidas absolutas, como TOT ou TOR, ou relativa, como aqueles baseados na absorção de luz visível pelo material em suspensão na atmosfera ou coletado sobre filtros. Esse segundo método é incomparavelmente mais simples e de menor custo que os primeiros. Nós optamos por empregar medidas por refletância. Neste caso pode-se usar os mesmos filtros da análise elementar por XRF-ED (PTFE ou policarbonato), pois ambas técnicas são não destrutivas. Todas operações envolvidas nas medições por refletância consomem algo em torno de um a dois minutos, em média, possibilitando a determinação de diversas centenas de amostras em poucos dias. De um modo geral, isso também é interessante numa perspectiva de avaliação de séries históricas, já que BC pode ser correlacionado com Black Smoke (BS), uma medida que órgãos de controle ambiental costumam realizar há muitos anos por refletância. Quincey 
(2007) e Heal \& Quincey (2012) discutem relações entre estas medidas, destacando que em Londres, por exemplo, elas são feitas desde 1920. Mas alertam, entretanto, para o cuidado que se deve ter já que a estrutura de BC, EC e OC, acompanham as diferenças ou mudanças de características regionais e temporais do aerossol e precisam ser contemporizadas.

Também há registros históricos de medidas relativas de BC realizadas desde 1980 por Aetalômetro, técnica que incide um feixe colimado de luz monocromática sobre o filtro com amostra coletada medindo a quantidade de luz absorvida por atenuação (Targino \& Krecl, 2016).

Thermal Optical-Reflectance (TOR) ou Thermal-Optical Transmittance (TOT) fornecem medidas absolutas de EC e OC, mas são destrutivas e necessitam de um filtro especial e de aparatos de medidas e amostragem exclusivos, tendo custo bem mais elevado.

\subsubsection{Refletância}

Concentrações de BC foram obtidas por refletômetro do tipo Smoke Stain Reflectometer modelo EEL43D da empresa Diffusion System, que devido à sua simplicidade é tradicionalmente usado para medidas de BC em amostras ambientais (Lack et al., 2014). A técnica baseia-se na alta seção de choque de absorção de luz pelo BC, na região do visível, e assume que toda absorção é devida ao BC presente na amostra.

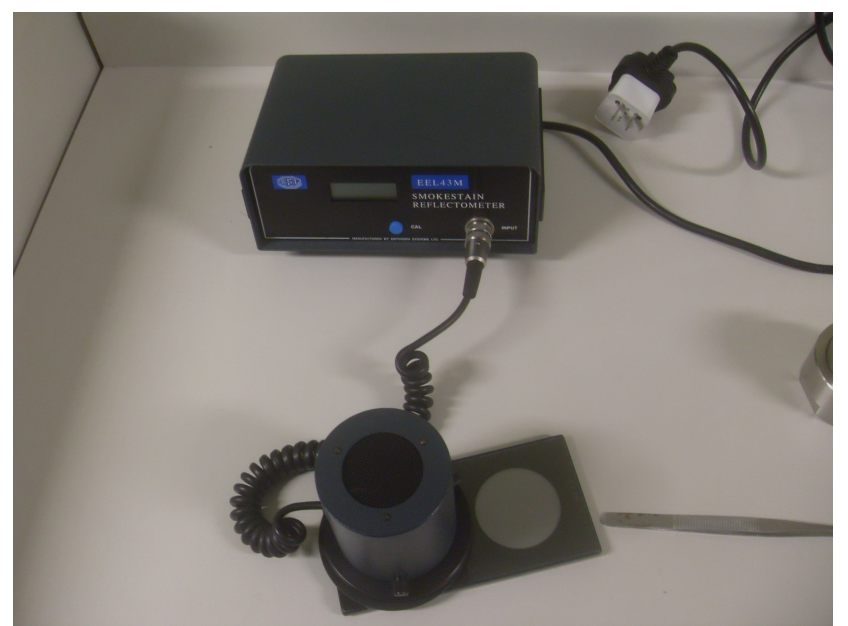

Figura 2.12: Refletômetro da Diffusion System modelo ELL43D e peças auxiliares de fixação no LAPAt

Na refletância, uma área definida da amostra é ilumindada por lâmpada de tungstênio, sendo parte da luz incidente absorvida pelas partículas do filtro e parte refletida. Uma fotocélula com orifício circular, localizada entre a lâmpada e a amostra, mede a porcentagem da luz refletida (I). Um filtro branco é usado para fixar o 100\% das leituras a cada 3 medidas. 
A absorção de luz que atravessa um meio com coeficiente de absorção $(\alpha)$ homogêneo segue um processo clássico. A intensidade I da luz em um ponto x da amostra (meio) homogênea decai $-d I$ ao atravessar uma espessura $d x$, sendo o decaimento diretamente proporcional a I:

$$
\frac{d I}{d x}=-\alpha \cdot I
$$

fazendo a separação das variáveis, pode-se integrar os dois lados da equação:

$$
\int_{I_{0}}^{I} \frac{d I}{I}=-\int_{0}^{D} \alpha d x
$$

Resultando em uma relação exponencial entre o decaimento da intensidade do feixe de luz incidente $\left(I_{0}\right)$ e a intensidade transmitida $(I)$, em função da espessura (D) da amostra:

$$
I=I_{0} \cdot \exp (-\alpha \cdot D)
$$

No caso da refletância o feixe de luz vai e volta pela amostra, ficando:

$$
I=I_{0} \cdot \exp (-\alpha \cdot 2 \cdot D)
$$

O detector opera sobre uma área fixa e, assim, a medida que nos interessa é a massa por unidade de área (A). Ao ser multiplicada pela área total de amostragem no filtro ela fornece a massa total coletada. A massa $m$ que o detetor observa é $m=\rho \cdot V=\rho \cdot D \cdot A$, onde $\rho$ é a densidade da amostra. Podemos usar esta relação para substituir $D$ na equação 2.23, ficando:

$$
I=I_{0} \cdot \exp \left(-\frac{2 \cdot \alpha}{\rho} \cdot \frac{m}{A}\right)
$$

Aplicando-se logarítimo nos dois lados da equação e rearranjando os termos, obtemos:

$$
\frac{m}{A}=K \cdot(2-\log I)
$$

onde o termo K é uma constante dada por $K=[2 \cdot(\alpha / \rho) \cdot \log (e)]^{-1}$ e a condição de $I_{0}=$ $100 \%$ foi imposta (lembrando que $\log 100=2$ ).

A relação linear entre m/A e $\log (I)$ oferece bom ajuste empírico quando se trabalha com $\mathrm{BC}$, permitindo a calibração do equipamento. Ressalve-se haver uma perda de linearidade para valores muito baixos de refletância (amostras muito carregadas). 


\subsubsection{Thermal Optical Transmittance}

Apresenta-se apenas os fundamentos gerais do TOT, pois o empregamos apenas para calibrar o método de refletância. As medidas de TOT foram realizadas por outros integrantes do projeto geral de pesquisa. O TOT é um método absoluto para medir carbono orgânico (OC) e carbono elementar (EC) e se baseia no fato de que ambos se convertem para gás em diferentes temperaturas e condições de oxidação (Birch, 1998).

Aquecendo a amostra paulatinamente em ambiente não oxidante (presença de He), ocorre progressiva volatização dos compostos orgânicos nas temperaturas mais baixas. A evaporação do carbono elementar ocorre acima de $580{ }^{\circ} \mathrm{C}$. Durante a fase de volatilização do OC, parte dele sofre pirólise, convertendo-se em EC e aumentando a concentração deste componente na amostra. Um sistema ótico com feixe de laser de intensidade controlada registra este acúmulo em função da perda de transmitância da amostra. Na fase de volatização do EC se contabiliza como OC todo o EC extraído da amostra até o ponto em que o sistema óptico indique ter sido retomada a sua transmitância original. Daí em diante é que se passa a contabilizar o EC originalmente presente na amostra. Faz-se a medida do $\mathrm{C}$, oxidando-o para $\mathrm{CO}_{2}$ ao passar por uma placa de dióxido de magnésio aquecida, que segue por um catalizador de níquel, onde o dióxido de carbono é reduzido a metano $\mathrm{CH}_{4}$. O $\mathrm{CH}_{4}$ é quantificado com um detector do tipo Flame Ionization Detector. Para análises TOT é necessário fazer a coleta em filtros de quartzo, aumentando os custos e tornando mais complexa a logística das medidas, pois é necessário montar ponto de medida paralelo ao da coleta para análise elementar.

\subsection{Modelos Receptores}

Modelo receptor é uma abordagem matemática para determinar e quantificar o efeito das fontes poluidoras do ar em amostras. Análise de Fatores (AF) e Positive Matrix Fatorization (PMF) são técnicas matemáticas de análise multivariada usadas em modelos receptores e permitem a identificação de fontes quando os seus perfis são desconhecidos.

Outro modelo receptor é Balanço Químico de Massa (CMB), usado quando se conhece o perfil das fontes locais e permite verificar o impacto das fontes nas concentrações medidas no amostrador. O CMB não foi usado nesta pesquisa, por falta de perfis de fontes adequados para a região.

A análise multivariada é uma técnica estatística utilizada para reduzir a dimensão de dados matriciais e permite manter a quantidade de informação contida inicialmente nos dados, 
armazenada na variância e covariância. Dá-se o nome de fator às novas variáveis reduzidas, que são ortogonais entre si, sendo o fator uma variável latente, pois não é uma grandeza diretamente medida, mas sim obtida a partir de outras variáveis observáveis.

As dimensões (variáveis) reduzidas de um conjunto de dados analíticos complexos podem ser interpretados como fonte(s) poluidora(s), como detalhado por Wang et al. (2012) e Mansha et al. (2012), em que o número de fatores extraídos dependerá dos limites de detecção dos equipamentos usados, número de amostras, resolução da amostragem, espécies medidas, entre outros, sendo o conhecimento do pesquisador, juntamente com informações das potenciais fontes poluidoras próximas ao ponto receptor, dados meteorológicos do período de coleta, inventário de emissões e outras informações imprescindíveis para fazer a associação fatorfonte(s).

Assim, o principal desafio em análises multivariadas é identificar se o fator de fato existe e se tem significado físico enquanto fonte(s) poluidora(s), sendo que número reduzido de amostras, baixa resolução da amostragem e outliers (eventos infrequentes de curta duração e com alta concentração) representam um desafio para modelos multivariados.

O princípio de conservação da massa é usado no modelo receptor, pois os poluentes emitidos pelas fontes em uma bacia aérea devem chegar no receptor. Aplicando-se a equação de conservação da massa para uma amostragem em que se coletou $i$ amostras e se mediu $j$ poluentes, tem-se:

$$
x_{i j}=\sum_{p=1}^{P} g_{i p} f_{p j}
$$

sendo,

- $x_{i j}=$ concentração na amostra receptora $i$ da espécie $j$;

- $f_{p j}=$ fração da espécie $j$ emitida pela fonte $p$;

- $g_{i p}=$ contribuição da fonte $p$ para amostra $i$;

\subsubsection{Análise de Fatores}

A técnica estatística de Análise de Fatores (AF) foi popularizada em diversas áreas das ciências após publicação do trabalho de Lourenz em 1956, que a nomeou de Análise de Funções Ortogonais Empíricas, 55 anos após a descoberta da mesma por Karl Pearson (Bartholomew et al., 2011). Consiste conceitualmente na redução da dimensionalidade dos dados para uma nova base contendo a menor dimensão possível relativamente à dimensão dos dados originais, 
baseando-se na decomposição da matriz de correlação ou covariância em autovalores e autovetores, de forma que as novas variáveis (fatores) sejam combinação linear das anteriores e que representem a máxima fração possível da variância contida naquelas variáveis.

Dadas as variáveis observáveis $\left(x_{1}, \ldots, x_{j}\right)$ com respectivas médias $\mu_{1}, \ldots, \mu_{j}$ a equação da AF pode ser escritas como:

$$
\frac{x_{i}-\mu_{i}}{\sigma_{i}}=l_{i 1} F_{1}+\cdots+l_{i p} F_{p}+\varepsilon_{i}
$$

Sendo $\mathrm{F}$ os fatores extraídos e $l_{i p}$ o peso (ou loading) da variável $i$ no fator $p$.

Deve-se evitar amostras medidas em paralelo ou repetidas na mesma rodada de AF devido ao efeito multicolinearidade e consequente piora na solução do ajuste. A comunalidade é igual a soma dos loading ao quadradro para cada variável e indica como ela foi explicada pelo atual ajuste, sendo que o zero indica que a variável não foi nada explicada pelos fatores extraídos e um que foi completamente explicada. O quanto da variabilidade global dos dados iniciais foi explica pelo modelo está contida na variância total explicada, sendo que os ajustes com valores acima de $80 \%$ são considerados bons. Retem-se ainda fatores com autovalores maiores que um e não degenerados (o gráfico scree facilita a investigação para identificação de fatores degenerados, pois exibe os autovalores associados aos fatores).

Para melhor interpretação dos resultados da AF, aplicou-se a rotação do tipo Varimax, que projeta os fatores em um novo sistema de eixos maximizando as variâncias e portanto alterando os autovalores (Kaiser, 1958).

\subsubsection{Positive Matrix Factorizarion}

Positive Matrix Factorizarion (PMF) é outro método multivariado usado em modelos receptores e permite determinar para conjunto de fatores $p$, o perfil $f$ das espécies de cada fonte e a contribuição da massa $g$ de cada fator para cada amostra individual (Norris et al., 2014).

O PMF resolve a equação de conservação de massa usando mínimos quadrados (diferentemente da AF, que reduz a dimensão dos dados decompondo a matriz de correlação em autovalores e autovetores) e tentará encontrar solução matemática para qualquer número de fatores, tendo eles significado físico ou não.

Supondo uma campanha da amostragem com $i$ amostras válidas e $j$ espécies medidas, a matriz das concentrações $c_{i j}$ pode ser decomposta em $g_{i k}$ e $f_{k j}$ conforme 2.28. O PMF procura um par das matrizes $g_{i k}$ e $f_{k j}$ que minimizem a função objeto $Q$ dada pela equação 2.29. 


$$
c_{i j}=\sum_{k=i}^{p} g_{i k} f_{k j}+e_{i j}
$$

$\mathrm{e}$

$$
Q=\sum_{i=1}^{n} \sum_{j=1}^{m}\left[\frac{e_{i j}}{u_{i j}}\right]^{2}
$$

Onde,

- $c_{i j}$ : Matriz de concentração;

- $u_{i j}$ : Matriz de incertezas (experimentais e analíticas);

- $p$ : Número de fatores informado pelo usuário;

- $g_{i k}$ : Contribuição dos fatores nas amostras (Factor Score);

- $f_{k j}$ : Perfil da fonte ou assinatura da fonte (Factor Loadings);

- $e_{i j}$ : Matriz dos resíduos escalados pelas incertezas.

O método PMF tem sido muito utilizado em pesquisas de poluição atmosférica, pois inclui algoritmo robusto e estável desenvolvido por Paatero \& Tapper (1994) que impede o aparecimento de valores negativos no perfil e na contribuição de fontes e, diferentemente da $\mathrm{AF}$, pondera o ajuste pelo inverso das incertezas nas concentrações, diminuindo assim, o peso de espécies com incertezas altas (equação 2.29). Daí a importância de uma adequada definição para as incertezas dos parâmetros medidos, como feito para XRF-ED e para intercalibração de BC usando MQM.

\section{Função Objeto}

Função objeto, em matemática, é uma função que precisa ser minimizada ou maximizada usando métodos numéricos para equações não lineares, pois não tem solução analítica. A matriz de resíduo $e_{i j}$ da equação 2.28 pode ser substítuida em 2.29 obtendo-se:

$$
Q=\sum_{i=1}^{n} \sum_{j=1}^{m}\left[\frac{c_{i j}-\sum_{k=i}^{p} g_{i k} f_{k j}}{u_{i j}}\right]^{2}
$$

A solução para equação 2.30 foi inicialmente implementada usando o método de GaussNewton (Paatero \& Tapper, 1994), mas na versão atual do software (PMF EPA 5.0) é usado o Método do Gradiente Conjugado (Norris et al., 2014), o qual inicia $g_{i k}$ e $f_{k j}$ randomicamente, ajustando-os iterativamente até alcançarem o menor $Q$ possível. 


\section{Resultados e Discussão}

\subsection{Calibração da Fluorescência de Raiox X}

Alvos padrões comerciais da Micromatter com incertezas de 5\% nas densidades superficiais foram utilizados no ajuste funcional da calibração do sistema XRF-ED, permitindo medição mesmo de elementos com alvos padrões inexistentes. Três calibrações foram realizadas no período de análises, maio de 2010 até julho de 2011, sendo a primeira antes do início das irradiações, em maio de 2010, uma intermediária, em novembro de 2010 e a última próximo do fim, em abril de 2011.

Após irradiação dos alvos de calibração, calculou-se os fatores de respostas correspondentes a partir da equação 2.3 , bem como as respectivas incertezas analíticas com a equação 2.4.

Polinômios oferecem uma boa versatilidade para a realização de ajustes funcionais empíricos a um conjunto de dados. Ao mesmo tempo facilitam a utilização de MQM, que pondera o peso do dado experimental pelo inverso de sua incerteza e permite obter incertezas confiáveis para os valores calculados. Para a linha $\mathrm{K}$ obtivemos melhores resultados realizando dois ajustes de grau 3: um de $Z=11$ até 26 e outro de $Z=22$ até 42 (figura 3.1). Na zona de sobreposição entre estas duas curvas, empregou-se o valor médio como fator de resposta. Para a linha L, um polinômio de grau 5 ofereceu um bom ajuste funcional para todos os pontos.

Os gráficos da figura 3.1 e as tabelas 3.1 e 3.2 apresentam os fatores de resposta medidos para cada elemento com alvo padrão disponível, as respectivas incertezas propagadas, os ajustes funcionais, os correspondentes fatores de respostas calculados e respectivas incertezas resultantes do ajuste por MQM.

Elementos com Z entre 29 e 42 apresentam picos no espectro tanto para linhas K quanto L. Porém, as linhas K são mais intensas e melhor definidas. Eles somente foram incluídos nos gráficos da linha L no intuito de aumentar a quantidade de pontos para o ajuste polinomial.

A incerteza do ajuste por MQM é dada pela diagonal da matriz de covariância de $[\tilde{Y}],\left[V_{\tilde{Y}}\right]$ (equação 2.12), onde a matriz [Y] é a matriz dos fatores de respostas [R] e [X] são os números 
atômicos $[\mathrm{Z}]$.

As incertezas percentuais ajustadas com MQM são tipicamente menores que aquelas declaradas pelo fabricante dos alvos de calibração. Isso é uma consequência natural de uma metodologia que busca os melhores valores a se ajustarem ao conjunto dos pontos experimentais ao invés de focar cada ponto individualmente - o que demandaria um grande número de alvos para cada elemento a analisar. Vejamos dois exemplos na calibração feita em maio de 2010: 1) para a linha $\mathrm{K}$ do $\mathrm{Ca}(\mathrm{Z}=20)$, para o qual havia dois alvos de calibração, obteve-se um $\mathrm{R}$ medido com incerteza de $3,5 \%$, contra $1,4 \%$ para o valor ajustado; 2 ) para o Ferro (26), com um alvo de calibração, esses valores foram 5,0\% e 2,6\%, respectivamente. Apenas para o $\mathrm{Na}(Z=11)$, a incerteza do $\mathrm{R}$ ajustado foi maior que o medido, porque se trata de um ponto extremo da curva em uma região onde o limite de detecção do sistema é muito alto. Por conseguinte, esse padrão de comportamento repete-se nas outras duas calibrações para as linhas K e L. Vê-se, portanto, que essa metodologia, ademais de fornecer a calibração mesmo para alguns elementos para os quais não se dispõe de alvos de calibração, permite uma significativa redução nas incertezas dos valores de concentração calculados. Além do valor intrínseco que isso tem nestas determinações, também tem papel importante para métodos estatísticos que em seus ajustes usam ponderação pela incertezas, caso do PMF, utilizado neste trabalho. 
linha K: Maio de 2010

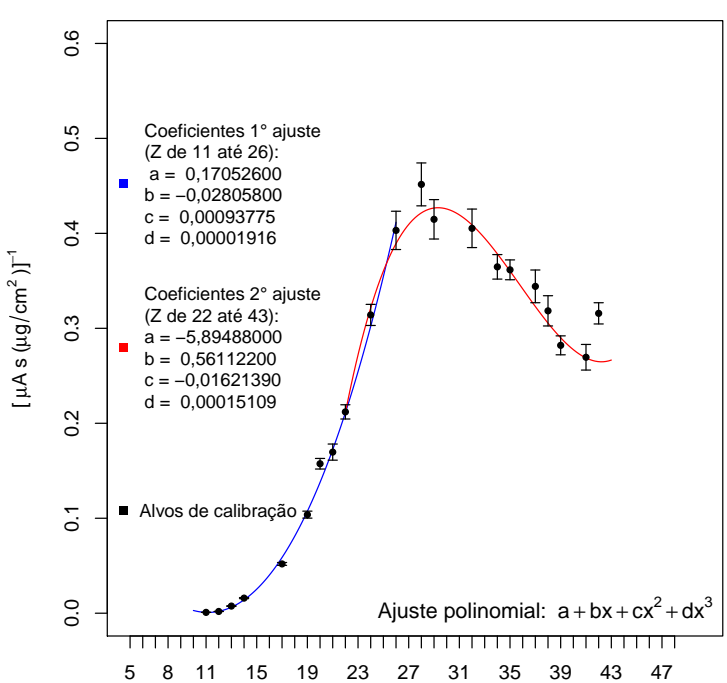

Z - Número Atômico

linha L: Maio de 2010

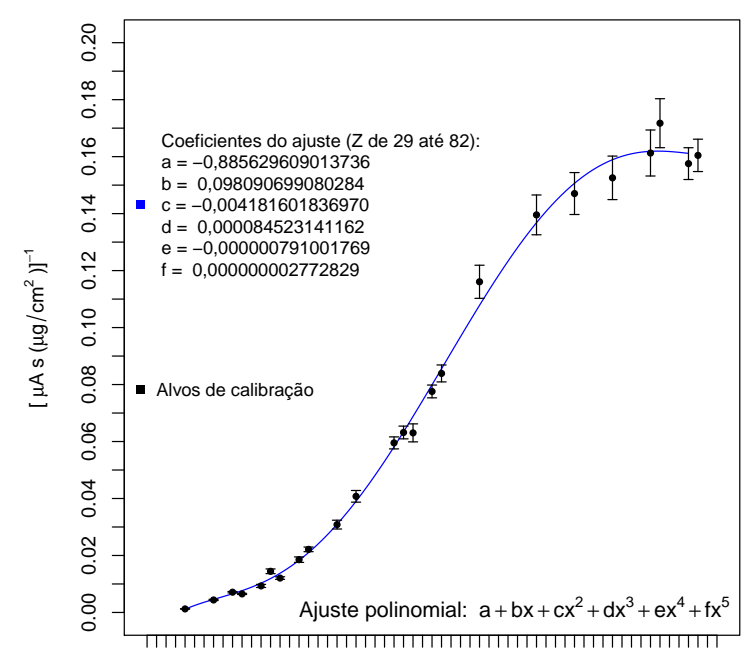

(1)

Z - Número Atômico linha K: Novembro de 2010

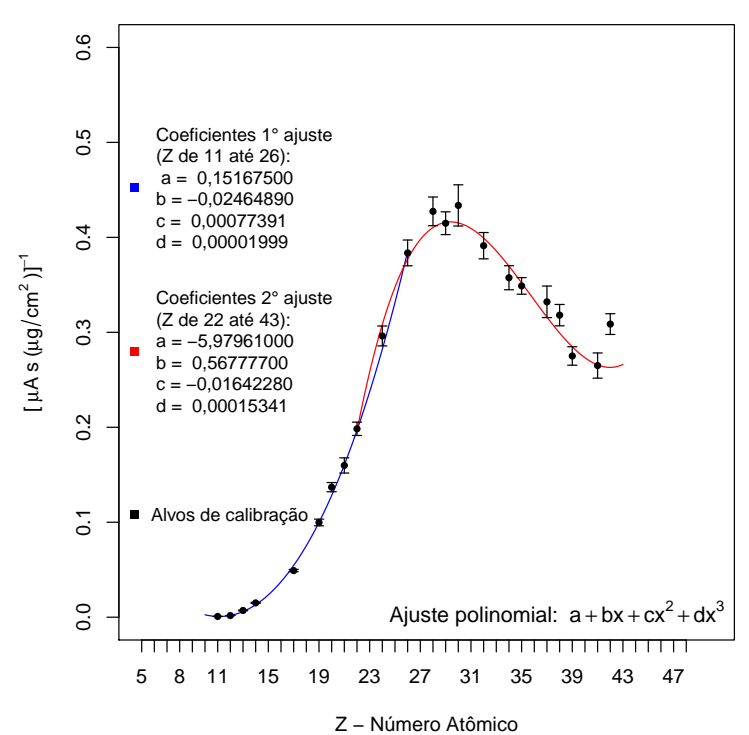

linha L: Novembro de 2010

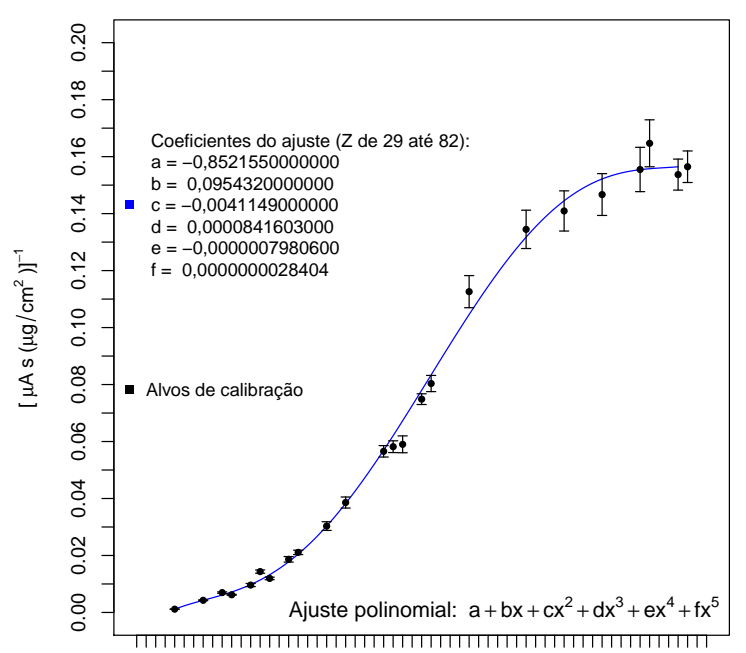

$\begin{array}{llllllllllllll}25 & 30 & 35 & 40 & 45 & 50 & 55 & 60 & 65 & 70 & 75 & 80 & 85\end{array}$

Z - Número Atômico linha K: Abril de 2011

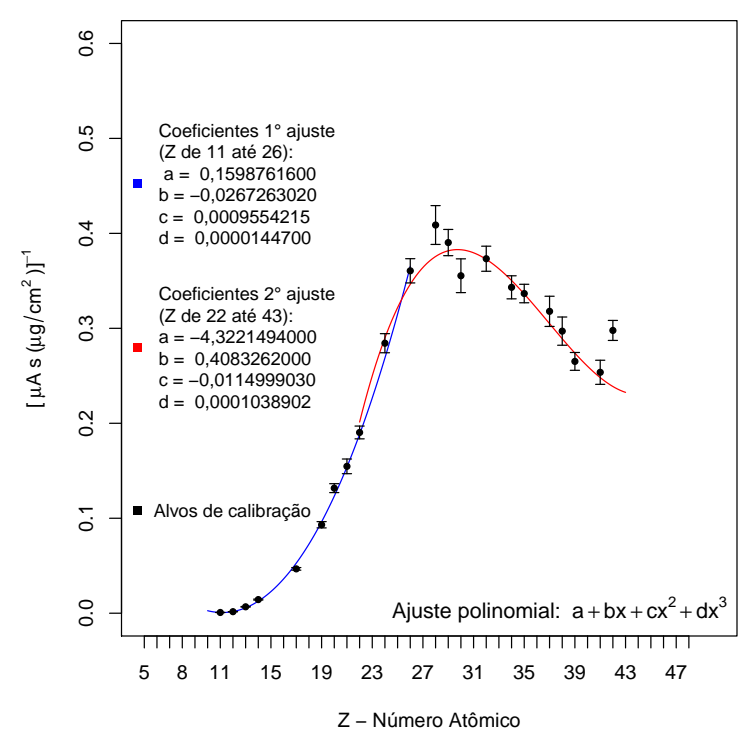

linha L: Abril de 2011

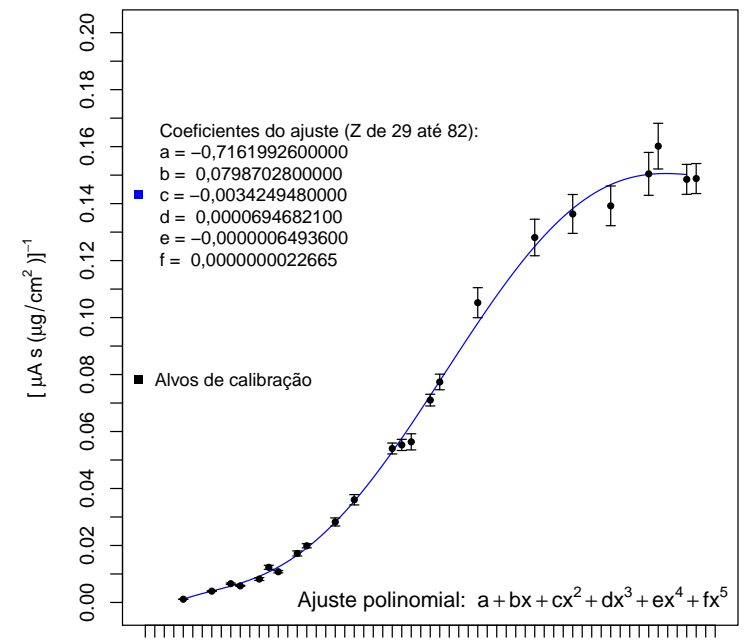

$\begin{array}{lllllllllllllll}25 & 30 & 35 & 40 & 45 & 50 & 55 & 60 & 65 & 70 & 75 & 80 & 85\end{array}$

Z - Número Atômico

Figura 3.1: Comparação das calibrações do XRF-ED nos 3 períodos. 
Tabela 3.1: Calibração da Fluorescência de Raiox X linha K

\begin{tabular}{|c|c|c|c|c|c|c|c|c|}
\hline \multirow[b]{2}{*}{$\mathrm{Z}$} & \multicolumn{2}{|c|}{ Maio 2010} & \multicolumn{2}{|c|}{ Novembro 2010} & \multicolumn{2}{|c|}{ Abril 2011} & \multicolumn{2}{|c|}{ Diferença relativa a Maio 2010} \\
\hline & medido & ajustado & medido & ajustado & medido & ajustado & Nov 2010 & Abr 2011 \\
\hline \multicolumn{7}{|c|}{$10^{3} \cdot\left[\mu \mathrm{A} \cdot \mathrm{s} \cdot\left(\mu \mathrm{g} / \mathrm{cm}^{2}\right)\right]^{-1}($ incerteza percentual \%) } & \multicolumn{2}{|c|}{$\%$} \\
\hline 11 & $0,889 \pm 0,057(6,4)$ & $0,860 \pm 0,057(6,6)$ & $0,799 \pm 0,038(4,8)$ & $0,784 \pm 0,038(4,8)$ & $0,778 \pm 0,051(6,6)$ & $0,752 \pm 0,050(6,6)$ & $-8,84$ & $-12,55$ \\
\hline 12 & $1,848 \pm 0,081(4,4)$ & $1,978 \pm 0,077(3,9)$ & $1,721 \pm 0,078(4,5)$ & $1,871 \pm 0,073(3,9)$ & $1,624 \pm 0,073(4,5)$ & $1,745 \pm 0,069(4,0)$ & $-5,42$ & $-11,76$ \\
\hline 13 & $7,51 \pm 0,38(5,1)$ & $6,35 \pm 0,15(2,4)$ & $7,10 \pm 0,36(5,1)$ & $5,94 \pm 0,14(2,4)$ & $6,75 \pm 0,34(5,0)$ & $5,69 \pm 0,13(2,3)$ & $-6,40$ & $-10,39$ \\
\hline 14 & $15,90 \pm 0,56(3,5)$ & $14,09 \pm 0,31(2,2)$ & $15,07 \pm 0,53(3,5)$ & $13,12 \pm 0,27(2,1)$ & $14,35 \pm 0,51(3,6)$ & $12,68 \pm 0,27(2,1)$ & $-6,88$ & $-10,06$ \\
\hline 15 & & $25,32 \pm 0,53(2,1)$ & & $23,53 \pm 0,46(2,0)$ & & $22,79 \pm 0,47(2,1)$ & $-7,07$ & $-10,01$ \\
\hline 16 & & $40,15 \pm 0,77(1,9)$ & & $37,29 \pm 0,67(1,8)$ & & $36,11 \pm 0,68(1,9)$ & $-7,13$ & $-10,05$ \\
\hline 17 & $51,9 \pm 1,5(2,9)$ & $58,7 \pm 1,0(1,7)$ & $49,1 \pm 1,2(2,4)$ & $54,51 \pm 0,88(1,6)$ & $46,7 \pm 1,4(3,0)$ & $52,74 \pm 0,89(1,7)$ & $-7,13$ & $-10,15$ \\
\hline 18 & & $81,1 \pm 1,2(1,5)$ & & $75,3 \pm 1,1(1,5)$ & & $72,7 \pm 1,1(1,5)$ & $-7,10$ & $-10,26$ \\
\hline 19 & $103,8 \pm 3,7(3,6)$ & $107,4 \pm 1,5(1,4)$ & $99,8 \pm 3,5(3,5)$ & $99,8 \pm 1,3(1,3)$ & $93,1 \pm 3,3(3,5)$ & $96,2 \pm 1,3(1,4)$ & $-7,04$ & $-10,38$ \\
\hline 20 & $157,4 \pm 5,6(3,6)$ & $137,8 \pm 1,8(1,3)$ & $137,0 \pm 4,9(3,6)$ & $128,2 \pm 1,6(1,2)$ & $131,7 \pm 4,7(3,6)$ & $123,3 \pm 1,6(1,3)$ & $-6,96$ & $-10,51$ \\
\hline 21 & $169,7 \pm 8,5(5,0)$ & $172,3 \pm 2,4(1,4)$ & $159,8 \pm 8,0(5,0)$ & $160,5 \pm 2,1(1,3)$ & $154,7 \pm 7,7(5,0)$ & $154,0 \pm 2,0(1,3)$ & $-6,88$ & $-10,65$ \\
\hline 22 & $212,0 \pm 7,5(3,5)$ & $211,1 \pm 5,6(2,7)$ & $198,4 \pm 7,0(3,5)$ & $196,6 \pm 5,1(2,6)$ & $190,3 \pm 6,7(3,5)$ & $194,8 \pm 4,9(2,5)$ & $-6,87$ & $-7,70$ \\
\hline 23 & & $263,2 \pm 5,3(2,0)$ & & $247,8 \pm 4,6(1,9)$ & & $238,3 \pm 4,4(1,8)$ & $-5,88$ & $-9,47$ \\
\hline 24 & $314 \pm 11(3,5)$ & $311,8 \pm 6,7(2,1)$ & $296 \pm 10(3,4)$ & $295,2 \pm 5,3(1,8)$ & $284 \pm 10(3,5)$ & $279,4 \pm 5,1(1,8)$ & $-5,32$ & $-10,41$ \\
\hline 25 & & $357,4 \pm 8,5(2,4)$ & & $339,6 \pm 6,5(1,9)$ & & $318,4 \pm 6,4(2,0)$ & $-4,99$ & $-10,91$ \\
\hline 26 & $403 \pm 20(5,0)$ & $400 \pm 10(2,5)$ & $384 \pm 14(3,6)$ & $381,2 \pm 6,3(1,7)$ & $361 \pm 13(3,6)$ & $355,8 \pm 6,5(1,8)$ & $-4,80$ & $-11,16$ \\
\hline 27 & & $409,3 \pm 9,6(2,3)$ & & $397,8 \pm 6,5(1,6)$ & & $364,1 \pm 6,8(1,9)$ & $-2,82$ & $-11,05$ \\
\hline 28 & $452 \pm 23(5,1)$ & $421,5 \pm 9,5(2,3)$ & $427 \pm 15(3,5)$ & $410,4 \pm 6,5(1,6)$ & $409 \pm 20(4,9)$ & $375,7 \pm 6,7(1,8)$ & $-2,64$ & $-10,88$ \\
\hline
\end{tabular}


Tabela 3.1 - Continuação da página anterior

\begin{tabular}{|c|c|c|c|c|c|c|c|c|}
\hline \multirow[b]{2}{*}{$\mathrm{Z}$} & \multicolumn{2}{|c|}{ Maio 2010} & \multicolumn{2}{|c|}{ Novembro 2010} & \multicolumn{2}{|c|}{ Abril 2011} & \multicolumn{2}{|c|}{ Diferença relativa a Maio 2010} \\
\hline & medido & ajustado & medido & ajustado & medido & ajustado & Nov 2010 & Abr 2011 \\
\hline \multicolumn{7}{|c|}{$10^{3} \cdot\left[\mu \mathrm{A} \cdot \mathrm{s} \cdot\left(\mu \mathrm{g} / \mathrm{cm}^{2}\right)\right]^{-1}$ (incerteza percentual \%) } & \multicolumn{2}{|c|}{$\%$} \\
\hline 29 & $415 \pm 21(5,1)$ & $426,6 \pm 9,0(2,1)$ & $415 \pm 12(2,9)$ & $415,9 \pm 6,2(1,5)$ & $390 \pm 14(3,6)$ & $381,7 \pm 6,4(1,7)$ & $-2,51$ & $-10,54$ \\
\hline 30 & & $425,6 \pm 8,3(2,0)$ & $434 \pm 22(5,1)$ & $415,3 \pm 5,8(1,4)$ & $355 \pm 18(5,1)$ & $382,8 \pm 6,0(1,6)$ & $-2,42$ & $-10,07$ \\
\hline 31 & & $419,4 \pm 7,6(1,8)$ & & $409,5 \pm 5,4(1,3)$ & & $379,5 \pm 5,6(1,5)$ & $-2,36$ & $-9,50$ \\
\hline 32 & $405 \pm 20(4,9)$ & $408,8 \pm 7,0(1,7)$ & $391 \pm 14(3,6)$ & $399,3 \pm 5,1(1,3)$ & $373 \pm 13(3,5)$ & $372,7 \pm 5,2(1,4)$ & $-2,32$ & $-8,84$ \\
\hline 33 & & $394,8 \pm 6,6(1,7)$ & & $385,8 \pm 4,9(1,3)$ & & $362,7 \pm 5,1(1,4)$ & $-2,28$ & $-8,13$ \\
\hline 34 & $365 \pm 13(3,6)$ & $378,3 \pm 6,5(1,7)$ & $357 \pm 13(3,6)$ & $369,8 \pm 5,0(1,4)$ & $343 \pm 12(3,5)$ & $350,4 \pm 5,2(1,5)$ & $-2,25$ & $-7,39$ \\
\hline 35 & $362 \pm 10(2,8)$ & $360,2 \pm 6,5(1,8)$ & $348,9 \pm 8,7(2,5)$ & $352,2 \pm 5,1(1,4)$ & $336,6 \pm 9,7(2,9)$ & $336,2 \pm 5,4(1,6)$ & $-2,22$ & $-6,67$ \\
\hline 36 & & $341,4 \pm 6,4(1,9)$ & & $334,1 \pm 5,2(1,6)$ & & $320,8 \pm 5,5(1,7)$ & $-2,16$ & $-6,03$ \\
\hline 37 & $344 \pm 17(4,9)$ & $322,8 \pm 6,1(1,9)$ & $332 \pm 17(5,1)$ & $316,2 \pm 5,2(1,6)$ & $318 \pm 16(5,0)$ & $304,9 \pm 5,5(1,8)$ & $-2,06$ & $-5,55$ \\
\hline 38 & $318 \pm 16(5,0)$ & $305,3 \pm 5,9(1,9)$ & $318 \pm 11(3,5)$ & $299,5 \pm 5,1(1,7)$ & $297 \pm 15(5,1)$ & $289,0 \pm 5,4(1,9)$ & $-1,92$ & $-5,33$ \\
\hline 39 & $282 \pm 10(3,5)$ & $289,9 \pm 6,2(2,1)$ & $275,1 \pm 9,7(3,5)$ & $284,9 \pm 5,0(1,8)$ & $265,2 \pm 9,4(3,5)$ & $273,9 \pm 5,1(1,9)$ & $-1,71$ & $-5,51$ \\
\hline 40 & & $277,3 \pm 7,8(2,8)$ & & $273,4 \pm 5,2(1,9)$ & & $260,0 \pm 5,2(2,0)$ & $-1,41$ & $-6,24$ \\
\hline \multirow[t]{2}{*}{41} & $270 \pm 13(4,8)$ & $269 \pm 11(4,1)$ & $265 \pm 13(4,9)$ & $265,9 \pm 6,4(2,4)$ & $254 \pm 13(5,1)$ & $248,1 \pm 6,3(2,5)$ & $-1,01$ & $-7,64$ \\
\hline & & & & & Média & (Incerteza) & $-4,41(0,43)$ & $-9,22(0,36)$ \\
\hline
\end{tabular}


Tabela 3.2: Calibração da Fluorescência de Raiox X linha L

\begin{tabular}{|c|c|c|c|c|c|c|c|c|}
\hline \multirow[b]{2}{*}{$\mathrm{Z}$} & \multicolumn{2}{|c|}{ Maio 2010} & \multicolumn{2}{|c|}{ Novembro 2010} & \multicolumn{2}{|c|}{ Abril 2011} & \multicolumn{2}{|c|}{ Diferença relativa a Maio 2010} \\
\hline & medido & ajustado & medido & ajustado & medido & ajustado & Novembro 2010 & Abril 2011 \\
\hline \multicolumn{7}{|c|}{$10^{3} \cdot\left[\mu \mathrm{A} \cdot \mathrm{s} \cdot\left(\mu \mathrm{g} / \mathrm{cm}^{2}\right)\right]^{-1}($ incerteza percentual \%) } & \multicolumn{2}{|l|}{$\%$} \\
\hline 29 & $1,244 \pm 0,067(5,4)$ & $1,249 \pm 0,067(5,4)$ & $1,157 \pm 0,036(3,1)$ & $1,135 \pm 0,036(3,2)$ & $1,131 \pm 0,061(5,4)$ & $1,126 \pm 0,061(5,4)$ & $-9,13$ & $-9,81$ \\
\hline 30 & & $2,428 \pm 0,098(4,0)$ & & $2,316 \pm 0,075(3,2)$ & & $2,192 \pm 0,077(3,5)$ & $-4,59$ & $-9,71$ \\
\hline 31 & & $3,42 \pm 0,14(4,1)$ & & $3,33 \pm 0,11(3,3)$ & & $3,12 \pm 0,10(3,2)$ & $-2,74$ & $-8,83$ \\
\hline 32 & $4,39 \pm 0,23(5,2)$ & $4,32 \pm 0,15(3,5)$ & $4,27 \pm 0,16(3,7)$ & $4,26 \pm 0,12(2,8)$ & $3,97 \pm 0,15(3,8)$ & $3,99 \pm 0,11(2,8)$ & $-1,53$ & $-7,83$ \\
\hline 33 & & $5,20 \pm 0,14(2,7)$ & & $5,17 \pm 0,12(2,3)$ & & $4,84 \pm 0,11(2,3)$ & $-0,63$ & $-6,91$ \\
\hline 34 & $7,12 \pm 0,26(3,7)$ & $6,12 \pm 0,13(2,1)$ & $6,98 \pm 0,25(3,6)$ & $6,12 \pm 0,11(1,8)$ & $6,59 \pm 0,24(3,6)$ & $5,75 \pm 0,11(1,9)$ & 0,04 & $-6,15$ \\
\hline 35 & $6,51 \pm 0,20(3,1)$ & $7,14 \pm 0,13(1,8)$ & $6,20 \pm 0,17(2,7)$ & $7,18 \pm 0,11(1,5)$ & $5,83 \pm 0,18(3,1)$ & $6,74 \pm 0,11(1,6)$ & 0,50 & $-5,61$ \\
\hline 36 & & $8,32 \pm 0,14(1,7)$ & & $8,38 \pm 0,13(1,6)$ & & $7,88 \pm 0,13(1,6)$ & 0,76 & $-5,31$ \\
\hline 37 & $9,32 \pm 0,55(5,9)$ & $9,69 \pm 0,18(1,9)$ & $9,61 \pm 0,55(5,7)$ & $9,77 \pm 0,16(1,6)$ & $8,21 \pm 0,49(6,0)$ & $9,18 \pm 0,16(1,7)$ & 0,87 & $-5,23$ \\
\hline 38 & $14,45 \pm 0,82(5,7)$ & $11,29 \pm 0,21(1,9)$ & $14,35 \pm 0,58(4,0)$ & $11,39 \pm 0,20(1,8)$ & $12,34 \pm 0,70(5,7)$ & $10,69 \pm 0,19(1,8)$ & 0,84 & $-5,33$ \\
\hline 39 & $12,07 \pm 0,45(3,7)$ & $13,15 \pm 0,26(2,0)$ & $11,94 \pm 0,45(3,8)$ & $13,24 \pm 0,23(1,7)$ & $10,78 \pm 0,40(3,7)$ & $12,42 \pm 0,22(1,8)$ & 0,71 & $-5,56$ \\
\hline 40 & & $15,29 \pm 0,29(1,9)$ & & $15,37 \pm 0,27(1,8)$ & & $14,39 \pm 0,26(1,8)$ & 0,52 & $-5,88$ \\
\hline 41 & $18,53 \pm 0,96(5,2)$ & $17,72 \pm 0,33(1,9)$ & $18,65 \pm 0,97(5,2)$ & $17,77 \pm 0,30(1,7)$ & $17,20 \pm 0,90(5,2)$ & $16,62 \pm 0,29(1,7)$ & 0,28 & $-6,25$ \\
\hline 42 & $22,15 \pm 0,81(3,7)$ & $20,46 \pm 0,37(1,8)$ & $21,09 \pm 0,78(3,7)$ & $20,47 \pm 0,34(1,7)$ & $19,89 \pm 0,73(3,7)$ & $19,11 \pm 0,32(1,7)$ & 0,03 & $-6,63$ \\
\hline 43 & & $23,51 \pm 0,40(1,7)$ & & $23,46 \pm 0,37(1,6)$ & & $21,86 \pm 0,35(1,6)$ & $-0,23$ & $-7,01$ \\
\hline 44 & & $26,87 \pm 0,44(1,6)$ & & $26,74 \pm 0,40(1,5)$ & & $24,89 \pm 0,38(1,5)$ & $-0,49$ & $-7,36$ \\
\hline 45 & $30,8 \pm 1,5(4,9)$ & $30,53 \pm 0,48(1,6)$ & $30,3 \pm 1,5(5,0)$ & $30,31 \pm 0,44(1,5)$ & $28,3 \pm 1,4(4,9)$ & $28,19 \pm 0,42(1,5)$ & $-0,73$ & $-7,69$ \\
\hline 46 & & $34,49 \pm 0,52(1,5)$ & & $34,15 \pm 0,48(1,4)$ & & $31,74 \pm 0,46(1,4)$ & $-0,96$ & $-7,98$ \\
\hline
\end{tabular}


Tabela 3.2 - Continuação da página anterior

\begin{tabular}{|c|c|c|c|c|c|c|c|c|}
\hline \multirow[b]{2}{*}{$\mathrm{Z}$} & \multicolumn{2}{|c|}{ Maio 2010} & \multicolumn{2}{|c|}{ Novembro 2010} & \multicolumn{2}{|c|}{ Abril 2011} & \multicolumn{2}{|c|}{ Diferença relativa a Maio 2010} \\
\hline & medido & ajustado & medido & ajustado & medido & ajustado & Nov 2010 & Abr 2011 \\
\hline \multicolumn{7}{|c|}{$10^{3} \cdot\left[\mu \mathrm{A} \cdot \mathrm{s} \cdot\left(\mu \mathrm{g} / \mathrm{cm}^{2}\right)\right]^{-1}$ (incerteza percentual \%) } & \multicolumn{2}{|c|}{$\%$} \\
\hline 47 & $40,8 \pm 2,0(4,9)$ & $38,72 \pm 0,57(1,5)$ & $38,6 \pm 1,9(4,9)$ & $38,26 \pm 0,53(1,4)$ & $36,1 \pm 1,8(5,0)$ & $35,53 \pm 0,51(1,4)$ & $-1,18$ & $-8,23$ \\
\hline 48 & & $43,21 \pm 0,62(1,4)$ & & $42,62 \pm 0,58(1,4)$ & & $39,56 \pm 0,56(1,4)$ & $-1,38$ & $-8,45$ \\
\hline 49 & & $47,95 \pm 0,69(1,4)$ & & $47,20 \pm 0,64(1,4)$ & & $43,81 \pm 0,62(1,4)$ & $-1,56$ & $-8,63$ \\
\hline 50 & & $52,90 \pm 0,75(1,4)$ & & $51,98 \pm 0,70(1,3)$ & & $48,25 \pm 0,68(1,4)$ & $-1,73$ & $-8,78$ \\
\hline 51 & $59,5 \pm 2,1(3,5)$ & $58,04 \pm 0,83(1,4)$ & $56,6 \pm 2,0(3,5)$ & $56,94 \pm 0,76(1,3)$ & $54,0 \pm 1,9(3,5)$ & $52,87 \pm 0,75(1,4)$ & $-1,88$ & $-8,90$ \\
\hline 52 & $63,2 \pm 2,2(3,5)$ & $63,33 \pm 0,90(1,4)$ & $58,2 \pm 2,1(3,6)$ & $62,05 \pm 0,82(1,3)$ & $55,3 \pm 2,0(3,6)$ & $57,64 \pm 0,81(1,4)$ & $-2,02$ & $-8,99$ \\
\hline 53 & $63,0 \pm 3,2(5,1)$ & $68,76 \pm 0,98(1,4)$ & $59,0 \pm 3,0(5,1)$ & $67,29 \pm 0,89(1,3)$ & $56,4 \pm 2,8(5,0)$ & $62,54 \pm 0,88(1,4)$ & $-2,15$ & $-9,04$ \\
\hline 54 & & $74,3 \pm 1,1(1,5)$ & & $72,61 \pm 0,96(1,3)$ & & $67,54 \pm 0,95(1,4)$ & $-2,26$ & $-9,08$ \\
\hline 55 & $77,6 \pm 2,2(2,8)$ & $79,9 \pm 1,1(1,4)$ & $74,9 \pm 1,9(2,5)$ & $78,0 \pm 1,0(1,3)$ & $71,0 \pm 2,1(3,0)$ & $72,6 \pm 1,0(1,4)$ & $-2,36$ & $-9,08$ \\
\hline 56 & $83,9 \pm 3,0(3,6)$ & $85,5 \pm 1,2(1,4)$ & $80,4 \pm 2,8(3,5)$ & $83,4 \pm 1,1(1,3)$ & $77,4 \pm 2,7(3,5)$ & $77,7 \pm 1,1(1,4)$ & $-2,46$ & $-9,07$ \\
\hline 57 & & $91,1 \pm 1,3(1,4)$ & & $88,8 \pm 1,2(1,4)$ & & $82,9 \pm 1,2(1,4)$ & $-2,54$ & $-9,03$ \\
\hline 58 & & $96,7 \pm 1,4(1,4)$ & & $94,1 \pm 1,3(1,4)$ & & $88,0 \pm 1,3(1,5)$ & $-2,61$ & $-8,98$ \\
\hline 59 & & $102,2 \pm 1,5(1,5)$ & & $99,4 \pm 1,4(1,4)$ & & $93,1 \pm 1,4(1,5)$ & $-2,68$ & $-8,90$ \\
\hline 60 & $116,1 \pm 5,8(5,0)$ & $107,5 \pm 1,6(1,5)$ & $112,6 \pm 5,6(5,0)$ & $104,6 \pm 1,5(1,4)$ & $105,2 \pm 5,3(5,0)$ & $98,1 \pm 1,5(1,5)$ & $-2,74$ & $-8,81$ \\
\hline 61 & & $112,8 \pm 1,8(1,6)$ & & $109,6 \pm 1,6(1,5)$ & & $103,0 \pm 1,6(1,6)$ & $-2,79$ & $-8,70$ \\
\hline 62 & & $117,8 \pm 1,9(1,6)$ & & $114,5 \pm 1,8(1,6)$ & & $107,7 \pm 1,7(1,6)$ & $-2,84$ & $-8,57$ \\
\hline 63 & & $122,7 \pm 2,1(1,7)$ & & $119,2 \pm 1,9(1,6)$ & & $112,3 \pm 1,9(1,7)$ & $-2,88$ & $-8,43$ \\
\hline 64 & & $127,3 \pm 2,3(1,8)$ & & $123,6 \pm 2,1(1,7)$ & & $116,8 \pm 2,1(1,8)$ & $-2,91$ & $-8,28$ \\
\hline
\end{tabular}


Tabela 3.2 - Continuação da página anterior

\begin{tabular}{|c|c|c|c|c|c|c|c|c|}
\hline \multirow[b]{2}{*}{$\mathrm{Z}$} & \multicolumn{2}{|c|}{ Maio 2010} & \multicolumn{2}{|c|}{ Novembro 2010} & \multicolumn{2}{|c|}{ Abril 2011} & \multicolumn{2}{|c|}{ Diferença relativa a Maio 2010} \\
\hline & medido & ajustado & medido & ajustado & medido & ajustado & Nov 2010 & Abr 2011 \\
\hline \multicolumn{7}{|c|}{$10^{3} \cdot\left[\mu \mathrm{A} \cdot \mathrm{s} \cdot\left(\mu \mathrm{g} / \mathrm{cm}^{2}\right)\right]^{-1}$ (incerteza percentual \%) } & \multicolumn{2}{|c|}{$\%$} \\
\hline 65 & & $131,7 \pm 2,4(1,8)$ & & $127,8 \pm 2,3(1,8)$ & & $121,0 \pm 2,2(1,8)$ & $-2,93$ & $-8,12$ \\
\hline 66 & $139,6 \pm 7,0(5,0)$ & $135,8 \pm 2,7(2,0)$ & $134,5 \pm 6,7(5,0)$ & $131,7 \pm 2,5(1,9)$ & $128,1 \pm 6,4(5,0)$ & $125,0 \pm 2,4(1,9)$ & $-2,95$ & $-7,94$ \\
\hline 67 & & $139,5 \pm 2,9(2,1)$ & & $135,4 \pm 2,7(2,0)$ & & $128,7 \pm 2,6(2,0)$ & $-2,97$ & $-7,76$ \\
\hline 68 & & $143,0 \pm 3,1(2,2)$ & & $138,7 \pm 3,0(2,2)$ & & $132,2 \pm 2,9(2,2)$ & $-2,98$ & $-7,57$ \\
\hline 69 & & $146,1 \pm 3,3(2,3)$ & & $141,8 \pm 3,2(2,3)$ & & $135,4 \pm 3,1(2,3)$ & $-2,98$ & $-7,38$ \\
\hline 70 & $147,0 \pm 7,4(5,0)$ & $148,9 \pm 3,5(2,4)$ & $140,9 \pm 7,1(5,0)$ & $144,5 \pm 3,4(2,4)$ & $136,4 \pm 6,8(5,0)$ & $138,2 \pm 3,2(2,3)$ & $-2,98$ & $-7,18$ \\
\hline 71 & & $151,4 \pm 3,7(2,4)$ & & $146,9 \pm 3,6(2,5)$ & & $140,8 \pm 3,4(2,4)$ & $-2,97$ & $-6,98$ \\
\hline 72 & & $153,5 \pm 3,9(2,5)$ & & $149,0 \pm 3,7(2,5)$ & & $143,1 \pm 3,6(2,5)$ & $-2,96$ & $-6,78$ \\
\hline 73 & & $155,3 \pm 4,0(2,6)$ & & $150,7 \pm 3,8(2,5)$ & & $145,0 \pm 3,7(2,6)$ & $-2,94$ & $-6,60$ \\
\hline 74 & $152,6 \pm 7,6(5,0)$ & $156,7 \pm 4,0(2,6)$ & $146,7 \pm 7,3(5,0)$ & $152,2 \pm 3,9(2,6)$ & $139,2 \pm 7,0(5,0)$ & $146,7 \pm 3,7(2,5)$ & $-2,91$ & $-6,42$ \\
\hline 75 & & $157,9 \pm 4,0(2,5)$ & & $153,3 \pm 3,9(2,5)$ & & $148,0 \pm 3,7(2,5)$ & $-2,88$ & $-6,27$ \\
\hline 76 & & $158,8 \pm 4,0(2,5)$ & & $154,3 \pm 3,8(2,5)$ & & $149,0 \pm 3,6(2,4)$ & $-2,84$ & $-6,13$ \\
\hline 77 & & $159,4 \pm 3,8(2,4)$ & & $154,9 \pm 3,7(2,4)$ & & $149,8 \pm 3,5(2,3)$ & $-2,79$ & $-6,03$ \\
\hline 78 & $161,3 \pm 8,1(5,0)$ & $159,8 \pm 3,6(2,3)$ & $155,5 \pm 7,8(5,0)$ & $155,4 \pm 3,5(2,3)$ & $150,4 \pm 7,5(5,0)$ & $150,3 \pm 3,3(2,2)$ & $-2,74$ & $-5,97$ \\
\hline 79 & $171,7 \pm 8,6(5,0)$ & $160,1 \pm 3,4(2,1)$ & $164,7 \pm 8,2(5,0)$ & $155,8 \pm 3,2(2,1)$ & $160,2 \pm 8,0(5,0)$ & $150,5 \pm 3,1(2,1)$ & $-2,69$ & $-5,96$ \\
\hline 80 & & $160,2 \pm 3,1(1,9)$ & & $156,0 \pm 3,0(1,9)$ & & $150,6 \pm 2,9(1,9)$ & $-2,62$ & $-6,02$ \\
\hline 81 & & $160,3 \pm 3,1(1,9)$ & & $156,2 \pm 3,0(1,9)$ & & $150,4 \pm 2,9(1,9)$ & $-2,55$ & $-6,15$ \\
\hline 82 & $157,5 \pm 5,6(3,6)$ & $160,4 \pm 3,5(2,2)$ & $153,7 \pm 5,4(3,5)$ & $156,4 \pm 3,4(2,2)$ & $148,5 \pm 5,3(3,6)$ & $150,2 \pm 3,2(2,1)$ & $-2,48$ & $-6,37$ \\
\hline
\end{tabular}


Tabela 3.2 - Continuação da página anterior

\begin{tabular}{|c|c|c|c|c|c|c|c|c|}
\hline \multirow[b]{2}{*}{$\mathrm{Z}$} & \multicolumn{2}{|c|}{ Maio 2010} & \multicolumn{2}{|c|}{ Novembro 2010} & \multicolumn{2}{|c|}{ Abril 2011} & \multicolumn{2}{|c|}{ Diferença relativa a Maio 2010} \\
\hline & medido & ajustado & medido & ajustado & medido & ajustado & Nov 2010 & Abr 2011 \\
\hline & \multicolumn{6}{|c|}{$10^{3} \cdot\left[\mu \mathrm{A} \cdot \mathrm{s} \cdot\left(\mu \mathrm{g} / \mathrm{cm}^{2}\right)\right]^{-1}$ (incerteza percentual \%) } & \multicolumn{2}{|c|}{$\%$} \\
\hline 83 & $160,4 \pm 5,7(3,6)$ & $160,6 \pm 4,3(2,7)$ & $156,5 \pm 5,5(3,5)$ & $156,8 \pm 4,2(2,7)$ & $148,8 \pm 5,3(3,6)$ & $149,9 \pm 4,0(2,7)$ & $-2,40$ & $-6,70$ \\
\hline & & & & & Média & (Incerteza) & $-2,02(0,22)$ & $-7,48(0,18)$ \\
\hline
\end{tabular}


Ressaltamos, ainda, que calibrações periódicas são necessárias para atualizar os fatores de resposta devido às variações na eficiência do equipamento. Podem, ainda, vir a sinalizar eventuais avarias no sistema. A figura 3.2 mostra uma gradual queda do desempenho da XRF-ED durante esta análise, ao longo das três calibrações realizadas. A diferença média no fator de resposta em relação a maio de 2010 foi de $-4,41 \pm 0,43 \%$ para novembro 2010 e $-9,22 \pm 0,36 \%$ para abril de 2011 , na linha $K$, enquanto na linha L foi de $-2,02 \pm 0,22 \%$ e $-7,48 \pm 0,18 \%$, respectivamente. Essa é uma tendência esperada, devido ao envelhecimento do tubo de raios X (alvo de Rh no nosso caso) e à perda de eficiência no detector. Por conseguinte, a substituição de um destes componentes pede sempre uma imediata recalibração do equipamento.

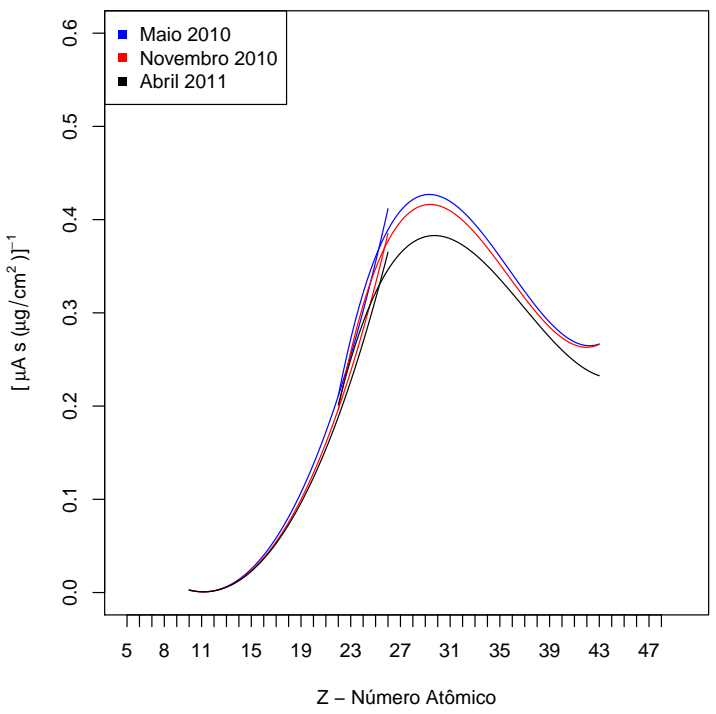

(a) linha $\mathrm{K}$

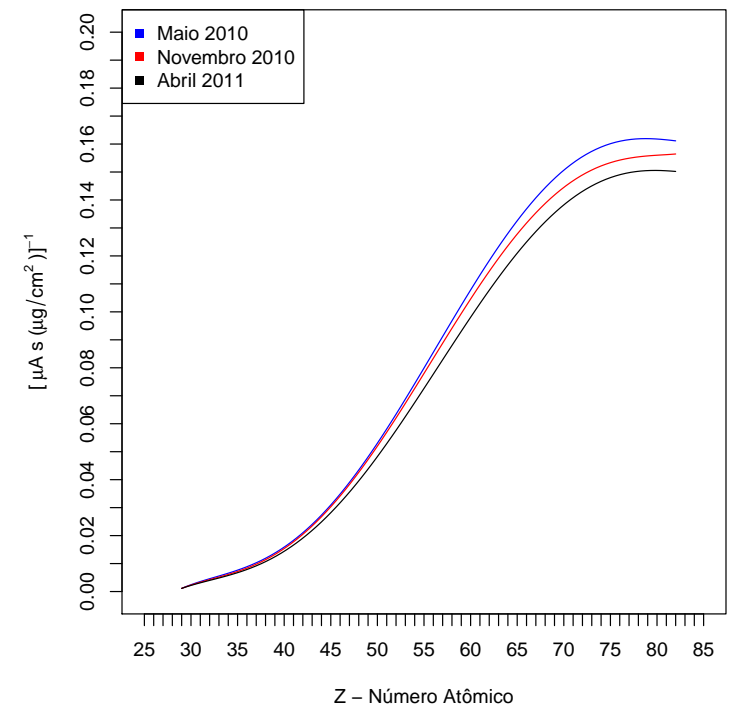

(b) linha $\mathrm{L}$

Figura 3.2: Comparação das calibrações da XRF-ED nos 3 períodos.

\subsubsection{Comparação interlaboratorial com a US-EPA}

Entre as 2898 amostras enviadas para serem analisadas por XRF no LAPAt, 92 foram previamente quantificadas por XRF na US-EPA. O Prof. Dr. Majid Ezzati, no intuito de fazer um teste cego sobre a qualidade das nossas medidas, para verificação da exatidão e precisão dos resultados, não nos passou tal informação. Somente depois que enviamos os resultados de um primeiro pacote de análises, é que fomos chamados a discutir esta intercomparação, que mostrou uma qualidade muito boa.

Esse tipo de procedimento representa uma boa prática analítica e tem sido particularmente recomendada para pesquisas ambientais. Kang et al. (2014) aponta que a precisão de medidas 
elementares usando XRF tornou-se importante nos últimos anos porque as concentrações de MP ambiente estão diminuído, devido a leis mais rigorosas e ao desenvolvimento tecnológico, chegando próximas aos limites de deteç̧ão para algumas cidades. Sugere a intercomparação com outros laboratórios como medida necessária para avaliar a qualidade dos resultados. Considera necessário não apenas intercomparação entre laboratórios que trabalham com XRF, mas intercomparação com equipamentos de outros laboratórios que funcionam com princípios físicos diferentes, caso de Nejedlỳ et al. (1998), que encontrou concordância entre medidas de XRF e PIXE (Particle-Induced X-ray Emission) intra-laboratoriais.

A intercomparação dos resultados das medidas das 92 amostras da XRF do LAPAt e da XRF da US-EPA estão expostos nos gráficos da figura 3.3. Verifica-se boa concordância, isto é, pontos bem alinhados em relação à linha 1:1 (linha vermelha) para os elementos com concentrações adequadamente definidas acima do limite de detecção: Al, S, K, Ca, Sr e Zn e $\mathrm{Pb}$ a menos de um outlier, mostrando que as medidas estão correlacionadas e concordantes em valores absolutos. Outro elementos como $\mathrm{Si}$, Ti, Fe, Mn e Br provavelmente tiveram problemas de ajuste do espectro, por isso a leve flutuação.

Os valores para $\mathrm{V}$ e $\mathrm{P}$ mostraram-se mais dispersos por estarem próximos aos respectivos limites de detecção do equipamento de XRF da US-EPA. A linha K do Cl se sobrepõe a linha $\mathrm{L}$ do $\mathrm{Rh}$ (tubo de raios X usado no equipamento do LAPAt), dificultando a medida do mesmo.

Foi realizada uma regressão linear simples, sem barra de erro para o ajuste, pois os valores enviados pela US-EPA não continham incertezas, se incluída as incertezas, seria possível refinar essa comparação. A interlaboratorial possibilitou a validação do método de calibração desenvolvido no LAPAt, em confronto com uma instituição com o nível de reconhecimento da US-EPA. 

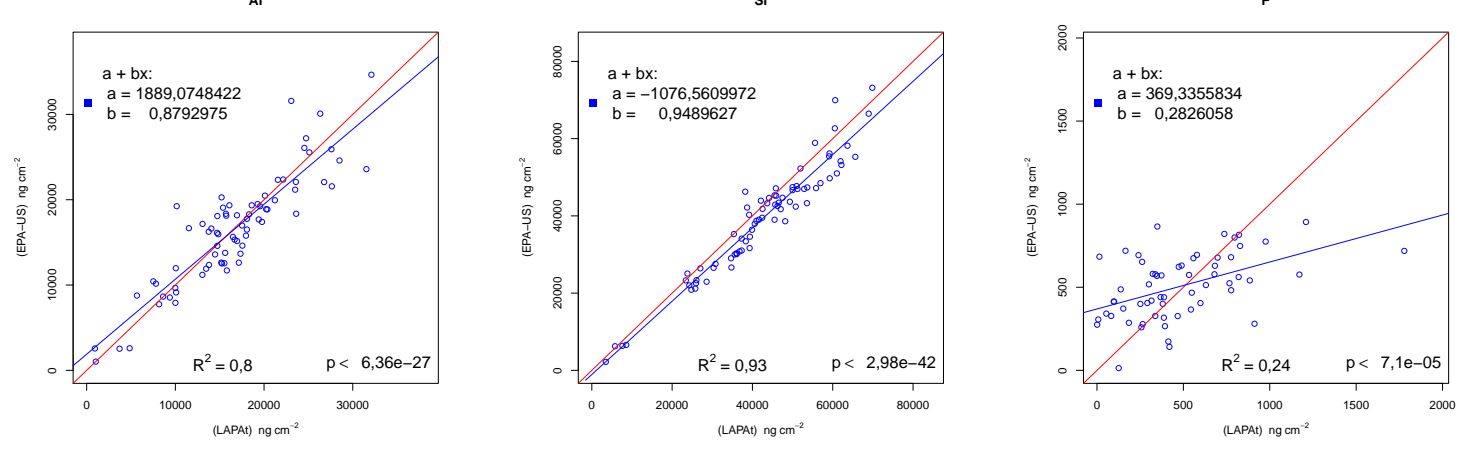

s

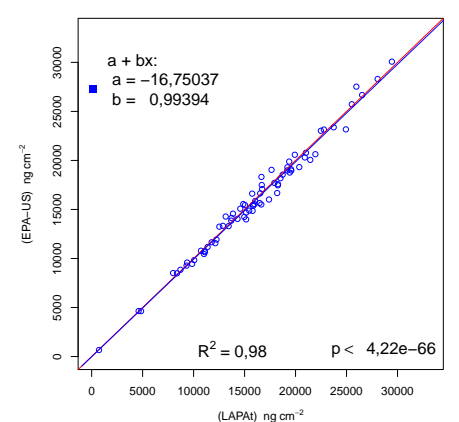

cl
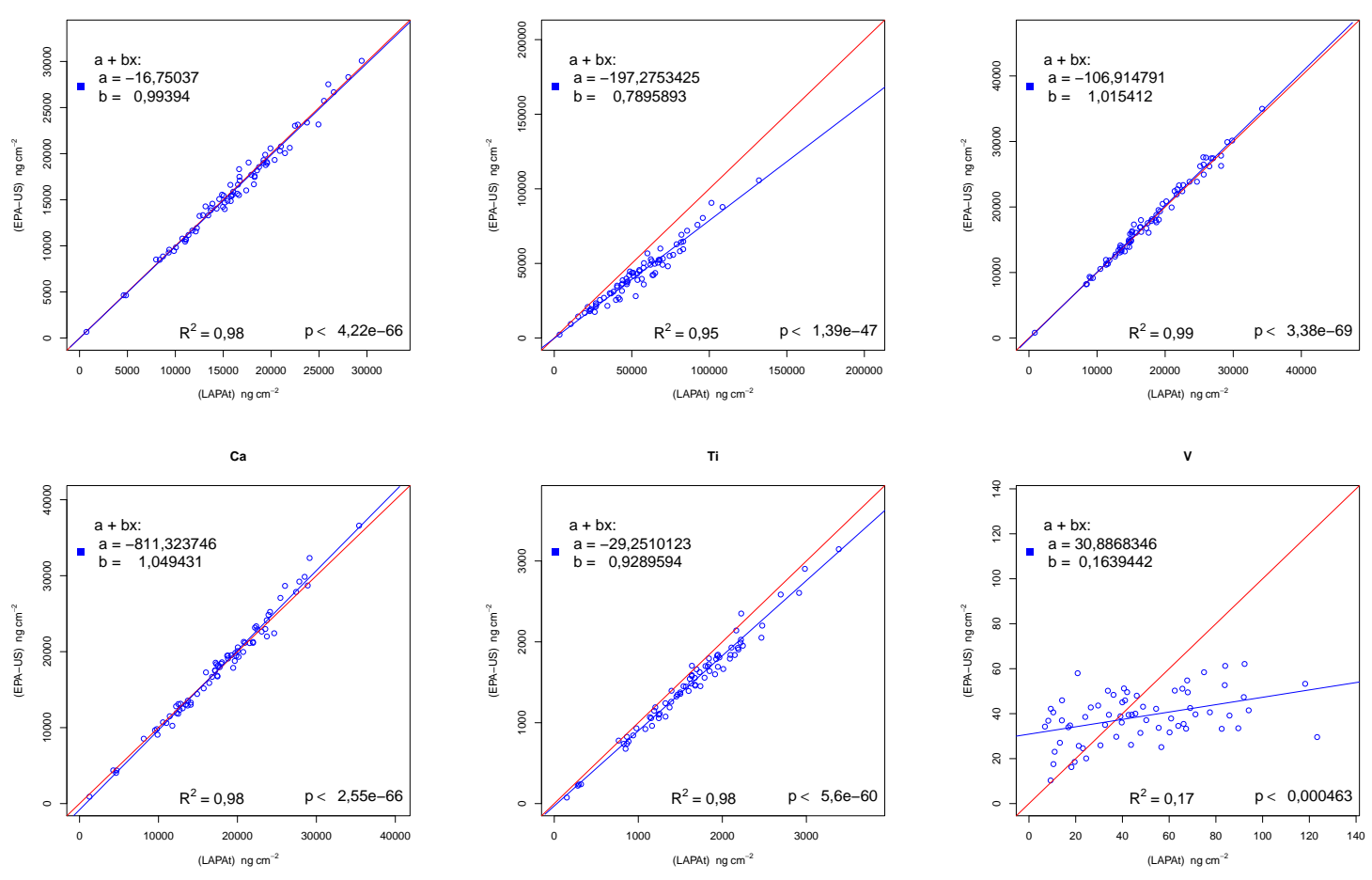

Mn
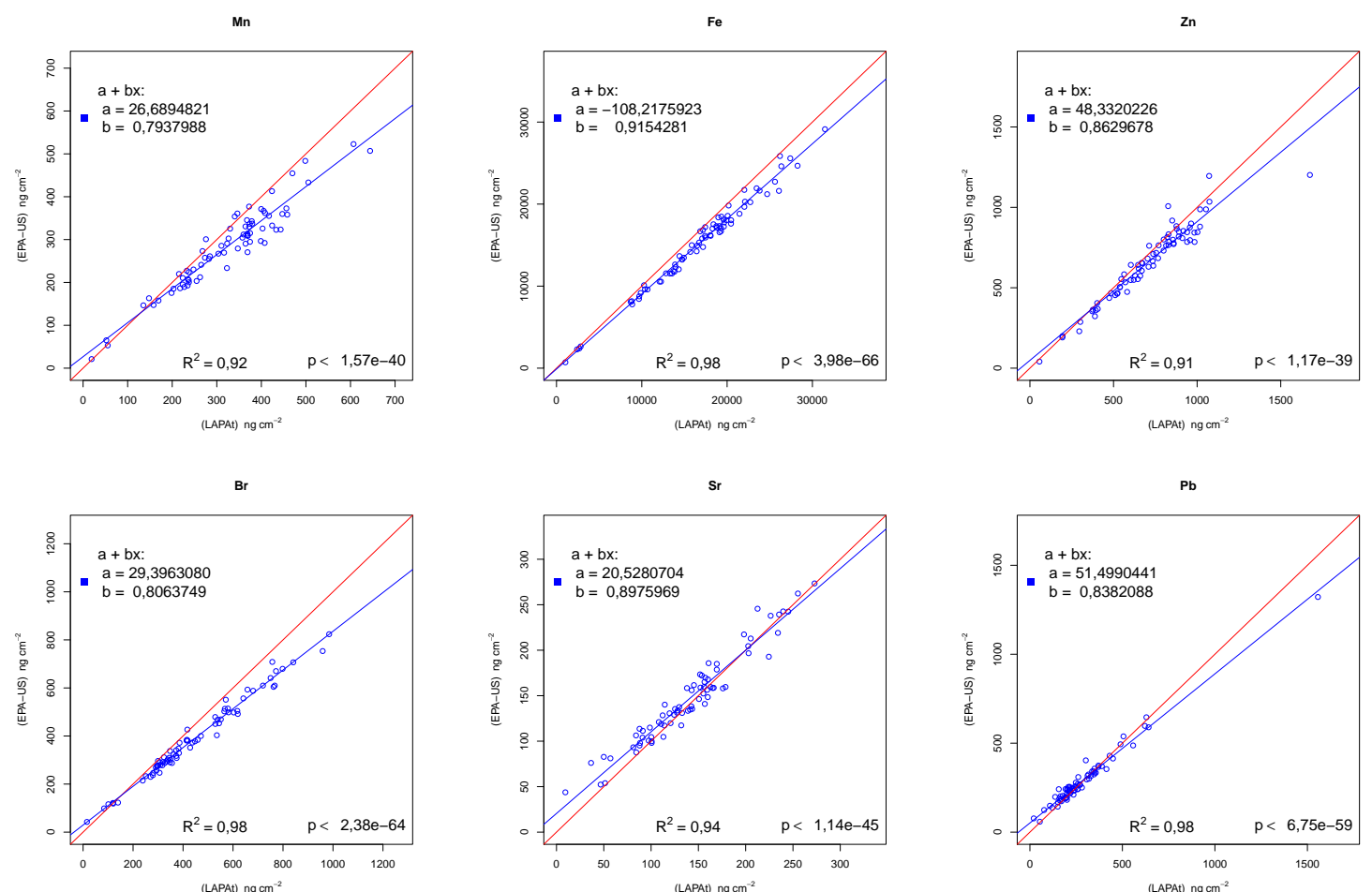

$\mathrm{Pb}$

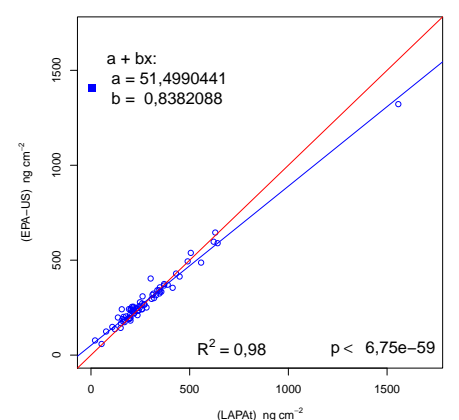

Figura 3.3: Comparação das análises de XRF no LAPAt e na US-EPA. 


\subsection{Black Carbon}

Medidas de BC pela técnica de refletância apresentam a vantagem de poderem ser realizadas sobre os mesmos filtros empregados para análises gravimétricas, XRF ou mesmo em técnicas destrutivas que posteriormente possam vir a ser realizadas sobre eles, como cromatografia iônica ou espectroscopia de massa. Isso promove a redução das incertezas provenientes de análises que pedem diferentes amostradores coletados em paralelo. Também pode diminuir significativamente a dimensão da instrumentação em uma pesquisa. Entretanto, a refletância é uma medida indireta, cujo resultado depende das características do aerossol amostrado. Utilizando o método absoluto TOT para algumas amostras, foi possível intercalibrar as medidas de refletância com esse método absoluto, permitindo a quantificação do BC nas demais amostras.

\subsubsection{Calibração da refletância usando BC Monarch 71}

Alvos padrões produzidos no laboratório do antigo GEPA-IFUSP (Grupo de Estudos de Poluição do Ar), hoje Laboratório de Física Atmosférica (LFA-IFUSP), com concentrações conhecidas do BC de referência Monarch 71 (M71) (Clarke et al., 1986), foram usados por décadas em equipamentos de refletância alocados nestes laboratórios e no LAPAt, para a calibração de refletância versus densidade superficial de BC em filtros que coletaram aerossol atmosférico.

A tabela 3.3 mostra um conjunto de valores medidos em 2007 para estes padrões (com respectivas médias e incertezas), sobre os quais foi feita uma calibração no Lapat, seguindo exatamente os mesmos procedimentos do GEPA/LFA-IFUSP. Os novos parâmetros então ajustados ofereciam resultados apenas 2,3\% menores que a calibração anterior (1994), do GEPA/LFA-IFUSP. Isso revela equipamentos uniformes e grande estabilidade destes padrões. Entretanto, essa sistemática de calibração padecia de três problemas.

O primeiro deles refere-se à estreita faixa de valores oferecidas por estes padrões que, como pode ser visto na referida tabela, variam entre $30 \%$ e $85 \%$, não cobrindo a região acima de $85 \%$ ou abaixo de $30 \%$, esta última onde posicionam-se os filtros carregados que encontramos no experimento de Gana. Mesmo assim, se fosse considerada a linearidade que predomina na relação entre densidade de $\mathrm{BC}$ e $\log$ da refletância, equação 2.25, e acrescida no ajuste a massa zero, para qual a refletância é $100 \%\left(\log _{10} 100=2\right)$, poder-se-ia estender o ajuste para uma faixa apreciável de valores. Mas a função adotada para os ajustes foi uma parábola. 
Esse foi um segundo problema para esta calibração, como se pode verificar na figura 3.4, essa função distancia-se bastante de um ajuste linear conforme nos deslocamos em direção a $\log _{10}$ 10, ponto em que a relação da massa com o log da refletância começa a perder a linearidade. O gráfico da figura 3.9a mostra que a margem de erro em alvos carregados cresce com o ajuste de $2^{\circ}$ grau, quando confrontado com a calibração baseada em TOT, para filtros coletados em Gana. Note-se, entretanto, que na zona de refletância onde havia alvos padrões, as diferenças com o método absoluto, por óbvio, são semelhantes.

A calibração do refletômetro do LAPAt para 2007 usando alvos padrões M71 com ajuste de primeiro grau está no gráfico da figura 3.4, com respectivos dados apresentados na tabela 3.3 .

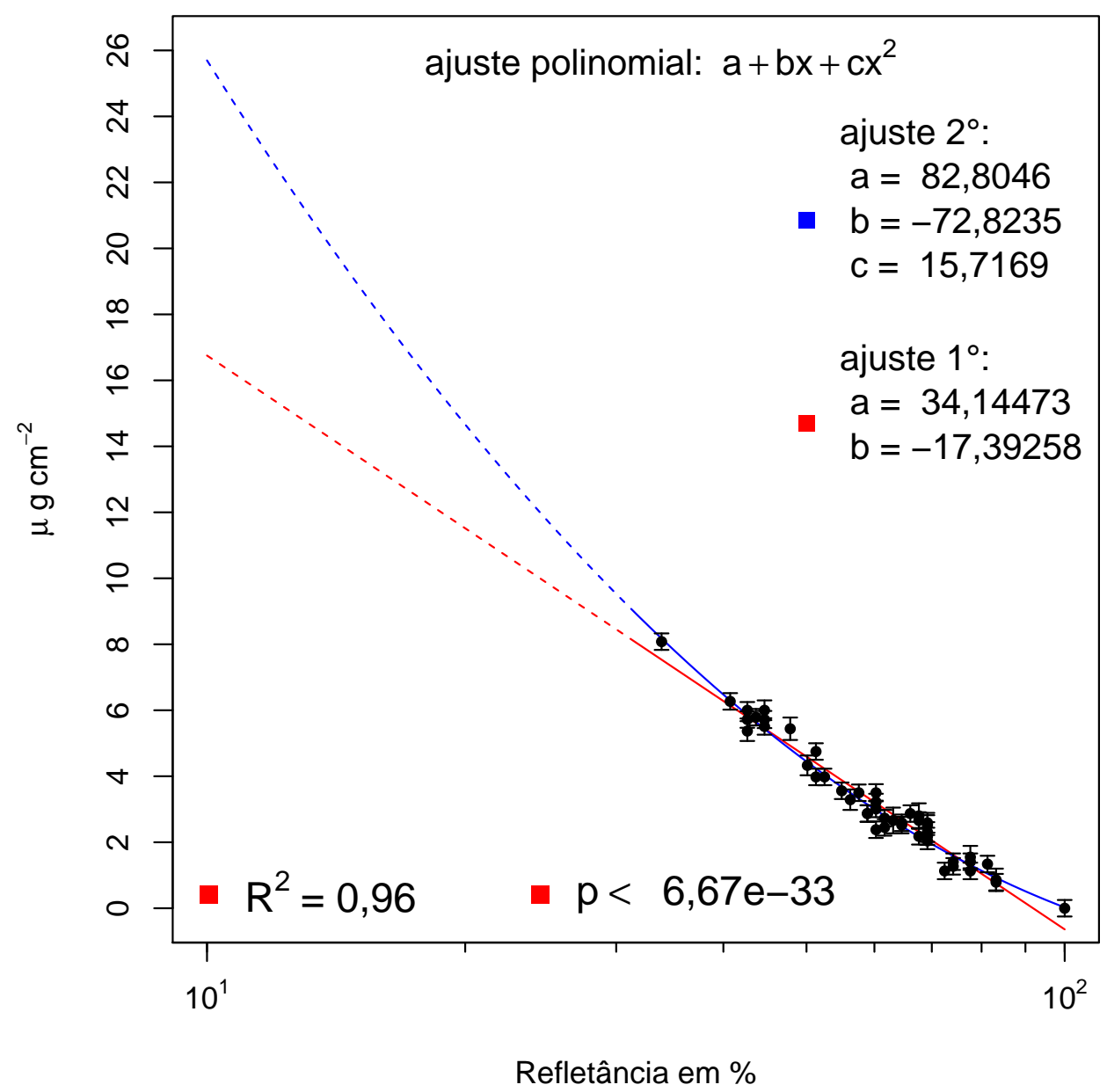

Figura 3.4: Calibração do refletômetro do LAPAt em 2007 usando alvos padrões M71. 
Tabela 3.3: Calibração do refletômetro do LAPAt em 2007 usando alvos padrões M71.

\begin{tabular}{|c|c|c|c|c|c|c|}
\hline \multirow[t]{2}{*}{ ID } & \multicolumn{4}{|c|}{ Refletâncias (\%) } & \multirow{2}{*}{$\begin{array}{c}\text { Alvo Padrão } \\
\mu \mathrm{g} / \mathrm{cm}^{2}\end{array}$} & \multirow{2}{*}{$\begin{array}{l}\text { Ajustado } \\
\mu \mathrm{g} / \mathrm{cm}^{2}\end{array}$} \\
\hline & 1 & 2 & 3 & média & & \\
\hline & 100,0 & 100,0 & 100,0 & 100,0 & $0,00 \pm 0,25$ & $-0,64$ \\
\hline 2 & 33,8 & 33,6 & 33,9 & 33,8 & $8,08 \pm 0,25$ & 7,53 \\
\hline 3 & 65,6 & 66,0 & 66,6 & 66,1 & $2,87 \pm 0,25$ & 2,49 \\
\hline 4 & 69,0 & 68,5 & 69,0 & 68,8 & $2,52 \pm 0,30$ & 2,14 \\
\hline 5 & 61,0 & 60,8 & 60,7 & 60,8 & $3,50 \pm 0,26$ & 3,19 \\
\hline 6 & 84,0 & 83,2 & 83,9 & 83,7 & $0,86 \pm 0,34$ & 0,75 \\
\hline 7 & 68,3 & 67,9 & 67,8 & 68,0 & $2,80 \pm 0,38$ & 2,32 \\
\hline 8 & 51,5 & 50,5 & 51,3 & 51,1 & $4,75 \pm 0,25$ & 4,40 \\
\hline 9 & 68,2 & 67,8 & 68,5 & 68,2 & $2,66 \pm 0,25$ & 2,32 \\
\hline 10 & 81,2 & 80,7 & 81,3 & 81,1 & $1,34 \pm 0,25$ & 0,92 \\
\hline 12 & 69,4 & 68,9 & 69,4 & 69,2 & $2,59 \pm 0,30$ & 2,14 \\
\hline 13 & 60,4 & 59,9 & 60,3 & 60,2 & $3,22 \pm 0,25$ & 3,19 \\
\hline 14 & 61,4 & 61,3 & 61,3 & 61,3 & $2,73 \pm 0,25$ & 3,01 \\
\hline 15 & 69,9 & 69,5 & 70,2 & 69,9 & $2,04 \pm 0,25$ & 2,14 \\
\hline 16 & 64,9 & 64,7 & 65,1 & 64,9 & $2,52 \pm 0,25$ & 2,66 \\
\hline 17 & 52,8 & 52,4 & 53,0 & 52,7 & $3,98 \pm 0,25$ & 4,23 \\
\hline 18 & 42,9 & 42,7 & 42,9 & 42,8 & $5,37 \pm 0,30$ & 5,79 \\
\hline 19 & 63,0 & 62,6 & 63,2 & 62,9 & $2,66 \pm 0,39$ & 2,84 \\
\hline 20 & 60,0 & 59,4 & 60,0 & 59,8 & $3,01 \pm 0,25$ & 3,19 \\
\hline 21 & 55,0 & 55,0 & 55,4 & 55,1 & $3,56 \pm 0,25$ & 3,88 \\
\hline 22 & 73,6 & 73,6 & 74,0 & 73,7 & $1,27 \pm 0,25$ & 1,62 \\
\hline 23 & 58,6 & 58,5 & 58,8 & 58,6 & $2,87 \pm 0,25$ & 3,36 \\
\hline 24 & 58,0 & 58,2 & 58,5 & 58,2 & $2,87 \pm 0,25$ & 3,36 \\
\hline 25 & 73,7 & 73,5 & 73,4 & 73,5 & $1,41 \pm 0,25$ & 1,62 \\
\hline 26 & 59,9 & 59,8 & 60,3 & 60,0 & $2,38 \pm 0,25$ & 3,19 \\
\hline 27 & 62,3 & 62,1 & 62,3 & 62,2 & $2,45 \pm 0,25$ & 3,01 \\
\hline 28 & 43,3 & 43,2 & 43,4 & 43,3 & $5,79 \pm 0,25$ & 5,62 \\
\hline 29 & 42,9 & 42,9 & 42,7 & 42,8 & $6,00 \pm 0,25$ & 5,79 \\
\hline 30 & 44,7 & 44,4 & 44,6 & 44,6 & $5,72 \pm 0,26$ & 5,45 \\
\hline 31 & 50,9 & 50,4 & 51,0 & 50,8 & $3,98 \pm 0,25$ & 4,40 \\
\hline 32 & 47,3 & 47,3 & 47,4 & 47,3 & $5,44 \pm 0,34$ & 4,93 \\
\hline 33 & 44,5 & 44,3 & 44,6 & 44,5 & $6,00 \pm 0,30$ & 5,45 \\
\hline 34 & 44,4 & 43,9 & 44,4 & 44,2 & $5,51 \pm 0,25$ & 5,45 \\
\hline 35 & 69,4 & 69,6 & 69,7 & 69,6 & $2,18 \pm 0,26$ & 2,14 \\
\hline 36 & 68,5 & 69,0 & 69,2 & 68,9 & $2,31 \pm 0,30$ & 2,14 \\
\hline 37 & 64,8 & 64,8 & 64,9 & 64,8 & $2,59 \pm 0,25$ & 2,66 \\
\hline 38 & 56,8 & 57,1 & 57,4 & 57,1 & $3,50 \pm 0,25$ & 3,53 \\
\hline 39 & 67,2 & 67,4 & 67,6 & 67,4 & $2,18 \pm 0,25$ & 2,32 \\
\hline 40 & 76,8 & 77,0 & 77,2 & 77,0 & $1,41 \pm 0,25$ & 1,27 \\
\hline 41 & 82,9 & 83,4 & 83,5 & 83,3 & $0,79 \pm 0,25$ & 0,75 \\
\hline 42 & 71,6 & 71,4 & 73,2 & 72,1 & $1,13 \pm 0,25$ & 1,79 \\
\hline 43 & 77,1 & 77,1 & 77,8 & 77,3 & $1,55 \pm 0,34$ & 1,27 \\
\hline 44 & 40,5 & 40,4 & 40,8 & 40,6 & $6,27 \pm 0,25$ & 6,14 \\
\hline 45 & 76,5 & 76,5 & 77,3 & 76,8 & $1,13 \pm 0,25$ & 1,27 \\
\hline 46 & 49,8 & 49,8 & 50,3 & 50,0 & $4,33 \pm 0,30$ & 4,58 \\
\hline 47 & 55,8 & 56,0 & 56,3 & 56,0 & $3,29 \pm 0,31$ & 3,71 \\
\hline 48 & 42,3 & 42,2 & 42,6 & 42,4 & $5,72 \pm 0,25$ & 5,79 \\
\hline
\end{tabular}


Procuramos construir uma calibração mais consistente, produzindo alvos de calibração que cobrissem toda a faixa de valores entre 0 a $100 \%$ de refletância. Mas não encontramos mais o BC M71 para comercializar, assim usamos o BC de referência (ASTM-N762) do IPT com o qual produzimos 27 padrões depositados em filtros de policarbonato (nuclepore fino de $37 \mathrm{~mm}$, orifícios de 0,4 $\mu \mathrm{m}$ ) usando amostrador dicotômico (diâmetro de corte em 2,5 $\mu \mathrm{m}$ ) na câmara de ressuspensão do laboratórios da Divisão de Qualidade do Ar da CETESB.

Os valores de refletância nesses filtros variaram de 3,1\% até 98,7\%, mais um "zero"de massa teórico com refletância 100\%. As massas foram medidas em microbalança analítica \pm 1 g. A figura 3.5 mostra o ajuste entre massa de BC depositada versus o log da refletância medida. Pode-se ver que o ajuste linear foi excelente, indicando que a calibração deve perder linearidade apenas em refletâncias inferiores a 5\%.

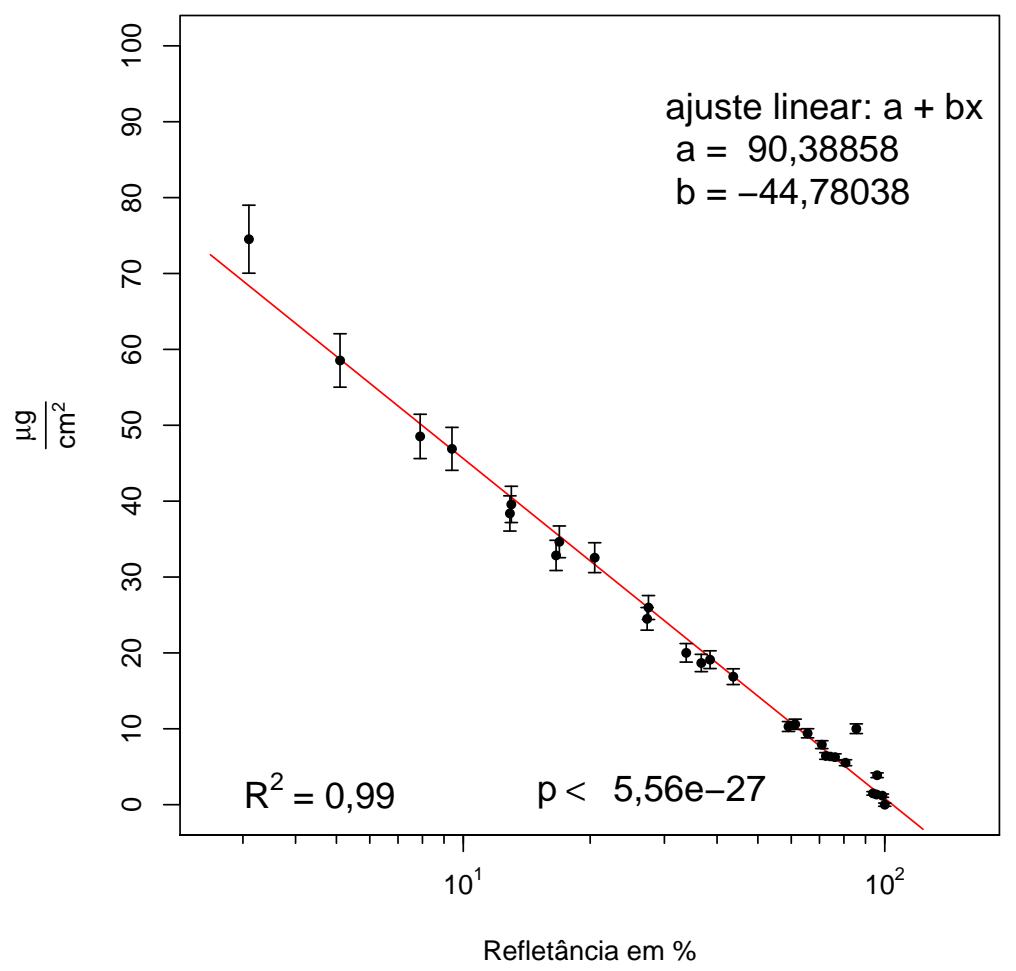

Figura 3.5: Reflêtancia e pesagem dos padrões produzidos na CETESB com BC de referência ASTM-N762. 
Tabela 3.4: Reflêtancia e pesagem dos padrões produzidos na CETESB com BC de referência ASTM-N762.

\begin{tabular}{ccccc}
\hline ID & $\begin{array}{c}\text { Refletância (\%) } \\
\pm 1,1 \%\end{array}$ & $\begin{array}{c}\text { Gravimetria } \\
\mu \mathrm{g} / \mathrm{cm}^{2}\end{array}$ & $\begin{array}{c}\sigma_{\text {efetivo }} \\
\mu \mathrm{g} / \mathrm{cm}^{2}\end{array}$ & $\begin{array}{c}\text { Ajustado } \\
\mu \mathrm{g} / \mathrm{cm}^{2}\end{array}$ \\
\hline zero & 100,0 & $0,00 \pm 0,21$ & 0,50 & $0,83 \pm 0,21$ \\
BC37-1 & 95,9 & $3,88 \pm 0,31$ & 0,57 & $1,64 \pm 0,20$ \\
BC37-1.2 & 85,6 & $10,01 \pm 0,64$ & 0,83 & $3,85 \pm 0,18$ \\
BC37-1.3 & 76,2 & $6,27 \pm 0,43$ & 0,74 & $6,11 \pm 0,18$ \\
BC37-1.4 & 70,9 & $7,91 \pm 0,52$ & 0,83 & $7,52 \pm 0,19$ \\
BC37-1.5 & 65,6 & $9,41 \pm 0,60$ & 0,92 & $9,03 \pm 0,21$ \\
BC37-1.6 & 61,3 & $10,60 \pm 0,67$ & 1,0 & $10,35 \pm 0,23$ \\
BC37-1.7 & 43,7 & $16,9 \pm 1,0$ & 1,5 & $16,93 \pm 0,37$ \\
BC37-1.8 & 27,5 & $26,0 \pm 1,6$ & 2,3 & $25,93 \pm 0,59$ \\
BC37-1.9 & 27,3 & $24,5 \pm 1,5$ & 2,2 & $26,08 \pm 0,60$ \\
BC37-1.10 & 93,8 & $1,49 \pm 0,23$ & 0,54 & $2,07 \pm 0,20$ \\
BC37-1.11 & 95,6 & $1,34 \pm 0,23$ & 0,53 & $1,70 \pm 0,20$ \\
BC37-1.12 & 98,7 & $1,19 \pm 0,22$ & 0,51 & $1,08 \pm 0,21$ \\
BC37-1.13 & 80,7 & $5,53 \pm 0,39$ & 0,69 & $5,00 \pm 0,18$ \\
BC37-1.14 & 38,5 & $19,1 \pm 1,2$ & 1,7 & $19,39 \pm 0,43$ \\
BC37-1.15 & 20,5 & $32,5 \pm 2,0$ & 3,0 & $31,65 \pm 0,74$ \\
BC37-1.16 & 16,9 & $34,6 \pm 2,1$ & 3,4 & $35,40 \pm 0,84$ \\
BC37-1.17 & 12,9 & $38,4 \pm 2,3$ & 4,2 & $40,66 \pm 0,98$ \\
BC37-1.18 & 13,0 & $39,6 \pm 2,4$ & 4,2 & $40,51 \pm 0,98$ \\
BC37-1.19 & 9,4 & $46,9 \pm 2,8$ & 5,6 & $46,8 \pm 1,2$ \\
BC37-1.20 & 3,1 & $74,5 \pm 4,5$ & 15 & $68,4 \pm 1,7$ \\
BC37-1.21 & 7,9 & $48,5 \pm 2,9$ & 6,5 & $50,2 \pm 1,2$ \\
BC37-1.22 & 16,6 & $32,9 \pm 2,0$ & 3,4 & $35,75 \pm 0,85$ \\
BC37-1.23 & 33,8 & $20,0 \pm 1,2$ & 1,8 & $21,92 \pm 0,49$ \\
BC37-1.24 & 5,1 & $58,5 \pm 3,5$ & 9,6 & $58,7 \pm 1,5$ \\
BC37-1.25 & 36,7 & $18,7 \pm 1,1$ & 1,7 & $20,32 \pm 0,45$ \\
BC37-1.26 & 59,1 & $10,30 \pm 0,65$ & 1,0 & $11,06 \pm 0,24$ \\
BC37-1.27 & 72,5 & $6,42 \pm 0,44$ & 0,77 & $7,08 \pm 0,18$ \\
\hline
\end{tabular}

As barras de erros nas massas correspondem ao erro efetivo $\sigma_{\text {efetivo, o qual é a adição }}$ (soma dos quadrados) do erro propagado da refletância (eixo x) com o erro de medida da massa (eixo y). Como a relação entre x e y é linear, a incerteza em y devido a x pode ser escrita como:

$$
\sigma_{y_{x}}=\frac{\partial y}{\partial x} \cdot \sigma_{x}
$$

Usada na soma dos quadrados para calcular a incerteza efetiva em y, $\sigma_{\text {efetiva }}$ :

$$
\sigma_{\text {efetiva }}=\sqrt{\sigma_{y}^{2}+{\sigma_{y x}}^{2}}
$$

Como a menor medida na leitura do aparelho digital de refletância é 0,1\% (o \% aqui é a unidade de medida para refletância) é muito baixa, estimamos a incerteza na refletância a partir da oscilação na alvura do substrato de amostragem calculando o desvio padrão para sete 
amostras brancas $(\sigma=0,957 \%)$. Aplicamos correção de fator 1,11 devido ao espaço amostral pequeno (Helene \& Vanin, 1981), resultando em $\sigma=1,06 \%$.

Infelizmente, como veremos a seguir, no confronto com TOT, o BC utilizado mostrou ter características bastante diversas do $\mathrm{BC}$ encontrado regularmente na atmosfera, introduzindo um erro sistemático da ordem de um fator 5. 


\subsubsection{Calibração com TOT - Experiência nos túneis Jânio Quadros e Rodoanel}

Em maio de 2011, simultaneamente ao período de análises das amostras de Gana, conduzia-se experimento para analisar as emissões veiculares na cidade de São Paulo. As medidas foram feitas no interior dos túneis Jânio Quadros e Rodoanel, que têm características de circulação predominante de veículos leves e pesados (ou diesel), respectivamente.

Tomou-se amostragens simultâneas de $M P_{2,5}$, por amostrador MiniVol com filtros de quartzo e por amostrador Partisol com filtros de policarbonato, sendo o primeiro para medida absoluta de EC por TOT e o segundo para análises de XRF-ED, medida relativa de BC por refletância e para cromatografia iônica.

Tamanha era a poluição dos caminhões que os filtros coletados no Rodoanel ficaram saturados para medidas de BC por refletância (valores próximos a zero), o que impossibilitou usá-los para fins de calibração. No túnel Jânio Quadros as refletâncias variaram de 4,9 a $57,1 \%$, permitindo a calibração da refletância por TOT.

A determinação BC por TOT nos filtros de quartzo foi conduzida pelo Dr. Pierre Herckes, do Departamento de Química e Bioquímica da Universidade Estadual do Arizona. Contouse com 16 filtros coletados no túnel Jânio Quadros. O gráfico da figura 3.6 apresenta a intercalibração com ajuste linear entre as medidas de TOT nas amostras dos filtros de quartzo e a refletância das 16 amostras correspondentes nos filtros de policarbonato. Nota-se a boa qualidade do ajuste linear de calibração da densidade superficial de massa de BC versus o log da refletância por TOT no túnel Jânio Quadros.

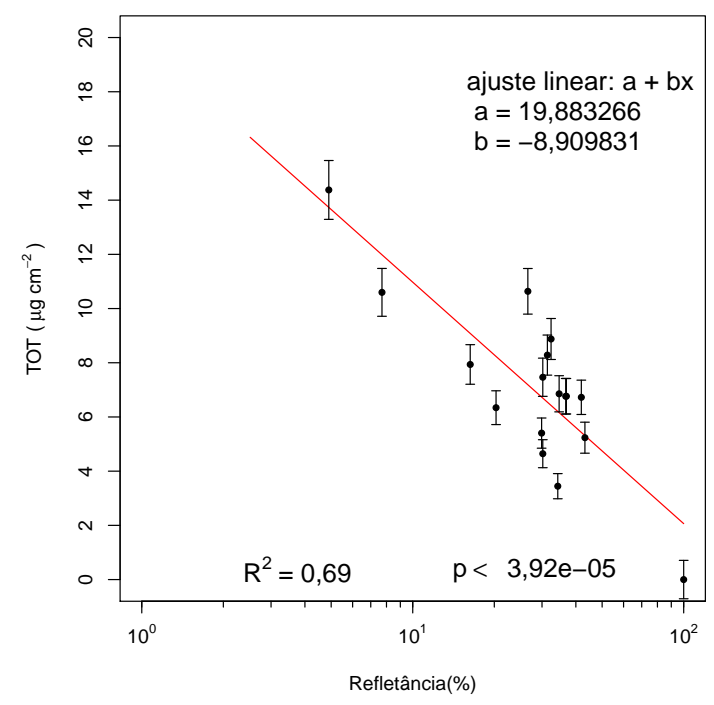

Figura 3.6: Intercalibração TOT e Reflêtancia para amostragem paralela no túnel Jânio Quadros. 
Buscou-se, também, confrontar a massa obtida pela calibração com os alvos de BC comercial elaborados no laboratório da CETESB, com a massa obtida pela calibração via TOT, gráfico da figura 3.7 e tabela 3.5. Apesar da excelente relação linear de ambas calibrações, os valores de massa calculados diferiram em aproximadamente um fator 5 , sendo as massas calculadas com a calibração da CETESB maiores que a por TOT. Como já mencionamos, isso significa que o BC comercial (ASTM-N762) tem propriedades diferentes daquele BC que compõe o aerossol coletado no túnel do Jânio Quadros, provavelmente, sua granulometria seria mais grossa, o que gera menos superfície de absorção por muito mais massa coletada, hipótese essa que poderia ser investigada em trabalho futuro. Neste sentido, ele não seria indicado para calibrações realistas de equipamentos de refletância.

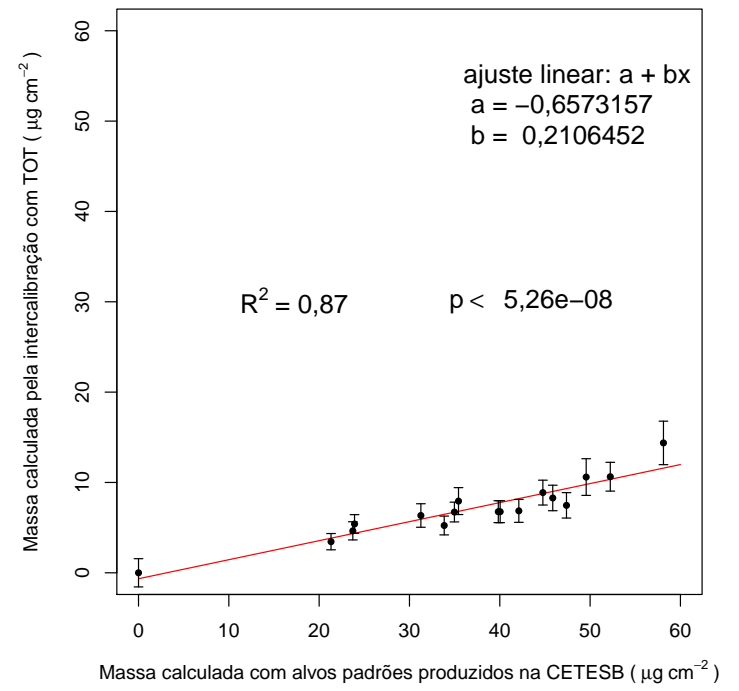

Figura 3.7: Comparação da massa de BC das amostras do túnel Jânio Quadros calculada usando calibração por TOT versus calibração a partir dos alvos padrões produzidos na CETESB.
Tabela 3.5: Comparação da massa de BC das amostras do túnel Jânio Quadros calculada usando calibração por TOT(1) versus calibração a partir dos alvos padrões produzidos na $\operatorname{CETESB}(2)$.

\begin{tabular}{ccc}
\hline ID & TOT $^{1}$ & CETESB $^{2}$ \\
\multicolumn{2}{c}{$\mu \mathrm{g} / \mathrm{cm}^{2}$} \\
\hline zero & $0,00 \pm 0,65$ & $0,0 \pm 1,4$ \\
JQ-01 & $8,88 \pm 0,72$ & $44,8 \pm 1,2$ \\
JQ-02 & $6,34 \pm 0,58$ & $31,3 \pm 1,2$ \\
JQ-03 & $7,47 \pm 0,66$ & $47,4 \pm 1,2$ \\
JQ-04 & $14,4 \pm 1,0$ & $58,1 \pm 2,2$ \\
JQ-05 & $10,64 \pm 0,80$ & $52,2 \pm 1,4$ \\
JQ-06 & $7,94 \pm 0,68$ & $35,4 \pm 1,3$ \\
JQ-07 & $6,72 \pm 0,61$ & $34,98 \pm 0,91$ \\
JQ-08 & $5,24 \pm 0,55$ & $33,85 \pm 0,89$ \\
JQ-09 & $3,45 \pm 0,44$ & $21,32 \pm 0,79$ \\
JQ-10 & $6,76 \pm 0,62$ & $40,0 \pm 1,0$ \\
JQ-11 & $5,40 \pm 0,53$ & $23,92 \pm 0,89$ \\
JQ-12 & $6,85 \pm 0,63$ & $42,1 \pm 1,1$ \\
JQ-13 & $10,60 \pm 0,80$ & $49,6 \pm 1,9$ \\
JQ-14 & $8,28 \pm 0,70$ & $45,9 \pm 1,2$ \\
JQ-15 & $4,64 \pm 0,49$ & $23,73 \pm 0,88$ \\
JQ-16 & $6,77 \pm 0,62$ & $39,8 \pm 1,0$ \\
\hline
\end{tabular}




\subsubsection{Intercalibração de TOT e refletância para Acra}

Como discutido na descrição da metodologia analítica para BC, as características de tamanho, forma geométrica e seção de choque de absorção de luz das partículas de BC variam de região para região. Por esses motivos, é importante fazer a comparação de método indireto com método direto (Quincey, 2007). Taha et al. (2007) também aponta que há uma limitação da técnica de refletância quando filtros de teflon são usados, pois em altas concentrações (refletâncias inferiores a 20\%), ocorre saturação, e a relação exponencial da equação 2.25 passa a não valer mais.

Dos 2898 filtros PTFE coletados no experimento de Gana, 52 tiveram medidas paralelas em filtros de quartzo para $M P_{2,5}$, analisados por TOT. Os filtros coletados em Acra apresentaram refletância pequena, pois além da alta poluição atmosférica o tempo de amostragem de 48 horas contribuiu para que as amostras ficassem muito carregadas. Buscou-se então proceder como no experimento do túnel Jânio Quadros em São Paulo, intercalibrando a refletância com as medidas de TOT disponíveis, de forma a estimar os valores de BC em todos filtros PTFE de $M P_{2,5}$. O gráfico da figura 3.8 e a tabela mostram o ajuste realizado, já contabilizando um ponto de massa zero no ajuste. A incerteza efetiva considera o erro do TOT e da refletância, além dos $8 \%$ de amostragem paralela.

Assumimos como incerteza para os valores de refletância (medido em porcentagem) o desvio padrão corrigido das medições de 7 filtros em branco (média =0,96\% x 1,11=1,06\%), corrigidos para as estatísticas de poucos dados, utilizando 7 valores).

O gráfico da figura 3.9a mostra a relação entre a calibração do BC por TOT e o resultado que teríamos se empregássemos a calibração tradicionalmente feita com M71. Neste último caso o ajuste foi feito com uma reta, como diz a relação derivada para absorção, e uma curva parabólica, como usualmente empregada no laboratório. Na região onde existem alvos padrões, os ajustes de primeiro e segundo grau apresentam concordância com os valores obtidos por TOT, mas em altas concentrações, o ajuste linear proveria resultados mais próximos daqueles obtidos por calibração TOT, mesmo assim com diferenças em torno de $25 \%$.

Fazendo-se a mesma comparação para filtros analisados em Recife (Santos et al., 2014), as diferenças oscilavam entre um fator 1,4 e 2,4 (figura 3.9b).

O uso de refletância mostrou-se bastante eficiente para determinação de BC, sendo aconselhável, entretanto, prover a calibração de um conjunto de filtros com um sistema de medida absoluto como o TOT. 


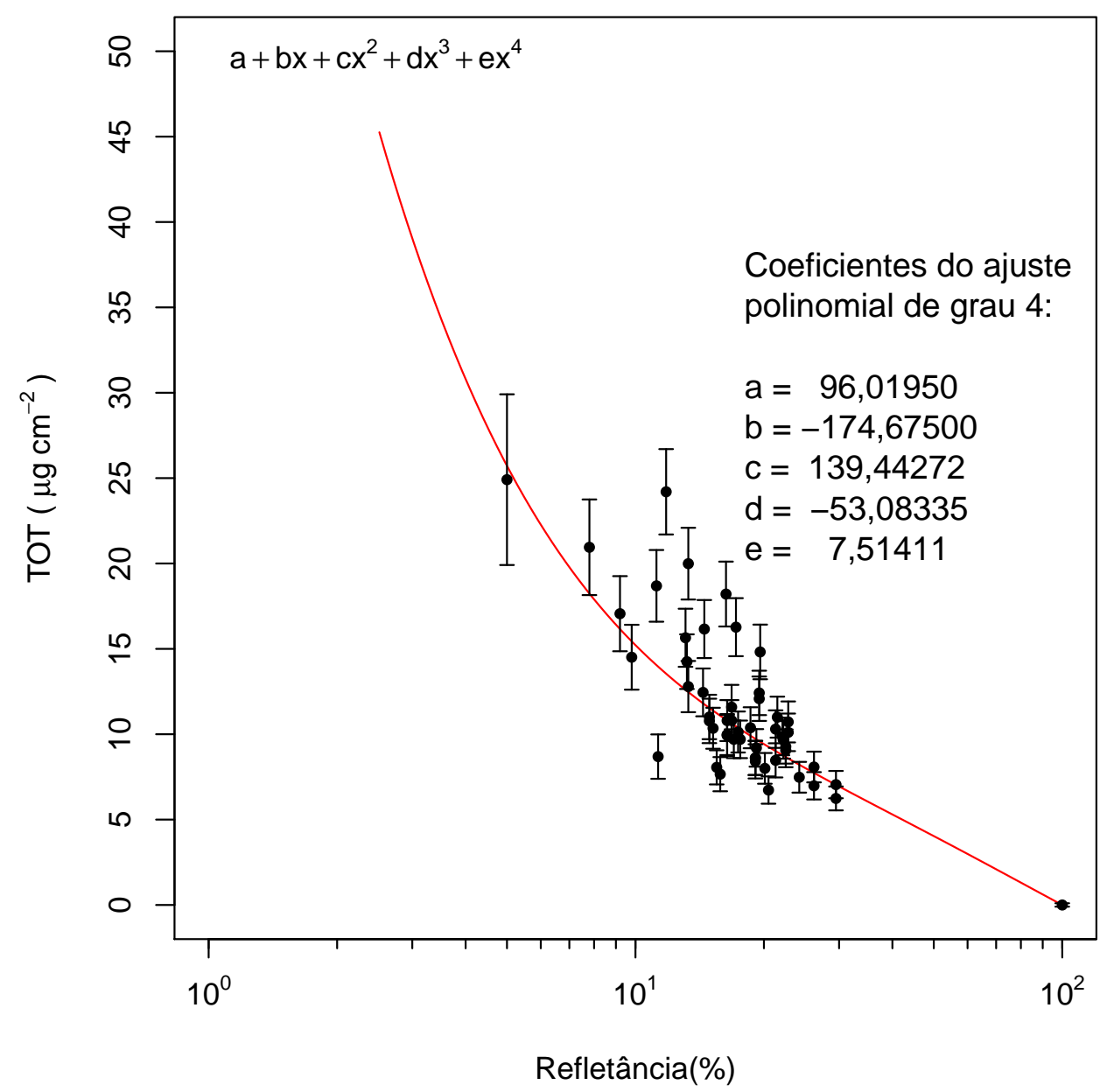

Figura 3.8: Intercalibração entre TOT e refletância em Acra.

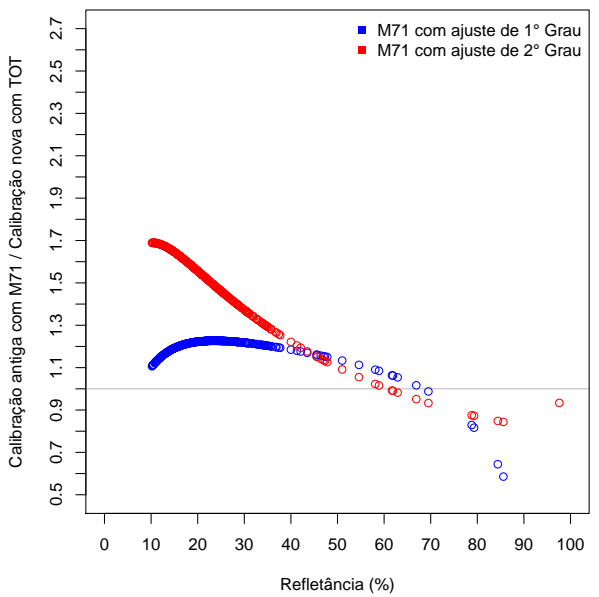

(a) Acra

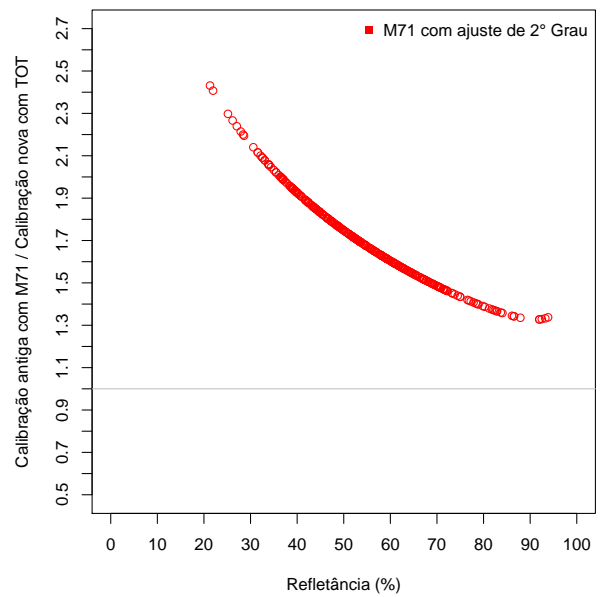

(b) Recife

Figura 3.9: Razão dos valores de BC medidos por refletância e calibrados por TOT e M71 para Recife e Acra. 
Tabela 3.6: Intercalibração entre TOT e refletância para Acra.

\begin{tabular}{|c|c|c|c|c|c|}
\hline ID-Quartzo & ID-PTFE & refletância (\%) & TOT & $\sigma_{\text {efetivo }}$ & Ajustado \\
\hline & & $\pm 1,1 \%$ & & $\mu \mathrm{g} / \mathrm{cm}^{2}$ & \\
\hline branco & branco & 100 & $0,00 \pm 0,10$ & 0,10 & $-0,00 \pm 0,12$ \\
\hline GHA408QC & ACC431MS & 29,5 & $6,24 \pm 0,51$ & 0,70 & $7,04 \pm 0,44$ \\
\hline GHA407QC & ACC431MS & 29,5 & $7,05 \pm 0,54$ & 0,80 & $7,04 \pm 0,44$ \\
\hline GHA405QC & ACC421MS & 26,2 & $6,98 \pm 0,55$ & 0,80 & $7,74 \pm 0,28$ \\
\hline GHA346QC & ACC366MS & 26,2 & $8,08 \pm 0,55$ & 0,90 & $7,74 \pm 0,28$ \\
\hline GHA315QC & ACC020MS & 24,2 & $7,48 \pm 0,57$ & 0,90 & $8,21 \pm 0,23$ \\
\hline GHA342QC & ACC312MS & 22,8 & $10,11 \pm 0,58$ & 1,1 & $8,58 \pm 0,21$ \\
\hline GHA343QC & ACC312MS & 22,8 & $10,72 \pm 0,60$ & 1,2 & $8,58 \pm 0,21$ \\
\hline GHA423QC & ACC692MS & 22,5 & $9,07 \pm 0,60$ & 1,0 & $8,66 \pm 0,21$ \\
\hline GHA422QC & ACC692MS & 22,5 & $9,28 \pm 0,60$ & 1,0 & $8,66 \pm 0,21$ \\
\hline GHA413QC & ACC654MS & 22,2 & $9,67 \pm 0,62$ & 1,1 & $8,75 \pm 0,21$ \\
\hline GHA330QC & ACC145MS & 22,1 & $9,87 \pm 0,62$ & 1,1 & $8,78 \pm 0,21$ \\
\hline GHA418QC & ACC675MS & 21,5 & $11,00 \pm 0,63$ & 1,2 & $8,95 \pm 0,20$ \\
\hline GHA424QC & ACC708MS & 21,3 & $8,47 \pm 0,63$ & 1,0 & $9,01 \pm 0,20$ \\
\hline GHA426QC & ACC708MS & 21,3 & $10,30 \pm 0,63$ & 1,1 & $9,01 \pm 0,20$ \\
\hline GHA442QC & AFR077MS & 20,5 & $6,73 \pm 0,65$ & 0,80 & $9,26 \pm 0,20$ \\
\hline GHA440QC & ACC471MS & 20,1 & $8,00 \pm 0,66$ & 0,90 & $9,39 \pm 0,20$ \\
\hline GHA347QC & ACC387MS & 19,6 & $14,82 \pm 0,66$ & 1,6 & $9,56 \pm 0,21$ \\
\hline GHA416QC & ACC672MS & 19,5 & $12,08 \pm 0,68$ & 1,3 & $9,59 \pm 0,21$ \\
\hline GHA417QC & ACC672MS & 19,5 & $12,42 \pm 0,68$ & 1,3 & $9,59 \pm 0,21$ \\
\hline GHA308QC & GHA910MS & 19,2 & $9,20 \pm 0,68$ & 1,1 & $9,69 \pm 0,21$ \\
\hline GHA415QC & ACC657MS & 19,1 & $8,41 \pm 0,69$ & 1,0 & $9,73 \pm 0,21$ \\
\hline GHA414QC & ACC657MS & 19,1 & $8,60 \pm 0,70$ & 1,0 & $9,73 \pm 0,21$ \\
\hline GHA304QC & GHA833MS & 19,1 & $8,62 \pm 0,70$ & 1,0 & $9,73 \pm 0,21$ \\
\hline GHA420QC & ACC683MS & 18,6 & $10,38 \pm 0,71$ & 1,2 & $9,91 \pm 0,21$ \\
\hline GHA404QC & ACC391MS & 17,6 & $9,70 \pm 0,71$ & 1,1 & $10,29 \pm 0,21$ \\
\hline GHA411QC & ACC641MS & 17,4 & $10,13 \pm 0,72$ & 1,2 & $10,38 \pm 0,21$ \\
\hline GHA341QC & ACC290MS & 17,2 & $16,27 \pm 0,72$ & 1,7 & $10,46 \pm 0,21$ \\
\hline GHA404QC & ACC412MS & 17 & $9,70 \pm 0,72$ & 1,1 & $10,54 \pm 0,21$ \\
\hline GHA445QC & AFR055MS & 16,8 & $10,80 \pm 0,74$ & 1,2 & $10,63 \pm 0,21$ \\
\hline GHA320QC & ACC047MS & 16,8 & $11,59 \pm 0,74$ & 1,3 & $10,63 \pm 0,21$ \\
\hline GHA311QC & GHA945MS & 16,4 & $9,93 \pm 0,74$ & 1,2 & $10,80 \pm 0,22$ \\
\hline GHA310QC & GHA945MS & 16,4 & $9,98 \pm 0,74$ & 1,2 & $10,80 \pm 0,22$ \\
\hline GHA303QC & GHA820MS & 16,4 & $10,80 \pm 0,75$ & 1,2 & $10,80 \pm 0,22$ \\
\hline GHA446QC & ACC983MS & 16,3 & $18,21 \pm 0,75$ & 1,9 & $10,85 \pm 0,22$ \\
\hline GHA301QC & GHA750MS & 15,8 & $7,66 \pm 0,78$ & 1,0 & $11,08 \pm 0,23$ \\
\hline GHA305QC & GHA884MS & 15,5 & $8,06 \pm 0,80$ & 1,0 & $11,23 \pm 0,24$ \\
\hline GHA329QC & ACC150MS & 15,2 & $10,35 \pm 0,82$ & 1,2 & $11,38 \pm 0,25$ \\
\hline GHA428QC & ACC709MS & 14,9 & $10,78 \pm 0,82$ & 1,3 & $11,54 \pm 0,26$ \\
\hline GHA429QC & ACC709MS & 14,9 & $11,01 \pm 0,84$ & 1,3 & $11,54 \pm 0,26$ \\
\hline GHA402QC & ACC408MS & 14,5 & $16,16 \pm 0,91$ & 1,7 & $11,75 \pm 0,27$ \\
\hline GHA430QC & ACC718MS & 14,4 & $12,45 \pm 0,93$ & 1,4 & $11,81 \pm 0,28$ \\
\hline GHA335QC & ACC199MS & 13,3 & $12,79 \pm 0,94$ & 1,5 & $12,47 \pm 0,35$ \\
\hline GHA344QC & ACC326MS & 13,3 & $19,99 \pm 0,98$ & 2,1 & $12,47 \pm 0,35$ \\
\hline GHA438QC & AFR080MS & 13,2 & $14,2 \pm 1,0$ & 1,6 & $12,53 \pm 0,36$ \\
\hline GHA441QC & AFR056MS & 13,1 & $15,7 \pm 1,0$ & 1,7 & $12,60 \pm 0,36$ \\
\hline GHA448QC & ACC981MS & 11,8 & $24,2 \pm 1,0$ & 2,5 & $13,54 \pm 0,48$ \\
\hline GHA300QC & GHA736MS & 11,3 & $8,7 \pm 1,1$ & 1,3 & $13,96 \pm 0,54$ \\
\hline GHA436QC & ACC987MS & 11,2 & $18,7 \pm 1,1$ & 2,1 & $14,05 \pm 0,55$ \\
\hline GHA435QC & ACC982MS & 9,8 & $14,5 \pm 1,2$ & 1,9 & $15,44 \pm 0,74$ \\
\hline GHA302QC & GHA777MS & 9,2 & $17,1 \pm 1,2$ & 2,2 & $16,16 \pm 0,84$ \\
\hline GHA307QC & GHA893MS & 7,8 & $20,9 \pm 1,4$ & 2,8 & $18,2 \pm 1,2$ \\
\hline GHA $434 \mathrm{QC}$ & ACC995MS & 5 & $24,9 \pm 1,4$ & 5,0 & $25,7 \pm 4,6$ \\
\hline
\end{tabular}




\subsection{Concentrações Ambientais}

Medidas de concetrações da massa de MP são usadas para avaliação da qualidade do ar, as quais relacionam-se à saúde, mas que também associam-se a danos a vegetais, materiais e ao meio ambiente em geral. As legislações fundamentam-se sobre estudos de impactos à saúde, atribuíveis a poluentes, em curto ou longo espaço de tempo. Procura-se definir, em função disso, os limites que permitem boa qualidade de vida ao cidadão.

Fruto de reuniões de trabalho internacionais, a OMS (2015) definiu limites para os principais poluentes antropogênicos da atualidade, as quais são diretrizes indicadas para todos os países. Mas, pela própria constituição deste organismo internacional, cada país tem autonomia para definir sua própria legislação, podendo ou não acatá-las. De qualquer modo, ao sustentar padrões assentados sobre estudos de riscos e danos à saúde, atuais e de amplo reconhecimento internacional, ela cria um referencial para instituições e movimentos sociais que pressionam por melhores níveis de qualidade de vida em cada país.

Em estudos mais detalhados, é possível aprofundar a análise de dados com identificação e quantificação de espécies que compõem o MP (elementos, compostos, misturas, ou fatores diversos que interferem em sua concentração). Além de revelar os fatores mais significativos nas concentrações determinadas, ou nos efeitos sobre a saúde, eles possibilitam ajustes de métodos estatísticos para identificar e estimar perfis das principais fontes poluidoras. Assim, nesta seção serão expostos inicialmente os resultados das concentrações para comparação com limites de legislações e com padrões sugeridos pela OMS, e na próxima seção, serão aplicados métodos estatísticos multivariados, AF e PMF, para levantamento de fontes.

A campanha de amostragem nos quatro bairros, conforme já registramos, resultou em um total de 2898 amostras que foram analisadas por refletância e XRF-ED no LAPAt. Concentrações médias, análises estatísticas gerais e levantamento de fontes, para os onze locais em conjunto, foram apresentados em 2011 no 23th Congress of the International Society for Environmental Epidemiology (Zhou et al., 2011) e publicadas em (Zhou et al., 2013) e (Zhou et al., 2014). Mas estes trabalhos tinham um olhar mais voltado às questões de saúde pública, tratando o $P M_{10}$ e $P M_{2,5}$, sem separar o $P M_{2,5-10}$. Isso limita a capacidade de discernir o MP originário de processos mecânicos ou de conversão gás-partícula, bem como de possíveis interações entre eles.

Nesta pesquisa em particular, aprofundou-se os estudos exclusivamente no bairro de Nima, em dois locais, Sam Road e Nima Road, com 791 amostras válidas obtidas entre 11 de novembro de 2006 e 15 de agosto de 2008. Além da separação do MP grosso, informações 
sobre a circulação regional de ventos nas discussões foram incoporadas, o que contribui no processo de discernimento de prováveis fontes que chegam aos amostradores.

Daqui em diante, medidas realizadas na Sam Road serão referidas como área residencial e na Nima Road como avenida, para melhor refletir as características de ambas.

\subsubsection{Material Particulado Inalável $M P_{10}$}

O presumível interesse na saúde pública como elemento central na definição de padrões de qualidade do ar nas legislações específicas, termina dependendo de aspectos políticos, sociais e econômicos de cada país. Em virtude disso, há entre estes, uma multiplicidade de limites para as espécies legisladas.

O padrão de qualidade do ar para $M P_{10}$ ambiental vigente em Gana, referendado pela EPA-GH (2015a), é apresentado na tabela 3.7. Nota-se que há limites específicos para os meses em que ocorre o Harmatão, refletindo o efeito deste fenômeno no MP local. Regiões consideradas como zonas industriais ou de comércio também têm limites mais permissivos, revelando uma priorização do Governo aos interesses negociais no país, em detrimento da saúde e bem estar da população.

Tabela 3.7: Padrões de Qualidade do Ar para $M P_{10}$ Ambiental em Gana Ghana (2015a)

\begin{tabular}{|c|c|c|c|}
\hline Tipo da média & $\begin{array}{c}\text { regiões } \\
\text { sensíveis }^{1} \\
\mu g / m^{3} \\
\end{array}$ & $\begin{array}{c}\text { zonas } \\
\text { residenciais e rurais } \\
\mu \mathrm{g} / \mathrm{m}^{3}\end{array}$ & $\begin{array}{c}\text { zonas } \\
\text { industriais e comerciais } \\
\mu \mathrm{g} / \mathrm{m}^{3}\end{array}$ \\
\hline diária & 110 & 150 & 260 \\
\hline anual geométrica & 70 & 100 & 200 \\
\hline mensal (durante Harmatão) & 100 & 200 & 500 \\
\hline
\end{tabular}

Na tabela 3.8 compara-se os padrões de $M P_{10}$ entre Brasil, Gana e OMS, com a observação de que em Gana a média anual é calculada geometricamente, o que a torna tanto menor que a média aritmética, quanto mais extremos forem os valores registrados.

Tabela 3.8: Padrões para média anual de $M P_{10}$ no Brasil (CONAMA, 1990), Gana (Ghana, 2015a) e OMS (WHO, 2015).

\begin{tabular}{cccc}
\hline Tipo da média & $\begin{array}{c}\text { Brasil } \\
\mu / m^{3}\end{array}$ & $\begin{array}{c}\text { Gana (residencial e rural) } \\
\mu / m^{3}\end{array}$ & $\begin{array}{c}\text { OMS } \\
\mu / m^{3}\end{array}$ \\
\hline $\begin{array}{c}\text { diária } \\
\text { anual }\end{array}$ & 150 & 150 & 50 \\
(aritmética) & 100 (geométrica) & 20 (aritmética) \\
\hline
\end{tabular}

O gráfico da figura 3.10 mostra as concetrações medidas (com distâncias do eixo em escala logaritímica para melhor vizualização dos dados) nos dois sítios em função do tempo, sinalizando os padrões diários da tabela anterior. 
Observa-se, que para verificação do atendimento ou não de padrão anual previstos na legislação de Gana, será necessário remover as amostras de 2006 e 2008, mantendo somente as de 2007, pois foi o único ano deste experimento com medidas uniformemente distribuídas em todos meses. A confrontação com parâmetros legais será realizada somente para dar noção relativa e qualitativa dos resultados obtidos na campanha e não para observância estrita de atendimento ou não da lei.

Sendo assim, o índice de ultrapassagens do padrão diário foi 16,24 \% na área residencial e $19,60 \%$ na avenida, quando considerado o padrão de $150 \mu \mathrm{g} / \mathrm{m}^{3}$ praticado pela EPA-GH e no Brasil. Em relação ao padrão de média diária da OMS, $50 \mu \mathrm{g} / \mathrm{m}^{3}$, mais restritivo, o índice de ultrapassagens foi alto para os dois sítios: 59,90 \% na área residencial e 90,95\% na avenida.

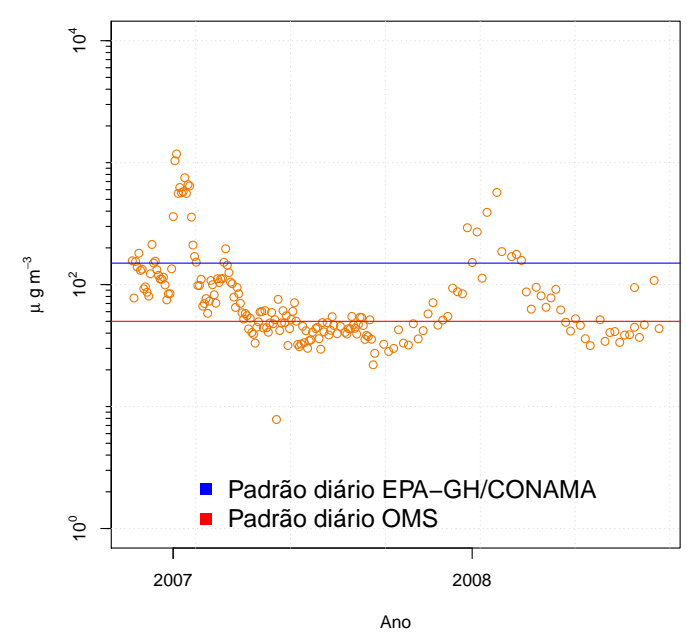

(a) Área residencial (Sam Road)

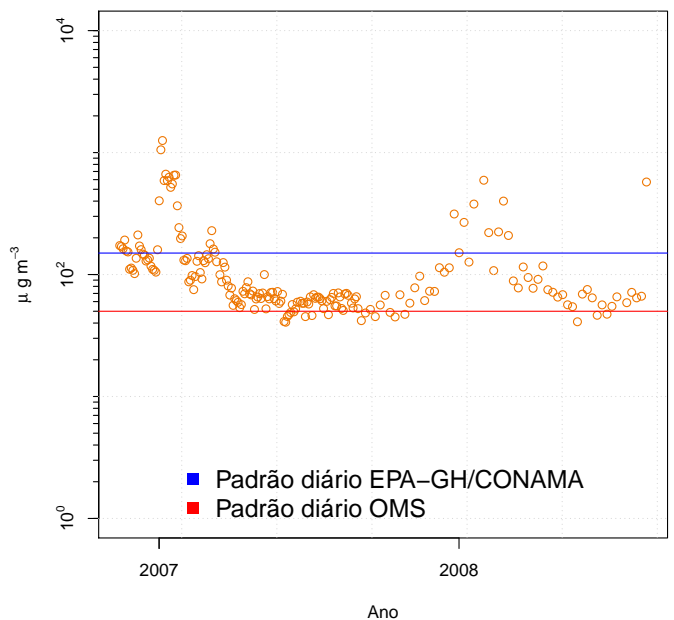

(b) Avenida (Nima Road)

Figura 3.10: Concentrações de $M P_{10}$ ao longo da campanha de amostragem.

Regiões localizadas próximas ao deserto do Saara sofrem mais diretamente eventos extremos de poluição. Kaku et al. (2016) ao estudar partículas no Golfo Pérsico, a leste do deserto do Saara, relatou que em períodos de chegada de poeira, $76 \pm 7 \%$ da massa total de MP é comprometida com partículas da crosta terrestre, ou seja, de solo.

A separação dos dias em que ocorrem ventos do Harmatão dos outros dias é importante, pois além de ser previsto na lei local, permite realizar a comparação separando uma dinâmica mais antropogênica de outra natural, ligada a esse fenômeno.

O critério de identificação dos dias de Harmatão, entretanto, não é simples, pois o fenômeno não é ininterrupto durante os meses em que ocorre. Classificando todos dias de novembro até março como Harmantão, corre-se o risco de perder informações importantes de fontes locais com atividades nesse período, comprometendo análises estatísticas de AF e PMF. 
Considerando o fato dos silicatos serem os principais constituintes da crosta terrestre, e tendo em vista o convívio com esse fenômeno, Aboh et al. (2009) sugere como critério para identificação dos dias de ocorrência do Harmatão os de concentrações de silício no $M P_{10}$ maiores que $10 \mu \mathrm{g} / \mathrm{m}^{3}$, entre os meses de novembro e março.

Quando desconsidera-se o Harmatão, seguindo esse critério, não há mais ultrapassagens do padrão diário de $150 \mu \mathrm{g} / \mathrm{m}^{3}$ na área residencial e na avenida o índice de ultrapassagem cai de $19,60 \%$ para 0,88 \%. Para o padrão OMS de $50 \mu \mathrm{g} / \mathrm{m}^{3}$ na área residencial as ultrapassagens diminuem para 31,25\% (antes 59,90\%) e na avenida para 84,21\% (antes 90,95\%).

Tabela 3.9: Estatística descritiva das concentrações de $M P_{10}$ conjunta (área residencial e avenida) somente para os dias de ocorrência de vento do Harmatão. 54 amostras na área residencial e 59 na avenida

\begin{tabular}{ccccccc}
\hline & $\mathrm{n}$ & Média $\left(\mathrm{ng} / \mathrm{m}^{3}\right)$ & Des. Pad. Média & Mediana & Mínimo & Máximo \\
\hline massa $\left(\mu \mathrm{g} / \mathrm{m}^{3}\right)$ & 113 & 269,18 & 22,98 & 154,69 & 71,08 & 1255,81 \\
$\mathrm{Na}$ & 113 & 309,57 & 21,19 & 299,50 & 15,55 & 1229,21 \\
$\mathrm{Mg}$ & 113 & 1774,96 & 115,12 & 1339,46 & 407,59 & 5394,46 \\
$\mathrm{Al}$ & 113 & 12021,70 & 745,76 & 8448,66 & 3593,44 & 33891,11 \\
$\mathrm{Si}$ & 113 & 30454,03 & 2041,39 & 21250,52 & 10070,41 & 94110,45 \\
$\mathrm{P}$ & 113 & 75,61 & 3,62 & 66,86 & 0,69 & 221,52 \\
$\mathrm{~S}$ & 113 & 1355,33 & 30,38 & 1357,65 & 417,12 & 2577,30 \\
$\mathrm{Cl}$ & 113 & 2224,87 & 71,99 & 2139,17 & 825,96 & 4946,92 \\
$\mathrm{~K}$ & 113 & 3893,35 & 225,79 & 2746,07 & 1178,82 & 11311,72 \\
$\mathrm{Ca}$ & 113 & 6557,63 & 491,41 & 4283,79 & 2084,93 & 25195,60 \\
$\mathrm{Ti}$ & 113 & 968,91 & 77,35 & 594,85 & 234,58 & 3780,84 \\
$\mathrm{~V}$ & 113 & 16,78 & 1,38 & 10,34 & 4,77 & 73,57 \\
$\mathrm{Mn}$ & 113 & 158,09 & 14,08 & 91,80 & 39,14 & 751,72 \\
$\mathrm{Fe}$ & 113 & 8848,80 & 718,83 & 5242,67 & 2248,68 & 35885,59 \\
$\mathrm{Zn}$ & 113 & 93,18 & 5,16 & 69,97 & 27,40 & 247,75 \\
$\mathrm{Br}$ & 113 & 41,39 & 2,42 & 32,58 & 11,33 & 167,48 \\
$\mathrm{~Pb}$ & 113 & 37,83 & 1,83 & 30,15 & 15,06 & 103,25 \\
\hline
\end{tabular}

A tabela 3.9 apresenta a média, desvio padrão da média, mediana, mínimo e máximo para as concentrações de MP Inalável, $M P_{10}$ para dias de ocorrência do Harmatão, classificados segundo sugestão de Aboh et al. (2009). A concentração total média foi 269,2 $\pm 23,0 \mu \mathrm{g} / \mathrm{m}^{3}$, tendo como elemento mais representativo o Si, 11,3\% da massa total. A ambiguidade (talvez estratégica) da lei define um intervalo de média mensal de $M P_{10}$ no Harmantão de 100 à 500 $\mu \mathrm{g} / \mathrm{m}^{3}$, dependendo de como a região é classificada: sensível, residencial, rural, industrial ou comercial, abrindo brechas que permitem definir regiões baseado em interesses puramente econômicos, pois limites de $500 \mu \mathrm{g} / \mathrm{m}^{3}$ mesmo com a poeira pesada do Harmatão serão dificilmente alcançados. A mediana, permite ter uma ideia de assimetrias na distribuição de um conjunto de dados. Neste caso ela foi de $154,7 \mu \mathrm{g} / \mathrm{m}^{3}$, indicando que houve extremos com 
valores altos, já que a média foi de $269,2 \mu \mathrm{g} / \mathrm{m}^{3}$. O máximo alcançou $1255,8 \mu \mathrm{g} / \mathrm{m}^{3}$, mas no geral apenas alguns dias tiveram concentrações extremamente elevadas.

Excluíndo-se as concentrações de $M P_{10}$ medidas nos dias de ocorrência do Harmantão, obtém-se as estatísticas descritivas apresentadas na tabela 3.10.

Tabela 3.10: Estatística descritiva das concentrações de $M P_{10}$ conjunta, (Sam Road e Nima Road) excluindo-se os dias do Harmantão.

\begin{tabular}{ccccccc}
\hline & $\mathrm{n}$ & Média $\left(\mathrm{ng} / \mathrm{m}^{3}\right)$ & Des. Pad. Média & Mediana & Mínimo & Máximo \\
\hline massa $\left(\mu g / \mathrm{m}^{3}\right)$ & 226 & 57,12 & 2,52 & 53,69 & 7,83 & 573,95 \\
$\mathrm{Na}$ & 226 & 1063,95 & 42,82 & 861,30 & 68,64 & 4849,80 \\
$\mathrm{Mg}$ & 226 & 256,91 & 7,42 & 234,98 & 84,76 & 828,07 \\
$\mathrm{Al}$ & 226 & 1753,97 & 68,75 & 1532,92 & 161,02 & 4831,94 \\
$\mathrm{Si}$ & 226 & 3753,49 & 134,93 & 3407,37 & 342,13 & 9851,02 \\
$\mathrm{P}$ & 226 & 31,28 & 0,91 & 29,88 & 5,26 & 77,19 \\
$\mathrm{~S}$ & 226 & 803,15 & 21,31 & 724,71 & 116,87 & 3213,98 \\
$\mathrm{Cl}$ & 226 & 2201,22 & 61,44 & 2045,63 & 294,29 & 6866,16 \\
$\mathrm{~K}$ & 226 & 1125,65 & 18,89 & 1101,88 & 181,13 & 2932,63 \\
$\mathrm{Ca}$ & 226 & 1332,26 & 39,26 & 1278,41 & 255,19 & 3149,87 \\
$\mathrm{Ti}$ & 226 & 138,84 & 5,10 & 127,80 & 15,52 & 398,10 \\
$\mathrm{~V}$ & 226 & 3,21 & 0,10 & 3,00 & 0,33 & 8,80 \\
$\mathrm{Mn}$ & 226 & 19,99 & 0,58 & 19,41 & 4,55 & 46,54 \\
$\mathrm{Fe}$ & 226 & 1384,17 & 44,02 & 1331,82 & 145,14 & 3502,11 \\
$\mathrm{Zn}$ & 226 & 46,16 & 1,18 & 43,99 & 14,14 & 136,23 \\
$\mathrm{Br}$ & 226 & 28,97 & 1,28 & 22,87 & 8,96 & 117,18 \\
$\mathrm{~Pb}$ & 226 & 20,37 & 0,48 & 19,21 & 7,13 & 87,79 \\
\hline
\end{tabular}

Entretanto, para melhor comparação com os padrões anuais, e inclusão de todas sazonalidades de um ano, na tabela 3.11 apresenta-se médias aritméticas e geométricas exclusivas para 2007, que teve medidas ao longo de todo ano.

Tabela 3.11: Médias de $M P_{10}$ para o ano de 2007.

\begin{tabular}{cccccc|cccccc}
\hline & \multicolumn{1}{c|}{ sem Harmatão } & \multicolumn{5}{c}{ com Harmatão } \\
& $\mathrm{n}$ & $\bar{x}$ & $\bar{x}_{g}$ & $\sigma$ & $\bar{\sigma}$ & $\mathrm{n}$ & $\bar{x}$ & $\bar{x}_{g}$ & $\sigma$ & $\bar{\sigma}$ \\
\hline residencial & 87 & 44,91 & 43,14 & 11,87 & 1,12 & 136 & 115,12 & 67,72 & 186,39 & 13,28 \\
avenida & 89 & 61,57 & 60,55 & 11,52 & 1,08 & 138 & 131,65 & 88,99 & 183,62 & 13,02 \\
ambas & 176 & 53,33 & 51,21 & 14,34 & 0,95 & 274 & 123,45 & 77,70 & 184,85 & 9,29 \\
\hline \multicolumn{1}{c}{ Média aritmética; $\bar{x}_{g}$ Média geométrica; $\sigma$ Desvio padrão; $\bar{\sigma}$ Desvio padrão da média } \\
\hline \multicolumn{10}{l}{}
\end{tabular}

A média aritmética da concentração de $M P_{10}$ durante a campanha de amostragem foi de $57,1 \pm 2,5 \mu \mathrm{g} / \mathrm{m}^{3}$, maior que a média anual para 2007 de $53,33 \pm 0,95 \mu \mathrm{g} / \mathrm{m}^{3}$. A média geométrica, $51,21 \pm 0,95 \mu \mathrm{g} / \mathrm{m}^{3}$, ficou abaixo da média anual no país em qualquer tipo de zona $\left(70,100\right.$ ou $\left.200 \mu \mathrm{g} / \mathrm{m}^{3}\right)$.

Já a média aritmética foi de $57,1 \pm 2,5 \mu \mathrm{g} / \mathrm{m}^{3}$, foi quase três vezes do recomendado pela 
OMS, $20 \mu \mathrm{g} / \mathrm{m}^{3}$. Nota-se que a média agora está próxima da mediana, $53,7 \mu \mathrm{g} / \mathrm{m}^{3}$, pois os dias do Harmatão, eventos extremos, foram excluídos.

Podemos comparar estes resultados com a RMSP, por exemplo. Estudo de 2008, realizado por Souza et al. (2014), quantificou e caracterizou a composição química das partículas na RMSP, reportando $64 \mu \mathrm{g} / \mathrm{m}^{3}$ para média de $M P_{10}$ durante o período do estudo, com variações entre 30 e $122 \mu \mathrm{g} / \mathrm{m}^{3}$.

Por outro lado, o acompanhamento da Companhia Ambiental do Estado de São Paulo (CETESB), que possui rede de monitoramento de qualidade do ar em todo estado (CETESB, 2014), a média de $M P_{10}$ tem caído nas últimas décadas, saindo de $58 \mu \mathrm{g} / \mathrm{m}^{3}$ em 2003 para 40 $\mu \mathrm{g} / \mathrm{m}^{3}$ em 2012. Em 2013, a estação da rede que registrou maior média foi a de Parelheiros, $44 \mu \mathrm{g} / \mathrm{m}^{3}$, e a menor Ibirapuera, $29 \mu \mathrm{g} / \mathrm{m}^{3}$. Assim, quando excluímos os dias de Harmatão, as concetrações de massa total de $M P_{10}$ de Acra são similares às encontradas na RMSP.

Outro estudo realizado em Acra por Aboh et al. (2009), no distrito de Kwabenya, região periférica e semi-rural, $11 \mathrm{~km}$ a noroeste de Nima, realizou coleta de MP em 2006 e 2007 e obteve concentração média de $179 \mu \mathrm{g} / \mathrm{m}^{3}$ sobre todas as amostras de $M P_{10}$ (portanto, média não anual). Entretanto, quando o autor removeu as medidas dos dias de Harmatão, a média diminui para $77 \mu \mathrm{g} / \mathrm{m}^{3}$, valor um pouco maior do que os $53,33 \mu \mathrm{g} / \mathrm{m}^{3}$ encontrados em Nima.

Tabela 3.12: Estatística descritiva da área residencial (Sam Road) e avenida (Nima) para $M P_{10}$.

\begin{tabular}{ccccc}
\hline & \multicolumn{2}{c}{ Residencial $\left(\mathrm{ng} / \mathrm{m}^{3}\right)$} & \multicolumn{2}{c}{ Avenida $\left(\mathrm{ng} / \mathrm{m}^{3}\right)$} \\
& com Harmatão & sem Harmatão & com Harmatão & sem Harmatão \\
\hline$M P_{10}\left(\mu \mathrm{g} / \mathrm{m}^{3}\right)$ & $113,8 \pm 11,5$ & $46,9 \pm 1,4$ & $134,0 \pm 11,6$ & $67,2 \pm 4,6$ \\
$\mathrm{Na}$ & $766,8 \pm 45,8$ & $1052,7 \pm 65,6$ & $802,1 \pm 41,2$ & $1075,0 \pm 55,6$ \\
$\mathrm{Mg}$ & $725,0 \pm 66,3$ & $245,4 \pm 11,3$ & $787,7 \pm 69,1$ & $268,2 \pm 9,5$ \\
$\mathrm{Al}$ & $4785,0 \pm 446,2$ & $1432,3 \pm 92,5$ & $5626,4 \pm 451,4$ & $2070,0 \pm 92,8$ \\
$\mathrm{Si}$ & $11757,1 \pm 1177,8$ & $3147,7 \pm 188,8$ & $13410,3 \pm 1199,9$ & $4348,6 \pm 176,5$ \\
$\mathrm{P}$ & $39,3 \pm 2,0$ & $24,1 \pm 1,0$ & $55,9 \pm 2,3$ & $38,3 \pm 1,2$ \\
$\mathrm{~S}$ & $937,0 \pm 28,4$ & $752,1 \pm 33,1$ & $1048,9 \pm 26,5$ & $853,3 \pm 26,3$ \\
$\mathrm{Cl}$ & $2040,1 \pm 60,1$ & $2048,0 \pm 88,7$ & $2360,3 \pm 58,1$ & $2351,7 \pm 83,1$ \\
$\mathrm{~K}$ & $1903,7 \pm 127,2$ & $1034,4 \pm 29,1$ & $2120,3 \pm 126,1$ & $1215,3 \pm 21,1$ \\
$\mathrm{Ca}$ & $2658,2 \pm 247,6$ & $1060,0 \pm 48,7$ & $3421,0 \pm 269,2$ & $1599,7 \pm 50,2$ \\
$\mathrm{Ti}$ & $371,3 \pm 40,1$ & $111,9 \pm 6,7$ & $451,6 \pm 41,8$ & $165,4 \pm 6,8$ \\
$\mathrm{~V}$ & $7,0 \pm 0,7$ & $2,8 \pm 0,1$ & $8,1 \pm 0,7$ & $3,6 \pm 0,1$ \\
$\mathrm{Mn}$ & $58,9 \pm 7,0$ & $16,6 \pm 0,8$ & $69,5 \pm 7,3$ & $23,3 \pm 0,8$ \\
$\mathrm{Fe}$ & $3472,5 \pm 368,2$ & $1132,1 \pm 58,7$ & $4131,7 \pm 381,2$ & $1631,9 \pm 56,8$ \\
$\mathrm{Zn}$ & $53,9 \pm 2,7$ & $40,7 \pm 1,7$ & $67,6 \pm 2,7$ & $51,5 \pm 1,5$ \\
$\mathrm{Br}$ & $31,7 \pm 1,5$ & $28,5 \pm 1,9$ & $33,3 \pm 1,5$ & $29,4 \pm 1,7$ \\
$\mathrm{~Pb}$ & $24,1 \pm 1,0$ & $19,3 \pm 0,8$ & $27,5 \pm 1,0$ & $21,4 \pm 0,5$ \\
\hline
\end{tabular}

Por fim, a tabela 3.12 apresenta as médias em separado para a área residencial (Sam Road) e a avenida (Nima). As diferenças entre o dois locais são mínimas, mas quando há presença 
de Harmatão, elas são levementes camufladas. Enquanto na presença do fenômeno, a massa média de $M P_{10}$ residencial equivale a $0,84 \%$ da avenida, sem ele, essa equivalência é de 0,70 \%. Com a exclusão do Harmatão, as diferenças entre os dois pontos são melhores expressadas, pois o mesmo ocorre com os demais elementos. A avenida, como esperado devido ao tráfego de veículos e ao comércio, a carrega as maiores concentrações.

\subsubsection{Material Particulado Fino $\left(M P_{2,5}\right)$}

Arku et al. (2008) e Dionisio et al. (2010b) foram pioneiros em conduzir levantamento da concentração de $M P_{2,5}$ em Acra. A recomendação da OMS para $M P_{2,5}$ é de $10 \mu \mathrm{g} / \mathrm{m}^{3}$ para média anual e $25 \mu \mathrm{g} / \mathrm{m}^{3}$ para média diária, sendo que em um ano o padrão diário não deve ser ultrapassado em mais que 1\% das amostragens. Assim como no Brasil (a menos do Estado de São Paulo), não há regulamentação para $M P_{2,5}$ em Gana.

A figura 3.11 apresenta as concentrações de $M P_{2,5}$ (eixo com distâncias logarítmicas), com a sinalização do padrão diário da OMS. Os índices de ultrapassagens foram de 66,49 e 92,0 \% para área residencial e avenida, respectivamente. Removido o Harmatão, os índices caem para 48,8 e 86,9\%, respectivamente, queda muito menor do que a observada no $M P_{10}$, pois o Harmatão tem origem em processos mecânicos, impactando menos no particulado fino. A participação média de $M P_{2,5}$ no $M P_{10}$ foi de $64,41 \%$ e de $51,99 \%$ quando excluído o Harmatão.

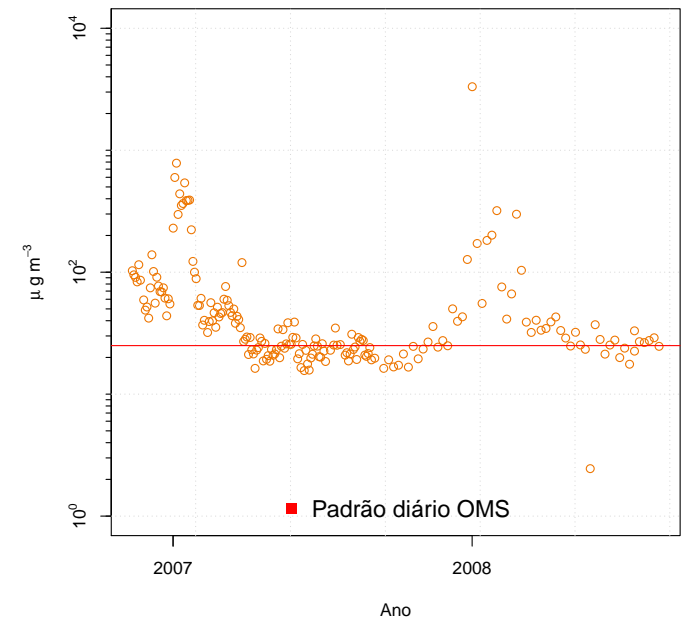

(a) Área residencial (Sam Road)

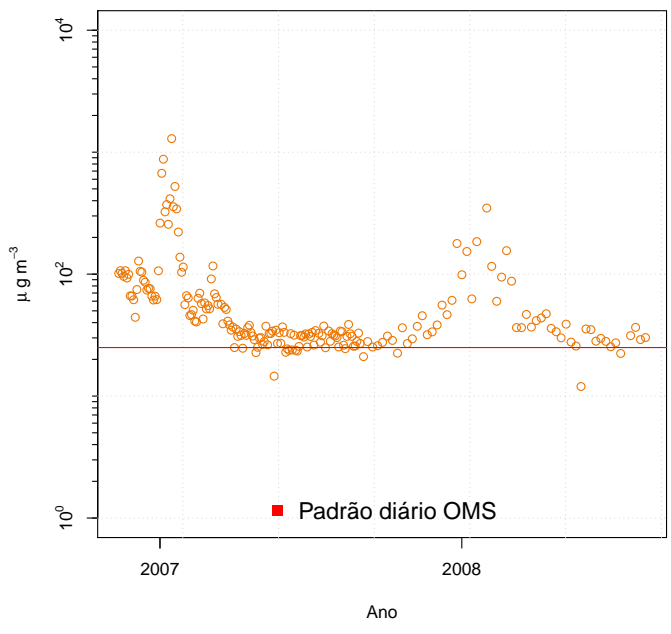

(b) Avenida (Nima Road)

Figura 3.11: Concentrações de $M P_{2,5}$ ao longo da campanha de amostragem. Padrão da OMS para média diária de $M P_{2,5} 25 \mu \mathrm{g} / \mathrm{m}^{3}$ sinalizado.

Na tabela 3.14 encontra-se a estatística descritiva conjunta para as concentrações de $M P_{2,5}$ 
(residencial e avenida) e a tabela 3.13 as respectivas médias exclusivas para o ano de 2007.

Tabela 3.13: Médias de $M P_{10}$ para o ano de 2007.

\begin{tabular}{cccccc|c|ccccc}
\hline & \multicolumn{4}{c|}{ sem Harmatão } & \multicolumn{6}{c}{ com Harmatão } \\
& $\mathrm{n}$ & $\bar{x}$ & $\bar{x}_{g}$ & $\sigma$ & $\bar{\sigma}$ & $\mathrm{n}$ & $\bar{x}$ & $\bar{x}_{g}$ & $\sigma$ & $\bar{\sigma}$ \\
\hline residencial & 87 & 44,91 & 43,14 & 11,87 & 1,12 & 136 & 115,12 & 67,72 & 186,39 & 13,28 \\
avenida & 89 & 61,57 & 60,55 & 11,52 & 1,08 & 138 & 131,65 & 88,99 & 183,62 & 13,02 \\
ambas & 176 & 53,33 & 51,21 & 14,34 & 0,95 & 274 & 123,45 & 77,70 & 184,85 & 9,29 \\
\hline
\end{tabular}

$\bar{x}$ Média aritmética; $\bar{x}_{g}$ Média geométrica; $\sigma$ Desvio padrão; $\bar{\sigma}$ Desvio padrão da média

A participação do BC na massa foi de 10,49 \% e, se considerado o Harmatão, diminui para 4,20\%, que dilui a contribuição das fontes locais de combustão. Na RMSP, Andrade et al. (2012) encontrou 35,7 \% de BC na massa em medidas de 2007 e 2008, bem maior que em Nima. O BC é um indicador de fontes de combustão, principalmente de veículos pesados, chegando a valores de $50 \%$ ou mais, em cidades com muito tráfego, caso de RMSP.

Tabela 3.14: Estatística descritiva das concentrações de $M P_{2,5}$ conjunta (residencial e avenida) excluindo-se os dias do Harmantão

\begin{tabular}{ccccccc}
\hline & $\mathrm{n}$ & Média $\left(\mathrm{ng} / \mathrm{m}^{3}\right)$ & Des. Pad. Média & Mediana & Mínimo & Máximo \\
\hline massa $\left(\mu g / \mathrm{m}^{3}\right)$ & 245 & 29,70 & 0,67 & 28,06 & 2,45 & 119,89 \\
$\mathrm{Na}$ & 245 & 336,04 & 14,27 & 273,35 & 13,09 & 1433,52 \\
$\mathrm{Mg}$ & 245 & 108,13 & 7,60 & 70,48 & 1,10 & 670,30 \\
$\mathrm{Al}$ & 245 & 719,60 & 49,85 & 413,34 & 86,04 & 4313,96 \\
$\mathrm{Si}$ & 245 & 1453,07 & 109,66 & 805,06 & 129,79 & 9508,96 \\
$\mathrm{P}$ & 245 & 14,31 & 0,48 & 13,82 & 0,21 & 36,92 \\
$\mathrm{~S}$ & 245 & 604,56 & 15,64 & 546,00 & 42,98 & 1336,87 \\
$\mathrm{Cl}$ & 245 & 457,66 & 18,62 & 396,70 & 25,23 & 2102,09 \\
$\mathrm{~K}$ & 245 & 857,60 & 14,14 & 845,76 & 72,43 & 1532,29 \\
$\mathrm{Ca}$ & 245 & 353,21 & 15,13 & 287,66 & 26,40 & 1362,13 \\
$\mathrm{Ti}$ & 245 & 47,20 & 2,91 & 30,20 & 5,30 & 256,36 \\
$\mathrm{~V}$ & 245 & 1,84 & 0,06 & 1,62 & 0,39 & 7,75 \\
$\mathrm{Mn}$ & 245 & 9,26 & 0,39 & 7,44 & 2,02 & 38,10 \\
$\mathrm{Fe}$ & 245 & 445,55 & 23,84 & 333,98 & 46,57 & 2062,89 \\
$\mathrm{Zn}$ & 245 & 30,74 & 1,30 & 26,18 & 0,75 & 261,66 \\
$\mathrm{Br}$ & 245 & 23,48 & 1,07 & 17,90 & 5,50 & 103,59 \\
$\mathrm{~Pb}$ & 245 & 15,46 & 0,28 & 14,48 & 7,38 & 28,54 \\
$\mathrm{BC}\left(\mu g / m^{3}\right)$ & 245 & 3,12 & 0,04 & 3,07 & 0,39 & 5,70 \\
\hline
\end{tabular}

Devido ao impacto na saúde causado pelo o $M P_{2,5}$, acrescido recente facilidade de acesso a tecnologias para medida e caracterização do mesmo, na última década, cientistas do mundo inteiro realizaram pesquisas de levantamento dos níveis de concentrações elementares de $M P_{2,5}$, permitindo comparações importantes entre cidades, com características distintas em relação a fontes de poluição naturais ou antropogênicas. 
Reuniu-se dados de concentrações médias elementares de $M P_{2,5}$ de oito países considerados em desenvolvimento pelo Fundo Monetário Internacional (FMI), pertencentes a América do Sul, África (norte e sul), Ásia e Europa e que tiveram campanhas de amostragem em períodos próximos ao deste trabalho. As cidades com suas respectivas médias e períodos de medidas estão relacionadas na tabela 3.15 composta por Cidade do México (Díaz et al., 2014), Cairo (Boman et al., 2013), Pequim (Yang et al., 2011), Nairóbi (Gaita et al., 2014), Brasil (Miranda et al., 2012), Rijeka (Ivošević et al., 2015), Córdoba (Achad et al., 2014) e mais duas pesquisas realizadas em outros distritos de Acra, Kwabenya (Aboh et al., 2009) e Ashaiman (Ofosu et al., 2012).

Em Kwabenya e Ashaiman, regiões de Acra, foram reportadas concentrações levemente inferiores às de Nima. Neste caso também dispúnhamos de resultados com e sem Harmatão. A diminuição da massa média de todos elementos nestas duas situações foi similar entre Nima e Kwabenya. A redução do Si em Kwabenya, por exemplo, baixou de 4500 para $425 \mu \mathrm{g} / \mathrm{m}^{3}$ (cerca de 10 vezes) e de 7011 para $1453 \mu \mathrm{g} / \mathrm{m}^{3}$ (cerca de 5 vezes) em Nima. As medidas de Ashaiman, $22 \mathrm{~km}$ a nordeste de Nima, foram feitas entre fevereiro e agosto, e portanto, não afetadas pelo Harmatão.

Considerando o Harmatão, as concentrações médias observadas para a maioria dos elementos do $M P_{2,5}$ em Nima foram superiores a todas outras cidades, com exceção de Pequim. Por outro lado, removendo-se o Harmatão, apesar de ainda haver concentrações altas, os valores tornam-se mais equiparados.

O estudo realizado por Díaz et al. (2014) em Cuajimalpa de Morelos, distrito da Cidade do México, capital do México, apresenta as menores concentrações, pois o local, segundo os autores, apesar de próximo de uma grande zona industrial, não é afetado diretamente por ela, em função da altitude (2760 m do nível do mar) e das condições climáticas favoráveis à dispersão de poluentes, com massa média menor que a metade da encontrada em Nima, 12 e $29,7 \mu \mathrm{g} / \mathrm{m}^{3}$, respectivamente.

Com relação ao Cairo, capital do Egito, Nima obteve concentrações menores, em torno da metade, para a maioria dos elementos. O Egito está localizado no norte da África e na parte leste do deserto do Saara, sendo assim, sofre influência direta e constante do mesmo. Daí suas altas concentrações. Diferente do Harmatão, que é sazonal, neste caso não é trivial excluir o impacto do deserto (fonte natural) da poluição das fontes locais Boman et al. (2013).

A China é conhecida mundialmente por sua poluição, resultado de condições climáticas desfavoráveis à dispersão de poluentes, pouca chuva e pouco vento, em conjunto com desenfreada industrialização. As inúmeras indústrias de diversas naturezas, usinas de carvão, tráfego 
de veículos, entre outras, explicam índices altíssimos, como o de BC, 8,19 $\mu \mathrm{g} / \mathrm{m}^{3}$, medido em Pequim, capital do país, por Yang et al. (2011). Mesmo considerando os dias de Harmatão, as concentrações de Nima foram inferiores às de Pequim.

Quênia, assim como Gana, faz parte da SSA, e sua capital, Nairóbi, tem condições econômicas e sociais similares às de Acra, com recente industrialização, transporte público precário, frota veicular velha, queima de biomassa, entre outros. Gaita et al. (2014) realizou estudo detalhado de Nairóbi comparando regiões periféricas e centrais. Encontrou concentrações pouco menores que as de Nima, com porcentagem de participação de BC na massa de 15\%, contra 10,49\% em Acra, indicando atividade de combustão, em especial, queima de biomassa e veículos, como principais fontes na cidade (reportado no levantamento de fontes com PMF realizado no artigo).

Nima apresentou concentrações ao menos três vezes maiores que as reportadas para o Brasil, em estudo que avaliou seis cidades brasileiras: São Paulo, Rio de Janeiro, Belo Horizonte, Curitiba, Recife e Porto Alegre (Miranda et al., 2012). Para São Paulo, em particular, Andrade et al. (2012) reportou média de $M P_{2,5}$ durante seu estudo de $28 \mu \mathrm{g} / \mathrm{m}^{3}$, próximo da média de $29,7 \mu \mathrm{g} / \mathrm{m}^{3}$ encontrada em Acra.

A cidade de Rijeka, na Croácia, é pequena, e possui apenas 130 mil habitantes, porém aloca polo industrial que inclui terméletrica e refinaria de óleo e no estudo de Ivošević et al. (2015) apresentou concentração de enxofre $\left(789 \mathrm{ng} / \mathrm{m}^{3}\right)$ e BC $\left(3,4 \mu \mathrm{g} / \mathrm{m}^{3}\right)$ maiores que os encontrados em Nima, tanto em absoluto, quanto relativamente à massa média de $M P_{2,5}(20,6$ $\mu \mathrm{g} / \mathrm{m}^{3}$ ). Por fim, Achad et al. (2014) detalhou o $M P_{2,5}$ em Córdoba, Argentina, encontrando massa média de $50,1 \mu \mathrm{g} / \mathrm{m}^{3}$, maior que em Nima, devido a região ser zona industrial e de alta movimentação de caminhões. 
Tabela 3.15: Médias elementares e média da massa de $M P_{2,5}$ encontradas em Nima e comparadas com outras regiões do mundo: Kwabenya (Aboh et al., 2009), Ashaiman (Ofosu et al., 2012), Cidade do México (Díaz et al., 2014), Cairo (Boman et al., 2013), Pequim (Yang et al., 2011), Nairóbi (Gaita et al., 2014), Brasil ${ }^{d}$ (Miranda et al., 2012), Rijeka (Ivošević et al., 2015) e Córdoba (Achad et al., 2014).

\begin{tabular}{|c|c|c|c|c|c|c|c|c|c|c|c|c|}
\hline & \multicolumn{2}{|c|}{$\begin{array}{l}\text { Este estudo } \\
\text { Nima }^{a, b} \\
2006-2008\end{array}$} & \multicolumn{2}{|c|}{$\begin{array}{c}\text { Acra } \\
\text { Kwabenya }^{a, b} \\
2006-2007\end{array}$} & $\begin{array}{c}\text { Acra } \\
\text { Ashaiman } \\
2008\end{array}$ & $\begin{array}{c}\text { México } \\
\text { Cidade do México } \\
\text { 2004-2005 }\end{array}$ & $\begin{array}{c}\text { Egito } \\
\text { Cairo } \\
2010-2011\end{array}$ & $\begin{array}{c}\text { China } \\
\text { Pequim } \\
\text { 2008-2009 }\end{array}$ & $\begin{array}{c}\text { Quênia } \\
\text { Nairóbi } \\
2008-2010\end{array}$ & $\begin{array}{c}\text { Brasil }^{d} \\
2007-2008\end{array}$ & $\begin{array}{c}\text { Croácia } \\
\text { Rijeka } \\
2013-2015\end{array}$ & $\begin{array}{c}\text { Argentina } \\
\text { Córdoba } \\
2010-2011\end{array}$ \\
\hline \multicolumn{13}{|c|}{$n g / m^{3}$} \\
\hline$M P_{2,5}{ }^{c}$ & 29,7 & 79,8 & 22,9 & 96,5 & 21,6 & 12 & 51 & 118,5 & 18 & & 20,6 & 50,1 \\
\hline $\mathrm{BC}^{c}$ & 3,1 & 3,4 & 1,7 & 2,5 & 2,07 & & 3,7 & 8,19 & 2,7 & & 3,4 & \\
\hline $\mathrm{Na}$ & 336 & 272 & & & 743 & & 610 & & & 117 & 117 & \\
\hline $\mathrm{Mg}$ & 108 & 436 & & & 94,4 & & & 290 & & & 22 & 73 \\
\hline $\mathrm{Al}$ & 720 & 2897 & 342 & 1430 & 806 & & & 790 & & 43,9 & 44 & 383 \\
\hline $\mathrm{Si}$ & 1453 & 7011 & 425 & 4500 & 1159 & & & 1790 & & 125,3 & 110 & 1509 \\
\hline $\mathrm{P}$ & 14 & 25 & & & & & & & & 10,9 & 2,8 & \\
\hline $\mathrm{S}$ & 605 & 793 & 442 & 524 & 391 & 600 & 1200 & & 640 & 496,6 & 789 & 336 \\
\hline $\mathrm{Cl}$ & 458 & 603 & & & 145 & 37 & 2200 & 2300 & 480 & 66,6 & 54 & \\
\hline $\mathrm{K}$ & 858 & 1545 & 260 & 731 & 487 & 96 & 470 & 3520 & 310 & 225,3 & 194 & 628 \\
\hline $\mathrm{Ca}$ & 353 & 1248 & 41,7 & 432 & 287 & 130 & 2900 & 900 & 310 & 64 & 88 & 308 \\
\hline $\mathrm{Ti}$ & 47,2 & 205 & 12,6 & 100 & 59 & 9 & 100 & 80 & 54 & 5,5 & 3,4 & 22 \\
\hline $\mathrm{V}$ & 1,8 & 4,4 & & & 2,9 & 10 & 9,6 & 30 & 41 & 1,53 & 3,4 & 0,5 \\
\hline $\mathrm{Mn}$ & 9,3 & 36 & 3,5 & 19 & 27,4 & 3 & 24 & 90 & & 11,71 & 4,4 & 12 \\
\hline $\mathrm{Fe}$ & 446 & 1853 & 109 & 845 & 987 & 100 & 1000 & 1130 & 350 & 108,3 & 93 & 301 \\
\hline $\mathrm{Zn}$ & 31 & 41,0 & 5,5 & 9,5 & 164 & 12 & 200 & 530 & 91 & 29,7 & 14 & 17 \\
\hline $\mathrm{Br}$ & 23,5 & 27,4 & 5,7 & 6,8 & 32,4 & 5 & 21 & 30 & 12 & 3,75 & 2,6 & \\
\hline $\mathrm{Pb}$ & 15,5 & 19,3 & 2,1 & 3,5 & 43,9 & 9 & 86 & 240 & 22 & 8,39 & 6,8 & \\
\hline
\end{tabular}

\footnotetext{
${ }^{a}$ Removendo Harmatão

${ }^{b}$ Incluindo Harmatão

${ }^{c}$ Dimensão de $\mu \mathrm{g} / \mathrm{m}^{3}$

${ }^{d}$ Média para seis cidades: São Paulo, Rio de Janeiro, Belo Horizonte, Curitiba, Recife e Porto Alegre.
} 
Por fim, a tabela 3.16 apresenta as médias elementares e da massa de $M P_{2,5}$ em separado para a área residencial (Sam Road) e a avenida (Nima). Apesar das diferenças pequenas entre os dois sítios, diferente do $M P_{10}$, a média da massa de $M P_{2,5}$, quando inclusos os dias de Harmatão, apresenta maior valor na área residencial, 83,3 $\mu \mathrm{g} / \mathrm{m}^{3}$, que na avenida, $76,4 \mu \mathrm{g} / \mathrm{m}^{3}$. Entretanto, corrigindo o efeito do Harmatão, a avenida volta a ter maior concentração, 31,9 $\mu \mathrm{g} / \mathrm{m}^{3}$, contra $27,5 \mu \mathrm{g} / \mathrm{m}^{3}$ da área residencial.

Tabela 3.16: Estatística descritiva da área residencial (Sam Road) e avenida (Nima) para $M P_{2,5}$.

\begin{tabular}{ccccc}
\hline & \multicolumn{2}{c}{ Residencial $\left(\mathrm{ng} / \mathrm{m}^{3}\right)$} & \multicolumn{2}{c}{ Avenida $\left(\mathrm{ng} / \mathrm{m}^{3}\right)$} \\
& com Harmatão & sem Harmatão & com Harmatão & sem Harmatão \\
\hline$M P_{2,5}\left(\mu g / \mathrm{m}^{3}\right)$ & $83,3 \pm 18,1$ & $27,5 \pm 1,1$ & $76,4 \pm 9,5$ & $31,9 \pm 0,7$ \\
$\mathrm{Na}$ & $281,0 \pm 16,1$ & $356,2 \pm 21,8$ & $261,1 \pm 13,5$ & $315,7 \pm 18,3$ \\
$\mathrm{Mg}$ & $424,5 \pm 51,2$ & $118,4 \pm 11,8$ & $448,1 \pm 59,4$ & $97,8 \pm 9,5$ \\
$\mathrm{Al}$ & $2748,5 \pm 334,9$ & $701,1 \pm 75,3$ & $3043,5 \pm 385,6$ & $738,2 \pm 65,5$ \\
$\mathrm{Si}$ & $6716,6 \pm 883,0$ & $1440,8 \pm 167,9$ & $7301,5 \pm 1013,0$ & $1465,5 \pm 141,5$ \\
$\mathrm{P}$ & $22,6 \pm 1,5$ & $12,8 \pm 0,7$ & $28,0 \pm 1,7$ & $15,8 \pm 0,7$ \\
$\mathrm{~S}$ & $766,5 \pm 25,5$ & $585,1 \pm 21,7$ & $819,2 \pm 26,4$ & $624,2 \pm 22,5$ \\
$\mathrm{Cl}$ & $586,3 \pm 38,6$ & $448,0 \pm 27,1$ & $619,8 \pm 37,1$ & $467,4 \pm 25,6$ \\
$\mathrm{~K}$ & $1492,6 \pm 108,7$ & $816,2 \pm 20,0$ & $1596,3 \pm 120,2$ & $899,3 \pm 19,4$ \\
$\mathrm{Ca}$ & $1141,1 \pm 165,0$ & $309,4 \pm 21,9$ & $1353,6 \pm 196,0$ & $397,3 \pm 20,2$ \\
$\mathrm{Ti}$ & $193,1 \pm 27,9$ & $44,4 \pm 4,3$ & $217,4 \pm 32,6$ & $50,0 \pm 3,9$ \\
$\mathrm{~V}$ & $4,2 \pm 0,5$ & $1,8 \pm 0,1$ & $4,5 \pm 0,6$ & $1,8 \pm 0,1$ \\
$\mathrm{Mn}$ & $33,6 \pm 5,0$ & $8,5 \pm 0,6$ & $38,4 \pm 6,0$ & $10,0 \pm 0,5$ \\
$\mathrm{Fe}$ & $1746,4 \pm 253,8$ & $413,0 \pm 36,1$ & $1957,7 \pm 296,5$ & $478,4 \pm 30,9$ \\
$\mathrm{Zn}$ & $38,2 \pm 2,2$ & $28,3 \pm 1,4$ & $43,8 \pm 2,6$ & $33,2 \pm 2,2$ \\
$\mathrm{Br}$ & $27,0 \pm 1,4$ & $23,2 \pm 1,6$ & $27,7 \pm 1,4$ & $23,8 \pm 1,5$ \\
$\mathrm{~Pb}$ & $18,6 \pm 0,8$ & $14,9 \pm 0,4$ & $20,1 \pm 0,8$ & $16,0 \pm 0,4$ \\
$\mathrm{BC}\left(\mu \mathrm{g} / \mathrm{m}^{3}\right)$ & $3,1 \pm 0,1$ & $2,9 \pm 0,1$ & $3,6 \pm 0,1$ & $3,3 \pm 0,1$ \\
\hline
\end{tabular}




\subsection{Meteorologia local e Harmatão}

Para melhor entendimento das fontes poluídoras, analisa-se a seguir a dinâmica de ventos a partir de dados da estação meteorológia do aeroporto de Acra (Kotoka International Airport) disponibilizados no site da National Oceanic and Atmospheric Administration - United States Department of Commerce (NOAA). As rosas dos ventos foram plotadas usando a biblioteca openair desenvolvida por Carslaw \& Ropkins (2012).

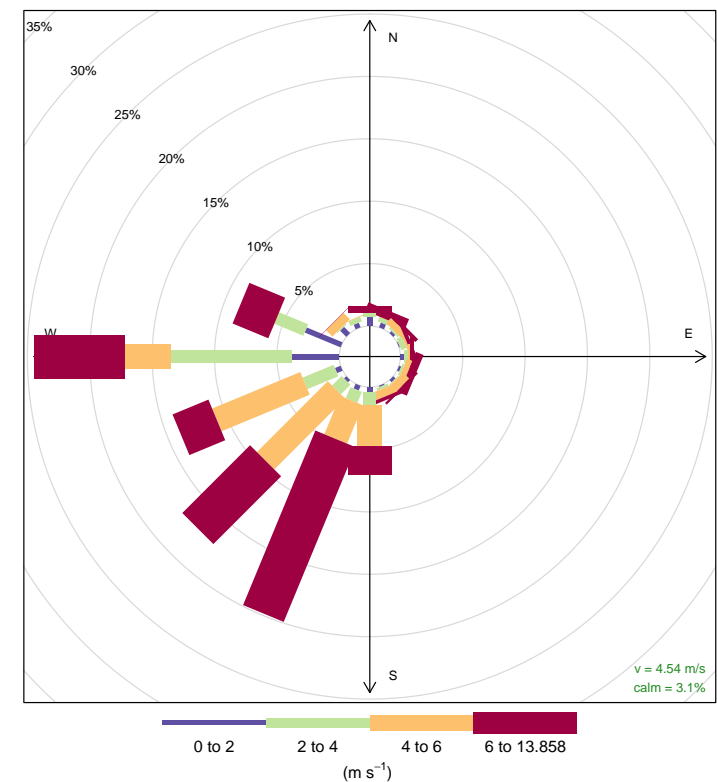

Figura 3.12: Rosa do ventos para Acra/2007.

A figura 3.12 mostra a distribuição de frequência da direção dos ventos em conjunto como a intensidade para o ano de 2007, sendo que a direção predominante de origem dos ventos de superfície está no quadrante sudoeste.

Acra é uma região litorânea e na observação horária média do período de amostragem (gráfico da figura 3.13), a direção e intensidade dos ventos apresentam forte componente regional, associável à brisa marinha.

A brisa marinha, de vento próximo da direção sul (oceano), começa a se formar a partir do amanhancer, enfraquecendo o vento oeste, que persistiu durante a noite, e ganha mais intensidade particularmente a partir de 12h. Ganha intensidade e desloca-se à direção oeste na medida em que as horas avançam (deslocamento à direita do sentido do movimento - ação típica do efeito de Coriolis no hemisfério Norte). Verificamos ainda que durante o período noturno há maior incidência de calmaria e intensidade de ventos mais fracas, enquanto durante o dia os ventos médios são mais intensos, em função do ciclo de irradiação solar. 


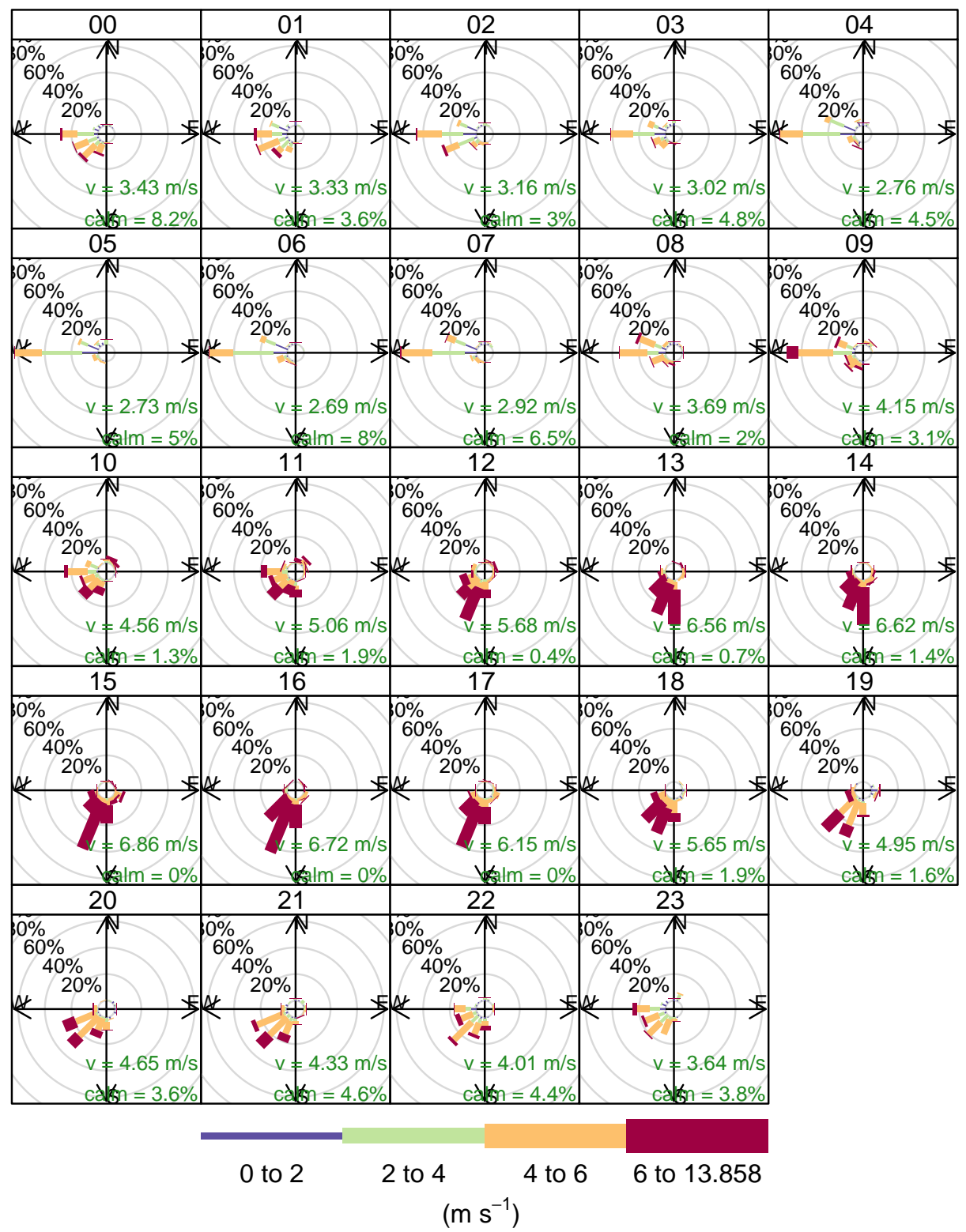

Figura 3.13: Rosa do ventos horária para Acra/2007.

Mensalmente, figura 3.14, pode-se acompanhar o comportamento sazonal do vento. No Verão temos maior quantidade de radiação solar, fortalecendo a formação de brisa marinha e, consequentemente, havendo maior tempo para a velocidade do vento intensificar-se e para processar-se um deslocamento para oeste (Coriolis).

Na maior parte do verão, Gana localiza-se, em termos de padrão global de circulação, no hemisfério sul, ou seja, ao sul da Zona de Convergência Intertropical (ZCIT). Neste período, as intensidades de vento são maiores e são menores as frequências de calmarias. No período do inverno, Gana posiciona-se a norte da ZCIT, e observa-se com isso maior incidência de ventos com origem neste hemisfério (veja-se particularmente o mês de janeiro), com velocidades médias do vento um pouco menores e maior percentual de calmaria. É nesta época que Gana 
e o deserto do Saara situam-se no mesmo sistema de circulação global, ocorrendo o Harmatão.

Nos meses de ocorrência do Harmatão (inverno), há um pequeno aumento da frequência de ventos de nordeste ao nível do solo (direção do Saara), mas a maior parte do particulado que este vento transporta passa por Gana em altitudes superiores (Breuning-Madsen \& Awadzi, 2005), interferindo pouco no predomínio da brisa marinha na circulação local.

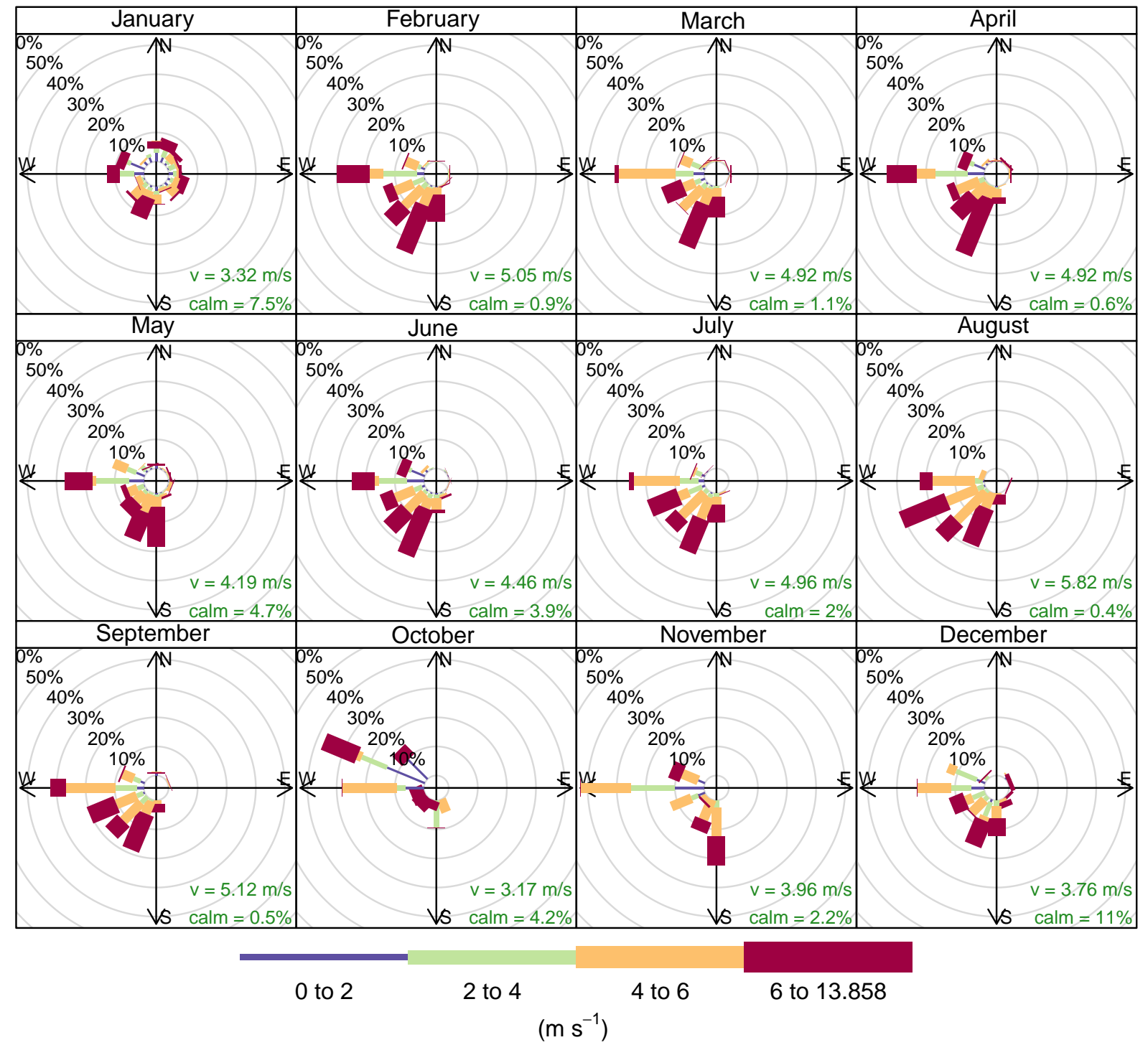

Figura 3.14: Rosa do ventos mensal para Acra/2007. 
Na rosa do ventos para o ano de 2007 (figura 3.12) nota-se que praticamente não há ventos de norte e nordeste. Mesmo no inverno (figura 3.14) quando Gana está no hemisfério norte em termos da circulação global, a frequência de ventos nordeste na superfície continua baixa. Como descrito por Breuning-Madsen \& Awadzi (2005), o Harmatão é um vento nordeste que transporta areia do deserto do Saara a altas altitudes $(1000 \mathrm{~m})$.

Para contraste dos ventos médios em altas altidudes com os de superfície, dados de reanálise disponibilizados pela ECMWF de dezembro de 2007 e janeiro de 2008 foram utilizados. Com recorte na longitude entre 20 oeste e 60 leste e latitude de 30 sul a 40 norte, selecionou-se assim o continente Africano e parte dos oceanos atlântico e índico. Os mapas da figura 3.16 mostram ventos próximos à superfície e também na altitude de 1000 metros (figura 3.15), para o período correspondente. Na superfície, é possível notar o regime de brisa marinha, com entrada de vento do mar. Em 1000 metros, os ventos de nordeste são muitos mais intensos e frequentes que na superfície, caracterizando a presença do Harmatão. 


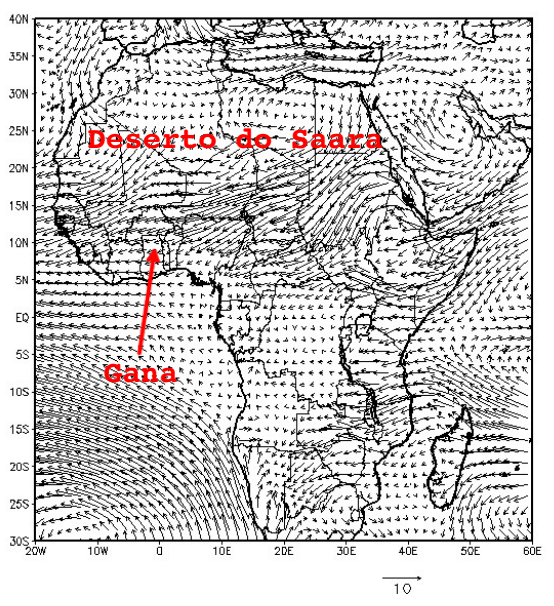

(a) Dezembro de 2007

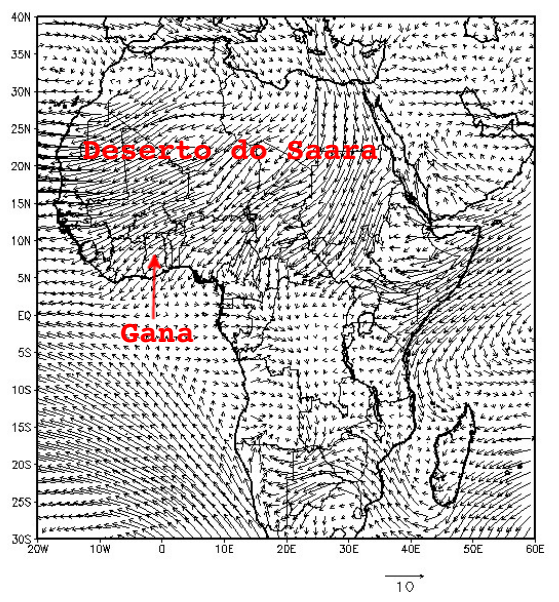

(b) Janeiro de 2008

Figura 3.15: Intensidade e direção do vento médio na altitude de 1000 metros sobre o continente Africano.

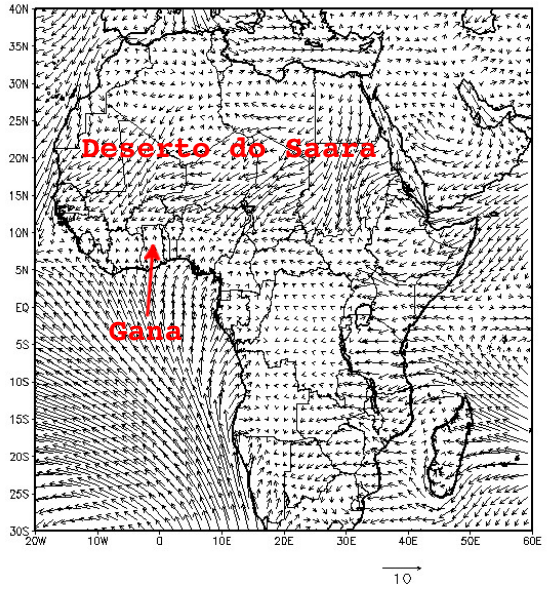

(a) Dezembro de 2007

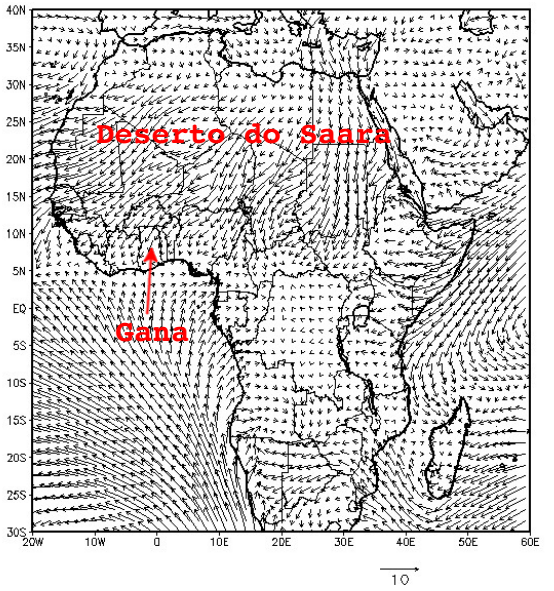

(b) Janeiro de 2008

Figura 3.16: Intensidade e direção do vento médio na superfície (10 metros) no continente Africano. 


\subsection{Identificação das fontes}

$\mathrm{Na}$ aplicação de modelos receptores, os valores faltantes foram preenchidos com o valor da metade do limite de detecção ( $\mathrm{LD} / 2)$, pois supõe-se que a concentração não detectada de um elemento que aparece frequentemente nas demais amostras esteja entre 0 e o LD, com igual probabilidade de ocorrência para cada valor. Assim, LD/2 seria a média e, portanto, o valor mais provável entre estes valores não detectados. Para a incerteza das concentrações, usou-se sugestão proposta por Polissar et al. (1998) de usar $(5 \cdot L D) / 6$.

Até então, foram frutos dessa pesquisa dois artigos publicados: um em 2013, intitulado Chemical composition and sources of particle pollution in affluent and poor neighborhoods of Accra, Ghana (Zhou et al., 2013), e outro em 2014, Chemical characterization and source apportionment of household fine particulate matter in rural, peri-urban, and urban West Africa (Zhou et al., 2014), nos quais realizou-se o levantamento de fontes usando PMF com todas as 2898 amostras $\left(M P_{10}\right.$ e $\left.M P_{2,5}\right)$ coletadas nos cinco sítios ambientais de amostragem. As fontes de MP que foram associadas aos fatores encontrados, com seus respectivos elementos caracterizadores, foram: queima de lixo sólido ( $\mathrm{Br}, \mathrm{Pb})$, poeira de solo e veículo (Al, $\mathrm{Si}, \mathrm{Ca}$, $\mathrm{Fe}, \mathrm{Zn}, \mathrm{BC}, \mathrm{Pb}$ ), solo (Al, Si, Mg, Ti, Mn, Fe), queima de biomassa (K, Cl, S, BC) e mar (Na, $\mathrm{Cl}, \mathrm{S}$ ). Estes fatores foram encontrados para os 4 bairros (5 sítios de coleta) do experimento e, portanto, foram escolhidos a partir de uma análise comuns às 4 regiões, caracterizando-se como um resultado genérico sobre Acra.

O presente trabalho aprofundou análises, dentro do projeto geral, focalizando o bairro de Nima, uma área popular e pobre da capital ganense. Algumas diferenças metodológicas distinguem esta outra etapa do estudo. Primeiramente, separamos o MP nas frações grossa e fina, ao invés de inalável e fina, como apresentado naquelas primeiras publicações. Pretendeuse desta forma melhor definir grupos de fontes, subtraindo os finos do inalável. Ou seja, descolou-se estas duas frações procurando apoiar-se nos seus distintos processos majoritários de geração, para melhor discriminação de fontes.

Por outro lado, além do PMF, utilizou-se a Análise de Fatores para dar maior suporte à identificação das fontes principais impactando aquela área. Avaliou-se, adicionalmente, o comportamento da circulação atmosférica local e como esta poderia apoiar a discriminação das possíveis fontes de MP coletadas nos amostradores. Registre-se, por fim, que neste ínterim foi publicado o novo censo de Gana, oferecendo atualizações no que diz respeito às fontes de energia empregadas para preparação de alimentos em Gana e em Acra (tabela 2.1), abrindo possibilidades de reconsiderar algumas interpretações feitas nos primeiros artigos. 


\subsubsection{Material Particulado Fino $\left(M P_{2,5}\right)$}

Os loadings encontrados para $\mathrm{AF}$ de $M P_{2,5}$ na área residencial estão na tabela 3.17 para 5 fatores retidos e 83,58 \% de variância total explicada em 123 amostras. Se houvéssemos incluindo os dias de Harmatão, contaríamos com 197 amostras e explicaríamos 90,8 \% da variância total, mas extraindo praticamente um único fator englobando a maioria dos elementos (tabela B.1 do apêndice B).

Com 5 fatores, na tabela 3.17, apesar do primeiro fator continuar preponderante, há uma melhor distribuição dos elementos e da variância entre os fatores, permitindo associá-los a fontes regionais. A variabilidade dos elementos foi bem explicada, obtendo-se comunalidades maiores que 0,7 para os elementos, a exceção do bromo $(\mathrm{Br})$ e zinco $(\mathrm{Zn})$ que tiveram comunalidade de 0,44 e 0,59 , respectivamente.

O fator predominante explica $43,78 \%$ da variância, tem altos loadings para os metais $(\mathrm{Al}$, Ti, V, Fe, Mn, Ca, Mg), Si e para a massa. Tais elementos são comumente encontrados em diversos tipos de solos, como os disponíveis no banco de dados SPECIATE da US-EPA (Simon et al., 2010). Podemos, portanto, associá-lo à re-suspensão de poeira do solo. A exceção seria o elemento vanádio, mas Aboh et al. (2009) também encontrou-o no fator poeira de solo em Acra, indicando que de algum modo o V está incorporado a esta fonte.

Ainda no primeiro fator, aparece secundariamente potássio $(\mathrm{K})$, que também pode estar presente em solos, especialmente se houver manipulação de fertilizante na região. Gana não produz nenhum tipo de fertilizantes, mas importa para uso em fazenda locais de pequeno porte (Fianko et al., 2011).

As partículas que compõem poeira de solo estão em sua maioria na fração grossa do Material Particulado $\left(M P_{2,5-10}\right)$, pois são geradas por processo mecânico. Assim, é notável que mesmo no $M P_{2,5}$ ela seja o principal fator, provavelmente explicável pelo grande número de ruas não pavimentadas em Acra.

O segundo fator predominante explica $12,36 \%$ da variância total e agrupa basicamente fósforo $(\mathrm{P})$, potássio $(\mathrm{K})$ e enxofre $(\mathrm{S})$. Considerando-se o registro de intenso uso de biomassa para cozimento (tabela 2.1), particularmente na área de Nima, essa seria uma associação óbvia a esta fonte (Reid et al. (2005) e tantos outros trabalhos que relacionam K,P,S e BC, como indicativos de queima de biomassa. Apenas o loading nulo para BC é que introduz uma dúvida, que apontaria para uma associação à vegetação local, manipulação da terra e uso de fertilizantes, por exemplo. Mas consideramos isso muito improvável, já que essa não é uma atividade que ocorra próximo de Nima, sendo o oposto do que observa-se em relação 
à queima de biomassa. Optamos, assim, por esta associação, considerando a possibilidade de ter ocorrido algum artefato da modelagem ao lidar com a diversidade de fontes geradoras de $\mathrm{BC}$, como veículos ou a queima de lixo. Ressalte-se, em particular, que o fato de nossas amostragens terem tido duração de 48h reduz a habilidade da AF separar alguns fatores.

O terceiro fator retido pode ser associado a veículos e explica $11,24 \%$ da variância total. É composto por BC, chumbo (Pb), zinco (Zn), potássio (K) e massa. Aboh et al. (2009) encontrou o mesmo fator em Kwabenya, $12 \mathrm{~km}$ noroeste de Nima. BC e Zn estão associados a veículos, devido à combustão incompleta e desgaste das pastilhas de freio e dos pneus dos automóveis, respectivamente. O chumbo $(\mathrm{Pb})$ foi banido da gasolina em Gana em 2003 devido à acordo internacional (Ghana, 2015a), mas continua associado, em concentrações bem menores, ao processo de mineração e/ou processamento do petróleo. Veja-se, por exemplo, a tabela 3.16 onde a concentração média de $\mathrm{Pb}$ foi $18,6 \pm 0,8 \mathrm{ng} / \mathrm{m}^{3}$ (área residencial com Harmatão), próximo de valores típicos encontrados em São Paulo $16 \pm 13 \mathrm{ng} / \mathrm{m}^{3}$ (Andrade et al., 2012), onde desde 1992 o uso do tetraetilchumbo foi banido no Brasil. Quanto ao loading significativo de K neste fator, reputamos novamente às dificuldades para o modelos separar espécies quando há elementos comuns entre fontes e má resolução temporal das amostragens.

O quarto fator explica $8,81 \%$ da variância, com sódio $(\mathrm{Na})$, cloro $(\mathrm{Cl})$ e conecta-se indubitavelmente à fonte mar, tendo secundariamente enxofre $(\mathrm{S})$, possivelmente devido à emissão de dimetil-sulfeto no mar. Partículas de $\mathrm{Na}$ e $\mathrm{Cl}$ geradas no mar estão mais concentradas na moda grossa $\left(M P_{2,5-10}\right)$, mas pela proximidade do ponto de amostragem com o mar, obteve-se concentrações suficientes para a extração deste fator. McInnes et al. (1994) observou que em pouco de tempo de residência na atmosfera, o $\mathrm{Cl}$ do sal marinho envelhecido é substituído por $\mathrm{SO}_{4}^{2-}$ como resultado da reação com ácido sulfúrico.

O quinto e último fator retido explicou 7,40 \% da variância e agrupou $\mathrm{Br}$ e $\mathrm{Pb}$, o que atribuímos à queima de lixo sólido e outros materiais a céu aberto. Acra, como comentado na introdução, comporta um dos maiores lixões de eletrônicos (e-waste) do mundo, e dentre outros problemas, ali são queimados componentes (como fios antichamas feitos de plásticos compostos de $\mathrm{Br}$ ) para obtenção do cobre $(\mathrm{Cu})$ em Agbogbloshie, 4 kilomêtros a sudoeste de Nima.

Como pode ser observado na rosa dos ventos para o ano de 2007 da figura 3.12, o vento predominante em Nima é de sudoeste, e portanto pode carregar material de Agbogbloshie para Nima. Assim, é provável que no fator 5, além da queima de lixo sólido local, também esteja representada uma porção de contaminação de Agbogbloshie.

A tabela 3.18 traz os resultados da Análise de Fatores do $M P_{2,5}$ na avenida. Os fatores 
principais extraídos foram essencialmente os mesmos que na área residencial, mudando em geral as distribuições dos loadings de alguns elementos, mas que não alteram as indicações das quatro principais fontes discutidas. Entretanto, observamos que o quinto fator passou a representar essencialmente o BC, enquanto que o $\mathrm{Br}$, cuja comunalidade já não havia sido bem explicada, distribuiu-se entre outros três fatores. Consideramos que isso deve-se novamente às dificuldades do modelo em separar uma espécie como o $\mathrm{BC}$, originada de múltiplas fontes locais significativas, especialmente sendo pobre a resolução temporal das amostragens. 
Tabela 3.17: Análise de Fatores na área residencial para $M P_{2,5}$ excluindo dias de ocorrência de vento Harmatão. $\mathrm{n}=123$.

\begin{tabular}{ccccccc}
\hline Espécie & Fator1 & Fator2 & Fator3 & Fator4 & Fator5 & Comunalidade \\
\hline$M P_{2,5}$ & 0,59 & 0,20 & 0,58 & 0,11 & $-0,21$ & 0,78 \\
$\mathrm{BC}$ & 0,02 & $-0,00$ & 0,81 & $-0,17$ & 0,13 & 0,71 \\
$\mathrm{Na}$ & $-0,33$ & 0,31 & $-0,12$ & 0,69 & 0,35 & 0,82 \\
$\mathrm{Mg}$ & 0,91 & 0,12 & 0,01 & 0,14 & 0,12 & 0,87 \\
$\mathrm{Al}$ & 0,98 & 0,07 & 0,08 & $-0,05$ & $-0,06$ & 0,99 \\
$\mathrm{Si}$ & 0,98 & 0,09 & 0,07 & $-0,04$ & $-0,09$ & 0,98 \\
$\mathrm{P}$ & 0,39 & 0,82 & $-0,12$ & $-0,06$ & 0,10 & 0,85 \\
$\mathrm{~S}$ & $-0,15$ & 0,90 & 0,06 & 0,29 & 0,14 & 0,94 \\
$\mathrm{Cl}$ & 0,14 & 0,07 & 0,15 & 0,92 & 0,03 & 0,9 \\
$\mathrm{~K}$ & 0,38 & 0,68 & 0,50 & 0,11 & 0,00 & 0,88 \\
$\mathrm{Ca}$ & 0,94 & 0,09 & 0,16 & 0,04 & $-0,03$ & 0,93 \\
$\mathrm{Ti}$ & 0,98 & 0,07 & 0,10 & $-0,04$ & $-0,07$ & 0,98 \\
$\mathrm{~V}$ & 0,74 & $-0,05$ & $-0,03$ & $-0,02$ & 0,41 & 0,72 \\
$\mathrm{Mn}$ & 0,97 & 0,06 & 0,16 & $-0,04$ & $-0,06$ & 0,98 \\
$\mathrm{Fe}$ & 0,98 & 0,05 & 0,13 & $-0,05$ & $-0,06$ & 0,99 \\
$\mathrm{Zn}$ & 0,10 & 0,04 & 0,60 & 0,24 & 0,12 & 0,44 \\
$\mathrm{Br}$ & $-0,09$ & 0,28 & 0,09 & 0,17 & 0,68 & 0,59 \\
$\mathrm{~Pb}$ & 0,08 & $-0,08$ & 0,52 & 0,06 & 0,65 & 0,71 \\
\hline $\mathrm{Explicada}(\%)$ & 43,78 & 12,36 & 11,24 & 8,81 & 7,40 & total = 83,58\% \\
\hline
\end{tabular}

Tabela 3.18: Análise de Fatores na avenida para $M P_{2,5}$ excluindo dias de ocorrência de vento Harmatão. $\mathrm{n}=122$.

\begin{tabular}{ccccccc}
\hline Espécie & Fator1 & Fator2 & Fator3 & Fator4 & Fator5 & Comunalidade \\
\hline$M P_{2,5}$ & 0,84 & 0,30 & 0,01 & 0,12 & 0,30 & 0,91 \\
$\mathrm{BC}$ & 0,08 & 0,07 & $-0,07$ & 0,07 & 0,94 & 0,9 \\
$\mathrm{Na}$ & $-0,33$ & 0,31 & 0,83 & $-0,09$ & 0,04 & 0,9 \\
$\mathrm{Mg}$ & 0,93 & 0,13 & 0,12 & $-0,02$ & $-0,03$ & 0,89 \\
$\mathrm{Al}$ & 0,99 & 0,03 & $-0,09$ & 0,01 & $-0,03$ & 0,99 \\
$\mathrm{Si}$ & 0,99 & 0,05 & $-0,07$ & 0,01 & $-0,04$ & 0,98 \\
$\mathrm{P}$ & 0,30 & 0,87 & $-0,11$ & 0,01 & $-0,09$ & 0,86 \\
$\mathrm{~S}$ & $-0,16$ & 0,89 & 0,26 & 0,18 & 0,10 & 0,93 \\
$\mathrm{Cl}$ & 0,16 & $-0,03$ & 0,87 & 0,16 & $-0,10$ & 0,83 \\
$\mathrm{~K}$ & 0,39 & 0,68 & 0,12 & 0,34 & 0,33 & 0,85 \\
$\mathrm{Ca}$ & 0,95 & 0,09 & 0,00 & 0,03 & $-0,05$ & 0,91 \\
$\mathrm{Ti}$ & 0,99 & 0,02 & $-0,10$ & 0,02 & $-0,04$ & 0,99 \\
$\mathrm{~V}$ & 0,69 & $-0,06$ & 0,15 & $-0,04$ & 0,27 & 0,57 \\
$\mathrm{Mn}$ & 0,96 & $-0,00$ & $-0,08$ & $-0,02$ & 0,17 & 0,95 \\
$\mathrm{Fe}$ & 0,98 & 0,02 & $-0,12$ & $-0,03$ & 0,02 & 0,98 \\
$\mathrm{Zn}$ & $-0,06$ & 0,18 & $-0,20$ & 0,60 & 0,17 & 0,47 \\
$\mathrm{Br}$ & $-0,14$ & 0,40 & 0,25 & 0,54 & $-0,23$ & 0,59 \\
$\mathrm{~Pb}$ & 0,11 & $-0,00$ & 0,17 & 0,84 & 0,01 & 0,74 \\
\hline Vxplicada (\%) & 45,49 & 13,44 & 9,76 & 8,73 & 7,19 & total $=84,61 \%$ \\
\hline
\end{tabular}


A AF é uma metodologia bastante apropriada para associar as fontes que podem ter gerado uma base de dados de MP. Neste trabalho, entretanto, a empregamos apenas qualitativamente, sem estendê-la para quantificar o peso das prováveis fontes. Neste particular, lançamos mão das análises de PMF. Diversas parametrizações foram testadas nesta modelagem e as soluções estáveis, portando significado físico, foram retidas. Perceba-se que na AF os fatores são ordenados segundo a fração da variância que eles explicam na base de dados. Mas como veremos ao fazermos o contraste com o PMF, isso não significa estar associado a maior massa explicada.

A tabela 3.19 apresenta o perfil dos fatores para a área residencial de $M P_{2,5}$ e o gráfico da figura 3.17 as respectivas contribuições percentual do fatores na massa total.

O Fator 1 tem perfil marcado por BC, $\mathrm{Pb}, \mathrm{Zn}, \mathrm{K}, \mathrm{V}$ e Mn, representando a maior parcela da massa $(40,0 \%)$ e sendo associado à fonte veicular. Na AF, esse era o fator 3, que explica uma variância mediana da base de dados.

Associamos o fator 2, com 73\% da massa de bromo, 15,1 \% de $\mathrm{Pb}$ e 15,1\% Zn à queima de lixo sólido e outros materiais a céu aberto, representando a menor contribuição para a massa total (4,65\%). Esse era o fator 5 na AF, o que também representava a menor fração de variância explicada.

O fator 3 é o segundo que mais contribui para massa $(22,2 \%)$ e agrega elementos identificáveis como poeira de solo, Al, Si, Ti, V, Fe, Mn, Ca, Mg. Também aparece secundariamente fósforo $(\mathrm{P})$, que poderia fazer parte da composição do solo, devido à materiais de construção (como gesso ou cimento, por exemplo) ou fertilizantes. O vanádio na AF aparecia quase que exclusivamente no fator 1, poeira de solo, enquanto no PMF sua massa está dividida entre veículos $(31,0 \%)$ e solo $(34,4 \%)$, uma distribuição pode justificar-se pela associação frequente deste elemento a veículos movidos a óleo diesel.

Contribuindo com 11,6\% da massa, o fator 4 é marcado por $\mathrm{Na}$ e $\mathrm{Cl}$, além de representar frações menores ( $16 \%$ ) da massa do enxofre (S) e Mg, marcas de aerossol marinho. Corresponde a $11,6 \%$ da massa total e também foi o $4^{\circ}$ fator identificado na AF.

O fator 5, representou 21,6\% da massa total. Além do P, K e S, também encontrados no fator 2 da AF, associado à queima de biomassa, ele tem $17 \%$ de $\mathrm{BC}$ (esperado para esse processo) e recepcionou quase metade da massa do sódio 40,4\% (o que também pode ser resultado da queima doméstica de biomassa).

Os resultados para $M P_{2,5}$ do PMF para a avenida estão na tabela 3.20 e no gráfico da figura 3.18. Na tabela 3.25 sintetiza-se os fatores, suas associações e os respectivos percentuais da massa total determinados pelo PMF para cada um dos fatores, na zona residencial e na 
avenida, auxiliando na articulação da discussão que se segue envolvendo resultados destas duas áreas, que apresentaram estrutura e dimensões similares.

O fator 1 na avenida é marcado principalmente por representar um alto percentual da massa do bromo (68,4\%), além de frações menores de outros metais, que já associamos à queima de lixo sólido. Ele explica apenas 3,86 \% da massa total. O fator 2, de contribuição 13,6 \% relacionamos, novamente, à fonte marinha. O fator 3 é composto por elementos conectáveis à ressuspensão de poeira do solo, contribuindo com $22,2 \%$ da massa total.

O fator 4, associado à queima de biomassa, registra aumento da sua fração no BC em relação à área residencial, de 19,6 \% para 31,6\% e, também, na contribuição sobre a massa total, de 21,6 para 28,8 \%. A região da avenida, possui comércios e venda de alimentos prontos para consumo, como churrasco, restaurantes, salgados etc, que são majoritariamente produzidos por queima de biomassa.

O fator 5, relacionado à fonte veicular, teve sua fração na massa total diminuída de 40,0 para 31,5\%. Apesar da maior movimentação de veículos nesta área, provavelmente ainda ficou abaixo do incremento comercial devido à queima de biomassa.

Apesar das fontes que associamos aos fatores na PMF estarem demarcadas por espécies que lhes são características, pode-se observar um entrelaçamento de elementos que não parece usual. O Zn e o $\mathrm{Pb}$, bem relacionados a veículos, são visíveis no que atribuímos à queima de biomassas, especialmente próximo à avenida. Por outro lado, o K no que seria fator veículos, chega a superar a parcela relativa à queima de biomassas. Como já discutido junto aos resultados de AF, amostragens com resolução temporal muito larga, como as $48 \mathrm{~h}$ empregada neste experimento, dificultam a demarcação dos fatores por promoverem uma mistura relativamente homogeneizada daquilo que as fontes emitiram. Mas as amostragens longas também acumulam toda a evolução de gases e partículas na atmosfera. Isso tanto pode retirar ou agregar elementos ao MP, por reações químicas, condensação homogênea ou heterogênea, agregação de espécies sobre a superfície de partículas, coagulação, coalescência, ou qualquer outro processo que transforme o estado inicial de uma partícula. Em amostragens longas, além daquele aerossol recém emitido, há um maior espaço para a acumulação do MP que evolui na atmosfera. Li et al. (2003) discutem o envelhecimento de partículas emitidas em queimadas, analisandoas individualmente por microscopia eletrônica de transmissão. Mostra diversas formas de agregados de sulfatos de cálcio e fosfatos, misturados com alcatrão e fuligem, registrando, também, adesões sobre partículas de mica muscovita, quartzo e esmectitas, que originam-se do solo. É possível que esse rearranjo nas espécies químicas, portanto, também seja resultado de uma evolução do material particulado. 


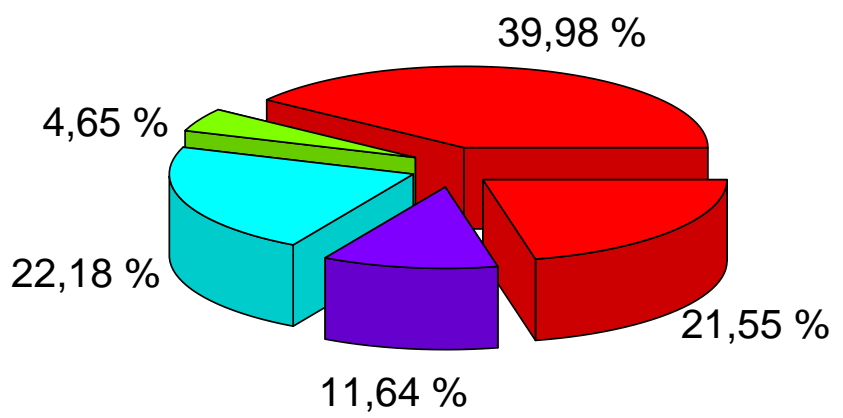

Fator1 = 40,0 $\pm 1,9 \%$

$\square$ Fator2 = 4,65 $\pm 0,43 \%$

$\square$ Fator3 $=22,2 \pm 2,8 \%$

- Fator $4=11,64 \pm 0,89 \%$

Fator5 $=21,6 \pm 1,7 \%$

Figura 3.17: Contribuição dos fatores na massa total para $M P_{2,5}$ na área residencial excluindo dias de ocorrência de vento Harmatão. seed $=123 \mathrm{n}=123$.
Tabela 3.19: Perfis (\%) do fatores na área residencial $M P_{2,5}$ excluindo dias de ocorrência de vento Harmatão. seed=123 e n= 123 .

\begin{tabular}{cccccc}
\hline & Fator1 & Fator2 & Fator3 & Fator4 & Fator5 \\
\hline$M P_{2,5}$ & 40 & 4,6 & 22,2 & 11,6 & 21,6 \\
$\mathrm{Na}$ & 0 & 6,5 & 0 & 53,1 & 40,4 \\
$\mathrm{Mg}$ & 0 & 0 & 73,7 & 16,3 & 10 \\
$\mathrm{Al}$ & 19 & 1,8 & 79,2 & 0 & 0 \\
$\mathrm{Si}$ & 18,9 & 0,1 & 79,7 & 0,8 & 0,4 \\
$\mathrm{P}$ & 4,6 & 0 & 33,7 & 0 & 61,6 \\
$\mathrm{~S}$ & 14,1 & 3,2 & 12,7 & 16,7 & 53,3 \\
$\mathrm{Cl}$ & 6,2 & 0 & 14,3 & 79,5 & 0 \\
$\mathrm{~K}$ & 37,6 & 5 & 14 & 10,7 & 32,7 \\
$\mathrm{Ca}$ & 21,1 & 0,2 & 60,5 & 10,8 & 7,4 \\
$\mathrm{Ti}$ & 19,9 & 0,5 & 77 & 2,1 & 0,4 \\
$\mathrm{~V}$ & 31 & 5,4 & 34,4 & 11,7 & 17,6 \\
$\mathrm{Mn}$ & 34,7 & 3,1 & 51,8 & 4,2 & 6,3 \\
$\mathrm{Fe}$ & 24,6 & 0,2 & 70,2 & 2,4 & 2,7 \\
$\mathrm{Zn}$ & 48,1 & 15,1 & 4,7 & 12,6 & 19,5 \\
$\mathrm{Br}$ & 9,9 & 73 & 8 & 8,8 & 0,3 \\
$\mathrm{~Pb}$ & 52,2 & 15,1 & 2,5 & 16,5 & 13,8 \\
$\mathrm{BC}$ & 62,4 & 9,8 & 0 & 11 & 16,9 \\
\hline
\end{tabular}




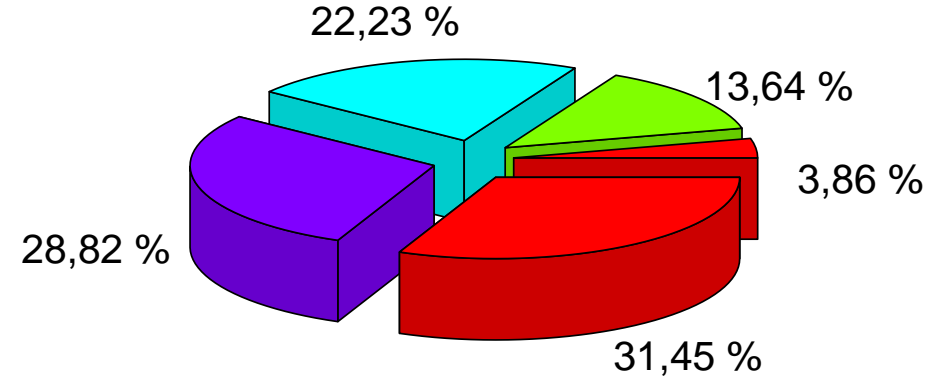

:

Figura 3.18: Contribuição dos fatores na massa total para $M P_{2,5}$ na avenida excluindo dias de ocorrência de vento Harmatão. seed $=123$ $\mathrm{n}=122$.
Tabela 3.20: Perfis (\%) do fatores avenida $M P_{2,5}$ excluindo dias de ocorrência de vento Harmatão. seed=123 e n= 122 .

\begin{tabular}{cccccc}
\hline & Fator1 & Fator2 & Fator3 & Fator4 & Fator5 \\
\hline$M P_{2,5}$ & 3,9 & 13,6 & 22,2 & 28,8 & 31,5 \\
$\mathrm{Na}$ & 13 & 45,8 & 0 & 38 & 3,2 \\
$\mathrm{Mg}$ & 3,8 & 9,8 & 86,4 & 0 & 0 \\
$\mathrm{Al}$ & 1,3 & 0 & 79,4 & 0 & 19,3 \\
$\mathrm{Si}$ & 0 & 0,9 & 78,4 & 0,8 & 19,9 \\
$\mathrm{P}$ & 8,2 & 0 & 36,2 & 55,6 & 0 \\
$\mathrm{~S}$ & 10 & 13,4 & 16,3 & 56,9 & 3,4 \\
$\mathrm{Cl}$ & 0 & 72,2 & 16,6 & 10,1 & 1,1 \\
$\mathrm{~K}$ & 7,8 & 13,2 & 15,1 & 37,9 & 26 \\
$\mathrm{Ca}$ & 4 & 7,7 & 63,7 & 9,1 & 15,4 \\
$\mathrm{Ti}$ & 1,1 & 1,8 & 77,1 & 0,4 & 19,6 \\
$\mathrm{~V}$ & 1,2 & 14 & 29,7 & 23,4 & 31,8 \\
$\mathrm{Mn}$ & 0,3 & 6,9 & 40,6 & 14,3 & 37,9 \\
$\mathrm{Fe}$ & 0 & 2,3 & 69,6 & 4,9 & 23,2 \\
$\mathrm{Zn}$ & 12,6 & 15,8 & 5,1 & 30,1 & 36,4 \\
$\mathrm{Br}$ & 68,4 & 7,5 & 0 & 1,6 & 22,5 \\
$\mathrm{~Pb}$ & 14,2 & 18,8 & 1,3 & 24 & 41,7 \\
$\mathrm{BC}$ & 4,9 & 15,1 & 0 & 31,6 & 48,4 \\
\hline
\end{tabular}




\subsubsection{Material Particulado Grosso $M P_{2,5-10}$}

Nas primeiras publicações referentes a este estudos, Arku et al. (2008) e Dionisio et al. (2010b), não houve separação entre $M P_{2,5}$ e $M P_{2,5-10}$. Nas amostras de Nima, essa separação possibilitou a identificação de fontes na fração grossa do material particulado. Lembramos que o experimento em paralelo com coleta de filtros de quartzo e posterior intercalibração de $\mathrm{BC}$ só foi realizado para $M P_{2,5}$ e portanto não há medidas de $\mathrm{BC}$ para $M P_{2,5-10}$.

Os loadings encontrados para Análise de Fatores de $M P_{2,5-10}$ na área residencial e na avenida estão nas tabelas 3.21 e 3.21. A menos de algumas mudanças nas projeções dos loadings, geralmente pequenas, percebe-se a mesma estrutura de fontes para os dois locais, tendo-se retido 4 fatores, que explicaram 93 e 86\% da variância destas duas bases de dados. A comunalidade foi maior que 0,7 para todos elementos.

O fator 1 explica sozinho essencialmente a metade da variância dos dados e tem projetados elementos componentes de poeira do solo $\mathrm{Al}, \mathrm{Si}, \mathrm{Ti}, \mathrm{Fe}, \mathrm{Mn}, \mathrm{Ca}, \mathrm{Mg}$, mais $M P_{2,5-10}$ e V, cuja presença também é registrada no solo local. A predominância de solo é um resultado comum para o $M P_{2,5-10}$.

O fator 2 é marcado por K, Zn, Pb, S, e Br. Aboh et al. (2009) identificou em Kwabenya um fator (explicando $17 \%$ da variância) composto por Zn, BC e Pb e o relacionou a uma mistura de fonte de indústria local e queima de biomassa. Mas os autores não explicam como essas fontes independentes acabaram correlacionando-se. Em nosso entender, o mais provável é que isso seja um efeito do envelhecimento de partículas, envolvendo as principais fontes locais - solo, veículos e queima de biomassa - já discutido ao final do item 3.5.1. Não deixa de ser possível, entretanto, que esse material provenha de empresas metalúrgicas situadas a aproximadamente $2 \mathrm{~km}$ a sudoeste de Nima (figura 2.2), o que poderia justificar, também as projeções não desprezíveis de $\mathrm{Na}$ e $\mathrm{Cl}$ neste fator.

O terceiro fator tem altos loadings de $\mathrm{Na}, \mathrm{Cl}$ e $\mathrm{S}$, ligando-se à fonte mar.

O quarto e último fator, marcado pelo Zn (e uma projeção de P na área residencial), também chama a atenção por conter loadings homogêneos das principais espécies ligadas ao solo (que também tem P). Partículas grossas contendo Zn têm forte conexão com o desgaste de componentes de veículos (pneus e freios). Cremos ser possível conectar este fator à ressuspensão de poeira da estrada. 
Tabela 3.21: Análise de Fatores na área residencial para $M P_{2,5-10}$ excluindo dias de ocorrência de vento Harmatão. $\mathrm{n}=112$.

\begin{tabular}{cccccc}
\hline Espécie & Fator1 & Fator2 & Fator3 & Fator4 & Comunalidade \\
\hline$M P_{2,5-10}$ & 0,88 & 0,36 & 0,14 & 0,17 & 0,96 \\
$\mathrm{Na}$ & $-0,21$ & 0,41 & 0,87 & $-0,11$ & 0,97 \\
$\mathrm{Mg}$ & 0,77 & 0,28 & 0,40 & $-0,20$ & 0,87 \\
$\mathrm{Al}$ & 0,96 & 0,08 & $-0,08$ & 0,21 & 0,98 \\
$\mathrm{Si}$ & 0,98 & 0,07 & $-0,09$ & 0,13 & 0,99 \\
$\mathrm{P}$ & 0,51 & $-0,06$ & $-0,20$ & 0,73 & 0,83 \\
$\mathrm{~S}$ & 0,16 & 0,89 & 0,38 & 0,04 & 0,97 \\
$\mathrm{Cl}$ & 0,07 & 0,42 & 0,89 & 0,04 & 0,97 \\
$\mathrm{~K}$ & 0,60 & 0,74 & 0,13 & 0,11 & 0,93 \\
$\mathrm{Ca}$ & 0,92 & 0,17 & 0,05 & 0,29 & 0,96 \\
$\mathrm{Ti}$ & 0,94 & 0,11 & $-0,04$ & 0,29 & 0,98 \\
$\mathrm{~V}$ & 0,81 & 0,36 & 0,04 & 0,04 & 0,79 \\
$\mathrm{Mn}$ & 0,96 & 0,16 & $-0,06$ & 0,11 & 0,97 \\
$\mathrm{Fe}$ & 0,94 & 0,12 & $-0,11$ & 0,24 & 0,97 \\
$\mathrm{Zn}$ & 0,37 & 0,54 & 0,20 & 0,62 & 0,84 \\
$\mathrm{Br}$ & 0,09 & 0,92 & 0,29 & 0,01 & 0,95 \\
$\mathrm{~Pb}$ & 0,22 & 0,93 & 0,18 & 0,04 & 0,94 \\
\hline Variância Explicada (\%) & 49,07 & 24,25 & 12,34 & 7,69 & total $=93,36 \%$ \\
\hline
\end{tabular}

Tabela 3.22: Análise de Fatores na avenida para $M P_{2,5-10}$ excluindo dias de ocorrência de vento Harmatão. $\mathrm{n}=116$.

\begin{tabular}{cccccc}
\hline Espécie & Fator1 & Fator2 & Fator3 & Fator4 & Comunalidade \\
\hline$M P_{2,5-10}$ & 0,92 & 0,21 & 0,05 & 0,25 & 0,95 \\
$\mathrm{Na}$ & $-0,22$ & 0,24 & 0,88 & $-0,15$ & 0,91 \\
$\mathrm{Mg}$ & 0,82 & 0,23 & 0,21 & $-0,18$ & 0,81 \\
$\mathrm{Al}$ & 0,93 & 0,18 & $-0,19$ & 0,22 & 0,98 \\
$\mathrm{Si}$ & 0,95 & 0,16 & $-0,12$ & 0,20 & 0,98 \\
$\mathrm{P}$ & 0,59 & 0,31 & $-0,52$ & 0,26 & 0,78 \\
$\mathrm{~S}$ & 0,25 & 0,84 & 0,32 & 0,02 & 0,88 \\
$\mathrm{Cl}$ & 0,07 & 0,25 & 0,94 & 0,10 & 0,97 \\
$\mathrm{~K}$ & 0,74 & 0,58 & $-0,06$ & 0,14 & 0,9 \\
$\mathrm{Ca}$ & 0,85 & 0,22 & 0,06 & 0,39 & 0,93 \\
$\mathrm{Ti}$ & 0,92 & 0,16 & $-0,15$ & 0,28 & 0,98 \\
$\mathrm{~V}$ & 0,80 & 0,16 & $-0,16$ & $-0,19$ & 0,73 \\
$\mathrm{Mn}$ & 0,95 & 0,17 & $-0,10$ & 0,16 & 0,96 \\
$\mathrm{Fe}$ & 0,92 & 0,13 & $-0,12$ & 0,23 & 0,93 \\
$\mathrm{Zn}$ & 0,50 & 0,36 & $-0,12$ & 0,69 & 0,87 \\
$\mathrm{Br}$ & 0,06 & 0,83 & 0,26 & 0,12 & 0,77 \\
$\mathrm{~Pb}$ & 0,51 & 0,66 & $-0,07$ & 0,20 & 0,74 \\
\hline Variância Explicada (\%) & 51,46 & 16,57 & 13,55 & 6,96 & total = 88,55\% \\
\hline
\end{tabular}


A AF ofereceu elementos preliminares para a análise por PMF. Ao extrairmos 5 fatores com esta modelagem, obtínhamos um fator que caracterizava-se como uma espécie de resíduo, com baixo percentual da massa (3,4\% na avenida e 7,5\% na área residencial), sem alterar as associações de fontes que já havíamos feito na AF. Optamos, assim pela extração de 4 fatores na análise por PMF (os resultados com 5 fatores estão no apêndice III).

Os resultados na área residencial estão na tabela 3.23 e no gráfico 3.19, enquanto para a avenida temos a tabela 3.24 e o gráfico 3.20 .

A tabela 3.26 sintetiza a individualização de fontes adotada e os correspondentes percentuais de massa a elas atribuídos. A ressuspensão de poeira de estrada e a ressuspensão de solo representam o maior aporte de massa no $M P_{2,5-10}$, totalizando $63,2 \%$ na avenida e $61,3 \%$ na área residencial.

Para o aerossol marinho o modelo estimou $16,4 \%$ na área residencial e $26,6 \%$ na avenida. Essa está mais próxima do oceano, mas o fato da PMF fechar as contas em $100 \%$ também força o rateio das massas entre os fatores. A adoção de 5 fatores neste caso, por exemplo, colocaria o aerossol marinho em 21,4 \% da massa. Por fim, temos o fator "envelhecimento de partículas"(envolvendo as principais fontes locais - solo, veículos e queima de biomassa), que consideramos também poder ser ligado a empresas metalúrgicas. O perfil dado pela PMF cremos reforçar a primeira hipótese. O modelo atribuiu 22,3 \% a esse fator na área residencial e $10,3 \%$ na avenida.

Assim, como discutido no artigo Zhou et al. (2013), medidas relativamente simples para limitar a ressuspensão de solo, reduziriam drasticamente os níveis de concentração do MP inalável local. 


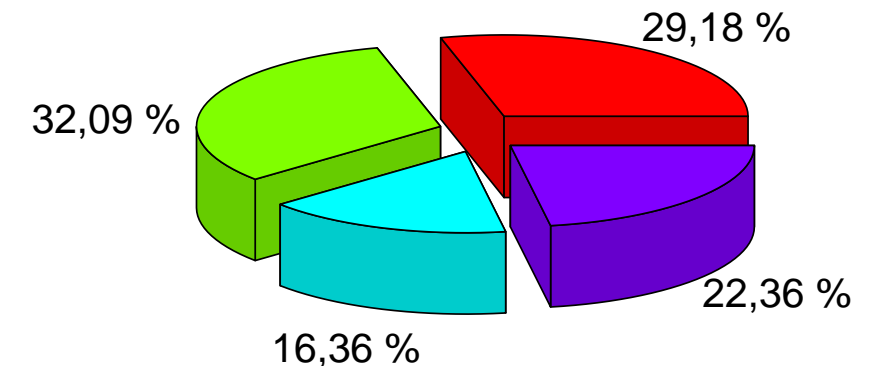

$16,36 \%$

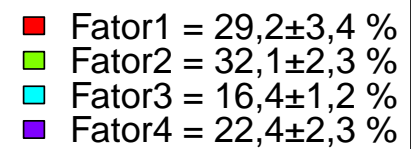

Figura 3.19: Contribuição dos fatores na massa total para $M P_{2,5-10}$ na área residencial excluindo dias de ocorrência de vento Harmatão. seed $=123 \mathrm{n}=123$.
Tabela 3.23: Perfis (\%) do fatores na área residencial $M P_{2,5-10}$ excluindo dias de ocorrência de vento Harmatão. seed=123 e n= 112 .

\begin{tabular}{ccccc}
\hline & Fator1 & Fator2 & Fator3 & Fator4 \\
\hline$M P_{2,5-10}$ & 29,2 & 32,1 & 16,4 & 22,3 \\
$\mathrm{Na}$ & 0,7 & 0 & 78,9 & 20,5 \\
$\mathrm{Mg}$ & 47,3 & 5,8 & 34,4 & 12,5 \\
$\mathrm{Al}$ & 48,1 & 37,6 & 4,6 & 9,7 \\
$\mathrm{Si}$ & 45,3 & 38 & 5,8 & 10,9 \\
$\mathrm{P}$ & 9,1 & 78,3 & 0 & 12,6 \\
$\mathrm{~S}$ & 6,7 & 0 & 15 & 78,3 \\
$\mathrm{Cl}$ & 8,1 & 15,8 & 56,3 & 19,8 \\
$\mathrm{~K}$ & 26,2 & 12,5 & 0 & 61,3 \\
$\mathrm{Ca}$ & 25,9 & 46,4 & 14,2 & 13,5 \\
$\mathrm{Ti}$ & 40,3 & 41,9 & 6,5 & 11,2 \\
$\mathrm{~V}$ & 44,4 & 39,9 & 10 & 5,7 \\
$\mathrm{Mn}$ & 41,9 & $\mathbf{3 4 , 3}$ & 5,8 & 18 \\
$\mathrm{Fe}$ & 37,6 & 42,6 & 7,5 & 12,3 \\
$\mathrm{Zn}$ & 0,2 & $\mathbf{5 3 , 3}$ & 5,9 & $\mathbf{4 0 , 6}$ \\
$\mathrm{Br}$ & 0 & 2,7 & 12,2 & $\mathbf{8 5 , 1}$ \\
$\mathrm{Pb}$ & 11,1 & $\mathbf{3 4 , 5}$ & 1,4 & 53,1 \\
\hline
\end{tabular}




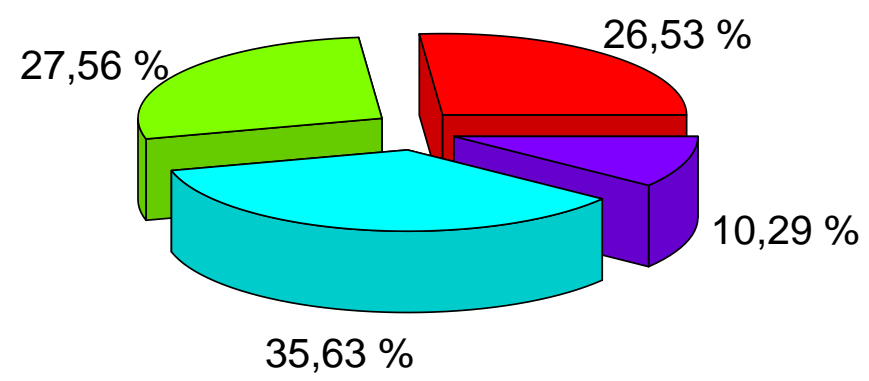

- Fator $1=26,5 \pm 2,0 \%$

$\square$ Fator2 $=27,6 \pm 1,6 \%$

$\square$ Fator3 $=35,6 \pm 2,8 \%$

Fator4 $=10,29 \pm 0,64 \%$

Figura 3.20: Contribuição dos fatores na massa total para $M P_{2,5-10}$ na avenida excluindo dias de ocorrência de vento Harmatão. seed $=$ $123 \mathrm{n}=116$.
Tabela 3.24: Perfis (\%) do fatores avenida $M P_{2,5-10}$ excluindo dias de ocorrência de vento Harmatão. seed=123 e n= 116 .

\begin{tabular}{ccccc}
\hline & Fator1 & Fator2 & Fator3 & Fator4 \\
\hline$M P_{2,5-10}$ & 26,6 & 27,6 & $\mathbf{3 5 , 6}$ & 10,3 \\
$\mathrm{Na}$ & 72,4 & 10,6 & 0 & 17 \\
$\mathrm{Mg}$ & 33,2 & 4,4 & $\mathbf{5 2 , 6}$ & 9,8 \\
$\mathrm{Al}$ & 15,1 & 25,4 & $\mathbf{5 2 , 2}$ & 7,3 \\
$\mathrm{Si}$ & 18,4 & 24,7 & $\mathbf{4 9 , 1}$ & 7,9 \\
$\mathrm{P}$ & 0 & 47,4 & 25 & 27,6 \\
$\mathrm{~S}$ & 26,3 & 7,8 & 16,1 & $\mathbf{4 9 , 8}$ \\
$\mathrm{Cl}$ & 57,4 & 20,6 & 10,2 & 11,9 \\
$\mathrm{~K}$ & 12,2 & 11,7 & 36,9 & 39,1 \\
$\mathrm{Ca}$ & 21,2 & 43,8 & 22,4 & 12,7 \\
$\mathrm{Ti}$ & 16 & 31,8 & 43,9 & 8,3 \\
$\mathrm{~V}$ & 22,7 & 13,1 & 60,9 & 3,2 \\
$\mathrm{Mn}$ & 17,8 & 25,5 & 47 & 9,7 \\
$\mathrm{Fe}$ & 21 & 24,4 & 48,8 & 5,8 \\
$\mathrm{Zn}$ & 8,3 & 56,3 & 3,9 & 31,5 \\
$\mathrm{Br}$ & 26,8 & 0 & 8 & $\mathbf{6 5 , 3}$ \\
$\mathrm{Pb}$ & 7,4 & $\mathbf{3 6 , 4}$ & 14,1 & 42,1 \\
\hline
\end{tabular}


Tabela 3.25: Síntese das associações dos fatores extraídos na AF e PMF com fontes poluidoras para $M P_{2,5}$.

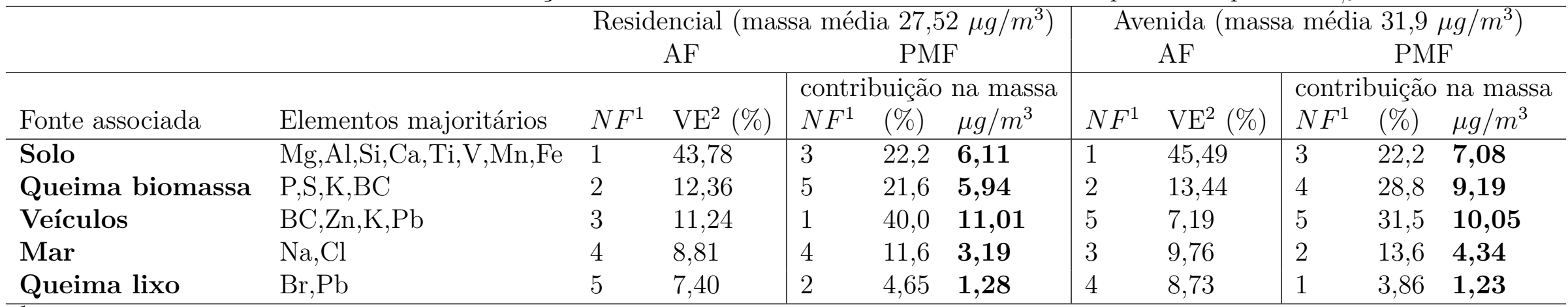

${ }^{1}$ NF: Número do Fator

${ }^{2}$ VE: Variância Explicada

Tabela 3.26: Síntese das associações dos fatores extraídos na AF e PMF com fontes poluidoras para $M P_{2,5-10}$.

\begin{tabular}{|c|c|c|c|c|c|c|c|c|c|c|c|}
\hline Fonte associada & Elementos majoritários & $N F^{1}$ & $\mathrm{VE}^{2}(\%)$ & $\begin{array}{l}\text { contr } \\
N F^{1}\end{array}$ & $\begin{array}{l}\text { uição } \\
(\%)\end{array}$ & $\begin{array}{l}\text { a massa } \\
\mu \mathrm{g} / \mathrm{m}^{3}\end{array}$ & $N F^{1}$ & $\mathrm{VE}^{2}(\%)$ & $\begin{array}{l}\text { contri } \\
N F^{1}\end{array}$ & $\begin{array}{l}\text { ouição } \\
(\%)\end{array}$ & $\begin{array}{l}\text { a massa } \\
\mu \mathrm{g} / \mathrm{m}^{3}\end{array}$ \\
\hline Envelhecido & $\mathrm{S}, \mathrm{K}, \mathrm{Zn}, \mathrm{Br}, \mathrm{Pb}$ & 2 & 24,25 & 4 & 22,36 & 5,65 & 2 & 16,57 & 4 & 10,29 & 3,42 \\
\hline Poeira de estrada & solo $+\mathrm{Zn}$ & 4 & 7,69 & 2 & 32,09 & 8,11 & 4 & 6,96 & 2 & 27,56 & 9,16 \\
\hline
\end{tabular}

${ }^{1}$ NF: Número do Fator

${ }^{2}$ VE: Variância Explicada 


\subsection{Composição elementar da poeira do Harmatão}

A poeira do deserto do Saara trazida pelo Harmatão faz aumentar as concentrações de partículas em mais de $400 \%$ para alguns dias do inverno. Casos extremos que, além de ofuscar fontes poluídoras antropogênicas locais, prejudicam análises estatísticas multivariadas, pois estas não realizam bem o ajuste quando há presença de eventos extremos (outliers).

Aboh et al. (2009) e Ofosu et al. (2013) sugerem a separação dos dias de Harmatão, quando o número de amostras coletadas permitem, para melhora dos ajustes da AF e PMF. Quando não removidos, o fator a eles associado sobrepõe-se aos demais, seja em massa total (PMF), ou em variabilidade $(\mathrm{AF})$.

O alto número de amostras coletadas em Nima possibilitou analisar separadamente o período do Harmatão. Estudaremos nesta seção somente os dias classificados com ocorrência de vento Harmatão, aplicando-se AF e PMF. Na Sam Road, área residencial, 51 amostras de $M P_{2,5}$ foram identificadas como Harmatão, e na Nima Road, avenida, 58.

Para buscar contornar o obscurecimento das fontes locais, impusemos o mesmo número de fatores que foram discriminados sem o Harmatão. Ou seja, consideramos que se algo deveria emergir da análise, não seria diverso do que ali estaria sem esse evento.

Os resultados de AF para $M P_{2,5}$ na área residencial e avenida para cinco fatores extraídos estão nas tabelas 3.27 e 3.28, respectivamente. A variância total explicada foi maior que $90 \%$ nos dois casos e quase todas espécies foram bem explicadas pelo ajuste, com comunalidades próximas de 1.

Apesar do ótimo ajuste da AF, uma rápida olhada nos laodings extraídos revela que o primeiro fator agrupa praticamente sozinho todas as espécies, mas trazendo com mais intensidade os elementos característicos da poeira do solo. Entendemos, assim, que ele representa especialmente o Harmatão e o solo local. O Br aparece isolado nos dois locais (fator 4 e 5, residencial e avenida, respectivamente), que caracterizamos anteriormente como queima de lixo sólido. Já nos demais fatores emergem apenas sinais confusos das fontes detectadas sem o Harmatão, alternando laodings de espécies que indicam ligações tanto com queima

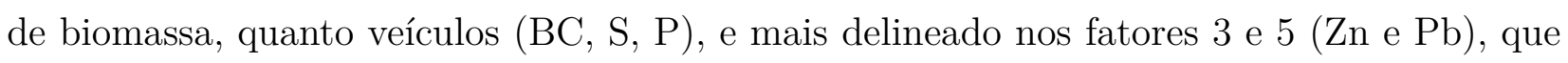
associamos a veículos, acompanhado com loadings altos de Na.

No PMF, os resultados para área residencial dos perfis dos fatores estão na tabela 3.29 e a contribuição para massa total no gráfico da figura 3.21. Para a avenida, os perfis estão na tabela 3.30 e a contribuição no gráfico da figura 3.22. Diferente da AF, o PMF conseguiu distinguir melhor os fatores, com a mesma associações de fontes que já fizemos: solo, veículos, 
queima de biomassa, mar, queima de lixo, mas que apresentam peculiaridades e devem ser vistos com cuidado. Na área residencial os fatores 1 e 5 seriam associáveis a solo, considerandose o primeiro mais ligado ao Harmatão e o último, a um solo local (por apresentar V, Zn e P). As espécies típicas de solo também aparecem, em menor percentual, nos fatores 3 e 4, mas neles encontramos entrelaçadas espécies traçadoras de queima de biomassa e veículos, bem como $\mathrm{Na}$ que pode vir do aerossol marinho. Na avenida os correspondentes para solo seriam os fatores 1 e 4, o mar aparece separado (fator 2) e o fator 3 representa a mistura veículos, queima de biomassa e frações de solo. O Br domina o fator 2 na área residencial e o 5 na avenida, que relacionaríamos à queima de lixo sólido. Acreditamos que esse mix veículos, biomassa, solo - possa ser resultado de processo de agregação de partículas finas, entre si, e/ou com partículas de solo, como resultado da evolução desse conjunto de partículas naquela atmosfera. Mas resta sempre a possibilidade deste ser um resultado recepcionando Zn, que podem originar-se do desgaste de componentes veiculares apenas das imprecisões que acompanham o predomínio do Harmatão.

Na AF para $M P_{2,5-10}$, tabelas 3.31 e 3.32, os 4 fatores extraídos apresentam problemas de definição. Teríamos na área residencial o fator 1, associável ao Harmartão, e fator 4, ao solo local (mas contendo também Zn, S que podem originar-se de veículos), que na avenida seriam os fatores 4 e 3 . O mar estaria marcando os fatores 2 e 1 - residencial e avenida respectivamente. O fator 3 da área residencial e o 2 na avenida, assemelham-se a uma espécie de sopa de finos e grossos em envelhecimento naquela atmosfera.

No PMF, tabelas 3.33 e 3.34, e gráficos 3.23 e 3.24, na avenida e na área residencial o fator solo contribuiu em mais de $60 \%$ para massa total, sendo que agora o fator mar somente apareceu na avenida (mais próxima do mar).

Assim, apesar do esforço para identificarmos o conjunto de fontes no período Harmatão, temos uma percepção consciente, ao observar os resultados dos modelos receptores, de que mesmo as fontes locais mais ponderáveis, tendem a ficar obscurecidas por esse fenômeno. Nestas circunstâncias, cuidado especial deve ser tomado com o PMF, que tenta encontrar solução, qualquer que seja o número de fatores inseridos. O processo numérico não é capaz de avaliar se isso faz sentido no problema atmosférico estudado. Devemos ter especial cautela, portanto, com os resultados sintetizados na tabela, no que se refere ao período do Harmatão. Mesmo com as limitações da AF neste caso, a PMF essas modelagens utilizam metodologias distintas para extrair fatores de uma base de dados, e a combinação destas duas metodologias também auxilia na avaliação da razoabilidade dos ajustes encontrados. A síntese das associações dos fatores de AF e PMF para o período do Harmatão estão nas tabelas 3.36 e 3.35. 
Tabela 3.27: Análise de Fatores na área residencial para $M P_{2,5}$ somente do dias de ocorrência de vento Harmatão. $\mathrm{n}=51$.

\begin{tabular}{ccccccc}
\hline Espécie & Fator1 & Fator2 & Fator3 & Fator4 & Fator5 & Comunalidade \\
\hline$M P_{2,5}$ & 0,20 & 0,13 & $-0,06$ & 0,07 & 0,94 & 0,94 \\
$\mathrm{BC}$ & $-0,21$ & 0,80 & 0,16 & $-0,01$ & 0,26 & 0,78 \\
$\mathrm{Na}$ & $-0,41$ & $-0,12$ & $-0,82$ & $-0,01$ & 0,14 & 0,88 \\
$\mathrm{Mg}$ & 0,93 & $-0,01$ & 0,18 & 0,16 & 0,07 & 0,93 \\
$\mathrm{Al}$ & 0,95 & 0,06 & 0,21 & 0,11 & 0,06 & 0,98 \\
$\mathrm{Si}$ & 0,96 & 0,02 & 0,18 & 0,13 & 0,07 & 0,98 \\
$\mathrm{P}$ & 0,74 & 0,41 & 0,03 & $-0,20$ & $-0,04$ & 0,76 \\
$\mathrm{~S}$ & 0,15 & 0,89 & 0,03 & 0,22 & $-0,06$ & 0,87 \\
$\mathrm{Cl}$ & 0,90 & $-0,11$ & 0,23 & 0,23 & 0,01 & 0,93 \\
$\mathrm{~K}$ & 0,89 & 0,20 & 0,32 & 0,16 & 0,15 & 0,98 \\
$\mathrm{Ca}$ & 0,96 & $-0,06$ & 0,13 & 0,12 & 0,09 & 0,96 \\
$\mathrm{Ti}$ & 0,97 & 0,01 & 0,17 & 0,09 & 0,08 & 0,99 \\
$\mathrm{~V}$ & 0,97 & 0,06 & 0,12 & 0,04 & 0,07 & 0,96 \\
$\mathrm{Mn}$ & 0,97 & $-0,01$ & 0,15 & 0,08 & 0,09 & 0,98 \\
$\mathrm{Fe}$ & 0,97 & 0,01 & 0,17 & 0,09 & 0,09 & 0,99 \\
$\mathrm{Zn}$ & 0,67 & 0,31 & 0,48 & 0,19 & 0,22 & 0,86 \\
$\mathrm{Br}$ & 0,17 & 0,15 & 0,05 & 0,93 & 0,06 & 0,91 \\
$\mathrm{~Pb}$ & 0,60 & 0,29 & 0,47 & 0,41 & 0,18 & 0,86 \\
\hline Variância Explicada (\%) & 59,21 & 10,53 & 8,54 & 7,38 & 6,28 & total $=91,95 \%$ \\
\hline
\end{tabular}

Tabela 3.28: Análise de Fatores na avenida para $M P_{2,5}$ somente dias de ocorrência de vento Harmatão. $\mathrm{n}=59$.

\begin{tabular}{ccccccc}
\hline Espécie & Fator1 & Fator2 & Fator3 & Fator4 & Fator5 & Comunalidade \\
\hline$M P_{2,5}$ & 0,96 & 0,17 & 0,10 & 0,12 & 0,09 & 0,99 \\
$\mathrm{BC}$ & 0,17 & 0,17 & 0,94 & $-0,05$ & $-0,07$ & 0,95 \\
$\mathrm{Na}$ & $-0,29$ & $-0,10$ & 0,05 & $-0,94$ & $-0,04$ & 0,98 \\
$\mathrm{Mg}$ & 0,95 & 0,11 & 0,09 & 0,16 & 0,08 & 0,95 \\
$\mathrm{Al}$ & 0,95 & 0,16 & 0,11 & 0,17 & 0,07 & 0,98 \\
$\mathrm{Si}$ & 0,96 & 0,15 & 0,09 & 0,15 & 0,08 & 0,98 \\
$\mathrm{P}$ & 0,66 & 0,65 & $-0,08$ & 0,08 & $-0,17$ & 0,9 \\
$\mathrm{~S}$ & 0,16 & 0,80 & 0,45 & 0,11 & 0,18 & 0,92 \\
$\mathrm{Cl}$ & 0,96 & 0,02 & 0,06 & $-0,03$ & 0,04 & 0,92 \\
$\mathrm{~K}$ & 0,93 & 0,23 & 0,14 & 0,17 & 0,14 & 0,98 \\
$\mathrm{Ca}$ & 0,97 & 0,12 & 0,05 & 0,10 & 0,07 & 0,98 \\
$\mathrm{Ti}$ & 0,97 & 0,16 & 0,06 & 0,14 & 0,06 & 0,99 \\
$\mathrm{~V}$ & 0,96 & 0,17 & 0,05 & 0,12 & 0,07 & 0,97 \\
$\mathrm{Mn}$ & 0,97 & 0,16 & 0,07 & 0,11 & 0,05 & 0,99 \\
$\mathrm{Fe}$ & 0,97 & 0,16 & 0,05 & 0,13 & 0,06 & 0,99 \\
$\mathrm{Zn}$ & 0,86 & 0,17 & 0,20 & 0,22 & 0,12 & 0,87 \\
$\mathrm{Br}$ & 0,17 & 0,05 & $-0,05$ & 0,04 & 0,96 & 0,96 \\
$\mathrm{~Pb}$ & 0,80 & 0,19 & 0,09 & 0,21 & 0,26 & 0,79 \\
\hline Vxplicada $(\%)$ & 67,14 & 7,98 & 6,82 & 6,69 & 6,31 & total = 94,94\% \\
\hline
\end{tabular}




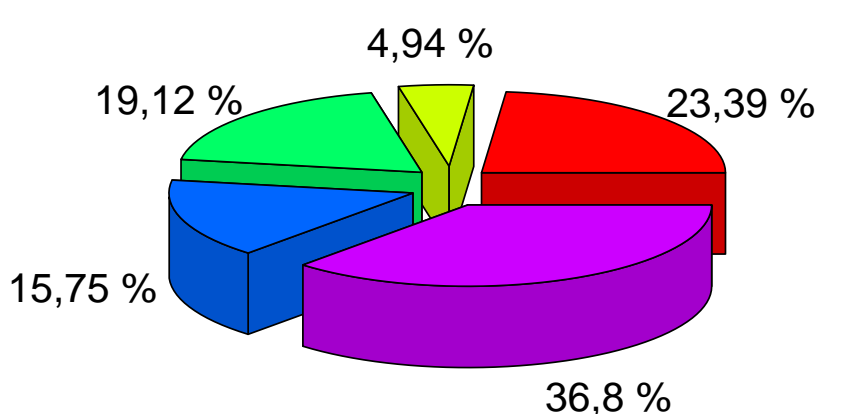

屉

Figura 3.21: Contribuição dos fatores na massa total para $M P_{2,5}$ na área residencial somente nos dias de ocorrência de vento Harmatão. seed $=123 \mathrm{n}=51$.
Tabela 3.29: Perfis (\%) do fatores para $M P_{2,5}$ na área residencial, somente nos de ocorrência de vento Harmatão. seed=123 e n= 51.

\begin{tabular}{cccccc}
\hline & Fator1 & Fator2 & Fator3 & Fator4 & Fator5 \\
\hline$M P_{2,5}$ & 23,4 & 4,9 & 19,1 & 15,7 & 36,8 \\
$\mathrm{Na}$ & 14,9 & 21,5 & 7,1 & 52,7 & 3,9 \\
$\mathrm{Mg}$ & 37,9 & 3,2 & 11,3 & 12,3 & 35,3 \\
$\mathrm{Al}$ & 33,7 & 2,7 & 10,8 & 15,6 & 37,2 \\
$\mathrm{Si}$ & 33,4 & 1,6 & 12,2 & 13,5 & 39,3 \\
$\mathrm{P}$ & 0 & 12,5 & 0 & 57,8 & 29,7 \\
$\mathrm{~S}$ & 11,1 & 26,9 & 1 & 60,2 & 0,8 \\
$\mathrm{Cl}$ & 76,8 & 3,6 & 5,1 & 14,5 & 0 \\
$\mathrm{~K}$ & 9,8 & 12,2 & 23,8 & 27,9 & 26,3 \\
$\mathrm{Ca}$ & 38,6 & 0,7 & 11,3 & 8,6 & 40,8 \\
$\mathrm{Ti}$ & 33,6 & 0,5 & 11 & 11,1 & 43,8 \\
$\mathrm{~V}$ & 27,9 & 3,3 & 6,7 & 18,9 & 43,2 \\
$\mathrm{Mn}$ & 32,1 & 0 & 11,7 & 10 & 46,3 \\
$\mathrm{Fe}$ & 32,3 & 0,7 & 12,3 & 11 & 43,8 \\
$\mathrm{Zn}$ & 0 & 13,5 & 45,2 & 33,6 & 7,7 \\
$\mathrm{Br}$ & 32,7 & 66,1 & 0 & 0 & 1,2 \\
$\mathrm{~Pb}$ & 12 & 19,6 & 33,8 & $\mathbf{3 4 , 5}$ & 0 \\
$\mathrm{BC}$ & 6,9 & 28 & 1 & $\mathbf{6 4 , 1}$ & 0 \\
\hline
\end{tabular}




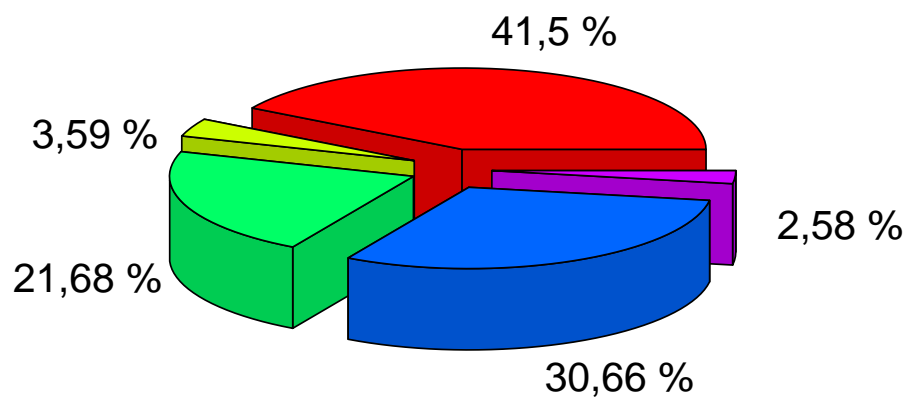

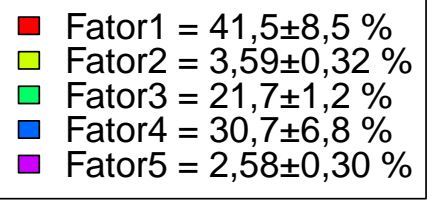

Figura 3.22: Contribuição dos fatores na massa total para $M P_{2,5}$ na avenida somente nos dias de ocorrência de vento Harmatão. seed $=$ $123 \mathrm{n}=59$.
Tabela 3.30: Perfis (\%) do fatores na avenida $M P_{2,5}$ somente nos de ocorrência de vento Harmatão. seed $=123$ e n $=59$.

\begin{tabular}{cccccc}
\hline & Fator1 & Fator2 & Fator3 & Fator4 & Fator5 \\
\hline$M P_{2,5}$ & 41,5 & 3,6 & 21,7 & 30,6 & 2,6 \\
$\mathrm{Na}$ & 0 & $\mathbf{5 5 , 7}$ & $\mathbf{3 4 , 6}$ & 0 & 9,7 \\
$\mathrm{Mg}$ & 70,8 & 0 & 15,7 & 7,4 & 6,1 \\
$\mathrm{Al}$ & $\mathbf{6 1 , 4}$ & 2,3 & 20,5 & 11,9 & 3,9 \\
$\mathrm{Si}$ & $\mathbf{6 5 , 1}$ & 0,9 & 17,9 & 12 & 4 \\
$\mathrm{P}$ & $\mathbf{3 0 , 6}$ & 0 & $\mathbf{6 9 , 1}$ & 0,3 & 0 \\
$\mathrm{~S}$ & 11,6 & 6,9 & $\mathbf{6 3 , 6}$ & 5,7 & 12,1 \\
$\mathrm{Cl}$ & $\mathbf{3 7}$ & $\mathbf{4 4}$ & 0,1 & 15,1 & 3,8 \\
$\mathrm{~K}$ & 25 & 4,5 & $\mathbf{3 3 , 8}$ & $\mathbf{3 1 , 2}$ & 5,4 \\
$\mathrm{Ca}$ & 50,2 & 6,3 & 15,6 & 24,9 & 3,1 \\
$\mathrm{Ti}$ & $\mathbf{5 5 , 8}$ & 2,7 & 17,8 & 21,6 & 2,2 \\
$\mathrm{~V}$ & $\mathbf{4 5 , 9}$ & 5,3 & 20,6 & 24,4 & 3,7 \\
$\mathrm{Mn}$ & 58,3 & 1,1 & 18 & 21 & 1,6 \\
$\mathrm{Fe}$ & $\mathbf{5 4 , 1}$ & 2,6 & 17,8 & 23,4 & 2,1 \\
$\mathrm{Zn}$ & 0 & 17,2 & $\mathbf{3 3 , 4}$ & 48,4 & 1 \\
$\mathrm{Br}$ & 2,5 & 0 & 0,8 & 21,1 & 75,5 \\
$\mathrm{~Pb}$ & 3,2 & 15,3 & $\mathbf{3 5 , 1}$ & 38,3 & 8,1 \\
$\mathrm{BC}$ & 13,3 & 16,1 & $\mathbf{6 0 , 9}$ & 0 & 9,8 \\
\hline
\end{tabular}


Tabela 3.31: Análise de Fatores na área residencial para $M P_{2,5-10}$ somente dos dias de ocorrência de vento Harmatão. $\mathrm{n}=49$.

\begin{tabular}{cccccc}
\hline Espécie & Fator1 & Fator2 & Fator3 & Fator4 & Comunalidade \\
\hline$M P_{2,5-10}$ & 0,80 & $-0,33$ & $-0,04$ & 0,01 & 0,75 \\
$\mathrm{Na}$ & $-0,37$ & 0,78 & $-0,15$ & $-0,10$ & 0,79 \\
$\mathrm{Mg}$ & 0,89 & 0,15 & 0,14 & 0,18 & 0,86 \\
$\mathrm{Al}$ & 0,93 & 0,04 & 0,15 & 0,24 & 0,94 \\
$\mathrm{Si}$ & 0,96 & 0,02 & 0,15 & 0,15 & 0,96 \\
$\mathrm{P}$ & 0,49 & $-0,20$ & 0,04 & 0,79 & 0,91 \\
$\mathrm{~S}$ & 0,10 & 0,56 & 0,44 & 0,58 & 0,85 \\
$\mathrm{Cl}$ & 0,10 & 0,88 & 0,23 & $-0,03$ & 0,84 \\
$\mathrm{~K}$ & 0,92 & $-0,01$ & 0,23 & 0,28 & 0,98 \\
$\mathrm{Ca}$ & 0,97 & $-0,04$ & 0,13 & 0,11 & 0,97 \\
$\mathrm{Ti}$ & 0,97 & $-0,10$ & 0,08 & 0,19 & 0,99 \\
$\mathrm{~V}$ & 0,93 & $-0,11$ & 0,19 & 0,15 & 0,94 \\
$\mathrm{Mn}$ & 0,96 & $-0,12$ & 0,05 & 0,17 & 0,97 \\
$\mathrm{Fe}$ & 0,96 & $-0,12$ & 0,12 & 0,18 & 0,99 \\
$\mathrm{Zn}$ & 0,73 & $-0,03$ & 0,31 & 0,09 & 0,64 \\
$\mathrm{Br}$ & 0,25 & 0,15 & 0,90 & 0,09 & 0,91 \\
$\mathrm{~Pb}$ & 0,78 & $-0,12$ & 0,40 & 0,07 & 0,79 \\
\hline Variância Explicada (\%) & 60,30 & 11,60 & 9,04 & 7,71 & total $=88,66 \%$ \\
\hline
\end{tabular}

Tabela 3.32: Análise de Fatores na avenida para $M P_{2,5-10}$ somente dos dias de ocorrência de vento Harmatão. $\mathrm{n}=58$.

\begin{tabular}{cccccc}
\hline Espécie & Fator1 & Fator2 & Fator3 & Fator4 & Comunalidade \\
\hline$M P_{2,5-10}$ & 0,94 & $-0,18$ & $-0,01$ & 0,07 & 0,91 \\
$\mathrm{Na}$ & $-0,32$ & 0,84 & $-0,24$ & $-0,11$ & 0,88 \\
$\mathrm{Mg}$ & 0,87 & 0,17 & 0,34 & 0,03 & 0,89 \\
$\mathrm{Al}$ & 0,90 & 0,06 & 0,27 & 0,22 & 0,93 \\
$\mathrm{Si}$ & 0,92 & 0,03 & 0,28 & 0,13 & 0,95 \\
$\mathrm{P}$ & 0,27 & 0,03 & $-0,02$ & 0,93 & 0,94 \\
$\mathrm{~S}$ & 0,15 & 0,63 & 0,64 & 0,25 & 0,89 \\
$\mathrm{Cl}$ & 0,05 & 0,86 & 0,37 & 0,12 & 0,89 \\
$\mathrm{~K}$ & 0,84 & 0,16 & 0,34 & 0,32 & 0,96 \\
$\mathrm{Ca}$ & 0,97 & $-0,08$ & 0,16 & 0,08 & 0,98 \\
$\mathrm{Ti}$ & 0,96 & $-0,09$ & 0,11 & 0,21 & 0,99 \\
$\mathrm{~V}$ & 0,91 & $-0,09$ & 0,03 & 0,22 & 0,88 \\
$\mathrm{Mn}$ & 0,97 & $-0,11$ & 0,10 & 0,14 & 0,98 \\
$\mathrm{Fe}$ & 0,96 & $-0,13$ & 0,10 & 0,21 & 0,99 \\
$\mathrm{Zn}$ & 0,66 & 0,27 & 0,25 & 0,49 & 0,81 \\
$\mathrm{Br}$ & 0,27 & 0,06 & 0,90 & $-0,05$ & 0,89 \\
$\mathrm{~Pb}$ & 0,74 & 0,04 & 0,35 & 0,37 & 0,81 \\
\hline Variância Explicada (\%) & 57,70 & 12,16 & 12,01 & 9,79 & total $=91,66 \%$ \\
\hline
\end{tabular}




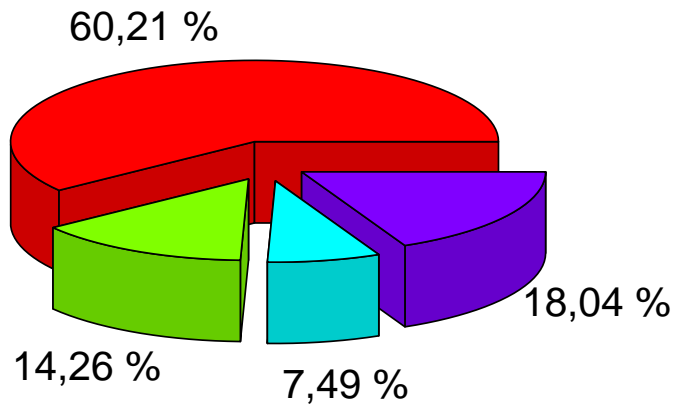

Fator $1=60,2 \pm 7,8 \%$

Fator2 $=14,3 \pm 3,7 \%$

Fator $3=7,5 \pm 6,8 \%$
Fator4 $=18,0 \pm 1,2 \%$

Figura 3.23: Contribuição dos fatores na massa total para $M P_{2,5-10}$ na área residencial somente nos dias de ocorrência de vento Harmatão. seed $=123 \mathrm{n}=49$.
Tabela 3.33: Perfis (\%) do fatores para $M P_{2,5-10}$ na área residencial, somente nos de ocorrência de vento Harmatão. seed=123 e n= 49 .

\begin{tabular}{ccccc}
\hline & Fator1 & Fator2 & Fator3 & Fator4 \\
\hline$M P_{2,5-10}$ & $\mathbf{6 0 , 2}$ & 14,3 & 7,5 & 18 \\
$\mathrm{Na}$ & 0 & 97,9 & 2,1 & 0 \\
$\mathrm{Mg}$ & 53,6 & 0,4 & 22,7 & 23,3 \\
$\mathrm{Al}$ & 59,2 & 7,9 & 1,2 & 31,7 \\
$\mathrm{Si}$ & $\mathbf{6 4 , 4}$ & 8,1 & 0 & 27,5 \\
$\mathrm{P}$ & 8,3 & 15,8 & 50,3 & 25,7 \\
$\mathrm{~S}$ & 21,8 & 0,1 & 9,9 & $\mathbf{6 8 , 2}$ \\
$\mathrm{Cl}$ & 0 & 10,9 & 0 & $\mathbf{8 9 , 1}$ \\
$\mathrm{K}$ & $\mathbf{5 7 , 2}$ & 11,8 & 0,8 & $\mathbf{3 0 , 2}$ \\
$\mathrm{Ca}$ & $\mathbf{6 4}$ & 12,2 & 0 & 23,8 \\
$\mathrm{Ti}$ & $\mathbf{6 4 , 8}$ & 13,2 & 1,9 & 20,1 \\
$\mathrm{~V}$ & 27,2 & 5,9 & $\mathbf{5 6 , 8}$ & 10,1 \\
$\mathrm{Mn}$ & $\mathbf{6 2 , 3}$ & 11,9 & 11,8 & 14 \\
$\mathrm{Fe}$ & $\mathbf{6 4 , 6}$ & 15,4 & 0,1 & 19,9 \\
$\mathrm{Zn}$ & 23 & 17,5 & 26,8 & 32,7 \\
$\mathrm{Br}$ & 5,8 & 0,3 & 72,4 & 21,4 \\
$\mathrm{~Pb}$ & 6,7 & 6,4 & 74,8 & 12,2 \\
\hline
\end{tabular}




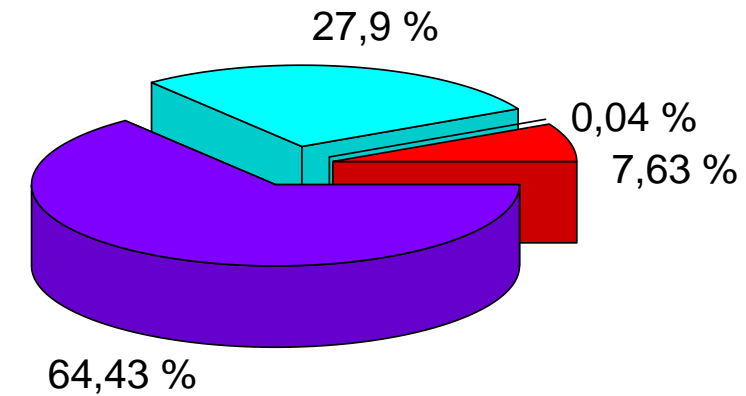

$\vec{\sigma}$

Figura 3.24: Contribuição dos fatores na massa total para $M P_{2,5-10}$ na avenida somente nos dias de ocorrência de vento Harmatão. seed $=123 \mathrm{n}=58$.
Tabela 3.34: Perfis (\%) do fatores na avenida $M P_{2,5-10}$ somente nos de ocorrência de vento Harmatão. seed $=123$ e $n=58$.

\begin{tabular}{ccccc}
\hline & Fator1 & Fator2 & Fator3 & Fator4 \\
\hline$M P_{2,5-10}$ & 7,6 & 0 & 27,9 & $\mathbf{6 4 , 4}$ \\
$\mathrm{Na}$ & 100 & 0 & 0 & 0 \\
$\mathrm{Mg}$ & 11,5 & 20,1 & 11,9 & 56,5 \\
$\mathrm{Al}$ & 20,4 & 3,3 & 30,9 & $\mathbf{4 5 , 4}$ \\
$\mathrm{Si}$ & 14,7 & 4,5 & 27,8 & 52,9 \\
$\mathrm{P}$ & 29,5 & 0 & 70,5 & 0 \\
$\mathrm{~S}$ & 20,4 & 69,1 & 0 & 10,5 \\
$\mathrm{Cl}$ & 71,9 & 1,1 & 14,4 & 12,6 \\
$\mathrm{~K}$ & 10,2 & 17,7 & 31,4 & 40,6 \\
$\mathrm{Ca}$ & 13 & 5,2 & 25,8 & $\mathbf{5 6}$ \\
$\mathrm{Ti}$ & 10,2 & 0,8 & 33,9 & $\mathbf{5 5 , 1}$ \\
$\mathrm{V}$ & 0,3 & 9 & 42,2 & 48,5 \\
$\mathrm{Mn}$ & 1,9 & 5,9 & 27,3 & $\mathbf{6 4 , 9}$ \\
$\mathrm{Fe}$ & 7,3 & 2,4 & $\mathbf{3 6}$ & $\mathbf{5 4 , 3}$ \\
$\mathrm{Zn}$ & 25,9 & 10,3 & $\mathbf{5 3 , 3}$ & 10,5 \\
$\mathrm{Br}$ & 4,2 & 56,5 & 10,4 & 28,8 \\
$\mathrm{~Pb}$ & 24,8 & 3 & 43,2 & 29 \\
\hline
\end{tabular}


Tabela 3.35: Síntese das associações dos fatores extraídos na AF e PMF com fontes poluidoras para $M P_{2,5}$ somente para os dias de Harmartão.

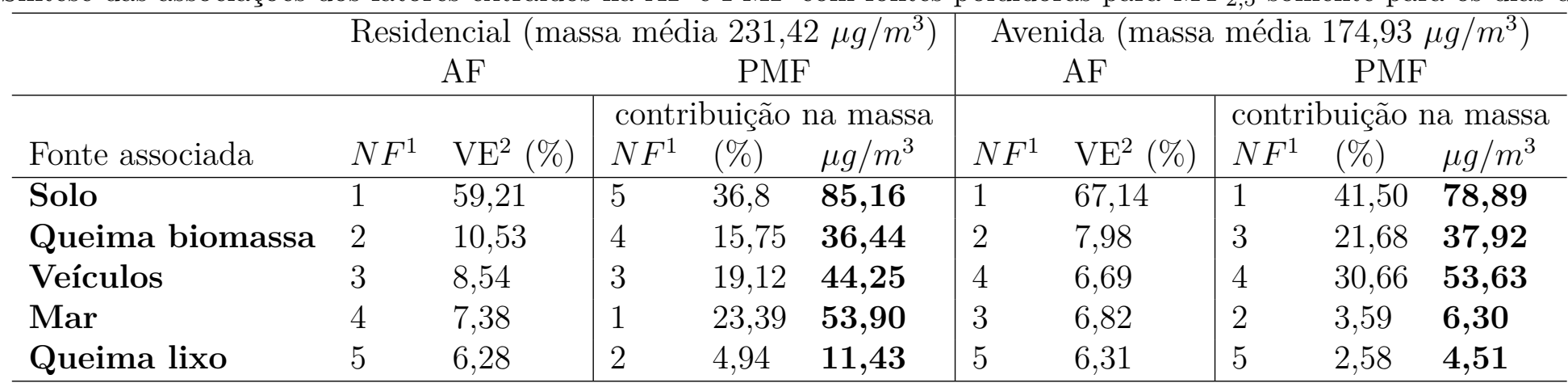

${ }^{1}$ NF: Número do Fator

${ }^{2}$ VE: Variância Explicada

Tabela 3.36: Síntese das associações dos fatores extraídos na AF e PMF com fontes poluidoras para $M P_{2,5-10}$ somente para os dias de Harmartão. Residencial (massa média 112,24 $\mu \mathrm{g} / \mathrm{m}^{3}$ ) $\quad$ Avenida (massa média 112,09 $\mathrm{\mu g} / \mathrm{m}^{3}$ )

\begin{tabular}{|c|c|c|c|c|c|c|c|c|c|c|}
\hline \multirow[b]{2}{*}{ Fonte associada } & \multirow[b]{2}{*}{$N F^{1}$} & $\mathrm{AF}$ & \multicolumn{3}{|c|}{$\mathrm{PMF}$} & \multicolumn{2}{|r|}{$\mathrm{AF}$} & \multicolumn{3}{|c|}{$\mathrm{PMF}$} \\
\hline & & $\mathrm{VE}^{2}(\%)$ & $\begin{array}{l}\text { contr } \\
N F^{1}\end{array}$ & $\begin{array}{l}\text { buiçãa } \\
(\%)\end{array}$ & $\begin{array}{l}\text { la massa } \\
\mu \mathrm{g} / \mathrm{m}^{3}\end{array}$ & $N F^{1}$ & $\mathrm{VE}^{2}(\%)$ & $\begin{array}{l}\text { contr } \\
N F^{1}\end{array}$ & $\begin{array}{l}\text { uição } \\
(\%)\end{array}$ & $\begin{array}{l}\mathrm{a} \text { massa } \\
\mathrm{\mu g} / \mathrm{m}^{3}\end{array}$ \\
\hline Solo & 1 & 60,30 & 1 & 60,21 & 67,57 & 1 & 57,70 & 4 & 64,43 & 72,22 \\
\hline Mar & 2 & 11,60 & 3 & 7,49 & 8,41 & 3 & 12,16 & 2 & 0,04 & 0,05 \\
\hline Poeira de estrada & 3 & 9,04 & 2 & 14,26 & 16,01 & 4 & 12,01 & 1 & 7,63 & 8,55 \\
\hline Envelhecido & 4 & 7,71 & 4 & 18,04 & 20,25 & 2 & 9,79 & 3 & 27,9 & 31,27 \\
\hline
\end{tabular}

${ }^{1}$ NF: Número do Fator

${ }^{2}$ VE: Variância Explicada 


\section{Conclusão}

Essa pesquisa contribuiu para enriquecer o conhecimento acerca de fontes poluidoras do ar em Acra, capital de Gana, além de servir como aporte para levantamentos de fontes poluidoras em cidades com características similares, isto é, aquelas que passaram ou estão passando por um intenso e rápido processo de transição de uma sociedade agrária para urbana e industrializada.

O uso combinado dos métodos estatísticos multivariados Análise de Fatores (AF) e Positive Matrix Factorization (PMF) permitiu identificar e estimar os perfis de fontes. Para o bom desempenho destes modelos, conseguiu-se particulares avanços em relação aos métodos analíticos empregados, especialmente quanto às metodologias para calibrá-los e definir as incertezas das medidas. Isso trouxe resultados positivos para o PMF, que pondera suas estimativas pelas incertezas das concentrações. Consideramos que o laboratório experimentou uma substancial melhoria na qualidade das medidas de concentrações químicas, analisadas por Fluorescência de Raios X (XRF) e das concentrações de Black Carbon (BC), medido por refletância intercalibrada por Thermal Optical Transmitance (TOT).

Usar uma série de alvos padrões, em combinação com o ajuste funcional da calibração do sistema XRF, mostrou-se uma estratégia eficaz. Isso permitiu a medição de todos elementos químicos $(10<\mathrm{Z}<83)$, mesmo quando não se dispunha de alvos padrões para alguns deles. O ajuste por Mínimos Quadrados Matricial ofereceu incertezas menores que as fornecidas pelo fabricante dos alvos padrões, melhorando substancialmente a precisão analítica na determinação dos elementos químicos.

Verificou-se, a partir do acompanhamento de calibrações regular do equipamento de XRF, que a sua eficiência decai com o uso, fenômeno natural, resultado de possível perda na eficiência do detector ou no tubo de raios X. Nas três calibrações que realizamos durante período de análise das amostras (mais de 3000), registramos um decréscimo da eficiência (medida pelo fator de resposta) da ordem de $9 \%$ para as linhas K e 7\% para as linhas L. Iremos completar esta avaliação, incorporando outras calibrações e uma estimativa baseada em horas de uso efetivo do equipamento, mas esses valores permitem dimensionar a necessidade de calibrações 
em função da exatidão necessária do equipamento. Ou seja, em um ano de uso intensivo do equipamento, sua resposta deslocou-se em $10 \%$.

As comparações, para um sub-conjunto de amostras, dos nossos resultados de XRF versus os da US-EPA (feita às cegas, já que desconhecíamos totalmente que estaria sendo realizada) tiveram ótima concordância para os elementos com concentrações acima do limite de detecção, validando nosso método de calibração em relação a essa importante agência de controle.

Ao empregarmos técnica de refletância para medida de Black Carbon pudemos utilizar os mesmos filtros analisados por XRF, o que deu melhor precisão aos dados, já que eliminou a incerteza por duplicidade de amostragem e equipamento. Ela ainda diminuiu significativamente os custos da pesquisa. Utilizando o método absoluto TOT em 52 amostras, para intercalibrar as medidas de refletância, foi possível a quantificação absoluta do BC em todas amostras. O emprego de mínimos quadrados matriciais no ajuste da função de calibração mostrou-se uma ferramenta robusta para tanto, provendo a incerteza para os valores calculados por essa função, necessários para o uso de PMF.

No período do Harmatão (quando vento de nordeste traz poeira do deserto do Saara) as concentrações de $M P_{2,5}$ e $M P_{10}$ elevam-se a um fator 10. O padrão diário de $M P_{10}$ em Gana foi ultrapassado em 16,24 \% dos dias na área residencial e 19,60 \% na avenida, enquanto a diretriz da OMS, mais restritiva, foi ultrapassada em 59,90\% dos dias na área residencial e 90,95 \% na avenida, principalmente nos períodos de ocorrência do Harmatão. A média geométrica anual em 2007 foi de $68 \mu \mathrm{g} / \mathrm{m}^{3}$ na área residencial e $89 \mu \mathrm{g} / \mathrm{m}^{3}$ na avenida, não ultrapassando esse padrão do país. As correspondentes médias aritméticas foram de 115 e 132 $\mu \mathrm{g} / \mathrm{m}^{3}$, em torno de 5 vezes a diretriz da OMS. Isso reflete a total inadequação do padrão local, tanto em relação ao tipo de média empregada (os efeitos sobre a saúde não respondem geometricamente) quanto por sua dimensão pouco atual em relação aos danos à saúde que deveriam limitar.

$\operatorname{Mar}(\mathrm{Na}, \mathrm{Cl})$, solo (Mg, Al, Si, Ca, Ti, V, Mn, Fe), emissões veiculares (BC, Zn, K, Pb), queima de biomassa $(\mathrm{P}, \mathrm{S}, \mathrm{K}, \mathrm{BC})$ e queima de lixo sólido e outros materiais a céu aberto $(\mathrm{Br}, \mathrm{Pb})$ foram as principais fontes encontras para $M P_{2,5}$. Para $M P_{2,5-10}$ as principais fontes encontradas foram: mar ( $\mathrm{Na}, \mathrm{Cl})$, solo $(\mathrm{Mg}, \mathrm{Al}, \mathrm{Si}, \mathrm{Ca}, \mathrm{Ti}, \mathrm{V}, \mathrm{Mn}, \mathrm{Fe})$, partículas envelhecidas de emissões veiculares, queima de biomassa e solo ( $\mathrm{S}, \mathrm{K}, \mathrm{Zn}, \mathrm{Br}, \mathrm{Pb}+$ solo) e poeira de estrada $(\mathrm{Zn}+$ solo $)$.

A poeira do solo, fonte de maior peso, representa um problema grave de poluição em Acra, pois há muitos terrenos descampado, que também acabam tornando-se depósitos de lixo a céu aberto. Somente avenidas principais e rodovias são pavimentadas. Apesar desta ser uma fonte 
característica de $M P_{2,5-10}$, pois é formada por processos mecânicos, em Acra ela também apareceu como principal fonte no $M P_{2,5}$, tamanha sua presença na atmosfera. Além disso, verificou-se, como em outros experimentos, que o fenômeno natural do Harmatã introduz um grande incremento de poeira do solo (vinda do Saara), no período do inverno.

O peso da biomassa seria uma consequência de que mais da metade da população de Acra queimava lenha ou carvão para cozimento de alimentos no período do estudo, enquanto no país esse percentual ultrapassava os $70 \%$.

Acra é uma cidade litorânea e teve a fonte mar muito bem caracterizada nas análises de $\mathrm{AF}$ e PMF, fato esse esperado e que fortaleceu a validade da metodologia experimental e teórica usada.

Por fim, a grande movimentação de veículos antigos em Acra, fenômeno comum em cidades de países em desenvolvimento que crescem sem planejamento, contribui para intensa poluição do ar, direta e indiretamente, seja pela exaustão dos resíduos de combustão nos motores, evaporação de combustíveis, desgaste de pneus e freios, ou por levantamento de partículas do solo ou participação na formação de aerossol secundário.

Estes resultados representam um caracterização valiosa do aerossol atmosférico na região de Acra, sendo importante no contexto do projeto principal que foi desenvolvido com a Faculdade de Saúde Pública de Harvard e com a Universidade de Gana, e que avaliou outras cidades da África Subsariana (SSA).

Nossos resultados, além de terem contribuído para a metodologia de análise de espécies do aerossol atmosférico, demostram a necessidade de políticas públicas à combate a poluição do ar, que pediria medidas perfeitamente tangíveis, como a pavimentação das vias, cobertura do solo com vegetação, incentivo ao uso de gás de cozinha, melhora no transporte público, que ajudariam a diminuir os altos índices de poluição observados. 


\section{Apêndice A: Software PMF EPA 5.0}

Segue-se roteiro prático desenvolvido para utilização do software PMF EPA 5.0, bem como algumas dicas e detalhes destacadas durante o intenso uso desse programa realizado nessa pesquisa.

Sendo $c_{i j}$ e $u_{i j}$ as matrizes de concentração e incerteza, respectivamente, ao se iniciar o programa, os seguintes itens devem ser satisfeitos antes de rodar análise:

- $c_{i j}$ e $u_{i j}$ não devem ter valores negativos;

- células vazias não são aceitas;

- nomes das colunas(espécies) e linhas(amostras) devem ser únicos;

- é ideal (mas não obrigatório) que os dados já estejam classificados pela data em ordem crescente.

É importante adequar as incertezas, dimunuindo ou aumetando as mesmas por um fator constante, pois o PMF pondera pelas mesmas, assim deve-se diminuir o peso das medidas com incertezas muito altas. Para tal, é possível usar o Signal Noise (S/N), que indica se a variabilidade nas medidas é real ou faz parte do ruído dos dados, e é calculado da seguinte forma:

- Se, $c_{i j}>u_{i j}$, então $S / N=\left(c_{i j}-u_{i j}\right) / u_{i j}$.

- Se, $c_{i j}<u_{i j}$, então $S / N=0$.

Espécie com a concentração menor que a incerteza, não apresentam ruído, e devem ser removidas da análise e espécies com valores muito próximos da incerteza, portanto com $\mathrm{S} / \mathrm{N}$ próximo de zero $(<0,5)$ também devem ser removidas da análise. Espécie nas quais a concentração é pelo menos duas vezes o valor da incerteza, isto é, S/N é maior ou igual à 1, são as ideais para análise, e não altera-se as incertezas. Quando S/N está entre 0,5 e 1, diminuímos o peso da espécie aumentando a incerteza em um fator 3, diretamento na planilha, ou na interface do PMF EPA. 
Após carregado as planilhas corretamente, já é possível rodar a análise, mas é aconselhável inspecionar e até alterar os dados se necessário. Segue uma lista de itens para se averiguar após carregamento dos dados:

- Há relação tipicamente linear entre concentração e incerteza? Se não, investigar o motivo;

- Adequação das incertezas baseado no S/N (bem como do conhecimento da espécie e do limite de detecção do método de medida);

- Marcar a massa total como Total Variable;

- Inspecionar gráficos de dispersão entre espécies nas quais se espera correlação, anticorrelação ou não correlação;

- Inspecionar gráficos de séries temporais para identificação de padrões temporais e removeção de outliers;

Por questões de reprodutibilidade da análise é importante fixar um seed antes de cada rodada. Devido ao inicio randômico é recomendado uma rodada de pelo menos 100 iterações para solução final e 10 para as rodadas testes.

Cada rodada que converge fornece dois valores para a função objeto $\mathrm{Q}, Q_{\text {verdadeiro }}$ e $Q_{\text {robusto }}$, sendo o primeiro calculado considerando todos os valores, mesmo os marcados para remoção, e o segundo os removendo. Assim, quando há poucos outliers, $Q_{\text {verdadeiro }}$ e $Q_{\text {robusto }}$ são próximos, mas incertezas muitos altas resultam em $Q_{\text {verdadeiro }}$ e $Q_{\text {robusto }}$ similares.

Escolhe-se a solução com menor $Q_{\text {robusto }}$, devendo-se testar se o ajuste resultou em Q mínimo global e não local. Pode-se rodar o software para diferentes valores de seed e acompanhar a estabilidade do Q, que se for mantida, significa que o Q é mínimo global.

Realizadas as adaptações necessárias nos dados, segue-se com a realização do ajuste na sequência a seguir:

1. Rodar o base run com 20 iterações, encolhendo o número de fatores variando de 3 até 10. Verificar a quantidade de fatores com significado físico;

2. Verificar a estabilidade dos $Q_{\text {verdadeiro }}$ e $Q_{\text {robusto }}$ que convergiram, se os Q's não forem estáveis, então não foi um bom ajuste (o mínimo não é global);

3. Regressão linear simples das concentrações das espécies ajustadas pelas medidas, que devem estar correlacionas; Remover amostras ou aumentar as incertezas das amostras que não foram bem ajustadas e rodar novamente o base run.

4. Série temporal das concentrações das espécies ajustadas sobreposta as medidas. Identificar pontos não bem ajustados, devido a fontes infrequentes, por exemplo, remover ou aumentar a incerteza desses dias e rodar novamente o base run; 
5. Análise residual. Verificar se a distribuição do resíduo é normal, usando o teste de Kolmogorov-Smirnov. Quando não é normal, há a indicação que o ajuste foi pobre para essa espécie. Novamente, diminuir o peso da espécie aumentando sua incerteza, ou remover a espécie da análise. 


\section{Apêndice B: Outros resultados de PMF e AF}

Resultado de AF sem a separação dos dias de ocorrência de vento Harmatão e rodadas de PMF para $M P_{2,5-10}$ com extração de 5 fatores.

Tabela B.1: Análise de Fatores na área residencial para $M P_{2,5}$ incluindo dias de ocorrência de vento Harmatão. $\mathrm{n}=197$.

\begin{tabular}{ccccccc}
\hline Espécie & Fator1 & Fator2 & Fator3 & Fator4 & Fator5 & Comunalidade \\
\hline$M P_{2,5}$ & 0,27 & 0,13 & 0,07 & 0,04 & 0,94 & 0,98 \\
$\mathrm{BC}$ & 0,00 & 0,67 & 0,28 & 0,42 & 0,18 & 0,74 \\
$\mathrm{Na}$ & $-0,27$ & $-0,04$ & 0,09 & $-0,90$ & $-0,02$ & 0,9 \\
$\mathrm{Mg}$ & 0,93 & 0,19 & 0,13 & 0,13 & 0,11 & 0,95 \\
$\mathrm{Al}$ & 0,94 & 0,21 & 0,12 & 0,17 & 0,11 & 0,98 \\
$\mathrm{Si}$ & 0,95 & 0,18 & 0,12 & 0,16 & 0,12 & 0,98 \\
$\mathrm{P}$ & 0,70 & 0,58 & $-0,07$ & 0,06 & 0,07 & 0,85 \\
$\mathrm{~S}$ & 0,31 & 0,86 & 0,19 & $-0,13$ & 0,05 & 0,9 \\
$\mathrm{Cl}$ & 0,86 & 0,01 & 0,26 & $-0,20$ & 0,05 & 0,85 \\
$\mathrm{~K}$ & 0,87 & 0,33 & 0,22 & 0,15 & 0,17 & 0,97 \\
$\mathrm{Ca}$ & 0,96 & 0,09 & 0,11 & 0,10 & 0,12 & 0,97 \\
$\mathrm{Ti}$ & 0,96 & 0,14 & 0,10 & 0,13 & 0,12 & 0,99 \\
$\mathrm{~V}$ & 0,95 & 0,17 & 0,07 & 0,10 & 0,12 & 0,95 \\
$\mathrm{Mn}$ & 0,96 & 0,11 & 0,09 & 0,11 & 0,12 & 0,98 \\
$\mathrm{Fe}$ & 0,96 & 0,14 & 0,10 & 0,12 & 0,12 & 0,99 \\
$\mathrm{Zn}$ & 0,69 & 0,28 & 0,37 & 0,15 & 0,22 & 0,76 \\
$\mathrm{Br}$ & 0,19 & 0,20 & 0,86 & $-0,10$ & 0,03 & 0,82 \\
$\mathrm{~Pb}$ & 0,66 & 0,25 & 0,50 & 0,16 & 0,20 & 0,81 \\
\hline Explicada $(\%)$ & 57,91 & 11,34 & 8,09 & 7,08 & 6,40 & total $=90,81 \%$ \\
\hline
\end{tabular}


Tabela B.2: Análise de Fatores na avenida para $M P_{2,5}$ incluindo dias de ocorrência de vento Harmatão. $\mathrm{n}=200$.

\begin{tabular}{ccccccc}
\hline Espécie & Fator1 & Fator2 & Fator3 & Fator4 & Fator5 & Comunalidade \\
\hline$M P_{2,5}$ & 0,96 & 0,18 & 0,10 & 0,10 & 0,14 & 0,99 \\
$\mathrm{BC}$ & 0,21 & 0,21 & 0,06 & 0,00 & 0,94 & 0,98 \\
$\mathrm{Na}$ & $-0,22$ & $-0,04$ & $-0,96$ & 0,04 & $-0,06$ & 0,98 \\
$\mathrm{Mg}$ & 0,92 & 0,24 & 0,16 & 0,11 & 0,12 & 0,96 \\
$\mathrm{Al}$ & 0,92 & 0,25 & 0,18 & 0,10 & 0,13 & 0,98 \\
$\mathrm{Si}$ & 0,94 & 0,24 & 0,16 & 0,10 & 0,12 & 0,98 \\
$\mathrm{P}$ & 0,63 & 0,69 & 0,18 & 0,02 & 0,08 & 0,92 \\
$\mathrm{~S}$ & 0,29 & 0,83 & $-0,03$ & 0,28 & 0,30 & 0,95 \\
$\mathrm{Cl}$ & 0,89 & 0,13 & $-0,24$ & 0,07 & 0,02 & 0,88 \\
$\mathrm{~K}$ & 0,90 & 0,30 & 0,13 & 0,17 & 0,19 & 0,98 \\
$\mathrm{Ca}$ & 0,96 & 0,17 & 0,11 & 0,09 & 0,10 & 0,98 \\
$\mathrm{Ti}$ & 0,96 & 0,20 & 0,14 & 0,09 & 0,10 & 0,99 \\
$\mathrm{~V}$ & 0,95 & 0,19 & 0,11 & 0,08 & 0,10 & 0,97 \\
$\mathrm{Mn}$ & 0,96 & 0,17 & 0,11 & 0,07 & 0,11 & 0,98 \\
$\mathrm{Fe}$ & 0,96 & 0,19 & 0,13 & 0,08 & 0,10 & 0,99 \\
$\mathrm{Zn}$ & 0,74 & 0,16 & 0,15 & 0,24 & 0,25 & 0,72 \\
$\mathrm{Br}$ & 0,18 & 0,16 & $-0,05$ & 0,95 & 0,00 & 0,96 \\
$\mathrm{~Pb}$ & 0,79 & 0,20 & 0,15 & 0,33 & 0,14 & 0,82 \\
\hline Vxplicada (\%) & 63,72 & 9,99 & 6,97 & 6,96 & 6,79 & total $=94,42 \%$ \\
\hline
\end{tabular}

Tabela B.3: Análise de Fatores na área residencial para $M P_{2,5-10}$ incluindo dias de ocorrência de vento Harmatão. $\mathrm{n}=183$.

\begin{tabular}{cccccc}
\hline Espécie & Fator1 & Fator2 & Fator3 & Fator4 & Comunalidade \\
\hline$M P_{2,5-10}$ & 0,89 & 0,10 & $-0,13$ & 0,01 & 0,82 \\
$\mathrm{Na}$ & $-0,30$ & 0,28 & 0,86 & $-0,18$ & 0,93 \\
$\mathrm{Mg}$ & 0,92 & 0,16 & 0,04 & 0,11 & 0,89 \\
$\mathrm{Al}$ & 0,92 & 0,13 & $-0,12$ & 0,26 & 0,94 \\
$\mathrm{Si}$ & 0,95 & 0,11 & $-0,12$ & 0,20 & 0,96 \\
$\mathrm{P}$ & 0,49 & 0,05 & $-0,16$ & 0,82 & 0,93 \\
$\mathrm{~S}$ & 0,07 & 0,86 & 0,41 & 0,07 & 0,91 \\
$\mathrm{Cl}$ & $-0,06$ & 0,36 & 0,91 & $-0,00$ & 0,95 \\
$\mathrm{~K}$ & 0,90 & 0,34 & $-0,03$ & 0,20 & 0,97 \\
$\mathrm{Ca}$ & 0,96 & 0,13 & $-0,09$ & 0,17 & 0,98 \\
$\mathrm{Ti}$ & 0,96 & 0,11 & $-0,11$ & 0,21 & 0,99 \\
$\mathrm{~V}$ & 0,94 & 0,18 & $-0,09$ & 0,14 & 0,95 \\
$\mathrm{Mn}$ & 0,97 & 0,09 & $-0,10$ & 0,15 & 0,97 \\
$\mathrm{Fe}$ & 0,96 & 0,11 & $-0,12$ & 0,20 & 0,98 \\
$\mathrm{Zn}$ & 0,55 & 0,48 & $-0,02$ & 0,41 & 0,7 \\
$\mathrm{Br}$ & 0,09 & 0,91 & 0,30 & $-0,02$ & 0,92 \\
$\mathrm{~Pb}$ & 0,48 & 0,83 & 0,07 & 0,06 & 0,92 \\
\hline Variância Explicada (\%) & 56,78 & 17,38 & 11,41 & 7,00 & total $=92,57 \%$ \\
\hline
\end{tabular}


Tabela B.4: Análise de Fatores na avenida para $M P_{2,5-10}$ incluindo dias de ocorrência de vento Harmatão. $\mathrm{n}=196$.

\begin{tabular}{cccccc}
\hline Espécie & Fator1 & Fator2 & Fator3 & Fator4 & Comunalidade \\
\hline$M P_{2,5-10}$ & 0,96 & $-0,10$ & 0,01 & 0,07 & 0,93 \\
$\mathrm{Na}$ & $-0,34$ & 0,87 & 0,01 & $-0,22$ & 0,92 \\
$\mathrm{Mg}$ & 0,89 & $-0,05$ & 0,26 & 0,17 & 0,88 \\
$\mathrm{Al}$ & 0,89 & $-0,15$ & 0,20 & 0,30 & 0,95 \\
$\mathrm{Si}$ & 0,93 & $-0,13$ & 0,20 & 0,21 & 0,96 \\
$\mathrm{P}$ & 0,35 & $-0,20$ & 0,04 & 0,86 & 0,9 \\
$\mathrm{~S}$ & 0,14 & 0,45 & 0,69 & 0,41 & 0,87 \\
$\mathrm{Cl}$ & $-0,05$ & 0,92 & 0,29 & 0,01 & 0,93 \\
$\mathrm{~K}$ & 0,88 & $-0,03$ & 0,28 & 0,34 & 0,96 \\
$\mathrm{Ca}$ & 0,96 & $-0,10$ & 0,14 & 0,15 & 0,98 \\
$\mathrm{Ti}$ & 0,96 & $-0,13$ & 0,09 & 0,21 & 0,99 \\
$\mathrm{~V}$ & 0,93 & $-0,08$ & 0,01 & 0,18 & 0,9 \\
$\mathrm{Mn}$ & 0,97 & $-0,12$ & 0,08 & 0,13 & 0,99 \\
$\mathrm{Fe}$ & 0,96 & $-0,13$ & 0,07 & 0,18 & 0,99 \\
$\mathrm{Zn}$ & 0,66 & 0,04 & 0,25 & 0,55 & 0,81 \\
$\mathrm{Br}$ & 0,23 & 0,14 & 0,92 & $-0,03$ & 0,91 \\
$\mathrm{~Pb}$ & 0,77 & $-0,06$ & 0,34 & 0,36 & 0,84 \\
\hline Variância Explicada (\%) & 59,12 & 11,63 & 10,86 & 10,73 & total $=92,34 \%$ \\
\hline
\end{tabular}




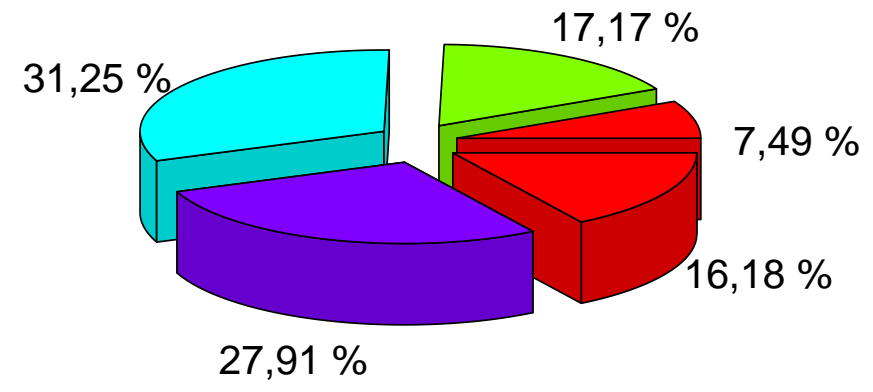

Tabela B.5: Perfis (\%) do fatores na área residencial $M P_{2,5-10}$ ex-

Figura B.1: Contribuição dos fatores na massa total para $M P_{2,5-10}$ na área residencial excluindo dias de ocorrência de vento Harmatão. seed $=123 \mathrm{n}=123$.

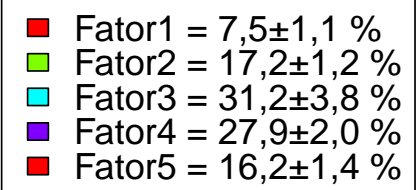

Fator $5=16,2 \pm 1,4 \%$ cluindo dias de ocorrência de vento Harmatão. seed=123 e n= 112 .

\begin{tabular}{cccccc}
\hline & Fator1 & Fator2 & Fator3 & Fator4 & Fator5 \\
\hline$M P_{2,5-10}$ & 7,5 & 17,2 & 31,3 & 27,9 & 16,2 \\
$\mathrm{Na}$ & 5,2 & 82,4 & 0 & 0 & 12,4 \\
$\mathrm{Mg}$ & 0 & 34,7 & 44,2 & 0 & 21,2 \\
$\mathrm{Al}$ & 3,3 & 4,8 & 51,1 & 30,9 & 9,8 \\
$\mathrm{Si}$ & 2,5 & 6,2 & 48 & 32 & 11,2 \\
$\mathrm{P}$ & 0 & 2,6 & 20,2 & 77,2 & 0 \\
$\mathrm{~S}$ & 21,3 & 16,9 & 0 & 0 & 61,8 \\
$\mathrm{Cl}$ & 11,2 & 57,6 & 9,8 & 14,1 & 7,3 \\
$\mathrm{~K}$ & 8,7 & 1,7 & 20 & 10,3 & 59,3 \\
$\mathrm{Ca}$ & 11,1 & 14,7 & 32,5 & 41,7 & 0 \\
$\mathrm{Ti}$ & 5,8 & 6,8 & 44,9 & 35,8 & 6,6 \\
$\mathrm{~V}$ & 10,7 & 8,8 & 48,6 & 31,9 & 0 \\
$\mathrm{Mn}$ & 8,8 & 5,8 & 44,5 & 27,8 & 13 \\
$\mathrm{Fe}$ & 3 & 8,1 & 41 & 37,1 & 10,7 \\
$\mathrm{Zn}$ & 8,1 & 9,4 & 6 & 53,8 & 22,8 \\
$\mathrm{Br}$ & 100 & 0 & 0 & 0 & 0 \\
$\mathrm{~Pb}$ & 43,2 & 0 & 14,2 & 30,6 & 12 \\
\hline
\end{tabular}




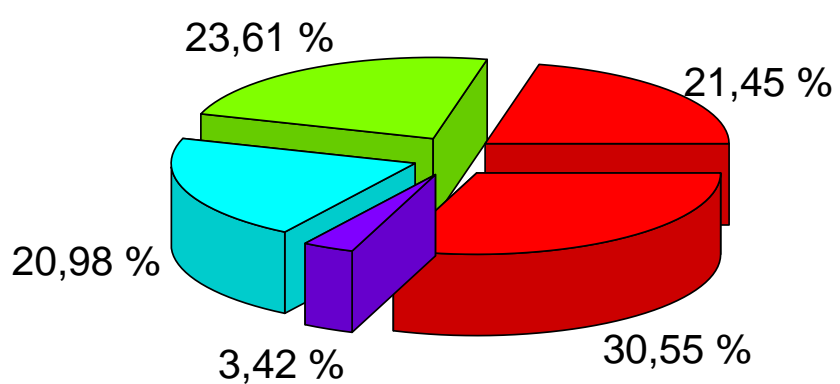

Figura B.2: Contribuição dos fatores na massa total para $M P_{2,5-10}$ na avenida excluindo dias de ocorrência de vento Harmatão. seed $=$ $123 \mathrm{n}=116$.
Tabela B.6: Perfis (\%) do fatores avenida $M P_{2,5-10}$ excluindo dias de ocorrência de vento Harmatão. seed=123 e $\mathrm{n}=116$.

\begin{tabular}{cccccc}
\hline & Fator1 & Fator2 & Fator3 & Fator4 & Fator5 \\
\hline$M P_{2,5-10}$ & 21,4 & 23,6 & 21 & 3,4 & 30,5 \\
$\mathrm{Na}$ & 70,5 & 17,3 & 2,8 & 9,4 & 0 \\
$\mathrm{Mg}$ & 18,5 & 31,7 & 0 & 14,7 & 35,1 \\
$\mathrm{Al}$ & 5,1 & 27,2 & 15,7 & 5,9 & 46,2 \\
$\mathrm{Si}$ & 9,5 & 28,1 & 18,4 & 4,8 & 39,1 \\
$\mathrm{P}$ & 0 & 25,1 & 49,4 & 7,5 & 18 \\
$\mathrm{~S}$ & 17 & 11 & 8,8 & 43,7 & 19,5 \\
$\mathrm{Cl}$ & 56,6 & 12 & 10 & 4 & 17,4 \\
$\mathrm{~K}$ & 0 & 20,7 & 12,4 & 35,7 & 31,2 \\
$\mathrm{Ca}$ & 22,4 & 7,2 & 28,3 & 0 & 42,1 \\
$\mathrm{Ti}$ & 9,4 & 20,7 & 19,1 & 3,6 & 47,3 \\
$\mathrm{~V}$ & 8,3 & 44,5 & 9,9 & 6,1 & 31,2 \\
$\mathrm{Mn}$ & 9,2 & 24,6 & 17,7 & 6,4 & 42,1 \\
$\mathrm{Fe}$ & 13,8 & 36,5 & 25,3 & 0 & 24,4 \\
$\mathrm{Zn}$ & 14,9 & 8,2 & 54,2 & 5,1 & 17,6 \\
$\mathrm{Br}$ & 17 & 0,1 & 3 & 59,3 & 20,6 \\
$\mathrm{~Pb}$ & 6,3 & 0 & 30,6 & 26,9 & 36,1 \\
\hline
\end{tabular}




\section{Bibliografia}

Aboh, I. J. K., Henriksson, D., Laursen, J., Lundin, M., Ofosu, F. G., Pind, N., Selin Lindgren, E., \& Wahnström, T. (2009). Identification of aerosol particle sources in semi-rural area of Kwabenya, near Accra, Ghana, by EDXRF techniques. X-Ray Spectrometry, 38(4), 348-353.

Achad, M., López, M. L., Ceppi, S., Palancar, G. G., Tirao, G., \& Toselli, B. M. (2014). Assessment of fine and sub-micrometer aerosols at an urban environment of Argentina. Atmospheric Environment, 92, 522-532.

Aiginger, H. \& Wobrauschek, P. (1974). A method for quantitative X-ray fluorescence analysis in the nanogram region. Nuclear Instruments and Methods, 114(1), 157-158.

Andrade, M. d. F., de Miranda, R. M., Fornaro, A., Kerr, A., Oyama, B., de Andre, P. A., \& Saldiva, P. (2012). Vehicle emissions and PM2.5 mass concentrations in six Brazilian cities. Air Quality, Atmosphere 83 Health, 5(1), 79-88.

Arbex, M. A., Santos, U. d. P., Martins, L. C., Saldiva, P. H. N., Pereira, L. A. A., Braga, A. L. F., et al. (2012). A poluição do ar e o sistema respiratório. J Bras Pneumol, 38(5), $643-655$.

Arku, R. E., Vallarino, J., Dionisio, K. L., Willis, R., Choi, H., Wilson, J. G., Hemphill, C., Agyei-Mensah, S., Spengler, J. D., \& Ezzati, M. (2008). Characterizing air pollution in two low-income neighborhoods in Accra, Ghana. Science of the total environment, 402(2), $217-231$.

Asampong, E., Dwuma-Badu, K., Stephens, J., Srigboh, R., Neitzel, R., Basu, N., \& Fobil, J. N. (2015). Health seeking behaviours among electronic waste workers in Ghana. BMC public health, 15(1), 1065.

Asante, K. A., Agusa, T., Biney, C. A., Agyekum, W. A., Bello, M., Otsuka, M., Itai, T., Takahashi, S., \& Tanabe, S. (2012). Multi-trace element levels and arsenic speciation in 
urine of e-waste recycling workers from Agbogbloshie, Accra in Ghana. Science of the Total Environment, 424, 63-73.

Bartholomew, D., Knott, M., \& Moustaki, I. (2011). Latent Variable Models and Factor Analysis: A Unified Approach (Wiley Series in Probability and Statistics). Wiley Hoboken, New Jersey.

Birch, M. E. (1998). Analysis of carbonaceous aerosols: interlaboratory comparison. Analyst, $123(5), 851-857$.

Boman, J., Shaltout, A. A., Abozied, A. M., \& Hassan, S. K. (2013). On the elemental composition of PM2. 5 in central Cairo, Egypt. X-Ray Spectrometry, 42(4), 276-283.

Bond, T. C., Doherty, S. J., Fahey, D., Forster, P., Berntsen, T., DeAngelo, B., Flanner, M., Ghan, S., Kärcher, B., Koch, D., et al. (2013). Bounding the role of black carbon in the climate system: A scientific assessment. Journal of Geophysical Research: Atmospheres, $118(11), 5380-5552$.

Brauer, M., Amann, M., Burnett, R. T., Cohen, A., Dentener, F., Ezzati, M., Henderson, S. B., Krzyzanowski, M., Martin, R. V., Van Dingenen, R., et al. (2012). Exposure assessment for estimation of the global burden of disease attributable to outdoor air pollution. Environmental science \& technology, 46(2), 652-660.

Breuning-Madsen, H. \& Awadzi, T. W. (2005). Harmattan dust deposition and particle size in Ghana. Catena, 63(1), 23-38.

Capote, R., López, E., \& Mainegra, E. (2000). WinQXAS Manual (Quantitative X-Ray Analysis System for Widows) Version 1.2.

Carslaw, D. C. \& Ropkins, K. (2012). Openair - an R package for air quality data analysis. Environmental Modelling \& Software, 27, 52-61.

CETESB (2014). Relatório de qualidade do ar no estado de Sao Paulo: 2014. CETESB.

Clarke, A. D., Noone, K. J., Heintzenberg, J., Warren, S. G., \& Covert, D. S. (1986). Aerosol light absorption measurement techniques: Analysis and intercomparisons. Atmospheric Environment (1986), 21(6), 1455-1465.

CONAMA (1990). Resolução Conama nº 003, de 28 de junho de 1990. Brasil^ dMinistério do Meio Ambiente. Conselho Nacional de Meio Ambiente. Diário Oficial da União. 
Díaz, R., López-Monroy, J., Miranda, J., \& Espinosa, A. (2014). PIXE and XRF analysis of atmospheric aerosols from a site in the West area of Mexico City. Nuclear Instruments and Methods in Physics Research Section B: Beam Interactions with Materials and Atoms, 318, $135-138$.

Dionisio, K. L., Arku, R. E., Hughes, A. F., Vallarino, J., Carmichael, H., Spengler, J. D., Agyei-Mensah, S., \& Ezzati, M. (2010a). Air pollution in Accra neighborhoods: spatial, socioeconomic, and temporal patterns. Environmental science \& technology, 44(7), 22702276 .

Dionisio, K. L., Rooney, M. S., Arku, R. E., Friedman, A. B., Hughes, A. F., Vallarino, J., Agyei-Mensah, S., Spengler, J. D., \& Ezzati, M. (2010b). Within-neighborhood patterns and sources of particle pollution: mobile monitoring and geographic information system analysis in four communities in Accra, Ghana. Environmental health perspectives, 118(5), $607-613$.

DVLA (2015). Driver and Vehicle Licensing Authority (DVLA) Ghana. http://dvla.gov . gh/. [Online; Acessado em 20 de Dezembro de 2015].

Dzubay, T., Jarrett, B., \& Jaklevic, J. (1974). Background reduction in x-ray fluorescence spectra using polarization. Nuclear Instruments and Methods, 115(1), 297-299.

EPA (2012). Report to Congress on Black Carbon. [Online; Acessado em 20 de Dezembro de 2015].

Ezzati, M., Lopez, A. D., Rodgers, A., \& Murray, C. J. (2004). Comparative quantification of health risks. Global and regional burden of disease attributable to selected major risk factors. Geneva: World Health Organization.

Fianko, J. R., Donkor, A., Lowor, S. T., Yeboah, P. O., et al. (2011). Agrochemicals and the Ghanaian environment, a review. Journal of Environmental Protection, 2(03), 221.

Finlayson-Pitts, B. J. \& Pitts Jr, J. N. (1999). Chemistry of the upper and lower atmosphere: theory, experiments, and applications. Academic press.

Gaita, S. M., Boman, J., Gatari, M. J., Pettersson, J. B., \& Janhäll, S. (2014). Source apportionment and seasonal variation of PM 2.5 in a Sub-Saharan African city: Nairobi, Kenya. Atmospheric Chemistry and Physics, 14(18), 9977-9991. 
Ghana (2003). Ghana Statistical Service: 2000 POPULATION AND HOUSING CENSUS. NATIONAL ANALYTICAL REPORT.

Ghana (2013). Ghana Statistical Service: 2010 POPULATION \&3 HOUSING CENSUS. NATIONAL ANALYTICAL REPORT.

Ghana (2015a). Environmental Protection Agency (EPA) Ghana. http://www.epa.gov.gh/ ghanalex/policies/. [Online; Acessado em 19 de Dezembro de 2015].

Ghana (2015b). National Information Technology Agency (NITA) 2012-2016 - Ghana Open Data Initiative. http://data.gov.gh/. [Online; Acessado em 11 de Dezembro de 2015].

Heal, M. R. \& Quincey, P. (2012). The relationship between black carbon concentration and black smoke: a more general approach. Atmospheric environment, 54, 538-544.

Helene, O. (2006). Metodos dos Mínimos Quadrados. Editora Livraria da Física.

Helene, O. A. M. \& Vanin, V. R. (1981). Tratamento estatístico de dados em física experimental. E. Blucher.

IBGE (2011). Instituto Brasileiro de Geografia e Estatística Censo Demográfico, 2010. IBGE.

Ivošević, T., Stelcer, E., Orlić, I., Radović, I. B., \& Cohen, D. (2015). Characterization and source apportionment of fine particulate sources at Rijeka, Croatia from 2013 to 2015. Nuclear Instruments and Methods in Physics Research Section B: Beam Interactions with Materials and Atoms.

Jacobson, L. d. S. V., de Souza Hacon, S., de Castro, H. A., Ignotti, E., Artaxo, P., Saldiva, P. H. N., \& de Leon, A. C. M. P. (2014). Acute effects of particulate matter and black carbon from seasonal fires on peak expiratory flow of schoolchildren in the Brazilian Amazon. PloS one, $9(8)$, e104177.

Janssen, N. A., Gerlofs-Nijland, M. E., Lanki, T., Salonen, R. O., Cassee, F., Hoek, G., Fischer, P., Brunekreef, B., \& Krzyzanowski, M. (2012). Health effects of black carbon. WHO Regional Office for Europe Copenhagen, Denmark.

Jenkins, R. (1988). X-Ray Fluorescence Spectrometry. John Wiley.

Jenkins, R., Manne, R., Robin, R., \& Senemaud, C. (1991). IUPAC-nomenclature system for x-ray spectroscopy. X-Ray Spectrometry, 20(3), 149-155. 
Kaiser, H. F. (1958). The varimax criterion for analytic rotation in factor analysis. Psychometrika, 23(3), 187-200.

Kaku, K. C., Reid, J. S., Reid, E. A., Ross-Langerman, K., Piketh, S., Cliff, S., Al Mandoos, A., Broccardo, S., Zhao, Y., Zhang, J., et al. (2016). Investigation of the relative fine and coarse mode aerosol loadings and properties in the Southern Arabian Gulf region. Atmospheric Research, 169, 171-182.

Kang, C.-M., Achilleos, S., Lawrence, J., Wolfson, J. M., \& Koutrakis, P. (2014). Interlab comparison of elemental analysis for low ambient urban PM2. 5 levels. Environmental science $\&$ technology, 48(20), 12150-12156.

Lack, D. A., Moosmüller, H., McMeeking, G. R., Chakrabarty, R. K., \& Baumgardner, D. (2014). Characterizing elemental, equivalent black, and refractory black carbon aerosol particles: a review of techniques, their limitations and uncertainties. Analytical and bioanalytical chemistry, 406(1), 99-122.

Lente, I., Ofosu-Anim, J., Brimah, A., \& Atiemo, S. (2014). Heavy metal pollution of vegetable crops irrigated with wastewater 41 Heavy Metal Pollution of Vegetable Crops Irrigated with Wastewater in Accra, Ghana. West African Journal of Applied Ecology, 22(1), 41-58.

Li, J., Pósfai, M., Hobbs, P. V., \& Buseck, P. R. (2003). Individual aerosol particles from biomass burning in southern Africa: 2, Compositions and aging of inorganic particles. Journal of Geophysical Research: Atmospheres, 108(D13).

Lim, S. S., Vos, T., Flaxman, A. D., Danaei, G., Shibuya, K., Adair-Rohani, H., AlMazroa, M. A., Amann, M., Anderson, H. R., Andrews, K. G., et al. (2013). A comparative risk assessment of burden of disease and injury attributable to 67 risk factors and risk factor clusters in 21 regions, 1990-2010: a systematic analysis for the Global Burden of Disease Study 2010. The lancet, 380(9859), 2224-2260.

Mansha, M., Ghauri, B., Rahman, S., \& Amman, A. (2012). Characterization and source apportionment of ambient air particulate matter (PM 2.5) in Karachi. Science of the total environment, 425, 176-183.

Marple, V. A., Rubow, K. L., Turner, W., \& Spengler, J. D. (1987). Low flow rate sharp cut impactors for indoor air sampling: design and calibration. Japca, 37(11), 1303-1307. 
McInnes, L., Covert, D., Quinn, P., \& Germani, M. (1994). Measurements of chloride depletion and sulfur enrichment in individual sea-salt particles collected from the remote marine boundary layer. Journal of Geophysical Research: Atmospheres, 99(D4), 8257-8268.

Meel, K. V. (2009). Application of high-energy polarized-beam energy-dispersive X-ray fluorescence for industrial and environmental purposes. PhD thesis, Universiteit Antwerpen, Faculteit Wetenschappen, Departement Chemie.

Miranda, R. M., de Fatima Andrade, M., Fornaro, A., Astolfo, R., de Andre, P. A., \& Saldiva, P. (2012). Urban air pollution: a representative survey of PM2.5 mass concentrations in six Brazilian cities. Air quality, atmosphere $\&$ health, 5(1), 63-77.

Montgomery, M. R. (2008). The urban transformation of the developing world. Science, 319(5864), 761-764.

Nejedlỳ, Z., Campbell, J., Teesdale, W., Dlouhy, J., Dann, T., Hoff, R., Brook, J., \& Wiebe, H. (1998). Inter-laboratory comparison of air particulate monitoring data. Journal of the Air $\&$ Waste Management Association, 48(5), 386-397.

Norris, G., Duvall, R., Brown, S., \& Bai, S. (2014). EPA Positive Matrix Factorizarion (PMF) 5.0 Fundamentals \& User Guide. Prepared for the US Environmental Protection Agency, Washington, DC, by the National Exposure Research Laboratory, Research Triangle Park.

Ofosu, F. G., Hopke, P. K., Aboh, I. J., \& Bamford, S. A. (2012). Characterization of fine particulate sources at Ashaiman in Greater Accra, Ghana. Atmospheric Pollution Research, 3(3), 301-310.

Ofosu, F. G., Hopke, P. K., Aboh, I. J., \& Bamford, S. A. (2013). Biomass burning contribution to ambient air particulate levels at Navrongo in the Savannah zone of Ghana. Journal of the Air $\&$ Waste Management Association, 63(9), 1036-1045.

Oliveira, M. G. L. (2007). EVOL UÇÃO DAS DISTRIBUIÇÕES DE TAMANHO EM MASSA E NÚMERO DO AEROSSOL ATMOSFÉRICO EM SÃO PAULO. PhD thesis, Dissertação Mestrado, Universidade de São Paulo.

Paatero, P. \& Tapper, U. (1994). Positive matrix factorization: A non-negative factor model with optimal utilization of error estimates of data values. Environmetrics, 5(2), 111-126. 
Petzold, A., Ogren, J., Fiebig, M., Laj, P., Li, S.-M., Baltensperger, U., Holzer-Popp, T., Kinne, S., Pappalardo, G., Sugimoto, N., et al. (2013). Recommendations for reporting Black Carbon measurements. Atmospheric Chemistry and Physics, 13(16), 8365-8379.

Polissar, A. V., Hopke, P. K., Paatero, P., Malm, W. C., \& Sisler, J. F. (1998). Atmospheric aerosol over Alaska: 2. Elemental composition and sources. Journal of Geophysical Research: Atmospheres, 103(D15), 19045-19057.

Prospero, J. M., Ginoux, P., Torres, O., Nicholson, S. E., \& Gill, T. E. (2002). Environmental characterization of global sources of atmospheric soil dust identified with the Nimbus 7 Total Ozone Mapping Spectrometer (TOMS) absorbing aerosol product. Reviews of geophysics, $40(1)$.

Quincey, P. (2007). A relationship between Black Smoke Index and Black Carbon concentration. Atmospheric Environment, 41(36), 7964 - 7968.

Reid, J., Koppmann, R., Eck, T., \& Eleuterio, D. (2005). A review of biomass burning emissions part II: intensive physical properties of biomass burning particles. Atmospheric Chemistry and Physics, 5(3), 799-825.

Rooney, M. S., Arku, R. E., Dionisio, K. L., Paciorek, C., Friedman, A. B., Carmichael, H., Zhou, Z., Hughes, A. F., Vallarino, J., Agyei-Mensah, S., et al. (2012). Spatial and temporal patterns of particulate matter sources and pollution in four communities in Accra, Ghana. Science of the Total Environment, 435, 107-114.

Santos, L. H., Kerr, A. A., Veríssimo, T. G., Andrade, M. d. F., de Miranda, R. M., Fornaro, A., \& Saldiva, P. (2014). Analysis of atmospheric aerosol (PM2. 5) in Recife city, Brazil. Journal of the Air \& Waste Management Association, 64(5), 519-528.

Scovronick, N., Adair-Rohani, H., Borgford-Parnell, N., et al. (2015). Reducing global health risks through mitigation of short-lived climate pollutants: scoping report for policymakers. Geneva: World Health Organization and Climate and Clean Air Coalition.

Seinfeld, J. H. \& Pandis, S. N. (2012). Atmospheric chemistry and physics: from air pollution to Climate Change. John Wiley \& Sons.

Simon, H., Beck, L., Bhave, P. V., Divita, F., Hsu, Y., Luecken, D., Mobley, J. D., Pouliot, G. A., Reff, A., Sarwar, G., et al. (2010). The development and uses of EPA's SPECIATE database. Atmospheric Pollution Research, 1(4), 196-206. 
Smith, K. R., Mehta, S., \& Maeusezahl-Feuz, M. (2004). Indoor air pollution from household use of solid fuels. In M. E. zzati, A. D. L. opez, A. Rodgers, \& C. J. Murray (Eds.), Comparative quantification of health risks: global and regional burden of disease attributable to selected major risk factors, volume 2 chapter 18 - Indoor air pollution from household use of solid fuels, (pp. 1435-93). World Health Organization.

Souza, D. Z., Vasconcellos, P. C., Lee, H., Aurela, M., Saarnio, K., Teinilä, K., \& Hillamo, R. (2014). Composition of PM2. 5 and PM10 collected at urban sites in Brazil. Aerosol and Air Quality Research, 14(1), 168.

Tabacniks, M. H. (2000). Análise de Filmes Finos por PIXE e RBS. Instituto de Física-USP. Disponível em http://www2.if.usp.br/ lamfi/pixe\&rbs.pdf, acesso 15/12/2015.

Taha, G., Box, G. P., Cohen, D. D., \& Stelcer, E. (2007). Black carbon measurement using laser integrating plate method. Aerosol Science and Technology, 41(3), 266-276.

Targino, A. C. \& Krecl, P. (2016). Local and Regional Contributions to Black Carbon Aerosols in a Mid-Sized City in Southern Brazil. Aerosol and Air Quality Research, 16, 125-137.

UN (2015). World Population Prospects - Population Division - United Nations. http: //esa.un.org/unpd/wpp/. [Online; Acessado em 09 de Dezembro de 2015].

Wang, Y., Hopke, P. K., Xia, X., Rattigan, O. V., Chalupa, D. C., \& Utell, M. J. (2012). Source apportionment of airborne particulate matter using inorganic and organic species as tracers. Atmospheric Environment, 55, 525-532.

WB (2015). The World Bank: Indicators - GDP. http://data.worldbank.org/indicator/ NY .GDP. PCAP.CD. [Online; Acessado em 14 de Dezembro de 2015].

WHO (2015). WHO World Health Organization: Ambient (outdoor) air quality and health. http://www. who.int/mediacentre/factsheets/fs313/en/. [Online; Acessado em 2 de Dezembro de 2015].

Yang, F., Tan, J., Zhao, Q., Du, Z., He, K., Ma, Y., Duan, F., \& Chen, G. (2011). Characteristics of PM 2.5 speciation in representative megacities and across China. Atmospheric Chemistry and Physics, 11(11), 5207-5219.

Yoneda, Y. \& Horiuchi, T. (1971). Optical Flats for Use in X-Ray Spectrochemical Microanalysis. Review of Scientific Instruments, 42(7), 1069-1070. 
Zhou, Z., Dionisio, K. L., Arku, R. E., Quaye, A., Hughes, A. F., Vallarino, J., Spengler, J. D., Hill, A., Agyei-Mensah, S., \& Ezzati, M. (2011). Household and community poverty, biomass use, and air pollution in Accra, Ghana. Proceedings of the National Academy of Sciences, 108(27), 11028-11033.

Zhou, Z., Dionisio, K. L., Verissimo, T. G., Kerr, A. S., Coull, B., Arku, R. E., Koutrakis, P., Spengler, J. D., Hughes, A. F., \& Vallarino, J. (2013). Chemical composition and sources of particle pollution in affluent and poor neighborhoods of Accra, Ghana. Environmental Research Letters, 8(4), 044025.

Zhou, Z., Dionisio, K. L., Verissimo, T. G., Kerr, A. S., Coull, B., Howie, S., Arku, R. E., Koutrakis, P., Spengler, J. D., \& Fornace, K. (2014). Chemical characterization and source apportionment of household fine particulate matter in rural, peri-urban, and urban West Africa. Environmental science \& technology, 48(2), 1343-1351. 